\title{
Influências de políticas de escalonamento no desempenho de simulações distribuídas
}

Bárbara Lopes Voorsluys 



\section{Influências de políticas de escalonamento no desempenho de simulações distribuídas}

Bárbara Lopes Voorsluys

Orientadora: Prof. Dra.Regina Helena Carlucci Santana

Dissertação apresentada ao Instituto de Ciências Matemáticas e de Computação - ICMC-USP, como parte dos requisitos para obtenção do título de Mestre em Ciências da Computação.

USP - São Carlos

$\mathrm{Março/2006}$ 



\section{Agradecimentos}

Primeiramente a Deus, por sempre me surpreender com as coisas que tem reservado para minha vida. Realmente, quando uma porta se fecha a outra que vai se abrir é muito mais gratificante.

À querida orientadora e professora Regina, pela confiança em mim depositada e pelas orientações.

Ao William (meu marido) pelo grande incentivo e dedicação. A sua companhia e seu amor foram fundamentais durante este trabalho. Você me surpreende...Te amo.

Ao Paulo e a Simone pelo incentivo, apoio, e principalmente pela amizade.

Aos meus pais, José e Elaine, pelo incentivo e compreensão pela minha ausência. Fundamentais também foram os meus sogros (meus segundos pais), Leonardo e Adelaide.

As minhas irmãs, Bruna, Beatriz e Bianca, e toda a minha família que sempre me apoiaram.

A grande amiga Vanessa, pela compreensão da minha ausência.

A professora Rosely Sanches, pelas conversas e pelo carinho demonstrado.

Não posso deixar de citar os Professores Dr. Philip Wilsey e Msc. Dale Martin (University of Cincinnati), responsáveis pelo desenvolvimento da ferramenta Warped, que se mostraram sempre dispostos a discutir sobre o trabalho.

À Beth, Laura e Ana Paula, por sempre estarem dispostas a ajudar no que fosse preciso, na secretaria da Pós-Graduação.

Aos amigos do laboratório: Valéria, Gustavo, Juliano, Michel, Caio, Célia, Hima Carla, Sarita, e muitos outros que de uma maneira ou de outra contribuíram para a realização do trabalho.

Ao pessoal da biblioteca, sempre dispostos a "caçar" qualquer artigo.

À tia da cantina, pelos "Bom dia" e pelos bolos maravilhosos.

A CAPES pelo apoio financeiro. 

" Viver apenas um dia e ouvir um bom ensinamento é melhor do que viver um século sem conhecer tal ensinamento.”

\section{Buda}





\section{Resumo}

Este trabalho analisa o impacto causado no desempenho de uma simulação distribuída quando técnicas de particionamento convencionais são empregadas. Essas técnicas não levam em conta informações inerentes ao estado da simulação. Pelo fato da execução de uma simulação também estar sujeita a sofrer interferências da plataforma, informações sobre a potência computacional de cada recurso utilizado e sobre o tipo de simulação, podem ser aplicadas em seu particionamento. Foram utilizadas informações estáticas, geradas através da avaliação da plataforma com benchmarks, e dinâmicas, obtidas através de índices de carga. Os resultados obtidos da utilização destas técnicas se mostram atrativos, principalmente quando o objetivo é a execução das simulações em ambientes que não disponibilizam políticas de escalonamento específicas e sim políticas convencionais. Nos estudos de casos avaliados, observaram-se ganhos satisfatórios, como a redução de até $24 \%$ do tempo de execução, um aumento de até $22 \%$ de eficiência e $79 \%$ menos rollbacks causados. Percebe-se que dependendo do tempo que se dispõe e dos objetivos pretendidos, as técnicas convencionais podem ser empregadas em simulações distribuídas. Este trabalho também contribui com o aperfeiçoamento das duas ferramentas utilizadas: WARPED e AMIGO. Uma interface de comunicação entre as duas ferramentas foi desenvolvida, ampliando assim seus campos de utilização. 



\section{Abstract}

This work analyses the impact caused on distributed simulation performance when conventional partitioning techniques are employed. These techniques do not take into account inherent information about the state of the simulation. Since a simulation execution is subject to platform interference, information about the type of simulations and about the computational power of resources may be applied to the partitioning process. Static performance information, generated from evaluating the platform with benchmarks has been employed, as well as dynamic load information provided by load indices. The results obtained with this approach are attractive, mainly when the objective is to execute simulations on environments which make conventional scheduling policies available, instead of specific policies. The evaluated case studies show satisfactory performance gains of up to $24 \%$ of reduction in execution time, $22 \%$ of improvement in efficiency and reduction of up to $79 \%$ in rollbacks. So, depending on the available time and the aimed objectives, it is worth using conventional techniques to assist distributed simulation partitioning. This work also contributes to the improvement of both tools used in it: Warped and AMIGO. A communication interface has been developed to integrate the tools, extending their capabilities. 



\section{Listas de Figuras}

Figura 2.1 Relação entre Evento, Processo e Atividade..................................................... 12

Figura 2.2 Ocorrência de Causa e Efeito. .............................................................................. 14

Figura 2.3 Chegada de uma mensagem com tempo menor que o do processo. ...................... 20

Figura 2.4 Etapas envolvidas quando uma mensagem atrasada é recebida......................... 22

Figura 2.5 Etapas envolvidas quando uma mensagem atrasada é recebida........................ 23

Figura 3.1 Arquitetura do ambiente AMIGO.................................................................. 40

Figura 3.2 Comunicação na camada inferior..................................................................... 42

Figura 3.3 Cabeçalho das mensagens trocadas na camada inferior.................................... 43

Figura 3.4 Utilização de um recurso no decorrer do tempo de uma simulação...................... 49

Figura 3.5 Modelos de filas, gráfico de interconexão, componentes fortemente acoplados e

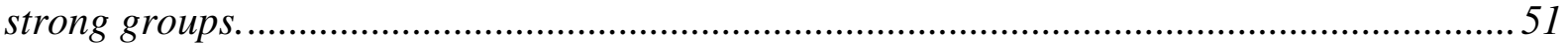

Figura 3.6 Estado dos processadores antes e depois de uma migração................................. 52

Figura 4.1 Diagrama de classes da interface com o AMIGO............................................ 72

Figura 4.2 Exemplo de um particionamento descentralizado............................................. 77

Figura 4.3 Exemplo de um particionamento centralizado................................................ 78

Figura 4.4 Fluxos dos particionamentos centralizado (a) e descentralizado (b)................... 79

Figura 4.5 Arquivo de configuração: escopo Partititioning................................................... 80

Figura 4.6 Arquivo com notas de benchmarks............................................................... 81

Figura 4.7 Organização dos objetos............................................................................ 83

Figura 4.8 Exemplo de uma saída com estatísticas da simulação.......................................... 89 



\section{Lista de Tabelas}

Tabela 4.1 Tabela de escolha do receptor da próxima mensagem. ..................................... 83

Tabela 5.1 Modelos que apresentam uma grande comunicação entre os objetos.................. 97

Tabela 5.2 Modelos que utilizam principalmente memória............................................... 98

Tabela 5.3 Modelos que efetuam muito processamento exigindo mais do recurso CPU....... 99

Tabela 5.4 Plataforma utilizada nos testes. ...................................................................... 100

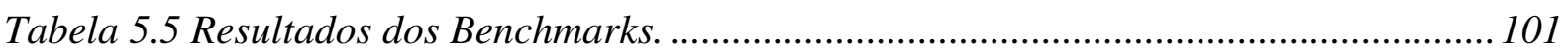

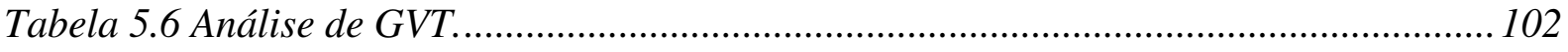

Tabela 5.7 Correlação entre variáveis - Correlação entre as variáveis GVT e tempo

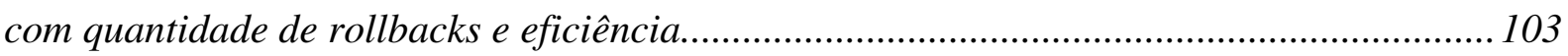

Tabela 5.8 Desvio padrão das médias para as execuções do modelo B com GVT 300......... 109

Tabela 5.9 Informações de três execuções de modelo P..................................................... 123

Tabela 5.10 Informações de execuções do modelo $\mathrm{G}$ em plataforma compartilhada/carga

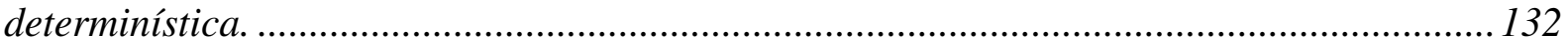

Tabela 5.11 Informações das execuções do modelo G na plataforma compartilhada com carga aleatória. 



\section{Lista de Gráficos}

Gráfico 5.1 Comportamento do tempo real com o aumento do GVT................................... 104

Gráfico 5.2 Comportamento da Eficiência com o aumento do GVT....................................... 105

Gráfico 5.3 Quantidade de Rollbacks ocorridas com o aumento do GVT............................ 105

Gráfico 5.4 Comportamento do tempo de 5, 10 e 15 execuções do modelo B...................... 107

Gráfico 5.5 Comportamento da eficiência de 5, 10 e 15 execuções do modelo B. ................ 108

Gráfico 5.6 Comportamento da quantidade de rollbacks ocorridas de 5, 10 e 15 execuções do

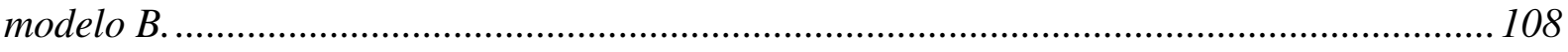

Gráfico 5.7 Comparativo do Tempo total de execução dos modelos do grupo Rede. ...........111

Gráfico 5.8 Comparativo da quantidade de rollbacks ocorridas durante a execução dos

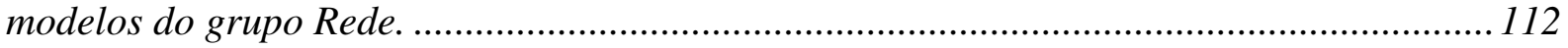

Gráfico 5.9 Comparativo da Eficiência final da execução dos modelos do grupo Rede....... 113

Gráfico 5.10 Comparativo do Tempo total de execução dos modelos do grupo memória....114

Gráfico 5.11 Comparativo da Quantidade de Rollbacks ocorridas durante a execução do

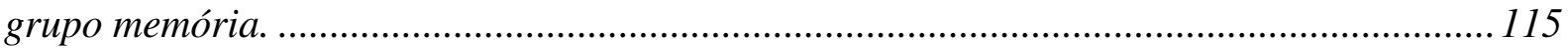

Gráfico 5.12 Comparativo da Eficiência final da execução do grupo memória. .................. 115

Gráfico 5.13 Tempo de execução de cada execução do “Modelo G”. .................................. 117

Gráfico 5.14 Quantidade de rollbacks de cada execução do "Modelo G”......................... 118

Gráfico 5.15 Eficiência de execuções do "Modelo $G$ ”....................................................... 118

Gráfico 5.16 Comparativo do Tempo total de execução do grupo сри. ............................... 119

Gráfico 5.17 Quantidade de rollbacks ocorridas no do grupo cpu. .................................... 120

Gráfico 5.18 Eficiência de execuções de cada modelo do grupo de CPU............................. 121

Gráfico 5.19 Tempo de execução do modelo P com diferentes benchmarks. ........................ 126

Gráfico 5.20 Quantidade de rollbacks ocorridos na execução do modelo P com diferentes

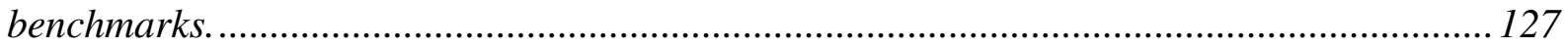

Gráfico 5.21 Eficiência obtida com a execução do modelo P com diferentes benchmarks... 128

Gráfico 5.22 Tempo de execução numa plataforma compartilhada com carga determinística.

Gráfico 5.23 Eficiência obtida numa plataforma compartilhada com carga determinística.134 
Gráfico 5.24 Quantidade de rollbacks ocorridos em plataforma compartilhada e com carga

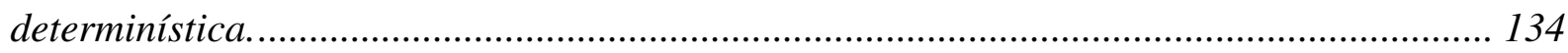

Gráfico 5.25 Tempo de execução numa plataforma compartilhada com carga aleatória.... 136 Gráfico 5.26 Eficiência obtida numa plataforma compartilhada com carga aleatória........ 137 Gráfico 5.27 Quantidade de rollbacks ocorridos numa plataforma compartilhada e com

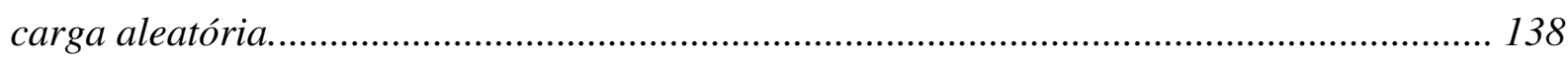




\section{Sumário}

CAPÍTULO 1 - INTRODUÇÃO .........................................................................................................

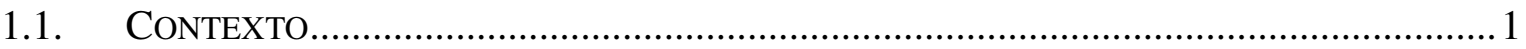

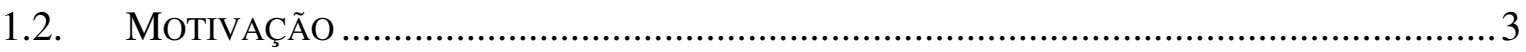

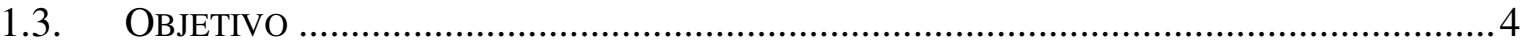

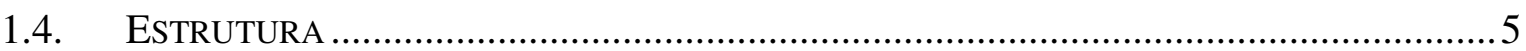

CAPÍTUlo 2 - SimulaÇão DistribuíDa ................................................................................

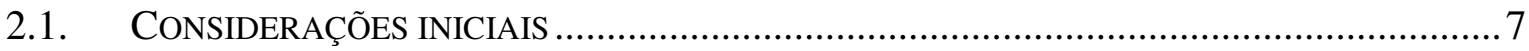

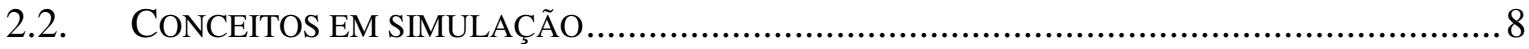

2.2.1. Componentes de uma simulação …………………..................................... 10

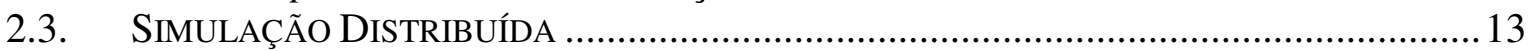

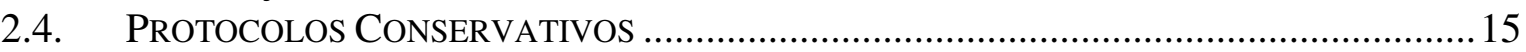

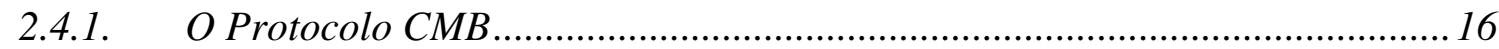

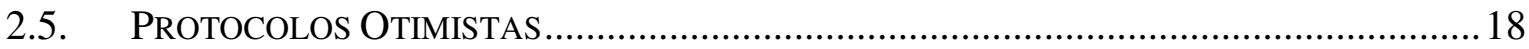

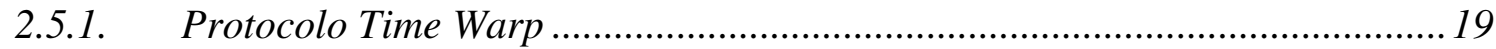

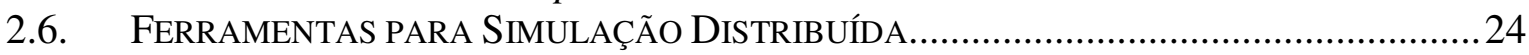

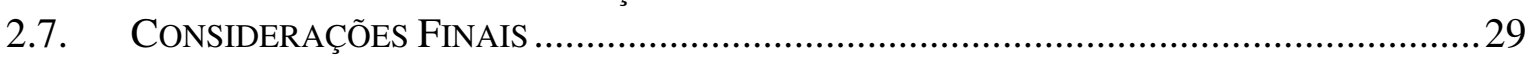

CAPÍTULO 3 - ESCALONAMENTO DE PROCESSOS …................................................................31

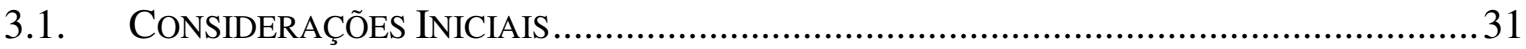

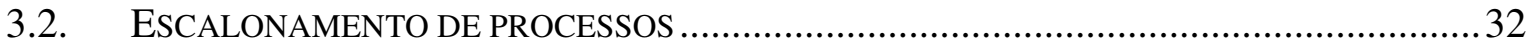

3.2.1. Terminologias......................................................................................... 33

3.3. AMIGO - DyNAMICAL FLEXIBLE SCHEDULING ENVIRONMENT ..............................38

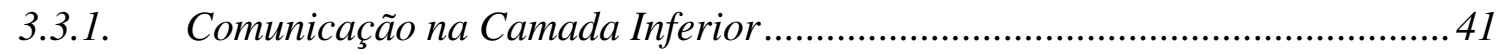

3.4. ESCALONAMENTO EM SIMULAÇÃo DistRIBUÍDA ………………………………........4

3.4.1. Falta de Balanceamento na Simulação Distribuída.........................................45

3.4.2. Algoritmos de Escalonamento e Balanceamento de Carga …...........................48

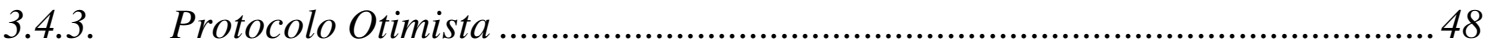

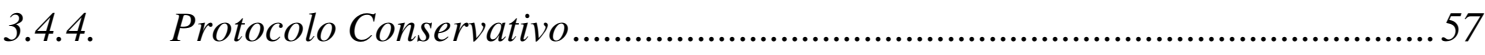

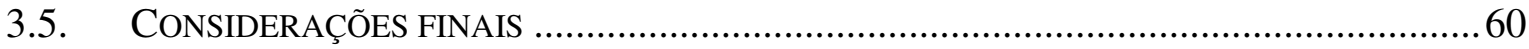

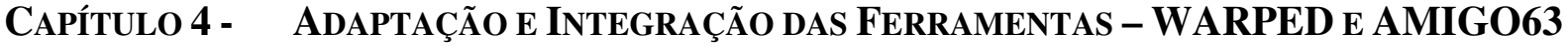

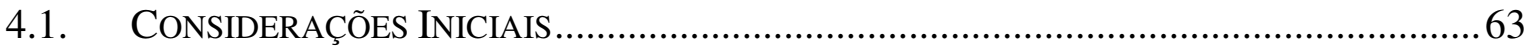

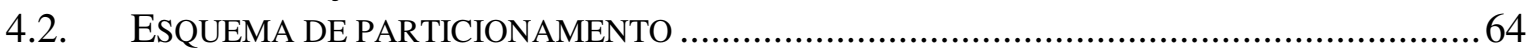

4.2.1. Avaliação da heterogeneidade ……………..............................................66

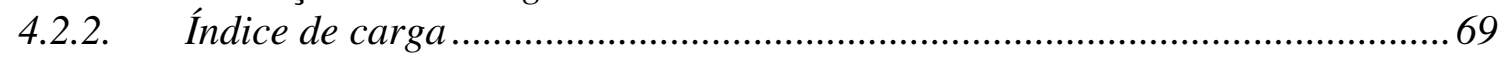

4.2.3. Algoritmo de particionamento.................................................................... 70

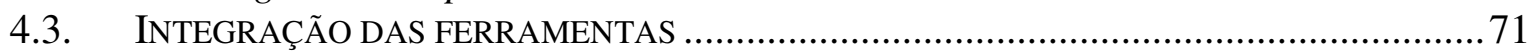

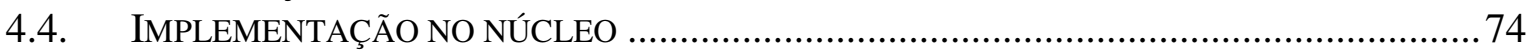

4.5. PARTICIONAMENTO CENTRALIZADO E DESCENTRALIZADO ……................................ 75

4.6. INFORMAÇÕES ADICIONADAS AO ARQUIVO DE CONFIGURAÇÃO...................................79 


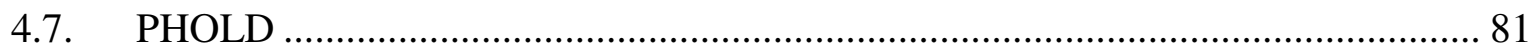

4.8. CORREÇÕES DE BUGS E OUTROS APERFEIÇOAMENTOS NO CÓDIGO DO WARPED ……. 85

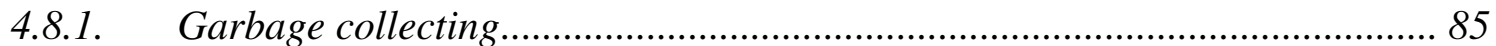

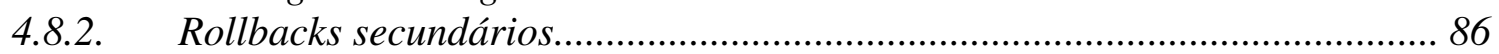

4.8.3. Desempenho do escalonamento dos objetos............................................... 87

4.8.4. Estatísticas da simulação.......................................................................... 88

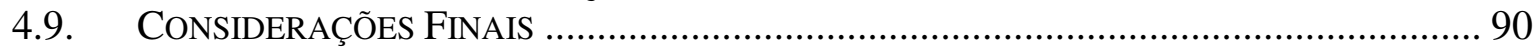

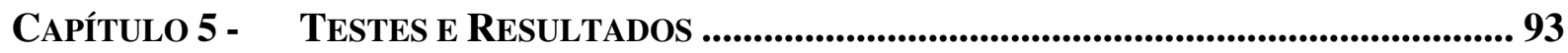

5.1. CONSIDERAÇÕES INICIAIS ............................................................................... 93

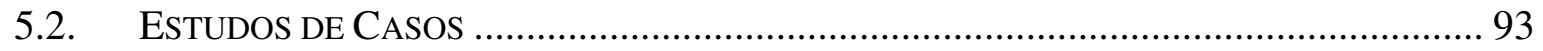

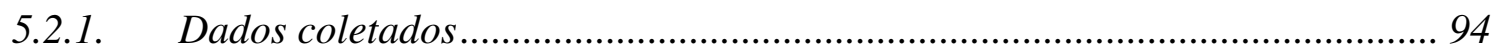

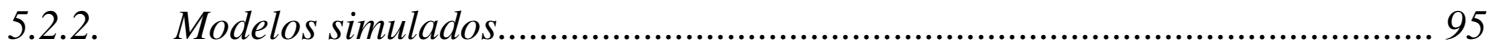

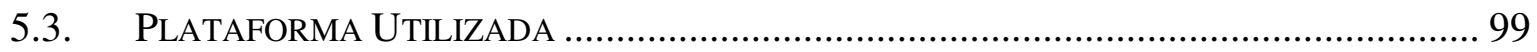

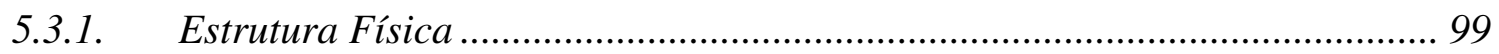

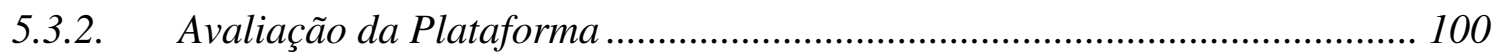

5.3.3. Definição do GVT (Tempo Virtual Global) ................................................. 101

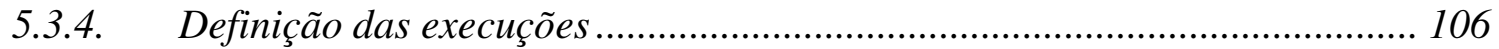

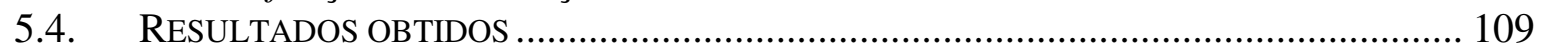

5.4.1. Ambiente heterogêneo e dedicado ............................................................... 110

5.4.2. Ambiente heterogêneo e compartilhado ..................................................... 128

5.5. CONSIDERAÇÕES FINAIS ................................................................................... 138

CAPÍTULO 6 - CONCLUSÕES ....................................................................................................... 140

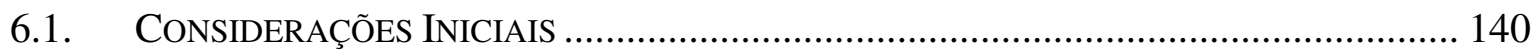

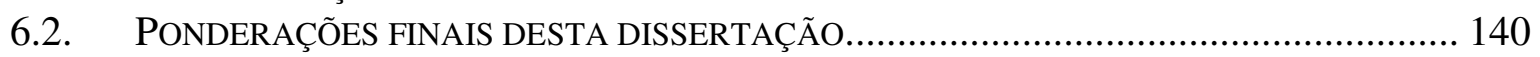

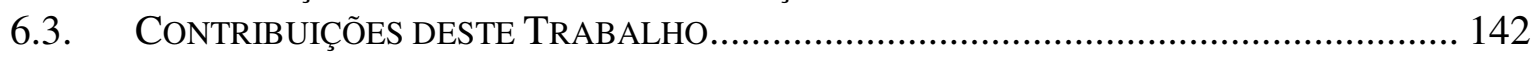

6.4. PROPOSTAS PARA TRABALHOS FUtUROS ........................................................ 145

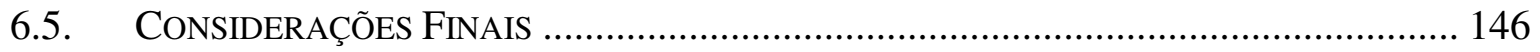

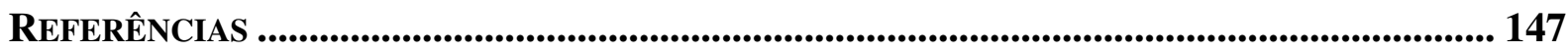

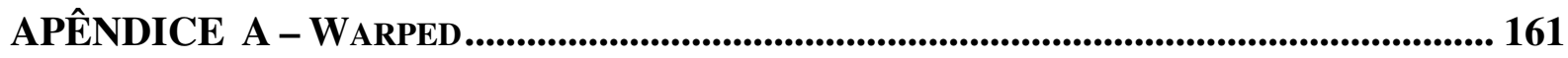

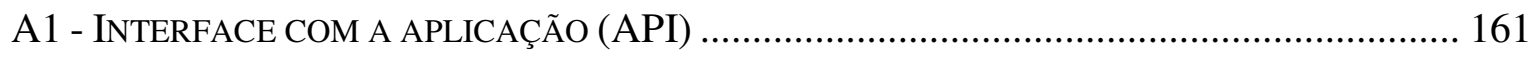

Al.1 - Classe Application..................................................................................... 162

A1.2 - Classe SimulationObject ………………………....................................... 163

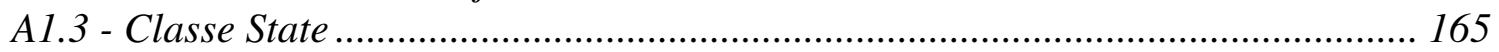

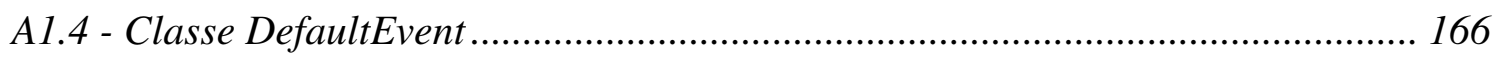

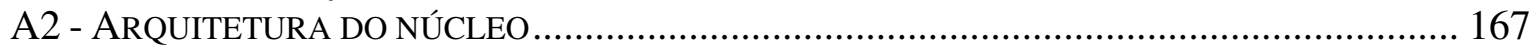

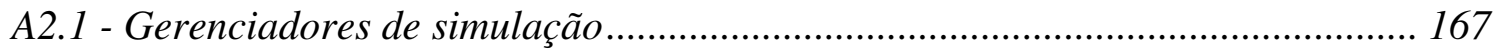

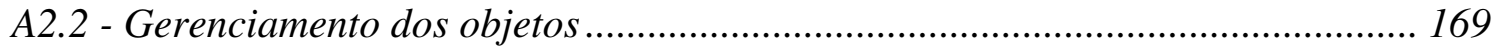

A2.3 - Escalonamento e listas de eventos ................................................................ 170

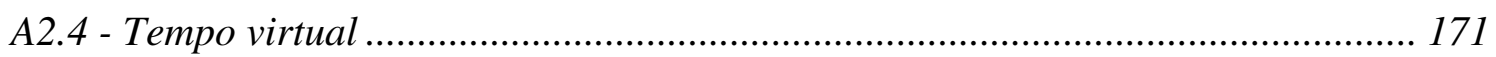

A2.5 - Salvamento de estados ............................................................................... 173

A2.6 - Particionamento dos objetos...................................................................... 173

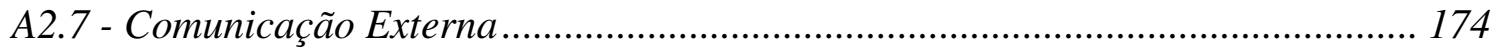

A3 - CONFIGURAÇÃ̃ AUTOMÁTICA DO SISTEMA ………………………………………... 175

A4 - EXEMPLO DE UM ARQUIVO DE CONFIGURAÇÃO DO WARPED ……………………….... 178

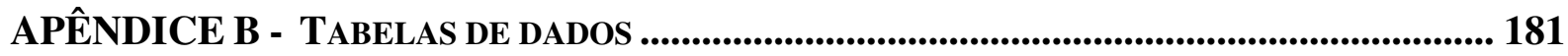




\section{Capítulo 1 - INTRODUÇ̃̃o}

\subsection{Contexto}

A complexidade dos sistemas computacionais modernos torna essencial a utilização de diferentes formas de avaliação de desempenho. Durante o projeto destes sistemas, é necessário o desenvolvimento de um modelo e sua solução de forma a obter uma validação inicial do projeto. A validação final do projeto pode ser realizada através da implementação de um protótipo do projeto proposto. Com a existência do protótipo ou do sistema real, pode-se optar por duas abordagens. A primeira é a obtenção de medidas do próprio sistema, utilizando-se monitores, para avaliações absolutas, ou benchmarks, quando se deseja comparar o sistema em questão com outros similares. A segunda abordagem é a modelagem deste sistema, que pode ser utilizada em sistemas existentes por diversas razões, dentre elas pode-se citar: quando o sistema não deve ser perturbado, quando se deseja avaliar soluções alternativas e quando se deseja avaliar características de difícil acesso através de medições.

Desta forma, a modelagem de sistemas computacionais pode ser utilizada tanto para avaliação de projetos como de sistemas em funcionamento. A utilização de modelos para avaliação de desempenho requer uma forma para a solução do modelo e obtenção de dados. A simulação tem sido largamente adotada devido a sua flexibilidade e baixo custo. No entanto, 
simulação apresenta algumas desvantagens, sendo a principal os altos tempos de simulação quando modelos complexos são considerados.

Com o objetivo de diminuir o tempo de processamento de uma simulação, duas abordagens foram propostas e têm sido estudadas: a SRIP (Single Replication in Parallel) (Jefferson, 1985; Misra, 1986; Fujimoto, 1990) e Múltiplas Replicações em Paralelo (MRIP - Multiple Replication in Parallel) (Heidelberger, 1988; Ewing et al., 1999). O que diferencia as abordagens SRIP e MRIP é o modo como o modelo será distribuído nos vários processadores disponíveis para a simulação.

Na abordagem SRIP, o sistema é particionado em processos lógicos e cada processo lógico é mapeado em um processador. Estes processos se comunicam através da troca de mensagens. Para garantir que os eventos sejam simulados na devida ordem, diversos protocolos de sincronização foram desenvolvidos, com o objetivo de sincronizar os tempos da simulação uma vez que a evolução de cada processo lógico depende dos eventos que podem ocorrer em outros processos lógicos.

Na abordagem MRIP o sistema não é particionado. Replicações independentes de um mesmo programa de simulação seqüencial são executadas em paralelo. Cada replicação envia seus resultados (variáveis estimadas) para um analisador global, onde as médias finais são calculadas. Quando a precisão requerida é atingida, a simulação é encerrada.

As duas abordagens citadas fazem uso dos benefícios de uma outra área que vem apresentando grandes avanços: a Computação Paralela, que tem como objetivo principal aumentar o desempenho, diminuindo o tempo para se obter um resultado (Almasi, 1994). Para se atingir o objetivo descrito acima é necessário o desenvolvimento de um programa paralelo eficiente e, principalmente, promover um escalonamento adequado para os diversos processos que deverão ser executados em paralelo. 
A computação paralela, antes restrita a domínios compostos de computadores específicos com processamento paralelo, em busca de melhor desempenho e uma melhor relação custo/benefício, tem sido constantemente empregada em sistemas computacionais distribuídos. Esse emprego permite associar as vantagens dos sistemas distribuídos com os objetivos da área de computação paralela.

O principal objetivo do escalonamento é distribuir serviços (processos, tarefas, threads, etc.) aos vários recursos de processamento (processadores, memória, discos, etc.) disponíveis. Esta atividade pode ser realizada de diferentes maneiras, dependendo da política de escalonamento adotada, a qual depende dos objetivos definidos.

Devido à importância do escalonamento em uma aplicação distribuída e sendo a simulação distribuída um tipo de aplicação distribuída, verifica-se a necessidade de se utilizar técnicas apropriadas para o escalonamento dos programas de simulação.

\subsection{Motivação}

Os algoritmos de escalonamento de processos de uso geral, que tem a função de mapear processos em processadores disponíveis, baseiam-se em informações sobre a plataforma e sobre as aplicações com o objetivo de maximizar a utilização dos recursos disponíveis.

A simulação distribuída também está sujeita a influência da plataforma e das características do modelo de simulação. Diversas técnicas podem ser encontradas na literatura da área (Carothers \& Fujimoto, 2000), que também baseiam suas decisões em informações relacionadas ao desempenho do sistema.

Diversos estudos sobre as abordagens de simulação distribuída, enfocando os protocolos utilizados, formas de implementação, etc. podem ser encontrados na literatura. Encontramse também estudos sobre a utilização de algoritmos para balanceamento de carga, específicos para simulação distribuída. Nesses algoritmos, alguns parâmetros específicos da simulação 
distribuída são utilizados visando melhorar o escalonamento inicial ou a migração dos processos. Apesar dos bons resultados obtidos com esses algoritmos, tem-se o problema da falta de flexibilidade, pois eles são específicos para simulação distribuída e, normalmente, não estão disponíveis em sistemas de uso geral.

Alguns estudos afirmam que os algoritmos de uso geral são insuficientes (Boukerche \& Das, 1997). Contudo, não há na literatura estudos comparativos entre estes tipos de algoritmos. Todos os trabalhos a que se teve acesso e que avaliam a utilização de algoritmos de escalonamento para simulação distribuída apresentam comparações entre as simulações sem algoritmos de escalonamento e com algoritmos específicos. Não foram encontrados trabalhos que demonstrem o desempenho das simulações com escalonamento convencional.

\subsection{Objetivo}

O objetivo deste trabalho é avaliar o quanto se estaria ganhando e o quanto se estaria perdendo se um algoritmo de escalonamento não específico, de simulação distribuída, fosse utilizado. A grande vantagem na utilização deste tipo de escalonamento não específico é a existência desta ferramenta em diversos sistemas distribuídos. Para alcançar este objetivo as seguintes fases devem ser consideradas:

- Investigação e análise de ferramentas para auxílio da execução da simulação e escalonamento;

- Adaptação das ferramentas para utilização;

- Escolha e implementação de modelos de simulação;

- Escolha de políticas de escalonamento de processos convencionais já implementadas; 
- Avaliação do desempenho das políticas para cada tipo de simulação distribuída;

- Comparação da avaliação de desempenho das políticas, considerando a execução do programa sem a política de escalonamento e com a política de escalonamento.

\subsection{Estrutura}

Esta dissertação está organizada visando fornecer a base necessária para contextualizar o trabalho e discutir os diversos aspectos que envolveram o seu desenvolvimento, e por fim, apresentar os resultados obtidos com relação ao desempenho das políticas convencionais. Dessa forma, os textos dos próximos capítulos estão organizados da seguinte maneira:

O capítulo 2 discorre sobre a área de simulação, abordando conceitos principais, a simulação distribuída e os protocolos de sincronização conservativos e otimistas. Neste capítulo também são comentadas as diversas ferramentas de simulação existentes.

O capítulo 3 apresenta uma revisão sobre escalonamento de processos, com pontos específicos sobre o assunto, como conceitos básicos, problemas com as diferenças de denominações na área, e ainda questões sobre algoritmos de escalonamento. A ferramenta de escalonamento $A M I G O$ é apresentada, e ainda são abordados estudos relativos ao escalonamento de processos em simulação distribuída, apresentando alguns trabalhos de pesquisa encontrados na literatura.

O capítulo 4 demonstra o trabalho que foi realizado para se fazer a integração das ferramentas escolhidas: WARPED e AMIGO. Neste capítulo também é apresentado o modelo implementado para a realização dos testes.

O capítulo 5 apresenta as políticas utilizadas, os testes realizados e uma análise sobre os resultados. 
Finalizando, o capitulo 6 apresenta as conclusões, contribuições do trabalho e ainda proposta de trabalhos futuros.

O apêndice A é o resultado do esforço dispensado para se entender e trabalhar com a ferramenta de simulação WARPED, escolhida para auxiliar no desenvolvimento deste trabalho.

O apêndice B apresenta os dados coletados durante a realização dos testes, dos quais os gráficos apresentados no capítulo 5 foram gerados. 


\section{Capítulo 2 - SimULAÇÃo DistribUídA}

\subsection{Considerações iniciais}

A simulação é uma técnica de avaliação muito usada em casos onde uma solução analítica se mostra muitas vezes complexa e intratável. E ainda, se apresenta de forma atraente por reduzir custos de projeto e desenvolvimento quando sistemas complexos são considerados. A execução de uma simulação seqüencial pode levar muito tempo, isso faz aumentar o interesse pela utilização da simulação distribuída.

Simulação é a imitação da operação de um processo do mundo real, sendo indispensável em 'metodologias de soluções de problemas', quando problemas do mundo real são considerados. É usada para descrever e analisar o comportamento de um sistema, ajudando a responder questões do tipo "O que acontecerá se...?", e ainda auxiliando o desenvolvimento de sistemas reais (Banks, 1998).

Tanto os sistemas existentes quanto os projetos de sistemas podem ser modelados com a simulação. Essa técnica tem sido amplamente empregada em várias áreas do conhecimento, como a medicina, devido ao grau de realismo que pode ser obtido de seus modelos, e também, a facilidade com a qual tais modelos podem ser apresentados para pessoas que não possuem domínio técnico (Hoover \& Perry, 1990). 
$\mathrm{Na}$ análise de desempenho de sistemas computacionais, a simulação é uma técnica bastante útil, pois, provê uma maneira adequada de predizer o desempenho ou comparar várias alternativas, variedades de cargas e ambientes, de um sistema.

Uma simulação realista, todavia, requer grande esforço computacional e o tempo de processamento necessário, muitas vezes, inviabiliza a simulação. Este cenário tem mudado com o uso de supercomputadores e de ambientes formados por processadores com grande capacidade de comunicação, onde o paralelismo pode ser explorado. Nesse caso, as técnicas de simulação devem ser adaptadas e a maneira tradicional e seqüencial deve ser substituída por técnicas de simulação distribuída que exploram convenientemente o paralelismo.

Este capítulo apresenta as principais questões sobre simulação distribuída, seus principais protocolos de sincronização, utilizados no desenvolvimento de programas de simulação distribuída, e ainda algumas ferramentas existentes para simulação.

\subsection{Conceitos em simulação}

A simulação distribuída se refere à distribuição da execução de um simples programa de simulação através de múltiplos processadores. Usualmente o termo simulação distribuída é aplicado para referir-se a uma simulação distribuída geograficamente. Enquanto que, simulação paralela tradicionalmente se refere à simulação executada em computadores paralelos fortemente acoplados. Porém, com outros paradigmas tais como, clusters de workstation e computação em grade esta distinção ficou menos clara. Neste trabalho o termo simulação distribuída será usado para se referenciar a todas as categorias de execução distribuída.

Simulação é a arte e a ciência de criar a representação de um sistema com o objetivo de realizar experimentos e avaliar seu desempenho (Gogf \& Mott, 1995). É uma experiência ou ensaio realizado com o auxílio de modelos. A simulação considera a execução de modelos 
que por sua vez representam as características do comportamento de um sistema físico real ou teórico.

Diversas são as definições de modelo encontradas na literatura (Bratley, 1987; Mchaney, 1991; Naim, 1995; Shannon, 1975), apesar de algumas delas serem muito restritivas, abordando apenas alguns aspectos ou tipos.

Modelo é uma descrição do sistema, sendo que para cada problema específico existe um modelo apropriado. Deste modo, pode-se ter várias descrições para o mesmo sistema, cada qual para a resolução de um problema particular. Modelos requerem uma técnica para sua representação e podem ser classificados baseando-se em diferentes características. Após a definição dos modelos, eles devem ser resolvidos utilizando-se algumas abordagens, como por exemplo, a simulação. Após gerar e compilar um programa de simulação, a descrição do sistema é traduzida em uma forma aceitável por um sistema de computação. O computador é então utilizado para exercitar o modelo de modo a produzir saídas que podem ser analisadas (Soares, 1990).

Ao criar um modelo, uma das tarefas mais difíceis que o modelador enfrenta é abstrair quais características são essenciais, e estabelecer uma relação entre elas. Para tomar esta decisão, deve estar bem definido qual o propósito do modelo e o que se espera obter dele.

Sistema pode ser descrito como uma coleção de itens, entre os quais se podem encontrar ou definir alguma relação, que são objetos de estudo ou interesse. Definido que modelo é uma descrição do sistema, pode-se acrescentar que modelo é uma abstração do sistema.

O estado de um sistema é definido por um conjunto de variáveis que contém todas as informações necessárias para descrever o sistema em qualquer tempo. A base para a classificação dos modelos são as alterações que ocorrem nas variáveis de estado do sistema e, em um grande número de simulações, o tempo é a principal variável independente. As demais variáveis incluídas na simulação são funções do tempo e portanto, variáveis dependentes. 
Fujimoto (1993) denomina a execução de um programa de simulação em uma máquina contendo várias unidades centrais de processamento de concurrent discrete event simulation (ou simplesmente simulação concorrente). Isso inclui execução em multiprocessadores fortemente acoplados (simulação paralela) e ambientes computacionais distribuídos (simulação distribuída). Alguns autores utilizam, de forma genérica, a sigla PDES (Parallel Discrete Event Simulation) (Fujimoto, 1990), enquanto outros utilizam a sigla DDES (Distributed Discrete Event Simulation) (Vries, 1990; Chiola \& Ferscha, 1993; Djemame et al., 1996). Ainda com relação à nomenclatura, Poplawski \& Nicol (1998) descreve um sistema de simulação paralela orientado a processo (mapeados em uma implementação Time Warp).

Uma variedade muito grande de sistemas, nas mais diversas e variadas áreas, ciências físicas, sociais, biológicas e econômicas, se utiliza da simulação com muita freqüência. As situações principais que justificam a utilização da simulação são (Gogf \& Mott, 1995; Maryansky, 1980):

- Como uma ferramenta para estudar e para definir um problema;

- Para a detecção de elementos críticos;

- Para a síntese e avaliação de soluções propostas; e

- Para o planejamento de desenvolvimentos futuros.

\subsubsection{Componentes de uma simulação}

Na modelagem para simulação há algumas características que constituem seus principais componentes. Esses componentes são:

- Entidades: significam os objetos que podem ser individualmente identificados e processados. Cada entidade possui características próprias. 
- Atividade: representa a menor unidade de trabalho no sistema, porém depende da visão particular que se tenha do mesmo. Uma atividade pode ser a execução de um passo de uma instrução ou a execução de uma tarefa em uma simulação macroscópica de um sistema computacional.

- Eventos: representam à mudança de estado de alguma entidade do sistema. O término de uma atividade é um evento cuja ocorrência pode iniciar outras atividades subseqüentes. Tais eventos controlam a seqüência de atividades dentro de um processo.

- Estado: indica características do sistema em um determinado instante de tempo.

- Relógio da simulação: constitui a variável que contém o valor do tempo simulado.

- Filas de Eventos: são estruturas usadas para modelar a espera de clientes (ou transações) por um tratamento, cuja taxa de chegada é superior à da capacidade de atendimento.

Um evento ocorre em um ponto isolado no tempo, no qual decisões devem ser tomadas para iniciar ou encerrar uma atividade. Um processo é então uma sequiência ordenada de eventos, podendo englobar várias atividades (Soares, 1992).

Um modelo de simulação discreta pode ser visto como uma coleção de processos interativos, cada processo composto por diversas atividades e com as interações controladas e coordenadas pela ocorrência de eventos (MacDougall, 1987). A relação entre os conceitos pode ser observada na figura 2.1 (Soares, 1992). 


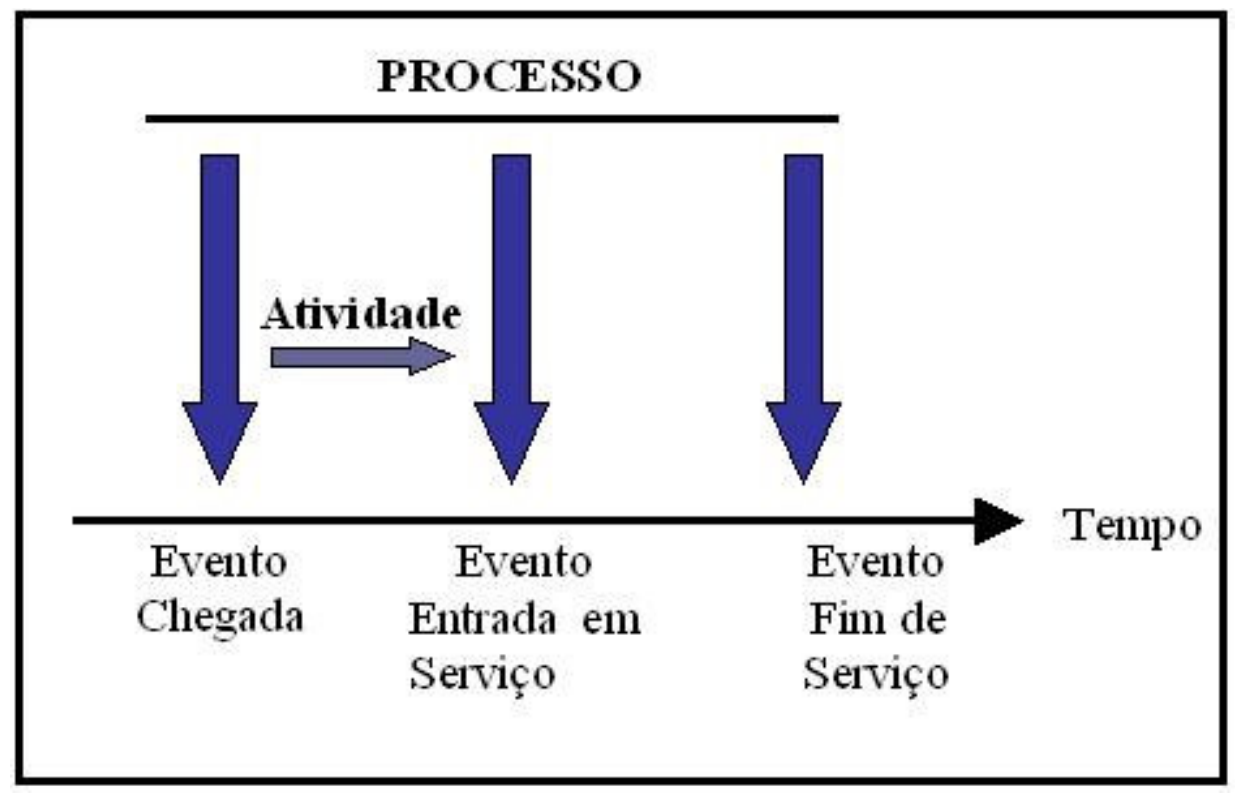

Figura 2.1 Relação entre Evento, Processo e Atividade.

Em simulação discreta, atividades, processos e eventos são construções utilizadas para descrever o seu comportamento. Desta forma, a elaboração de um modelo para simulação discreta pode ser realizada de três formas, de acordo como o sistema é visto:

- Simulação orientada a eventos: a simulação do sistema é produzida pela execução da lógica associada a cada evento, em uma seqüência ordenada no tempo;

- Simulação orientada a atividades: conforme o tempo simulado avança, as condições para o início ou fim de uma atividade são verificadas. A cada avanço no tempo, todo o conjunto de atividades é examinado para garantir que cada atividade seja levada em consideração;

- Simulação orientada a processos: nesta abordagem o processo é utilizado para definir a estrutura e a atividade de um componente do sistema sendo modelado, existindo então uma grande correspondência entre o sistema real e o modelo. 


\subsection{Simulação Distribuída}

A idéia de simulação distribuída foi proposta por Chandy em 1977 em uma série de conferências na Universidade de Waterloo, e por R. E. Bryant (1977) independentemente, e continua se desenvolvendo muito nas últimas décadas (Misra, 1986; Nicol \& Fujimoto, 1994).

A possibilidade de diminuição do tempo de execução da simulação (speedup), e a grande quantidade de capacidade computacional disponível em uma arquitetura distribuída, viabilizando a simulação de modelos mais robustos, são o grande incentivo para a utilização da simulação distribuída (Low et al., 1999).

A simulação distribuída faz uso principalmente de duas arquiteturas: a cliente-servidor e a peer-to-peer. A primeira como o nome mesmo já diz é formada por um ou mais computadores (como diversos computadores ligados numa rede local) a que clientes (usuários) podem se conectar através de um login. A segunda é formada também por tais servidores, e a simulação é distribuída através de muitas máquinas que podem estar interconectadas por uma grande rede (Fujimoto, 2003).

Como exemplos de aplicações que estão se beneficiando com o uso de simulação distribuída, podem-se citar a simulação de redes de telecomunicações e redes de longa distância, circuitos digitais, sistemas computacionais (Fujimoto, 2003; Jones \& Das, 2000; Simmonds et al., 2000), sistemas de produção (Zhang et al., 2000), e outros.

Na simulação distribuída o sistema a ser simulado é decomposto em um conjunto de $n$ subsistemas ou $n$ processos lógicos $P L_{0}, P L_{1}, \ldots, P L_{n}$, cada um representando um processo do sistema real. Cada processo lógico possui um relógio que indica o progresso da simulação. Quando um evento é processado, o relógio do processo é automaticamente avançado para o timestamp desse evento. Toda a interação entre os processos físicos é modelada através de mensagens de eventos contendo um timestamp, enviadas entre os correspondentes processos 
lógicos por canais de comunicação. Cada processo lógico contém uma parte do estado correspondente ao processo físico que modela, além de um relógio local, e um conjunto de variáveis de estado que não são compartilhadas entre os mesmos (Fujimoto, 2000).

Uma simulação constituída de processos lógicos que interagem por via de troca de mensagens (com timestamp) obedece ao relacionamento de causa e efeito se e somente se cada processo lógico executa os eventos em ordem crescente do timestamp (Overeinder et al., 1991).

Considere como exemplo, dois processos, $P L_{1}$ que executa o evento $E_{1}$ com timestamp 10 e o processo $P L_{2}$ que executa o evento $E_{2}$ com timestamp 20 (figura 2.2(a)). Se $E_{1}$ escalona um novo evento $E_{3}$ para execução em $P L_{2}$ com timestamp menor do que $20, E_{3}$ pode afetar o evento $E_{2}$, o que implica na necessidade de execução seqüencial dos três eventos (figura 2.2(b)) (Overeinder et al., 1991).

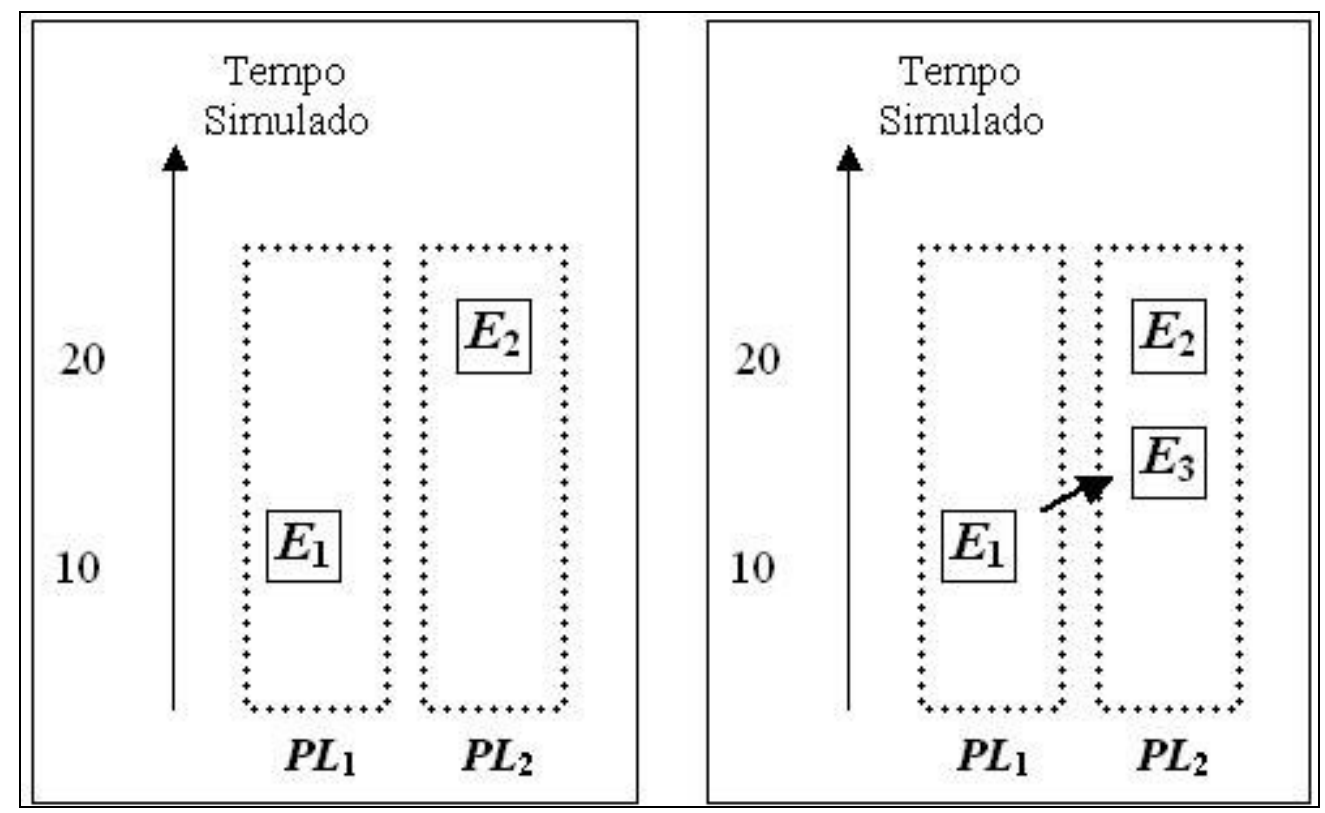

(a)

Figura 2.2 Ocorrência de Causa e Efeito.

(b)

A principal questão relacionada com a simulação distribuída refere-se à necessidade de sincronização entre os processos que a constituem, para se preservar a ordem de causa e efeito, e para isso são necessários protocolos que sincronizem os tempos de simulação dos pro- 
cessos lógicos. Utilizam-se dois tipos básicos de protocolos, os otimistas e os conservativos, a partir dos quais muitas variantes têm sido propostas. Os dois tipos citados serão apresentados nas seções seguintes.

\subsection{Protocolos Conservativos}

Os protocolos conservativos evitam a possibilidade da ocorrência de erros de causa e efeito, ou seja, sua preocupação está em determinar quando é seguro processar um evento. Nessas simulações, um processo lógico só tratará um evento se puder garantir que não chegará um outro com timestamp menor do que a do evento a ser tratado (Srinivasan \& Reynolds, 1995).

Os primeiros protocolos de simulação distribuída foram baseados em abordagens conservativas. Esses protocolos, desenvolvidos independentemente por Chandy e Misra (1979) e Bryant (1977) (por isso a denominação CMB (seção 2.4.1)), exigiam que a especificação dos canais que indicam a comunicação entre os processos fosse feita estaticamente e também que as mensagens chegassem em cada canal em ordem de timestamp. Garantindo-se que essas marcas de mensagens enviadas em um canal seja crescente é possível determinar quando é seguro executar um evento.

Um problema básico neste protocolo ocorre quando cada processo lógico se bloqueia, esperando indefinidamente por uma mensagem no canal de entrada que contém o menor valor de relógio, levando a simulação a um estado de deadlock.

O tratamento de deadlock é um dos principais enfoques dos vários protocolos conservativos existentes, os quais diferem basicamente quanto à forma desse tratamento. Alguns protocolos previnem o deadlock, enquanto outros permitem que a simulação entre em deadlock para depois detectá-lo e utilizam algum mecanismo para se recuperar (Fujimoto, 1990). 
Um conceito que deve ser abordado quando se trata de protocolos conservativos é o de “Lookahead", que desde que foi introduzido (Chandy \& Misra, 1979) tem sido interpretado de diferentes maneiras. Misra (1986) define lookahead como sendo o intervalo de tempo em que um processo pode inferir o futuro com absoluta certeza. Já Fujimoto (1990) define lookahead como a capacidade do processo em prever o que acontecerá, ou mais importante, o que não acontecerá, no tempo de simulação futuro. Se um processo no tempo de simulação $T$ pode prever com segurança todos os eventos que ele poderá gerar até o tempo de simulação $T+L$, pode se dizer que o processo tem lookahead $L$.

Lookahead não é um protocolo de simulação distribuída, mas uma técnica fundamental da qual os protocolos conservativos fazem uso. Diferentes modelos de simulação apresentam capacidade de lookahead distintos (Turner, 1998).

Muitos trabalhos apresentam pesquisas sobre o impacto do lookahead no desempenho de simulações distribuídas que utilizam protocolos conservativos (Cota \& Sargent, 1989; Fujimoto \& Nicol, 1992; Meyer \& Bagrodia, 1999; Preiss \& Loucks, 1990; Tatsumi, 2002).

\subsubsection{O Protocolo CMB}

No protocolo básico de sincronização CMB cada processo na simulação é forçado a conhecer quais outros processos interagem com ele próprio. Uma característica importante é que os pares de processos sempre interagem em tempos crescentes. Em outras palavras, se um processo $A$ interage com um processo $B$, mensagens de $A$ para $B$ são sempre geradas (e recebidas) em tempos com valores crescentes.

Existem muitas variantes para o protocolo CMB. Na sua forma básica, cada processo recebe suas mensagens em portas (entradas) separadas, considerando-se uma porta para cada processo. Cada processo deverá processar a mensagem que possuir o menor tempo de ocorrência entre todas as mensagens armazenadas em suas entradas. Quando um processo possuir 
uma ou mais entradas vazias, ele não poderá processar seguramente nenhum de seus eventos, pois não poderá prever a chegada de mensagens defasadas. Portanto, o processo ficará bloqueado esperando alguma mensagem chegar (Fujimoto, 1990).

O protocolo CMB evita que a simulação entre em deadlock através da utilização do conceito de mensagens nulas (Misra, 1986). Estas mensagens são utilizadas para atualizar os tempos nas filas de entradas dos processos.

As mensagens nulas são enviadas para os processos com os quais o processo em execução mantém comunicação. Estas mensagens são utilizadas apenas com o propósito de sincronização, ou seja, não correspondem a atividades do sistema físico. Uma mensagem nula com timestamp $t$, enviada por $P L_{\mathrm{i}}$ para um $P L_{\mathrm{j}}$, indica que $P L_{\mathrm{i}}$ não enviará mensagens a $P L_{\mathrm{j}}$ entre o valor corrente do relógio e o tempo $t$. Com o processo lógico recebendo os timestamps atualizados dos outros processos com quem mantém comunicação, ele saberá até que ponto é seguro continuar sua execução ou não.

Uma desvantagem do protocolo CMB consiste na sobrecarga provocada pelas mensagens nulas. Uma variação desta abordagem consiste em enviar mensagens nulas sob demanda e não após o processamento de cada evento (Chandy \& Misra, 1981). A freqüência dessa demanda pode ser dada por um timeout ou quando o menor relógio de todos os canais for o de uma fila vazia, indicando que o processo lógico está parado. Quando isso ocorre, a próxima mensagem é requisitada (nula ou não) do processo que envia para esse canal, e o processo lógico continua sua execução quando a resposta a esse pedido for recebida.

No entanto, pode ocorrer, por exemplo, do $P L_{1}$ fazer uma solicitação de avanço do relógio a $P L_{2}$, porém antes de $P L_{2}$ enviar uma mensagem de resposta ao processo $P L_{1}$ ele também necessitará fazer uma solicitação a outro $P L_{\mathrm{i}}$. Esta situação, de propagação de pedidos de avanço do relógio, pode formar um ciclo, gerando uma situação de deadlock. 
Segundo Misra (1986) a resolução do deadlock é difícil e pode ser efetuada determinando-se o mínimo dos próximos tempos de eventos. Para cada processo no conjunto de processos em deadlock, o tempo em que uma mensagem será enviada, contando que nenhuma mensagem posterior seja recebida até então, é determinado e o valor do relógio do processo com o menor relógio é avançado para esse tempo.

Segundo Fujimoto (1990) a maior desvantagem dos mecanismos conservativos consiste no fato de que estes não podem explorar totalmente o paralelismo disponível na aplicação. Considera-se, no pior caso, a abordagem conservativa pessimista, pois acaba algumas vezes forçando a abordagem seqüencial quando não é necessária.

Como vantagens, em comparação com os protocolos otimistas descritos a seguir, pode-se citar: consumo de memória moderado, implementação ‘simples' de estruturas de dados e controles, e somente eventos ‘seguros’ são processados.

\subsection{Protocolos Otimistas}

As abordagens otimistas utilizam algoritmos que permitem o progresso da simulação até onde for possível e, então, quando uma violação de causa e efeito ocorrer, utilizam um mecanismo de rollback para recuperar os estados dos processos lógicos para um estado consistente (Fujimoto, 2000). Esta recuperação pode ser feita de duas maneiras: através do Salvamento de Estados ou com utilização de Computação Reversa. Na primeira é feita a recuperação do estado da simulação para o último estado consistente salvo. Já a segunda é realizada a execução de operações inversas relativas às operações individuais que foram efetuadas durante a execução de um evento.

Este método tem por vantagens apresentar speedup potencialmente maior que os métodos conservativos, pois permite a exploração do paralelismo em situações onde erros de causa e efeito podem ocorrer, mas de fato não ocorrem. Além disso, a topologia das possíveis 
interações entre os processos não precisa ser previamente conhecida, já que permite a criação dinâmica de processos lógicos (Fujimoto, 1990).

O protocolo otimista mais conhecido, que será apresentado a seguir, é o Time Warp. E assim como o protocolo conservativo $\mathrm{CMB}$ vem sendo discutido amplamente na literatura nos últimos anos. Porém um consenso entre qual dos dois apresenta melhor desempenho não existe e por este motivo, muitas pesquisas são dedicadas para desenvolver protocolos que busquem explorar as vantagens que ambos apresentam. As soluções são baseadas em inserir características conservativas em protocolos puramente otimistas, ou então tornar um protocolo conservativo mais otimista. Assim tem-se, protocolos que utilizam uma forma de otimismo controlado, aproveitando as vantagens da abordagem otimista, como a exploração do paralelismo, sem ser afetado pelas sobrecargas de rollbacks e consumo de memória (Lobato et al., 2004).

\subsubsection{Protocolo Time Warp}

O Time Warp básico é o protocolo de simulação distribuída otimista mais difundido (Fujimoto, 2000) e tem como base o paradigma de Virtual Time proposto por Jefferson (1985), apresentando dois componentes principais: o mecanismo de controle local, e o mecanismo de controle global que serão discutidos posteriormente.

Um processo lógico na abordagem Time Warp é formado basicamente pelas seguintes estruturas: LVT (Local Virtual Time) que determina o relógio do processo é definido como o tempo de ocorrência do último evento processado; Lista de entrada de mensagens que armazena, em ordem crescente do timestamp, todas as mensagens recebidas (mensagens positivas) pelo processo; Lista de saída de mensagens armazena todas as mensagens enviadas (mensagens negativas / antimensagens) pelo processo, essa lista será utilizada em caso de 
rollback; e lista de estados que armazena cópia dos estados do processo, que são salvos periodicamente para viabilizar o rollback (Schof, 1998).

Como em qualquer protocolo otimista, no Time Warp os eventos são processados continuamente até que uma mensagem com tempo defasado chegue ao processo. Normalmente as implementações do Time Warp possuem mecanismos para gerenciamento dos eventos e infraestrutura que garantem o mecanismo de rollback para cada processo lógico. Quando um processo recebe uma mensagem com seu tempo no passado, a simulação é retornada para o último estado consistente antes da chegada desta mensagem. Um exemplo disto é ilustrado na figura 2.3.

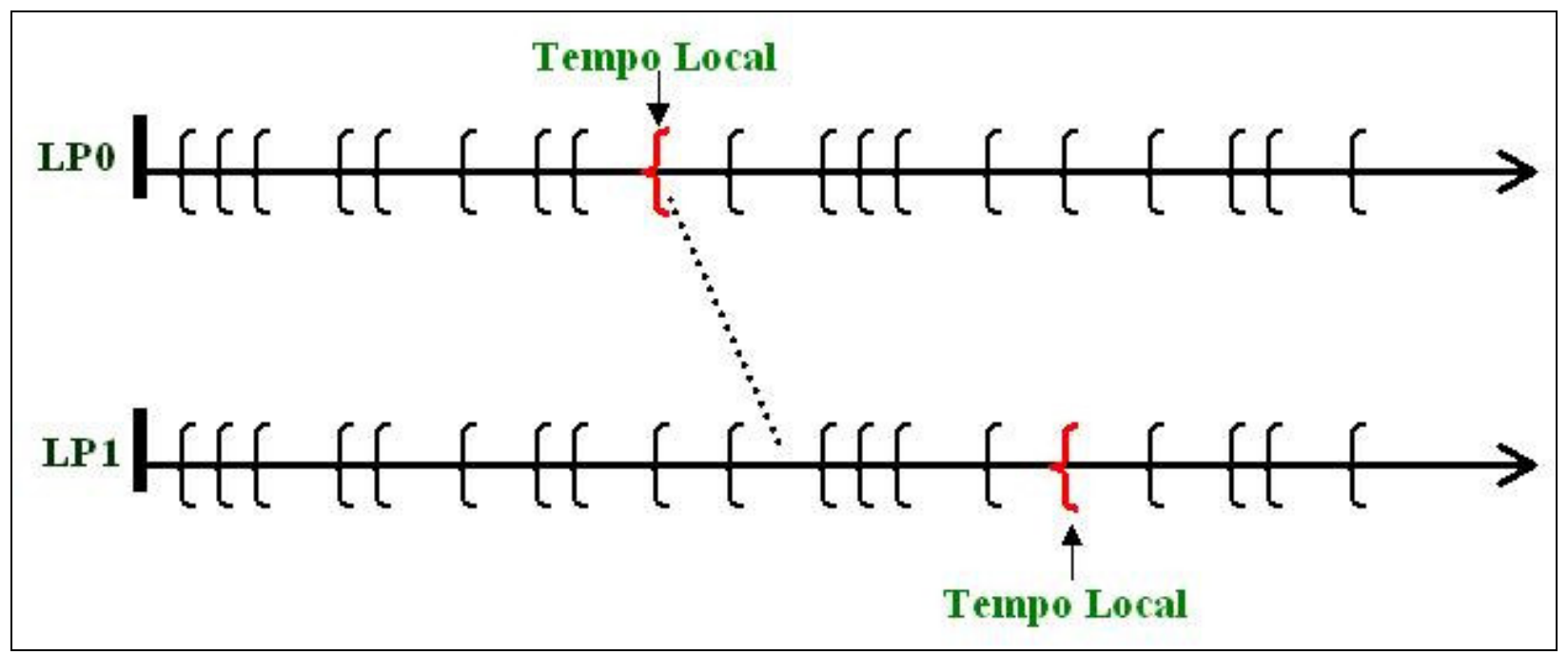

Figura 2.3 Chegada de uma mensagem com tempo menor que o do processo.

O mecanismo de controle global é responsável pelo gerenciamento de memória e detecção do fim da simulação. Neste caso, tem-se o Global Virtual Time (GVT), que é o valor correspondente ao menor valor calculado entre todos os LVTs da simulação, e todos os timestamps de mensagens enviadas, que estão em transito. Com o valor do $G V T$ calculado, todas as informações registradas com timestamp inferior ao seu podem ser descartadas (Hagenauer, 1999). 
Existem diferentes formas para o cálculo do GVT. Na abordagem centralizada o cálculo é de responsabilidade de um processo lógico (software) ou hardware específico. Esta abordagem tem a vantagem de influenciar pouco o desempenho da simulação, porém o custo e a complexidade são maiores. Outra abordagem é a distribuída, onde o trabalho de cálculo do GVT é distribuído por todos os processos lógicos. Esta forma pode ser aplicada de maneira local, onde cada processo lógico calcula o seu GVT e depois compara com os demais, sendo o menor deles o valor final. A abordagem distribuída pode ainda ser aplicada de forma global onde um único valor é cálculo considerando-se todos os processos lógicos (Lobato et al., 2004).

Quando um evento é processado ele pode gerar novos eventos, que serão escalonados através do envio de mensagens. Se um evento é retornado, o processo da simulação deve ser reiniciado com seus valores originais, e qualquer mensagem gerada deve ser cancelada com o envio de suas correspondentes antimensagens. Esta situação pode acarretar numa explosão em cascata de antimensagens.

O mecanismo de controle local do Time Warp é o responsável pela execução dos eventos da simulação na ordem correta do timestamp desses eventos. O otimismo do protocolo consiste em permitir que os processos lógicos executem os eventos até a ocorrência de algum erro de causa e efeito, verificando quando o processo recebe uma mensagem com timestamp menor que o $L V T$ do processo. Esta mensagem que causou o erro de causa e efeito é denominada de straggler (figura 2.4) (Fujimoto, 2000). 


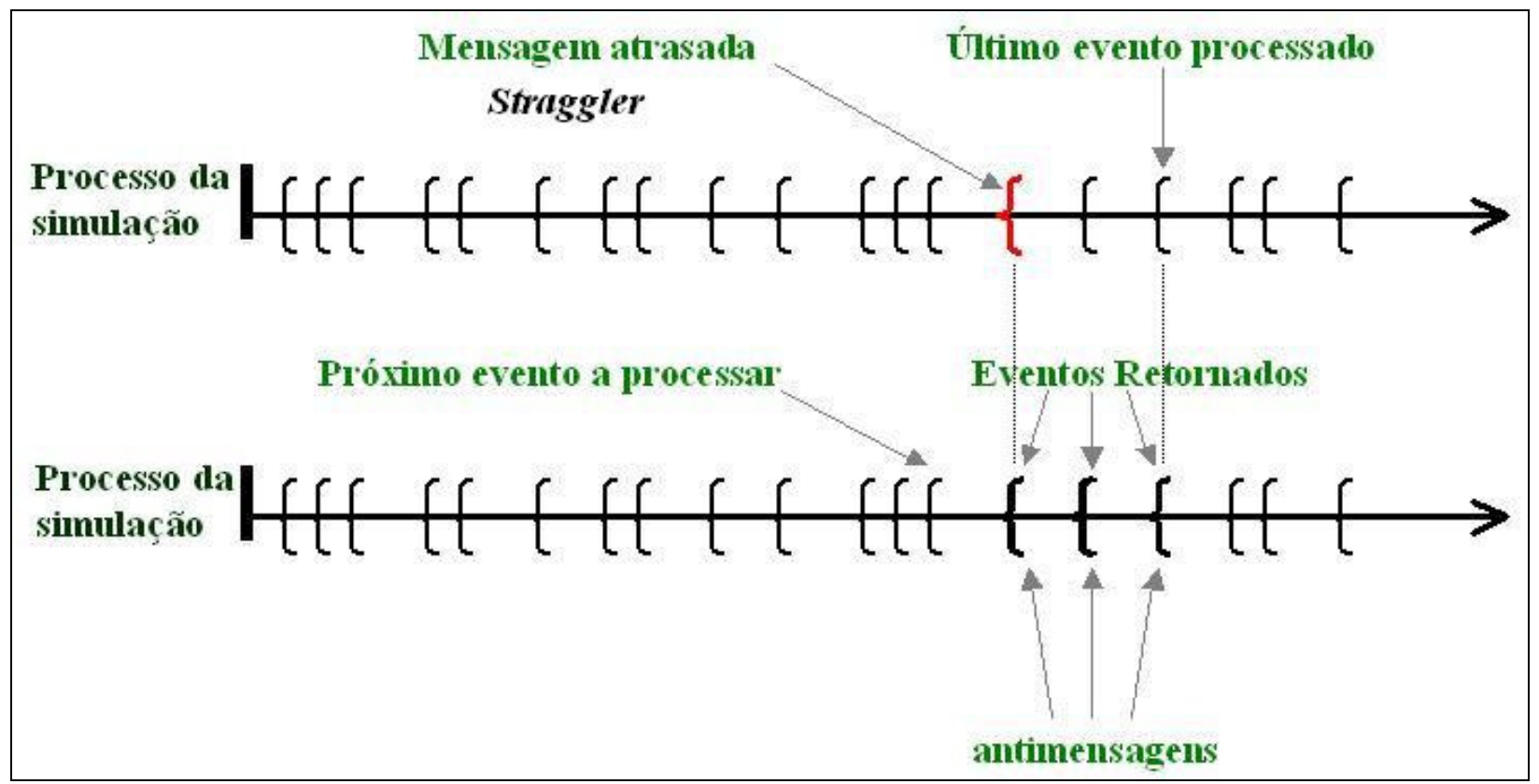

Figura 2.4 Etapas envolvidas quando uma mensagem atrasada é recebida.

Efetuar o rollback é a maneira pela qual o Time Warp desfaz as computações errôneas que tenham sido efetuadas. Para poder restaurar estados, o Time Warp se utiliza da lista de estado. Nesse processo de rollback, todas as mensagens enviadas, relativas aos estados que devem ser descartados, também necessitam ter seu envio anulado. Isso é feito através do envio de antimensagens (versões negativas das mensagens positivas enviadas por um processo). Se um processo lógico recebe uma antimensagem que corresponde a uma mensagem positiva que já executou, então esse também deve retornar para desfazer o efeito da mensagem positiva a ser anulada. Este procedimento pode ser realizado recursivamente até que todas as computações erradas sejam canceladas (Fujimoto, 1990).

O procedimento de salvamento de estados no Time Warp pode ser executado seguindo uma das seguintes abordagens (Lobato et al., 2004):

Copy state saving: todo o estado do processo é salvo após a execução de cada evento;

Sparse state saving: o estado do processo lógico é salvo periodicamente (fixo ou adaptativo), e quando for necessária a execução de um rollback é feita a restauração para o último estado consistente salvo antes do evento afetado. 
Incremental state saving: somente as partes do processo lógico que foram modificadas são salvas, e o salvamento poderá ocorrer ou no momento em que uma variável foi modificada, ou em intervalos fixos de tempo, quando todas as variáveis que sofreram modificações são salvas. Outra questão nessa abordagem é com relação à transparência ou não do salvamento. Na primeira a simulação se encarrega de verificar quais variáveis sofreram modificações, já na segunda o usuário é o responsável por apontar as variáveis que devem ser salvas.

Quando o rollback ocorre, a necessidade de cancelar algumas mensagens que foram enviadas para outros processos pode ser feita utilizando-se cancelamento Direto ou Indireto, como observado na figura 2.5 (Fujimoto, 1990; Lobato et al., 2004).

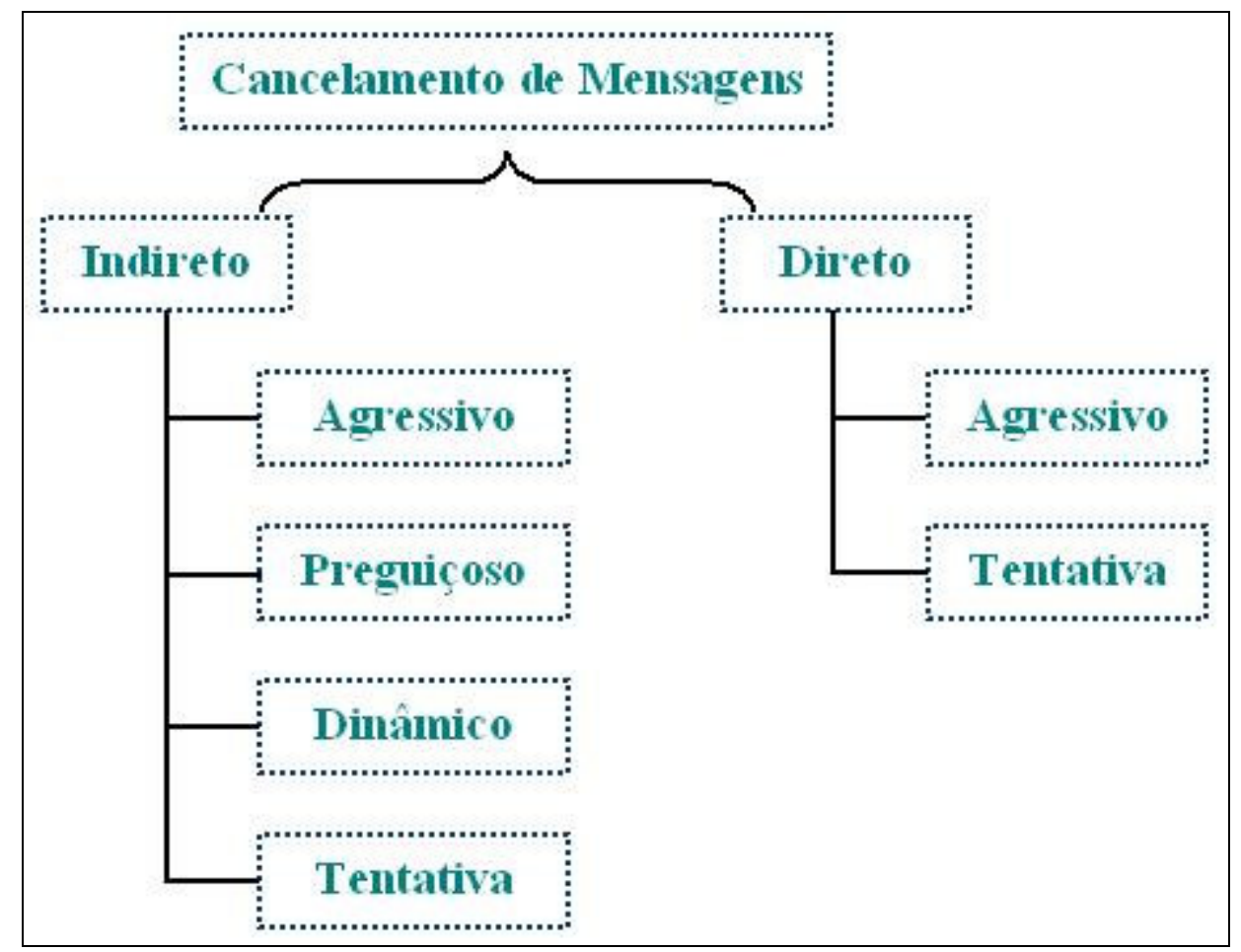

Figura 2.5 Etapas envolvidas quando uma mensagem atrasada é recebida.

O cancelamento indireto de uma mensagem é feito através do envio explícito de antimensagens, e o cancelamento direto através da eliminação das mensagens enviadas diretamente nas filas dos outros processos lógicos (em caso de memória compartilhada) ou na fila de saída do próprio processo (no caso de memória distribuída)(Lobato et al., 2004). O cancelamento indireto pode ser: 
- Agressivo: quando um processo efetua rollback para o tempo $T$, imediatamente são enviadas antimensagens de todas as mensagens anteriormente enviadas com timestamp maior que $T$;

- Preguiçoso: as antimensagens não são enviadas imediatamente após o rollback; espera-se a nova execução para verificar se esta não irá gerar as mesmas mensagens, sendo assim desnecessário o cancelamento dessas;

- Dinâmico: cada processo fica responsável por decidir como irá efetuar o cancelamento, agressivo ou preguiçoso.

- em Tentativa: um grupo de mensagens enviadas para um processo lógico pode ser cancelado por uma única antimensagem (utilizado no Tentative Time Warp).

O cancelamento direto pode ser agressivo ou em tentativa.

Um problema relacionado ao Time Warp é a necessidade de salvar periodicamente os estados dos processos lógicos, a sobrecarga gerada pode degradar o desempenho do mecanismo e tornar o gerenciamento de memória mais complexo. Dessa forma, a tarefa de salvar estados no Time Warp apresenta um alto custo e exige mecanismos que ajudem a minimizar a utilização do espaço de memória disponível. Diversos mecanismos para cancelamento de mensagens têm sido propostos, como por exemplo: Redução dos Estados Salvos (Das \& Fu-

jimoto, 1993), Otimismo Limitado (Madiseti et al., 1992; Prakash \& Subramarian, 1991), Retorno de mensagens e Cancellback (Akyildiz et al., 1992), e outros.

\subsection{Ferramentas para Simulação Distribuída}

Um problema na elaboração de uma simulação é a transcrição do modelo definido pelo usuário em um programa de simulação. Para ajudar o usuário neste processo de transcrição, 
tem-se as linguagens e os ambiente de simulação. Essas ferramentas oferecem ao usuário uma série de recursos que visam facilitar o desenvolvimento de uma simulação.

Existem linguagens de simulação paralelas que implementam os diferentes protocolos de sincronização disponíveis. Muitas suportam somente protocolos otimistas (Sim++, ModsimII, Apostle, SPEEDES), poucos suportam somente os conservativos e alguns ambos. Apesar dos protocolos conservativos terem uma implementação mais fácil, são os otimistas os mais utilizados. Porém, para Bagrodia (1996) explorando-se o lookahead nos modelos, pode ser possível extrair speedups significativos, utilizando protocolos conservativos.

Há várias linguagens e ambientes de simulação, sendo a maioria comerciais. A seguir são comentadas sobre algumas dessas ferramentas para simulação paralela e distribuída.

ParSMPL é um ambiente de simulação paralela que utiliza o mecanismo $C M B$ para efetuar a sincronização entre os processos lógicos. Utiliza como plataforma o ambiente de passagem de mensagens PVM (Ulson et al., 1997).

ModSim II é uma linguagem de simulação orientada a objetos baseada na linguagem Modula 2. Fornece construções para criação de objetos dinâmicos, comunicação e sincronização. Utiliza o sistema operacional TWOS para sincronizar a execução dos programas paralelos (Bagrodia, 1994).

PasaSol é um ambiente de simulação paralela desenvolvido em $C++$ e usa um ambiente como o PVM para distribuir cópias das tarefas e passagens de mensagens. As transações são implementadas como threads timestamped que migram de forma transparente entre os processadores para utilização dos recursos. O ambiente fornece domínios com funcionalidades adequadas à aplicação, como sistemas de manufatura, simulações de combate e circuitos lógicos digitais (Knop et al., 1996; Mascarenhas et al., 1996).

GPSS Paralelo, Knop et al., (1996) apresentam uma paralelização da linguagem de simulação GPSS. Foi implementado um tradutor $G P S S-C++$ e o código transformado é exe- 
cutado com o auxílio do ambiente de simulação paralela ParaSol. Segundo o autor, o mapeamento de GPSS para $C++$ é simples porque ParaSol, diferente dos demais ambientes de simulação paralela, é orientado a transação.

SPEEDES (Synchronous Parallel Environment for Emulation and Discrete Event Simulation) é um ambiente de simulação baseado em $C++$ que implementa um conjunto de protocolos de sincronização incluindo Time Warp e um algoritmo de janelas denominado Breathing Time Buckets (Bagrodia, 1994). É um ambiente completo e usado operacionalmente no Joint National Integration Center. Exemplos de simulações que utilizam o sistema SPEEDES são a MDWAR (Missile Defense Wargaming and Analysis Resource), e a JBI (Joint Battlespace Infosphere). Sabe-se que mais ou menos outras trinta organizações já estão considerando o seu uso. A principal desvantagem é que esta ferramenta é restrita a pesquisadores norte americanos (SPEEDES).

Maise é uma linguagem de simulação baseada em $C$ que pode ser executada utilizando uma variedade de protocolos de simulação que incluem um algoritmo seqüencial, algoritmos paralelos baseados na combinação da abordagem conservativa de mensagens nulas e eventos condicionais e um algoritmo otimista. Uma extensão de Maise é o MOOSE (Maise-based Object Oriented Simulation) versão orientada a objetos (Bagrodia, 1994).

Portable Parallel Discrete Event Simulation System sistema projetado para facilitar a simulação de aplicações reais utilizando protocolos PDES, na University of Exeter. O sistema fornece meios para comparar protocolos de simulação, podendo ser utilizado para verificar a adequabilidade das abordagens otimistas ou conservativas em áreas de aplicações específicas. Uma abordagem é o desenvolvimento de protocolos híbridos, pela adição de características conservativas às abordagens otimistas e vice-versa (Turner \& Xu, 1992).

COMPOSE (Conservative, Optimistic and Mixed Parallel Object-oriented Simulation Environment) é um biblioteca de simulação paralela, em $C++$, que suporta a execução de um 
modelo utilizando um algoritmo de simulação adaptativo, onde os submodelos podem ser sincronizados utilizando métodos conservativos ou otimistas, e um objeto pode mudar seu modo de sincronização de forma dinâmica (Martin \& Bagrodia, 1995).

PORTS (Parallel, Optimistic, Real-Time Simulator) é um sistema de simulação paralelo que executa em ambientes que impõem regras de tempo real na execução do programa de simulação (Ghosh et al., 1994).

PARSEC (PARallel Simulation Environment for Complex systems) o ambiente de simulação fornece interfaces com o usuário como as linguagens Parsec e Compose, e um editor gráfico para construção do modelo de simulação. Implementa vários protocolos de sincronização (otimistas e conservativos) utilizando uma biblioteca de comunicação portável, o que o torna disponível para uma variedade de plataformas de hardware (Bagrodia et al., 1998).

GTW (Georgia Tech Time Warp) é um ambiente de simulação paralela baseado no mecanismo Virtual Time (Jefferson, 1985). Foi projetado para dar suporte à execução eficiente de simulações de aplicações com eventos com granulosidade fina ${ }^{1}$. Fornece mecanismos para permitir ao programa de aplicação controlar o comportamento de otimismo excessivo do Time Warp. A interface com o programador oferece um conjunto mínimo de primitivas de simulação, permitindo que mecanismos mais sofisticados sejam implementados como rotinas de biblioteca (Das et al., 1994).

ASDA (Ambiente de Simulação Distribuída Automático) é um ambiente de simulação voltado à avaliação de desempenho de sistemas computacionais. O público alvo desta ferramenta são alunos, professores e pesquisadores interessados na avaliação de desempenho de sistemas computacionais, principalmente os baseados na teoria de redes de filas. Este ambiente foi proposto por Bruschi (2002) em seu doutorado e encontra-se em fase de implementação.

\footnotetext{
${ }^{1}$ Granulosidade fina se refere aos eventos que levam pouco tempo para serem processdos.
} 
DSIM é um simulador Time Warp que tem como alvo os clusters formados por milhares de processadores. Emprega uma nova técnica para o calculo do GVT chamada de "Time Quantum GVT', um algoritmo que não requer mensagens de reconhecimento, baseado em mensagens de tamanho constante e eficiente em clusters com um grande número de processadores. Esta implementação usa uma técnica chamada de Local Fóssil Collection ${ }^{l}$ para diminuir a sobrecarga de memória e para suportar um eficiente gerenciamento dos eventos. Detalhes de implementação podem ser consultados em Chen \& Szymanski (2005).

ROSS (Rensselaer's optimistic simulation system) também é um sistema Time Warp que promete alto desempenho, com baixo uso de memória e um kernel extremamente modular. Estas vantagens são obtidas com o uso de diferentes tecnologias: um framework de implemetação modular; algoritmo de GVT de Fujimoto; computação reversa e o uso de kernel processes $(K P s)$. Os KPs diminuem a sobrecarga causada pela operação de garbage collecting através da agregação das listas de eventos processados. As tecnologias e outras informações estão descritas em Carothers et al. (2002).

WARPED é um núcleo Time Warp de domínio público, escrito em $C++$ e desenvolvido pela University of Cincinnati (EUA), e está disponível para várias plataformas. Define uma interface padrão para o programador de aplicação, utilizando o ambiente de passagem de mensagens MPI (Message Passing Interface). O principal objetivo do Warped é disponibilizar para a comunidade de pesquisa um núcleo otimista que permita a análise do Time Warp; distribuído livremente, fácil de portar, simples de modificar e estender e fácil de acoplar a novas aplicações. Esta ferramenta foi escolhida para auxiliar no desenvolvimento deste trabalho, como o ambiente que executará a simulação distribuída (Martin et al., 2003).

O sistema Warped é implementado na linguagem $\mathrm{C}++$ e utiliza todas as funcionalidades de orientação a objetos disponíveis na linguagem. O projeto do código do sistema foi de-

\footnotetext{
${ }^{1}$ Também conhecida como Garbage Collection, onde a cada cálculo do GVT as mensagens antigas são apagadas.
} 
senvolvido de forma que o usuário especifica sua aplicação usando os recursos de herança, funções virtuais e sobrecarga diretamente a partir das classes do núcleo. As classes do usuário são compiladas juntamente com o código do núcleo resultando num único arquivo executável que contém tanto o núcleo quanto a aplicação. A linkedição estática pode fazer o arquivo executável adquirir um tamanho razoavelmente grande, o que não representa uma desvantagem, já que dessa forma não há a necessidade de instalar a biblioteca do Warped nas máquinas onde a simulação será executada.

Uma vantagem desse tipo de projeto é a flexibilidade proporcionada ao usuário que pode modificar o comportamento de qualquer funcionalidade do sistema apenas herdando classes e sobrecarregando métodos. É possível modificar facilmente funcionalidades como: algoritmo de cálculo do $G V T$, gerenciamento de filas, algoritmo de escalonamento de objetos, etc. Outra vantagem desse projeto orientado a objetos é a facilidade de anexar um núcleo diferente, por exemplo, para ter uma simulação seqüencial. Isso pode ser feito sem que a aplicação seja alterada.

Como desvantagem há o fato de que o usuário deve ter conhecimento de técnicas de programação orientada a objetos mesmo que a interação com o sistema seja apenas em nível de interface. $\mathrm{O}$ apêndice $\mathrm{A}$ apresenta detalhes de sua implementação.

\subsection{Considerações Finais}

Simulação é o processo de projetar um modelo de um sistema real e conduzir experimentos com este modelo com o propósito de entender seu comportamento e/ou avaliar estratégias para sua operação (Pegden et al., 1991). Pode ser considerada uma das ferramentas de análise de projeto, de operação de processos e sistemas em indústrias. A simulação vem sendo cada vez mais utilizada, devido a sua versatilidade, flexibilidade, potência computacional e baixo custo. 
Um problema discutido na simulação distribuída é a sincronização no processamento de eventos, que é necessária para que as relações de causa e efeito encontradas no sistema real sejam preservadas. Os protocolos para sincronização em simulação distribuída dividem-se em duas abordagens principais: conservativos e otimistas, que foram discutido no decorrer deste capítulo. E como ambos possuem vantagens e desvantagens, a escolha do melhor protocolo dependerá do sistema que se pretende simular.

A simulação distribuída apresenta diversos problemas similares aos encontrados na computação distribuída em geral. Alguns desses problemas podem ter soluções específicas para simulação distribuída e outros se resolvem com as técnicas gerais aplicadas a computação distribuída.

Considerando o grande valor da área de simulação para a evolução e melhor execução de diversos trabalhos nas mais variadas áreas, é que se tem o interesse de focalizar no estudo específico do escalonamento de processos em simulação distribuída, que será o assunto abordado conceitualmente e especificamente na área de simulação distribuída no próximo capítulo. 


\section{Capítulo 3 - ESCALONAMENTO DE PROCESSOS}

\subsection{Considerações Iniciais}

Escalonamento de processos é encontrado em áreas do conhecimento onde se deseja que serviços sejam divididos entre recursos, que realizarão algum processamento sobre esses serviços; exemplos de áreas são a engenharia de produção e a computação. Mas o ato de escalonar pode ser facilmente encontrado no dia-a-dia das pessoas, como por exemplo, na construção de uma casa, onde se tem vários pedreiros e vários materiais que serão usados em comum. Para que a construção ocorra de maneira esquematizada e sem transtornos, é necessário dividir entre os pedreiros os materiais e com isso cada um fica responsável por determinada parte da construção, pode-se chamar essa organização de "escalonamento de tarefas". Assim "escalonar em computação" é a preocupação dispensada quando para executar um processo (serviço) há a necessidade de colocá-lo para execução em um recurso de processamento apropriado.

Em sistemas distribuídos, que são sistemas constituídos por diversos computadores independentes conectados por uma rede de computadores, os processos são distribuídos (escalonados) entre os diferentes elementos de processamento integrantes do sistema, através de um processo de escalonamento, que pode ser balanceado ou não, sobrecarregando determina- 
das máquinas e deixando outras ociosas. Estes sistemas apresentam uma acentuada heterogeneidade entre cada elemento de processamento, e a não observância dessas diferenças de hardware e software pode acarretar num escalonamento ineficiente que prejudicará o desempenho global, trazendo conseqüências indesejáveis.

A literatura sobre escalonamento de processos é numerosa, contando com artigos que contribuem para o aperfeiçoamento da área. No entanto, percebe-se que as terminologias utilizadas são distintas e conflitantes. Este problema de terminologia na área é discutido em detalhes por Souza et al. (2000).

\subsection{Escalonamento de processos}

Para que um processo possa ser executado em um sistema qualquer, deve-se determinar quando ele poderá usar a $C P U$, quais recursos estarão disponíveis e ainda, no caso de sistemas distribuídos, deve-se definir em qual processador ele será executado. Esta atividade é de responsabilidade do escalonador de processos. O objetivo do escalonamento é resolver estas questões melhorando, na medida do possível, as métricas de desempenho global do sistema, tais como tempo de execução dos processos e a taxa de uso dos processadores. Contudo, estas melhorias não devem comprometer os aspectos de transparência e desempenho.

O escalonamento de processos é construído através de um algoritmo, que é organizado como um conjunto de componentes (partes), onde cada componente é responsável por uma porção da finalidade maior que é "escalonar processos". Uma forma comum de dividi-lo é em políticas responsáveis por diferentes partes do processo de escalonamento (Muniz, 1994; Shirazi et al., 1995 (a); Shivaratri et al., 1992).

Em se tratando de escalonamento de maneira geral pode-se dizer que existe um conjunto de atividades comuns, que são chamados de mecanismos, e que são usados de diferentes maneiras e em diferentes combinações para se implementar as políticas. Um exemplo de me- 
canismo, que surge quando se trata de escalonamento de processos em sistemas distribuídos, é a de migração ${ }^{1}$ de processos (ou partes deste).

A migração de processos busca reduzir o tempo gasto pelos processos na fila de espera por processamento, porém, o custo dispensado é uma sobrecarga no sistema de comunicação. A migração facilita o compartilhamento de carga entre os processadores, ou seja, distribuir de maneira igual a carga, respeitando as oscilações na capacidade de processamento do sistema, para obter um aumento no desempenho. Diferentes políticas utilizam migração com objetivos diferentes, por isso pode se dizer que um algoritmo de escalonamento implementa políticas, que por sua vez utilizam diversos mecanismos (Song et al., 1997).

As estratégias de escalonamento podem ser classificadas de diferentes formas dependendo do autor, e ainda levando-se em consideração as formas como foram feitas. Podem, por exemplo, ser classificadas segundo o grau de interação entre os processos no sistema, os quais podem necessitar de troca significativa de informações durante a sua execução ou podem rodar de forma essencialmente desconexa.

\subsubsection{Terminologias}

A literatura sobre escalonamento de processos é bastante ampla. Muitos artigos são encontrados para o aprimoramento da área, porém uma divergência muito grande é observada com relação às terminologias utilizadas nesses trabalhos. O trabalho de Souza (Souza et al., 2000) trata em detalhes os vários problemas existentes com a terminologia da área de escalonamento.

A seguir, alguns conjuntos de termos serão definidos de acordo com o que será utilizado no decorrer de todo o trabalho, segundo o estudo apresentado por Souza (2000).

\footnotetext{
${ }^{1}$ Entende-se por migração, neste escopo, a possibilidade de um processo mudar de máquina durante sua execução.
} 


\section{Processos, programas, tarefas, threads, aplicações e jobs}

Um processo é um programa em execução, contendo, além de um código fonte, uma entrada, uma saída e um estado (pilha, contador de programa e demais informações necessárias à execução do programa) (Tanenbaum, 1995). O termo tarefa é empregado como sinônimo de processo. Threads ou lightweight processes são, segundo Tanenbaum (1995), linhas de execução (concorrentes) que podem existir em um mesmo processo. Cada thread executa de forma sequiencial, similarmente a um processo, mas, compartilha, com outras threads, o mesmo espaço de endereçamento de memória do processo a que pertence. Já aplicação e job são termos usados no mesmo sentido e indicam a maior "entidade" de execução.

\section{Políticas, estratégias, mecanismos e algoritmos de escalonamento}

Política de escalonamento e estratégia de escalonamento tem o mesmo sentido. Ambos são usados para designar as decisões que devem ser tomadas em um escalonamento, determinando quais, quando e como os mecanismos serão empregados para que o escalonamento seja realizado.

Os mecanismos de escalonamento são os comandos e/ou instruções que, atuando como "ferramentas", desempenham as atividades básicas para a realização do escalonamento. Como exemplo pode-se citar as instruções que coletam informações sobre a carga de um sistema.

O termo algoritmo de escalonamento é utilizado como um termo mais genérico, responsável pela implementação das políticas e mecanismos utilizados no escalonamento. 
Escalonamento de processos, escalonamento de aplicações paralelas, balanceamento de carga, alocação de recursos.

Diferentes autores definem o termo escalonamento de diferentes formas (Feitelson \& Rudolph, 1995). Os termos escalonamento de processos e escalonamento de aplicações paralelas são utilizados dando-se ênfase ao que se está escalonando.

O termo alocação/gerenciamento de recursos é comumente empregado como sinônimo de escalonamento, apesar de Casavant e Kuhl (1988) afirmar que os dois termos executam a mesma atividade com ponto de vista diferentes. Enquanto o termo escalonamento aborda a questão em termos de processos e aplicações, ou seja, os consumidores de recursos; a alocação de recursos leva em consideração os próprios recursos.

Segundo Souza (2000), um erro comumente utilizado é o do termo balanceamento de carga como sinônimo de escalonamento realizado em tempo de execução da aplicação. Quando este termo deveria ser usado como um dos possíveis objetivos do escalonamento.

Várias taxonomias foram propostas para a área de escalonamento, com o objetivo de organizar o conhecimento adquirido na área e facilitar a comparação entre os trabalhos desenvolvidos (Souza, 2000). Dentre estas, a taxonomia de Casavant e Kuhl (1988) é uma das mais completas, muito utilizada e referenciada em trabalhos da área.

Uma questão que é muito discutida quando o assunto é escalonamento é sobre o tipo de aplicação. Levando-se em consideração o tipo de aplicação que está executando, as políticas de escalonamento poderão tratar adequadamente elas com diferentes requisitos. Os principais tipos são:

$\boldsymbol{C P U}$-Bound neste tipo de aplicação são encontradas uma alta demanda por processamento e baixa comunicação entre os processos (Araújo et al., 1999); 
Memory-Bound o objetivo do escalonamento é evitar falhas de página ${ }^{1}$ (Majumdar \& Parsons, 2000);

$\boldsymbol{I} / \boldsymbol{O}^{2}$ - Bound esta classe engloba as aplicações que realizam muitas operações em dispositivos de entrada/saída. Essas aplicações também podem ser classificadas como Disk-Bound (quando realizam muito acesso a disco) e Network-Bound (quando devido a alta comunicação, um alto tráfego na rede é gerado) (Ishii, 2004).

Diferentes tipos de informações contribuem consideravelmente para a qualidade do escalonamento, dependendo da quantidade de informações obtidas e disponíveis no momento em que as decisões precisam ser tomadas para a atribuição de processos. Uma dessas informações é a respeito da carga do processador, que permite avaliar o quanto um processador está carregado ou não. Para quantificar esta carga é utilizada uma métrica denominada na literatura por índice de carga, que é definida como sendo um valor não-negativo, iniciando em zero se o processador está ocioso e aumentando positivamente conforme a carga de trabalho aumenta (Branco, 2000; Ferrari \& Zhou, 1987; Kunz, 1991; Mehra \& Wah, 1993; Shirazi et al., 1995 (b)).

Exemplos de índices de carga são: índices baseados no tempo de execução/resposta; índices baseados no tamanho da fila de acesso ao recurso; índices baseados no percentual de utilização do recurso (Ferrari \& Zhou, 1987; Souza et al., 2000) e outros.

A grande dificuldade encontrada é no que se refere à obtenção destes índices de carga, pelo fato de não existir uma única regra correta que determine se um processador está carregado, moderado ou ocioso. O uso do termo genérico 'a carga de um processador' pode não ser

\footnotetext{
${ }^{1}$ Situação que ocorre em sistemas operacionais que utilizam memória virtual. Quando a memória principal é insuficiente, uma área do disco (memória secundária) é destinada a armazenar temporariamente dados de um programa que não estão sendo utilizados no momento. Quando o programa precisa desses dados ocorre uma falha de página. Então, o sistema operacional busca os dados no disco e coloca na memória principal.

${ }^{2}$ Input / Output - Entrada / Saída
} 
representativo, devido ao fato da necessidade por recursos variar de aplicação para aplicação (Tanenbaum, 1995; Ferrari \& Zhou, 1987).

Uma questão particular que deve ser considerada, principalmente em sistemas que apresentam heterogeneidade, é a normalização dos valores dos índices, que leve em consideração a diferença computacional dos processadores envolvidos.

Dependendo do objetivo que se queira atingir, serão determinados, um ou mais índices de carga e a função de cada uma das políticas de escalonamento. Discussões sobre índices de carga são encontradas em diversos trabalhos relacionados ao escalonamento de processos (Araújo et al., 1999; Clark et al., 1995; Dantas \& Zaluska, 1998; Santana \& Zaluska, 1988; Schnor et al., 1996; Zhou et al., 1993; Branco, 2004); entre outros.

Um dos objetivos do escalonamento de processos é a obtenção de uma distribuição uniforme de carga de trabalho entre as máquinas, de tal forma que não existam máquinas ociosas e outras sobrecarregadas. Assim utiliza-se o balanceamento de cargas, que trata a realocação de carga de trabalho entre os nós do sistema, obtendo assim, tempos de resposta menores, aumento na utilização dos recursos computacionais e ganho no desempenho do sistema.

A seguir será apresentada uma das ferramentas que são encontradas para auxiliar no gerenciamento e escalonamento de aplicações. O AMIGO (dynAMical flexIble schedulinG envirOnment) é uma ferramenta que foi proposta em um trabalho de doutorado no grupo de Sistemas Distribuídos e Programação Concorrente do ICMC-USP (Souza, 2000), que está em constante desenvolvimento e que será utilizada como o ambiente que auxiliará na execução das aplicações envolvidas neste trabalho. 


\subsection{AMIGO - DynAMical FlexIble SchedulinG Envi- rOnment}

O principal objetivo do escalonamento em plataformas distribuídas (como arquiteturas paralelas e sistemas de computação distribuída) é a distribuição de serviços para vários recursos de processamento existentes.

Além das diferentes necessidades, o escalonamento deve preocupar-se com outros fatores, os quais influenciam decisivamente no seu desempenho final (Shivaratri et al., 1992; Ferrari \& Zhou, 1987). Dentre esses fatores destacam-se:

$\checkmark$ A finalidade da plataforma computacional utilizada. O escalonamento adotado em uma arquitetura paralela a qual está executando aplicações paralelas difere do escalonamento adotado para um sistema distribuído com aplicações seqüenciais;

$\checkmark$ O hardware disponível. Os recursos de computação e comunicação, além da topologia impõem restrições à escolha de determinados escalonamentos. Exemplos são os ambientes heterogêneos e homogêneos e a grande variedade de organizações físicas dos meios de conexão dos elementos de processamento;

$\checkmark$ Ambientes multiusuários. A coexistência ou não de vários usuários, compartilhando os mesmos recursos computacionais, contribuem para gerar alterações extras no ambiente computacional, as quais, de alguma forma, também devem ser consideradas;

$\checkmark$ Diferentes classes de aplicações. Mesmo considerando apenas uma plataforma computacional, como por exemplo máquinas paralelas, há inúmeras classes de software diferentes, com necessidades variadas e, muitas vezes, conflitantes. Um exemplo são as aplicações interativas, batch e tempo real; 
$\checkmark$ Diferentes cargas de trabalho. Ambientes com altos e baixos índices de carga comportam-se de maneiras distintas, se considerado um mesmo algoritmo de escalonamento de processo.

Devido ao grande número de fatores que afetam decisivamente a atividade de distribuição de processos e, desse modo, o desempenho final das aplicações, é vital determinar e viabilizar o emprego do algoritmo de escalonamento que mais se adapta às reais necessidades do usuário.

Dentro deste contexto, o Grupo de Sistemas Distribuídos e Programação Concorrente do ICMC/USP propôs e está desenvolvendo o AMIGO (dynAMical flexIble schedulinG envirOnment), uma nova ferramenta de software capaz de incluir flexibilidade ao escalonamento de processos em plataformas paralelas, em tempo de execução da aplicação e de maneira totalmente transparente para o usuário (Souza, 2000). Através do AMIGO, as principais características que envolvem a atividade de distribuir processos em plataformas distribuídas podem ser alternadas, com o objetivo de fornecer ao usuário a melhor opção de escalonamento para a realidade atual do seu ambiente computacional.

A flexibilidade do $A M I G O$ deve-se à sua capacidade de alterar ou configurações com o objetivo de atender às necessidades dos usuários, por exemplo, inserir ou remover políticas de escalonamento. A parte dinâmica diz respeito à adequação do ambiente de acordo com o comportamento da plataforma perante novas situações, por exemplo, trocar a política de escalonamento ativa em tempo de execução.

O AMIGO é organizado em duas camadas principais. A camada superior é composta de uma interface gráfica na qual o usuário tem acesso a várias opções para configurar o ambiente e escolher a forma que as políticas de escalonamento serão usadas. A camada inferior opera independentemente da camada superior e oferece o suporte necessário para a realização de um escalonamento flexível e dinâmico por meio de três módulos: o middleware, responsá- 
vel pelo gerenciamento e execução das tarefas; o $A M I G O$ deamon (AMIGOD), e as políticas de escalonamento (Figura 3.1). Exemplos de middleware utilizados pelo AMIGO na camada inferior são: PVM (Parallel Virtual Machine), MPI (Message Passing Interface) e CORBA (Common Object Request Broker Architecture).

Inicialmente o $A M I G O$ foi projetado para executar com os ambientes de passagem de mensagens, porém, ele também pode ser utilizado por intermédio de outros softwares. Isso se dá graças a esta divisão em duas camadas. Adaptando-se a camada inferior para a plataforma e/ou software desejados, é possível utilizá-lo em outras situações, sem ser necessária a alteração da camada superior. Este é o caso deste trabalho, onde uma das contribuições é a conexão entre a ferramenta Warped com o AMIGO (capítulo 4). Detalhes da camada superior do AMI$G O$ são discutidos por Souza (2000).

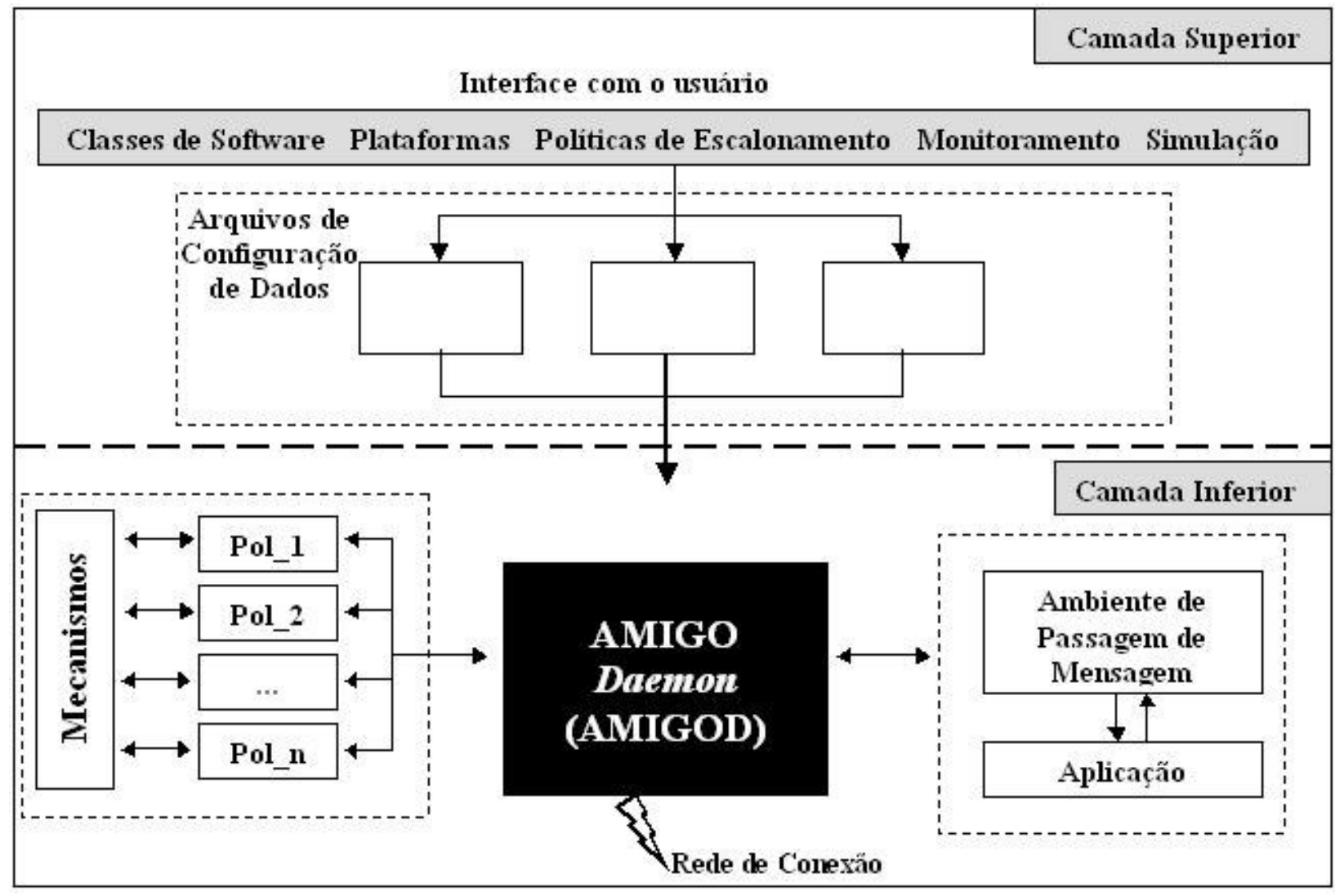

Figura 3.1 Arquitetura do ambiente AMIGO. (Retirado de Souza (2000)). 
O AMIGOD é um pequeno servidor distribuído que age como um elo entre as políticas de escalonamento e o ambiente de passagem de mensagem. Ele é executado em todos os processadores que serão usados no escalonamento. O AMIGOD não implementa nenhuma política, ficando responsável apenas pelo gerenciamento e roteamento das mensagens trocadas entre os módulos da camada inferior, assim como por manter ativas as políticas necessárias.

O AMIGOD é composto fundamentalmente por estruturas de dados, responsáveis por manter tabelas com as políticas que estão ativas no momento, tabelas da relação de processadores e também os mecanismos de comunicação entre os processos. Sendo que seus dados são sempre atualizados quando mudanças no escalonamento ocorrem. Como quando um processador é anexado, ou deixa o grupo de processadores .

As políticas de escalonamento são implementadas como processos independentes para permitir que sejam trocadas enquanto as aplicações estão executando (característica dinâmica do $A M I G O)$. As políticas precisam seguir um protocolo de comunicação especificado para trocar mensagens com os $A M I G O D$ s e com outras políticas. As principais características das políticas são: (1) sua independência do ambiente de passagem de mensagens, visto que a integração com esses ambientes é feita pelo $A M I G O D$ e (2) seu código específico, que as torna mais concisas e eficientes e permite que possuam quaisquer características e objetivos. $\mathrm{O}$ ambiente de passagem de mensagem é um cliente do $A M I G O$; que requisita ao $A M I G O$ informações sobre quais processadores devem ser usados para escalonar os processos; o $A M I G O$, por sua vez requisita esta informação à política ativa.

\subsubsection{Comunicação na Camada Inferior}

A comunicação realizada pela camada inferior é baseada nos protocolos TCP (Transmission Control Protocol) e UDP (User Datagrama Protocol), os quais são utilizados por 
intermédio da interface sockets. O AMIGO assume que todos os processadores que farão parte do escalonamento são capazes de se conectarem através desses mecanismos de comunicação.

A figura 3.2 apresenta a comunicação realizada pela camada inferior. Pode-se observar a existência de três tipos de conexões: entre o $A M I G O D$ e as políticas ativas; entre o $A M I-$ GOD e o ambiente de passagem de mensagem e entre os $A M I G O D$ s dos diferentes processadores. Outro ponto a ser observado é o tipo de comunicação, dentro do mesmo processador o protocolo utilizado é o TCP; e entre processadores diferentes o protocolo de comunicação é o UDP. Essas escolhas segundo Souza (2000) foram feitas por causa da capacidade escalar (comunicação $A M I G O D \leftrightarrow A M I G O D$ ) e à confiabilidade (no caso das comunicações $A M I$ $G O \mathrm{D} \leftrightarrow$ Políticas e $A M I G O \mathrm{D} \leftrightarrow$ ambiente de passagem de mensagem).

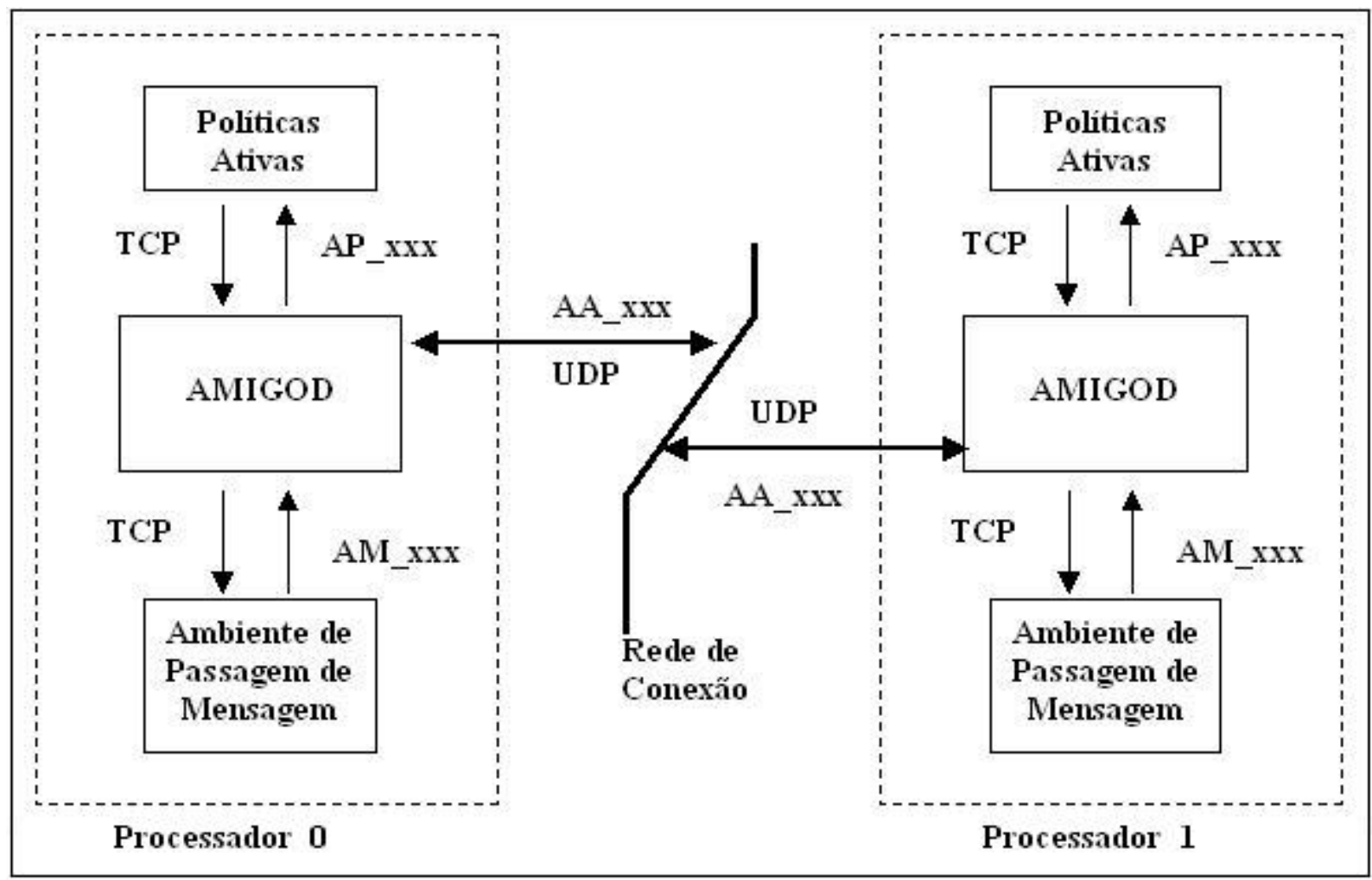

Figura 3.2 Comunicação na camada inferior.

(Retirado de Souza (2000)).

As mensagens trocadas na camada inferior possuem um cabeçalho para identificá-la. Esse cabeçalho, que é ilustrado na figura 3.3, possui dezesseis bytes e é formado por quatro 
campos principais: o código da mensagem, o destino da mensagem, a origem da mensagem e o tamanho do corpo da mensagem.

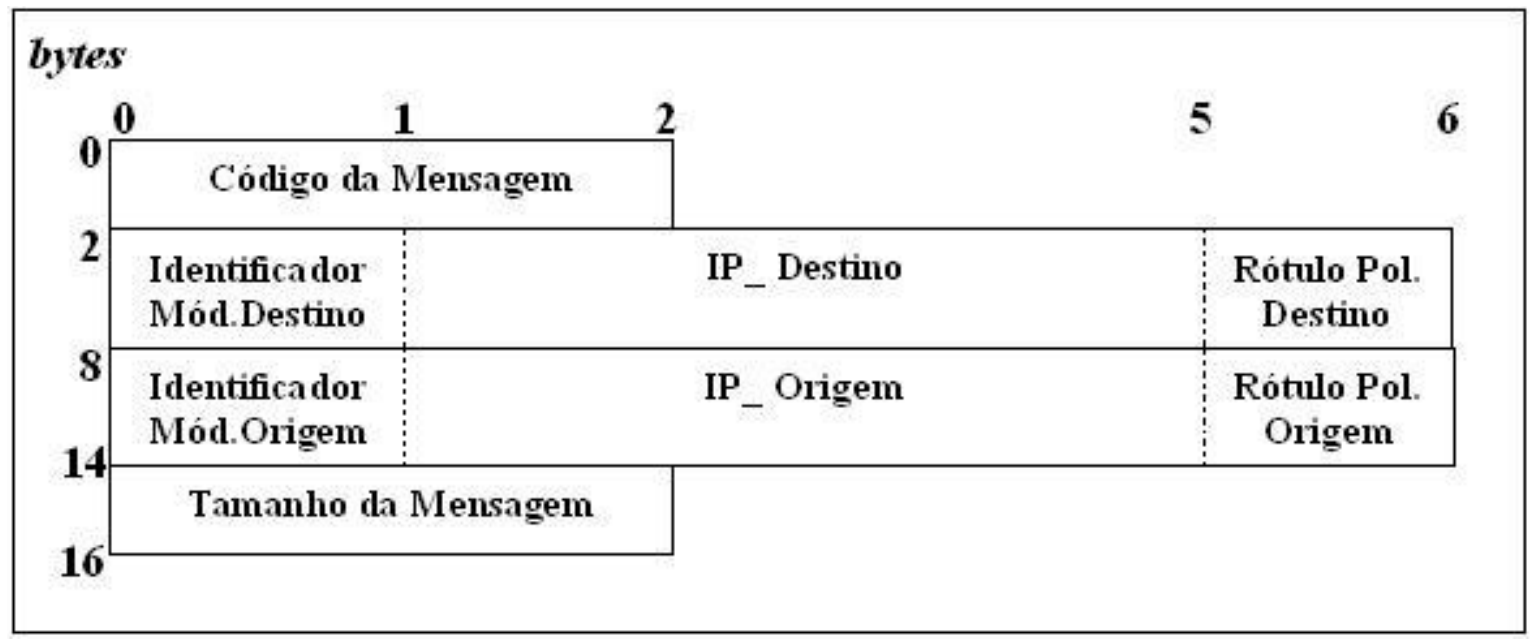

Figura 3.3 Cabeçalho das mensagens trocadas na camada inferior.

(Retirado de Souza (2000)).

O código define a finalidade da mensagem e quais módulos estão participando da comunicação. Por exemplo como é observado na figura 3.3, quando a comunicação é entre $A$ $M I G O D \leftrightarrow$ Políticas o prefixo é AP_. Se a mensagem é entre $A M I G O D \leftrightarrow$ Ambiente de passagem de mensagem, o prefixo é $\mathrm{AM}_{-}$. E se a mensagem é entre $A M I G O D \leftrightarrow A M I G O \mathrm{D}$ o prefixo é AA_. O significado do conteúdo detalhado de todas as mensagens está descrito em Souza (2000).

Os campos de origem e destino são formados por seis bytes, divididos da seguinte maneira: o primeiro é o identificador dos módulos destino/origem que estão participando da comunicação. Sendo "A" para identificar o módulo AMIGOD; ou "P" para uma política e "M" para o ambiente de passagem de mensagem. Os quatro próximos bytes representam o endereço IP dos processadores origem/destino que estão participando da comunicação. O último byte é usado para identificar, quando a origem e/ou destino for uma política, dentre as políticas ativas qual efetivamente está se comunicando.

O campo "tamanho da mensagem" determina quantos bytes devem ser lidos, referente ao corpo da mensagem, que pode ser zero também. 
Todos os detalhes de implementação e funcionamento desta ferramenta podem ser encontrados no trabalho de Souza (2000).

\subsection{Escalonamento em Simulação Distribuída}

Os algoritmos de escalonamento de processos de uso geral, construídos para plataformas computacionais distribuídas são geralmente destinados ao gerenciamento dos processos de programas paralelos. Uma das principais atividades realizadas por esses algoritmos é o mapeamento dos processos aos processadores disponíveis, isto é, escolher qual processo deve ser executado em qual processador. Muitas vezes isso é feito baseando-se em informações sobre a plataforma e sobre as aplicações. As informações coletadas pelos mecanismos responsáveis devem ser baseadas em métricas relacionadas com o desempenho da aplicação paralela, para que a correta utilização dessas informações possa contribuir para o aumento do desempenho do sistema. Por exemplo, um determinado algoritmo pode se basear em informações sobre a utilização do processador para decidir como será feito o mapeamento dos processos aos processadores; neste caso, deve-se atribuir mais processos aos processadores que estão sendo menos utilizados, buscando a maximização da utilização dos recursos disponíveis.

O desempenho de uma simulação distribuída também está sujeito a influências da plataforma e das características do modelo de simulação. Diversas técnicas para otimizar o desempenho de uma simulação podem ser encontradas na literatura (Carothers \& Fujimoto, 2000), dentre elas, destacam-se as técnicas de escalonamento e balanceamento de carga. O objetivo deste capítulo é apresentar os algoritmos de escalonamento e balanceamento de carga para simulação distribuída. Assim como os algoritmos construídos para escalonar processos de programas paralelos, os algoritmos destinados à simulação baseiam suas decisões em informações relacionadas ao desempenho do sistema. 
Os algoritmos feitos especificamente para simulação distribuída apresentam algumas semelhanças e diferenças com relação aos algoritmos de uso geral. Em especial, as diferenças existentes muitas vezes tornam os algoritmos de uso geral inadequados para o uso na simulação distribuída, principalmente por causa dos tipos de informações nas quais as decisões são baseadas (Boukerche \& Das, 1997; Deelman \& Szymanski, 1998).

Esta seção apresenta diversos exemplos de algoritmos de escalonamento feitos para simulação distribuída, e destaca as semelhanças com outros tipos de algoritmos de escalonamento bem como as diferenças mais importantes.

São apresentados algoritmos tanto para simulação conservativa como otimista, sendo que a maior parte dos exemplos encontrados é destinada à simulação otimista.

\subsubsection{Falta de Balanceamento na Simulação Distribuída}

As simulações conservativa e otimista têm seu desempenho afetado por fatores distintos. No caso da simulação conservativa, onde os processos lógicos (LPs) são freqüentemente bloqueados devido a restrições causais, o desempenho depende predominantemente do tempo que os LPs ficam impossibilitados de executar em paralelo. Por este motivo, problemas como garantir sincronização e evitar deadlocks devem ganhar atenção especial. Na simulação otimista os erros de causa e efeito não são evitados, portanto os $L P s$ sempre podem executar em paralelo. Neste tipo de simulação o principal limitante de desempenho é ocorrência de rollbacks, que se ocorridos em quantidade excessiva podem degradar muito o desempenho do sistema (Boukerche, 2002).

O problema de desbalanceamento de carga é aparente tanto na simulação otimista como na simulação conservativa. Segundo Carothers e Fujimoto (2000), na simulação otimista utilizando Time Warp é comum a seguinte situação: alguns LPs que são atribuídos a processadores sobrecarregados tendem a avançar muito devagar se comparados a outros LPs execu- 
tando em processadores com carga mais leve. Isso faz com que alguns $L P s$ avancem excessivamente em direção ao futuro da simulação podendo sofrer rollbacks causados por $L P s$ muito atrasados. Neste caso os rollbacks podem ser freqüentes e longos. A simulação conservativa, também se preocupa com as diferenças nas velocidades dos LPs. Um dos problemas que isso pode causar é um aumento significativo no tempo de espera dos LPs que permanecem bloqueados devido a restrições do protocolo (por exemplo, $C M B$ ) (Boukerche \& Das, 1997).

O aumento constante na utilização de estações de trabalho ou computadores pessoais conectados por uma rede de comunicação (clusters e NOWs) para execução de simulações indica uma tendência importante. Nessas plataformas há algumas preocupações que não existiam quando as simulações eram executadas apenas em plataformas dedicadas. Um programa utilizando o protocolo de simulação otimista Time Warp que se apresente bem balanceado numa plataforma com hardware dedicado, pode se tornar totalmente desbalanceado quando executado em máquinas onde há influências de outros usuários (Carothers \& Fujimoto, 2000).

Além da influência de usuários externos outros fatores contribuem para causar o problema da falta de balanceamento na simulação otimista. O desbalanceamento pode ser causado por fontes internas e externas. As fontes internas são advindas do próprio programa de simulação e as fontes externas são advindas da plataforma computacional multiusuário onde a simulação é executada em background. Existem três tipos de fontes internas de desbalanceamento: (1) população de eventos, (2) granulosidade dos eventos e (3) comunicação (Carothers \& Fujimoto, 2000).

A população de eventos é irregular quando o número de eventos processados num período do tempo de simulação difere de um $L P$ para outro. Desta forma alguns $L P s$ impõe uma maior sobrecarga ao processador onde estão executando já que precisam processar mais eventos para chegar ao mesmo ponto da simulação. Carothers e Fujimoto (2000) consideram a população irregular de LPs como um caso especial de população de eventos irregular. Nesta 
situação o número de LPs por processador difere significativamente fazendo com que certos processadores se tornem sobrecarregados por terem que processar mais $L P s$, e conseqüentemente mais eventos.

As diferenças na granulosidade dos eventos também provocam falta de balanceamento porque o tempo necessário para processar um evento varia de um $L P$ para outro. Mesmo que a população de eventos seja a mesma para todos os $L P S$, ainda assim um processador pode ser mais sobrecarregado do que outro já que os eventos a serem processados demandam mais tempo.

A última causa interna de desbalanceamento é a comunicação. Nesse caso, um LP ou um grupo de LPs muda seu padrão de comunicação fazendo com que comunicações remotas que não existiam passem a existir. $\mathrm{O}$ efeito dessa mudança de padrões é um aumento na carga dos LPs que passam a trocar mais mensagens com LPs de outros processadores.

Em plataformas multiusuárias como as $N O W s$, as interferências externas são bastante acentuadas. Carothers e Fujimoto (2000) citam duas fontes de interferências externas: (1) cargas dos usuários e (2) heterogeneidade dos processadores.

As cargas dos usuários são geradas por programas executados localmente ou remotamente no mesmo conjunto de máquinas onde a simulação está sendo executada em background. Estas cargas externas utilizam os mesmos recursos computacionais que os processos da simulação fazendo com que alguns LPs se tornem mais lentos, caso estejam sendo executados em máquinas onde o compartilhamento de processamento é alto. As cargas geradas pelo sistema (por exemplo, backup) também são consideradas como cargas de usuários.

A outra fonte externa de desbalanceamento corresponde à heterogeneidade dos processadores, onde o desempenho dos processadores é diferente em cada máquina que compõe a NOW. Para os processos da simulação os processadores mais lentos parecem estar mais sobrecarregados e provocam diferenças na taxa de progresso dos LPS. 


\subsubsection{Algoritmos de Escalonamento e Balanceamento de Carga}

As técnicas de escalonamento e balanceamento de carga são bastante difundidas na área de sistemas distribuídos. Nas últimas décadas muitos algoritmos destinados ao balanceamento de carga de aplicações paralelas em NOWs foram desenvolvidos; cada um destes algoritmos leva em consideração fatores que podem influenciar o desempenho das aplicações paralelas. Muitos destes fatores também afetam as simulações, no entanto, existem características que são inerentes à simulação distribuída, especialmente quando se trata da simulação otimista.

\subsubsection{Protocolo Otimista}

$\mathrm{Na}$ simulação distribuída otimista o conceito de utilização possui uma abordagem distinta das utilizada nos algoritmos de escalonamento para aplicações paralelas. Uma alta utilização do processador não significa necessariamente que um bom desempenho está sendo atingido já que o processador pode estar sendo mantido ocupado por computações que serão posteriormente desfeitas. A noção mais importante aqui é a eficiência da simulação, que é determinada pelo número de rollbacks ocorridos (Carothers \& Fujimoto, 2000). O conceito de utilização permanece ativo, mas somente são consideradas as computações úteis (que não sofrem rollback). Reiher e Jefferson (1990) chamam este conceito de utilização efetiva do processador, que é definida como "a fração de tempo na qual um processador executa computações que serão eventualmente consolidadas". Som e Sargent (2000) formalizam o conceito de utilização da seguinte forma: supõe-se que uma simulação iniciada no tempo 0 é observada até o tempo $T_{1}$; durante o intervalo $\left[T, T_{1}\right], 0<T<T_{1}$, o tempo de $c p u$ usado por um $L P L$ para executar computações que não sofreram rollback foi $T_{u}$; o resultado de $T_{u} /\left(T_{1}-T\right)$, que é um valor menor ou igual a 1 , corresponde à utilização de $L$ no intervalo $\left[T, T_{1}\right]$. O valor da utilização é diretamente proporcional ao número de rollbacks ocorridos. Muitos rollbacks indicam 
uma utilização baixa e uma utilização alta é caracterizada por poucos rollbacks, a figura 3.4 ilustra esta situação (Som \& Sargent, 2000).

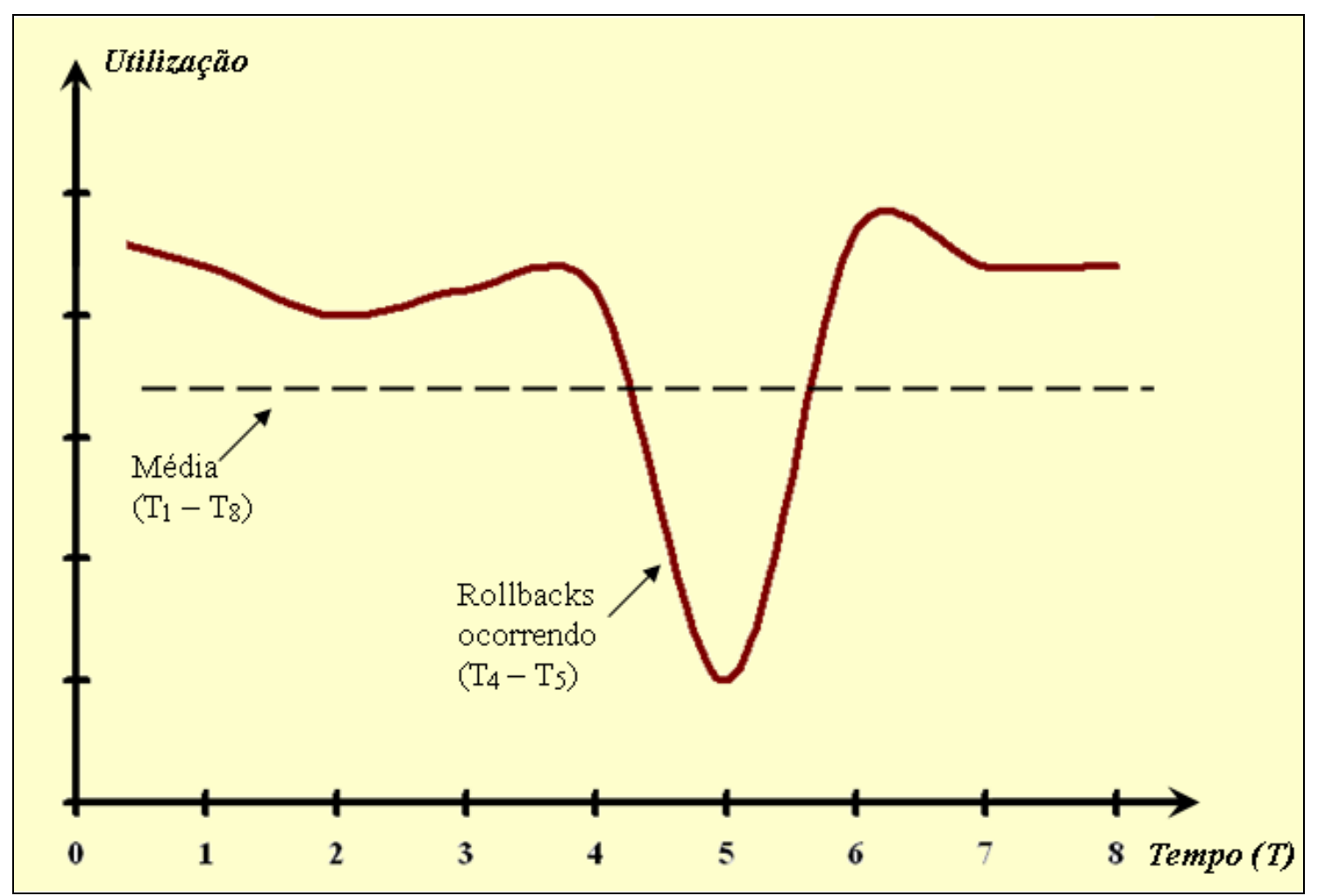

Figura 3.4 Utilização de um recurso no decorrer do tempo de uma simulação.

Um dos primeiros trabalhos que abordam o problema do balanceamento de carga na simulação otimista é o de Reiher e Jefferson (1990). O algoritmo desenvolvido baseia-se na utilização efetiva do processador para alterar o mapeamento dos processos aos processadores. A utilização é vista como a carga imposta ao processador pela computação útil realizada em um determinado intervalo. Segundo os autores, o balanceamento da carga é alcançado através do balanceamento das utilizações. $\mathrm{O}$ algoritmo calcula periodicamente as utilizações de cada $L P$ e a carga do processador (soma das utilizações dos LPs mapeados naquele processador). Se a carga não está balanceada é feita uma migração de $L P s$ dos processadores sobrecarregados para os menos carregados. Com esta migração pretende-se alterar a quantidade de processamento que cada $L P$ recebe, a fim de igualar a taxa de progresso dos $L P s$. Um $L P$ que está executando muito rapidamente sofre rollbacks causados pelos LPs mais lentos, portanto sua utilização diminui. Por sua vez, os $L P s$ mais lentos apresentam utilização alta já que não so- 
frem muitos rollbacks. Para igualar a taxa de progresso dos LPs o algoritmo altera o mapeamento dos processos de forma que os $L P s$ com baixa utilização recebem uma fatia menor do processamento obrigando-os a compartilhar o processador com outros $L P s$, e com isso sua velocidade é diminuída. Por outro lado, os $L P s$ com utilização alta são movidos para processadores mais ociosos para que tenham sua velocidade aumentada e passem a causar menos rollbacks nos outros LPs.

Outro trabalho que utiliza o conceito de utilização efetiva é o de Som e Sargent (2000). Este trabalho identifica algumas fraquezas no balanceamento de carga baseado em utilização apresentado por Reiher e Jefferson (1990) e inova com a introdução de novos conceitos, como o conceito de Strong Groups (SGs). Os $S G s$ são grupos de processos formados por $L P s$ que exercem forte influência uns nos outros. Estes grupos podem ser identificados a partir da análise do grafo de interconexão que descreve o modelo de simulação, e para tanto é necessário certo nível de conhecimento sobre o comportamento do modelo. Foi observado nesse estudo que, devido à dependência entre os LPs do mesmo SG, a taxa de progresso desses $L P s$ tende a convergir para o mesmo valor, sem qualquer intervenção no mapeamento dos processos. Assim, os $S G s$ podem ser vistos como uma única entidade e pode-se considerar a interação entre os grupos (figura 3.5). 


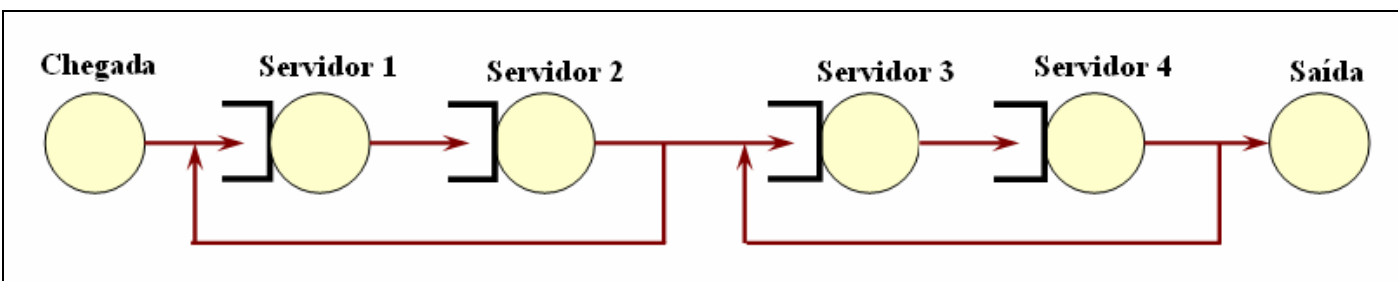

(a) Modelo de filas

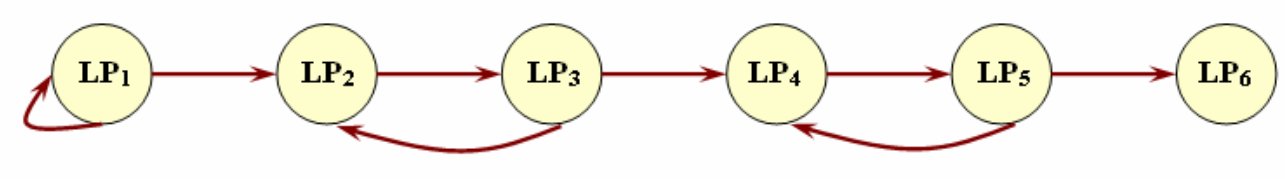

(b) Gráfico de Interconexão

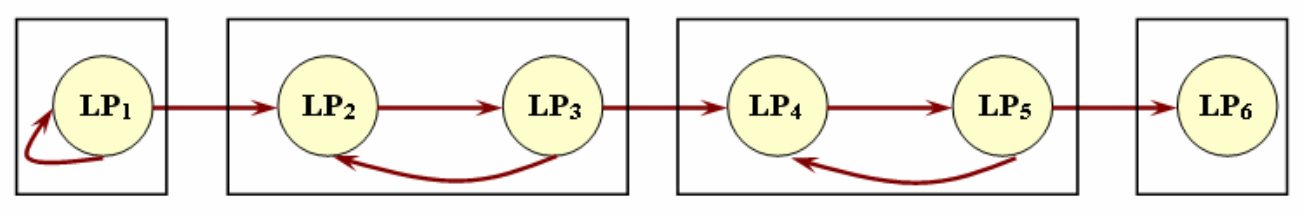

(c) Componentes fortemente conectados

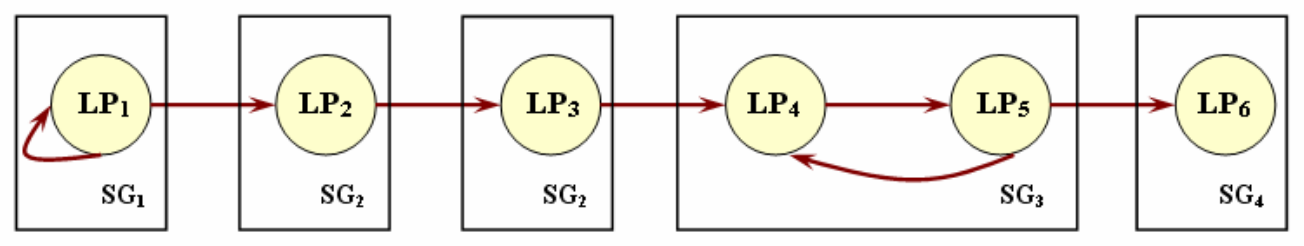

(d) Strong Groups

Figura 3.5 Modelos de filas, gráfico de interconexão, componentes fortemente acoplados e strong groups.

Segundo Som e Sargent (2000), a técnica de balanceamento baseado em utilização não é adequada quando os $L P S$ mais rápidos e os mais lentos não pertencem ao mesmo $S G$. Neste caso, pode não ocorrer nenhum rollback já que os processos não interagem entre si, ou os rollbacks podem ser bastante atrasados causando o uso ineficiente do processador ou até um problema de overflow. Isto se deve ao fato de que as migrações são feitas baseadas no valor da utilização, que reflete o número de rollbacks; como os rollbacks não ocorrem, nenhuma migração é feita, mesmo que as taxas de progresso dos LPs estejam desiguais. Ao contrário do algoritmo proposto por Reiher e Jefferson (1990), que utiliza os valores da utilização para alterar o mapeamento, o trabalho de Som e Sargent (2000) utiliza as informações sobre o ma- 
peamento para alterar os valores da utilização. O objetivo desta abordagem é encontrar valores de utilização bons para igualar a taxa de progresso de todos os $S G s$ do modelo de simulação. Para isto, tenta-se alcançar valores de utilização "alvo" para os $L P s$ de um mesmo SG. Como a taxa dos $L P S$ de um $S G$ é praticamente igual, para alterar a taxa de progresso de um SG em um fator $k$, basta alterar a taxa de progresso de todos os $L P s$ do grupo no mesmo fator $k$. A alteração da taxa de progressos de um $L P$ pode ser obtida reduzindo ou aumentando sua utilização, já que a utilização é diretamente proporcional à taxa de progresso. $\mathrm{O}$ algoritmo migra os $L P s$ necessários visando o alcance das utilizações alvo calculadas. Desta forma, espera-se que todos os $S G s$ progridam com taxas de progresso semelhantes. A figura 3.6 mostra a situação onde uma migração é necessária e como ficou a distribuição após a migração. No material pesquisado não é apresentada uma avaliação de desempenho do algoritmo proposto.

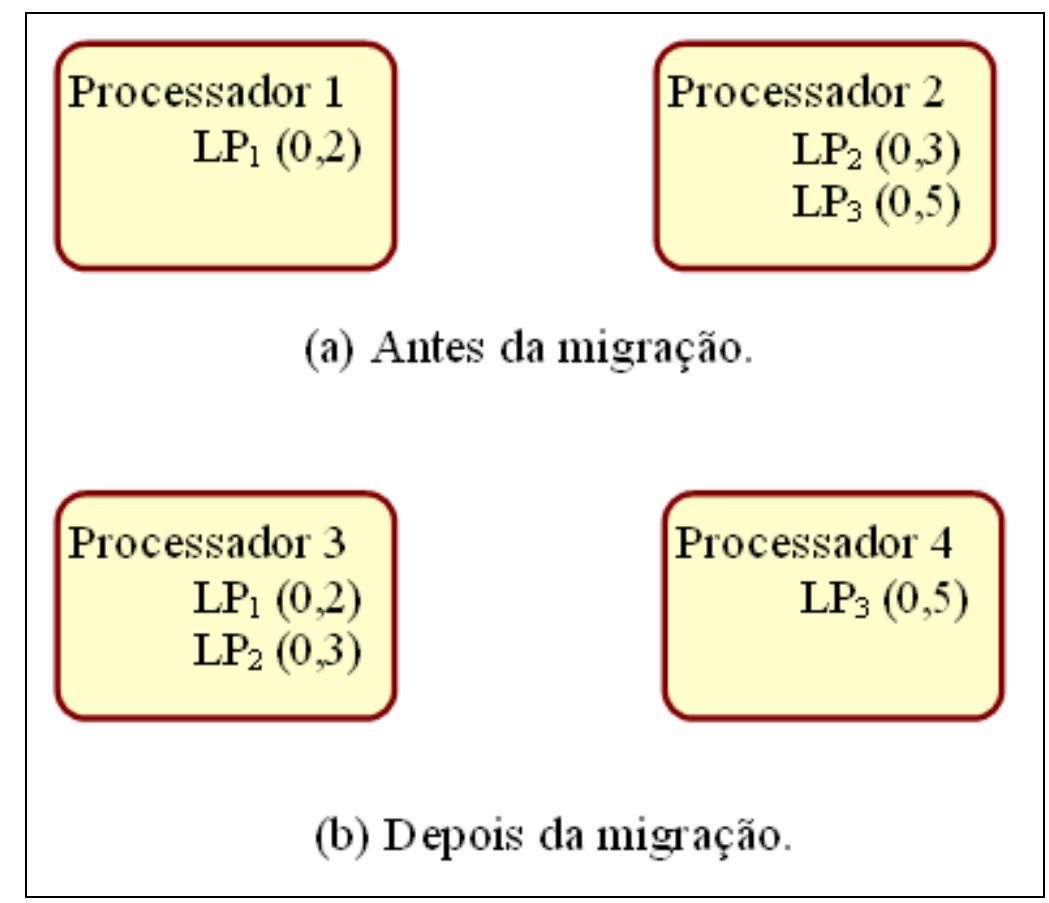

Figura 3.6 Estado dos processadores antes e depois de uma migração.

Som e Sargent (1993) apresentam uma heurística de mapeamento que em contraste dos estudos citados anteriormente, não utiliza o conceito de utilização. No entanto, o algoritmo criado também tem como objetivo igualar a taxa de progresso dos LPs para diminuir o número de rollbacks ocorridos. O estudo baseia-se em duas tarefas: (1) a identificação de e- 
ventos que, se executados, podem sofrer rollbacks, chamados de eventos de risco, e (2) a criação de uma heurística para tentar atrasar a execução dos eventos de risco. A identificação dos eventos de risco parte da seguinte afirmação: "Se um processo lógico Li pode escalonar eventos em um processo lógico $L j$, então $L i$ pode causar rollback em $L j$ '. Os eventos que devem ser atrasados são os eventos dos LPs que podem sofrer rollbacks. Os autores afirmam que uma boa maneira de atrasar a execução desses eventos é colocar os LPs que podem sofrer rollbacks no mesmo processador ou no menor número de processadores possível. Como a ocorrência de rollbacks demanda certa quantidade de processamento, os outros $L P$ s que poderiam sofrer rollbacks, que estão no mesmo processador, têm o seu progresso retardado, diminuindo as chances da ocorrência de um novo rollback. Os experimentos realizados com esse algoritmo resultaram em reduções de até $22 \%$ no número de rollbacks.

Em outro trabalho, Som \& Sargent (1998) criam um outro mecanismo para reduzir o número de rollbacks, mas que não é baseado no problema de mapeamento de processos aos processadores, como nos trabalhos anteriores. Em vez disso, o mecanismo emprega algoritmos probabilísticos na escolha do próximo evento que deve ser processado, nos casos onde há mais de um $L P$ no mesmo processador. O algoritmo mais utilizado para este fim em outros trabalhos é o LTF (Lowest Timestamp First, ou Menor Timestamp Primeiro). De vários eventos a serem executados no processador o algoritmo LTF escolhe o que possui menor timestamp, presumindo que este evento tem a menor chance de sofrer rollback devido à chegada de um evento com timestamp menor (straggler). O algoritmo probabilístico de Som e Sargent (1998) utiliza distribuições aleatórias geradas a partir de informações sobre eventos passados. Para cada evento que pode ser escolhido para executar é feita uma estimativa para saber qual a probabilidade deste evento sofrer rollback causado por um straggler, caso seja processado. O evento de menor probabilidade não é necessariamente o evento que possui o menor timestamp. O trabalho efetua previsão em vários níveis estimando a probabilidade das execuções 
de vários eventos futuros, e partir desta avaliação escolhe a seqüência de eventos mais promissora. Os ganhos com o uso deste algoritmo, sem a ajuda de qualquer algoritmo de mapeamento, variaram de $2 \%$ a $42 \%$ na redução do número de computações erradas.

Diversos outros trabalhos têm como objetivo comum corrigir a diferença existente nas taxas de progressos dos LPs para melhorar o desempenho dos LPs. Um dos diferenciais entre eles é a escolha da métrica utilizada para detectar esta diferença. Burdorf e Marti (1993) propõem uma abordagem onde periodicamente calculam-se a média e o desvio padrão dos valores dos relógios locais de todos os $L P s$ do sistema. Se a média dos relógios locais dos $L P S$ residentes em um determinado processador é maior que a média geral do sistema num fator de um desvio padrão, conclui-se que os $L P s$ desse processador estão avançando muito rapidamente em relação aos outros $L P s$ da simulação. Nesta situação outros $L P s$ são migrados para este processador para aumentar sua carga, e conseqüentemente diminuir sua velocidade de progresso. O LP escolhido para migração é aquele cujo relógio local possui o menor valor. Neste momento também ocorrem migrações entre outros processadores; os LPs que possuem o valor de seu relógio local abaixo da média (num fator de um desvio padrão) são migrados para os processadores onde estão executando os LPs com maior relógio local. Métricas parecidas baseadas em cálculos utilizando como base o relógio virtual local também são descritas em Schlagenhaft et al. (1995) e em Glazer e Tropper (1993).

Um dos trabalhos relacionados mais completos é o de Carothers e Fujimoto (2000). Onde é descrito o desenvolvimento da política de gerenciamento de carga BGE (Backgroud Execution). Este algoritmo, como o nome sugere, tem como principal objetivo possibilitar que simulações otimistas possam obter desempenho rodando em background em plataformas distribuídas, heterogêneas e compartilhadas por outros usuários. Este trabalho visa tratar dois problemas importantes, muitas vezes negligenciados pelos trabalhos anteriores, que são: a capacidade de adaptar a simulação para os processadores disponíveis em tempo de execução, 
visto que o conjunto de processadores pode mudar dinamicamente durante a execução; e a capacidade de lidar com o dinamismo das cargas externas que dificilmente podem ser controladas pelo protocolo de simulação, principalmente quando a simulação é executada em background em plataformas NOW. Dois componentes diferentes do algoritmo operam de maneira independente, um deles trata do balanceamento de carga realizando as migrações de LPs necessárias, e o outro é responsável por gerenciar o conjunto de processadores e decidir quais processadores usar. Ambos os componentes baseiam-se na mesma métrica, chamada de PAT (Processor Advance Time), que indica "a quantidade de tempo (real) que um processador necessita para avançar uma unidade do tempo virtual sem a presença de rollbacks". Este algoritmo só realiza migrações de grupos de $L P s$ e não de $L P s$ individuais. Para estimar o tempo que um grupo de LPs (cluster) leva para avançar uma unidade no tempo virtual uma outra métrica é utilizada, chamada de CAT (Cluster Advance Time), calculada a partir de medições do tempo de $C P U$ utilizado para processar os eventos dos $L P s$ de um cluster em intervalos passados; esta métrica corresponde ao tempo real necessário para um determinado cluster avançar uma unidade no tempo de simulação. A métrica $P A T$ de cada processador é calculada a partir do valor de CAT, considerando todos os clusters mapeados naquele processador. Quanto maior o valor de PAT mais sobrecarregado está o processador. Quando o componente de balanceamento de carga opera, primeiramente é escolhido um par de processadores que irão trocar processos. O processador com o maior valor de PAT (transmissor) deve enviar processos para algum que tenha um PAT menor (receptor); para escolher o receptor é considerado, além do valor de $P A T$, o custo de comunicação entre os processadores. Para cada processador participante da transferência, dois valores de PAT são definidos: um é calculado a partir do mapeamento atual e o outro é estimado através de um mapeamento hipotético resultante de uma possível migração. Se os valores estimados de $P A T$ indicam uma melhor situação que o valor atual, o mapeamento é ajustado para a melhor configuração (anteriormente hipotética) 
efetuando-se as migrações necessárias. O efeito da migração é que o PAT do transmissor após a transferência é equivalente ao PAT anterior menos a soma dos valores de $C A T$ dos clusters migrados. Conseqüentemente, o receptor tem seu PAT aumentado na mesma proporção. O algoritmo desenvolvido tenta encontrar diversas possibilidades de mapeamento possíveis a fim de minimizar a diferença dos $P A T$ dos processadores após a transferência; uma diferença baixa indica uma situação de igualdade nas taxas de progresso dos LPS do processador. A principal função do componente que gerencia o conjunto de processador é cuidar do efeito das cargas externas. Quando um processador perde todos seus LPs devido aos resultados de migrações realizadas, esse processador é retirado do conjunto dos processadores viáveis. Ele só é recolocado no conjunto quando sua carga atinge um valor duas vezes menor do que era antes de ser retirado do conjunto. Diversos experimentos foram realizados para provar a eficiência do algoritmo criado, e resultados variaram desde ganhos expressivos de mais de $100 \%$, até ganhos mais modestos, justificados pelas limitações dos modelos de simulação utilizados nos testes.

A utilização de técnicas de gerenciamento de carga é apenas uma das formas de otimizar o desempenho das simulações otimistas utilizando Time Warp. As técnicas criadas para este fim são conhecidas como mecanismos de garantia de estabilidade (Stability Assurance Mechanisms, ou SAMs), que monitoram o sistema Time Warp e fazem as mudanças necessárias para garantir uma execução eficiente. Outros $S A M s$ conhecidos incluem o controle de fluxo e as técnicas de gerenciamento adaptativo de buffers de memória (Carothers \& Fujimoto, 2000).

Alguns estudos utilizam mais de um método de garantia de estabilidade em conjunto, com o intuito de completar as limitações de um método com as potencialidades do outro. Este é o caso do estudo apresentado em Choe e Tropper (1999) que utiliza um mecanismo integrado empregando controle de fluxo e balanceamento de carga. O objetivo do controle de fluxo é 
retardar ao máximo a ocorrência de situações de desbalanceamento. O algoritmo de controle de fluxo é executado de modo contínuo para regular o trafego de mensagens entre pares de processadores. Para cada fluxo unidirecional de mensagens é atribuído um conjunto de tokens. Para enviar uma mensagem, o processador primeiro deve adquirir um token. Caso não haja tokens disponíveis, o processador é bloqueado. O número de tokens do conjunto é atualizado dinamicamente de acordo com um algoritmo estocástico de aprendizado. Em situações onde, apesar do uso do controle de fluxo, um desbalanceamento é detectado, o algoritmo de balanceamento de carga é chamado. Para medir a carga dos processadores esse algoritmo utiliza uma métrica baseada no número e no tamanho dos eventos executados no processador. Numa abordagem similar à de Carothers e Fujimoto (2000) o algoritmo controla a diferença entre as métricas dos processadores e tenta minimizá-la através de migrações.

\subsubsection{Protocolo Conservativo}

A quantidade de trabalhos que abordam o problema do escalonamento e balanceamento de carga para simulação conservativa é bastante limitada. Um dos trabalhos que abordam este assunto é o de Boukerche e Das (1997). Os autores utilizam uma versão otimizada do algoritmo de mensagens nulas desenvolvido por Chandy e Misra (1979). Este algoritmo usa mensagens com conteúdo nulo, mas com timestamp válido, para avisar aos processos lógicos que é seguro processar um determinado evento. Logo após processar um evento os LPs enviam mensagens nulas em todos os canais de saída (outros LPS). A métrica de carga utilizada por Boukerche e Das (1997) leva em conta o número de mensagens esperando na fila de cada canal de entrada do processador (ligações com outros $L P s$ ). São consideradas tanto as mensagens reais como as mensagens nulas. Para chegar a um valor que represente a carga do processador o algoritmo utiliza uma média baseada na quantidade de mensagens reais e nulas na fila de todos os canais do processador, e outros parâmetros como o tempo que o processador 
leva para processar uma mensagem. O objetivo do algoritmo é balancear a carga medida, ou seja, distribuir uniformemente as mensagens que trafegam de um $L P$ para outro. Para balancear a carga migram-se os LPs dos processadores mais sobrecarregados para os mais ociosos. Mas isto não é feito migrando-se qualquer $L P$; são escolhidos para residirem no mesmo processador os LPS que se comunicam mais freqüentemente (vizinhos), portanto antes de mover um $L P$ o algoritmo checa a melhor combinação para tentar juntar o maior número de vizinhos possível. Os resultados obtidos com este algoritmo foram significativos: médias variando de 30 a $50 \%$ de redução no tempo total de execução das simulações, dependendo do modelo utilizado.

No trabalho descrito em Boukerche e Das (2004) um técnica para reduzir o número de mensagens nulas na simulação conservativa foi desenvolvida. Em outro trabalho os autores mostram que o desbalanceamento de carga na simulação paralela com $C M B$ pode aumentar muito o número de mensagens nulas, anulando os ganhos de desempenho advindos da exploração do paralelismo (Boukerche e Das, 1999). A técnica para reduzir o número de mensagens nulas baseia-se no balanceamento de carga com migração para atingir o objetivo. Os autores implementam um esquema de balanceamento baseado em dois componentes, um processo balanceador de carga e um processo responsável por migrar LPs. O primeiro processo monitora a simulação e fornece informações para o segundo executar as migrações necessárias. A carga de cada processo é representada por uma métrica chamada pelos autores de "tamanho da fila do processador". Essa métrica representa a quantidade de trabalho futuro que o processador tem para fazer. O trabalho é definido pelo número de mensagens aguardando para serem processadas, incluindo mensagens nulas. $\mathrm{O}$ efeito geral do balanceamento é uma distribuição eqüitativa do número de mensagens nulas geradas pelos processadores.

O estudo de Gan et al. (2000) descreve um esquema para adicionar as técnicas de particionamento e balanceamento de carga no protocolo $C M B-S M P$, uma extensão do protocolo 
$C M B$ para máquinas de memória compartilhada que não utiliza mensagens nulas. A técnica de particionamento tem por objetivo escolher quais objetos são agrupados para formar um $L P$. É possível um particionamento simples sem agrupamento onde é criado um $L P$ para cada objeto da simulação, no entanto, este tipo de particionamento gera uma sobrecarga muito alta para a simulação. O esquema de particionamento de Gan et al. (2000) analisa o grafo de interconexão do modelo de simulação e tenta encontrar um bom particionamento que satisfaça alguns objetivos. O primeiro objetivo é maximizar o lookahead do LP. O lookahead corresponde ao tempo mínimo de serviço que um $L P$ leva para processar um evento, assim, durante este tempo os outros LPs podem processar seus eventos sem o risco de bloqueio. A informação de lookahead é obtida através do peso das arestas que ligam os LPs. O segundo objetivo é minimizar o desbalanceamento de objetos por $L P$. No grafo que descreve o modelo cada objeto possui um peso. Os objetos são agrupados nos $L P s$ de forma que no final cada um dos $L P s$ possuam pesos semelhantes. Um terceiro objetivo possível, mas que não foi tratado pelos autores, é otimizar a comunicação entre os LPs. Como o estudo é feito para máquinas de memória compartilhada, onde o custo de comunicação é baixo, os autores preferiram priorizar os dois primeiros objetivos. O esquema de balanceamento dinâmico de carga funciona de maneira que cada thread do sistema operacional é associado a um $L P$ em um dado momento. Qualquer thread do sistema pode simular qualquer $L P$. Os $L P s$ são guardados num pool e são escalonados de acordo com as restrições do protocolo de simulação. Existem dois pools de LPs, um ativo e outro passivo. Assim que um LP é retirado do pool ativo, ele é executado até que nenhum progresso possa mais ser feito, momento em que é colocado no pool passivo e outro $L P$ é retirado do pool ativo. Quando todos os $L P s$ do pool ativo são consumidos, os pools são invertidos. Os experimentos realizados pelos autores foram feitos para destacar a importância de cada componente do algoritmo (particionamento, balanceamento de carga e outros). Foi provado que os algoritmos são bons para os objetivos propostos. 
A simulação paralela síncrona é um dos mais simples protocolos de sincronização. Em contraste com os protocolos conservativos e otimistas, a simulação síncrona impõe barreiras de sincronização depois de cada passo da simulação. Dessa forma, todos os processos lógicos avançam no mesmo ritmo. Enquanto os protocolos conservativos e otimistas podem aproveitar melhor o paralelismo, a simulação síncrona tem a vantagem de possuir pouca sobrecarga advinda de mecanismos adicionais. A simulação síncrona também sofre com os efeitos do desbalanceamento de carga e requer mecanismos de balanceamento para melhorar o seu desempenho. Como nesse tipo de simulação um processo só pode avançar para o próximo passo quando todos tiverem executado o passo atual, o desbalanceamento faz com que os processos mais rápidos tenham que aguardar muito tempo sem executar operações.

Xu e Chung (2004) descrevem um modelo para analisar e prever o desempenho de uma simulação paralela síncrona através da estimativa de fatores como balanceamento de carga e o modelo de comunicação. Os autores não implementam as técnicas de balanceamento, mas estudam como os vários fatores afetam o desempenho da simulação.

\subsection{Considerações finais}

As grandes transformações tecnológicas ocorridas nos últimos anos permitiram que sistemas distribuídos se tornassem uma excelente alternativa de organização do processo computacional. Para que este sistema computacional seja utilizado de maneira eficiente ele deve ser auxiliado pelo escalonamento de processos, que define as regras de alocação dos processos aos processadores, e que se realizado de maneira eficiente, os objetivos a que se propõe o sistema serão alcançados.

Existem diversos fatores que podem influenciar um escalonamento e diversos objetivos possíveis, tornando muito difícil à existência de um algoritmo de escalonamento que seja 
bom para toda e qualquer situação. E é nesta questão que está à preocupação deste trabalho o escalonamento de processos em simulações distribuídas.

Muitos algoritmos de escalonamento e balanceamento de carga foram desenvolvidos para otimizar o desempenho de simulações distribuídas. Existem algoritmos tanto para simulação conservativa como para a simulação otimista, sendo que a última tem recebido mais atenção dos pesquisadores.

O principal objetivo dos algoritmos desenvolvidos para a simulação conservativa é maximizar as opções de paralelização dos modelos, já que as simulações deste tipo estão sujeitas a bloqueios constantes decorrentes das restrições impostas pelos protocolos. No caso da simulação otimista, a maioria dos algoritmos tem como principal objetivo minimizar o número de rollbacks ocorridos, já que esta característica é o principal limitante do desempenho deste tipo de simulação. O equilíbrio nas taxas de progresso dos LPs é apresentado como um objetivo comum para os dois tipos de simulação, já que as diferenças nessas taxas são as principais causas das instabilidades das simulações.

Embora muitos dos trabalhos pesquisados apresentem algoritmos com objetivos semelhantes, há muitas variações no emprego das técnicas para atingir esses objetivos. Uma característica que apresenta grande variação entre os trabalhos é a métrica de desempenho utilizada para avaliar a situação da simulação e proporcionar decisões sensatas. Pode-se perceber que praticamente todas as métricas propostas podem trazer benefícios para a simulação distribuída, desde que empregadas nos algoritmos apropriados.

Um ponto importante a observar é que há um consenso entre os autores pesquisados no que se refere à forte ligação entre as aplicações de simulação e seus algoritmos de escalonamento e balanceamento de carga. Alguns estudos afirmam que os algoritmos convencionais não são capazes de detectar as diferenças entre as taxas de progresso dos processos lógicos da simulação. Para que isto seja possível são necessárias que métricas específicas sejam analisa- 
das. Um exemplo de métrica que satisfaz esta necessidade é a utilização efetiva do processador, proposta por Reiher e Jefferson (1990) para uso na simulação otimista. Por outro lado, percebe-se uma limitação nos estudos que afirmam que os algoritmos convencionais são insuficientes, por exemplo (Boukerche e Das, 1997). Não se encontram na literatura estudos comparativos entre algoritmos convencionais e específicos. É provável que a ausência destes estudos se justifique pelo sucesso obtido com os algoritmos específicos para a simulação. Apesar da simulação fornecer muitas informações que se mostram úteis para minimizar o tempo da execução da simulação, esse fato não exclui a possibilidade de se utilizar algoritmos de escalonamento não específico com sucesso. Além disso, nenhum desses trabalhos discute o impacto de se utilizar esses algoritmos específicos. Todos esses algoritmos dependem da obtenção de dados específicos da simulação, que muitas vezes podem ser de difícil obtenção, ocasionando uma sobrecarga para a simulação.

Nenhum dos trabalhos estudados apresenta uma análise de como uma simulação distribuída se comportaria se fosse utilizado um particionamento não específico, que não dependesse das características específicas da simulação.

Uma grande vantagem na utilização de particionamento não específico é a existência desta ferramenta em diversos sistemas distribuídos. Desta forma, a proposta deste trabalho é avaliar o quanto se estaria ganhando e o quanto se estaria perdendo se um algoritmo não específico fosse utilizado. 


\section{Capítulo 4 - ADAPTAÇÃO E INTEGRAÇÃO DAS FERRAMENTAS - WARPED E AMIGO}

\subsection{Considerações Iniciais}

Originalmente o $A M I G O$ foi concebido para auxiliar os ambientes de passagem de mensagens, como $P V M$ e $M P I$, na distribuição dos processos através dos nós de uma plataforma distribuída. O suporte a múltiplas políticas independentes é uma característica que contribuiu para o sucesso da integração do $A M I G O$ com o WARPED, permitindo que a política criada para auxiliar no particionamento de objetos fosse facilmente acoplada ao $A M I G O$. Inicialmente, a seção 4.2 descreve o novo esquema de particionamento balanceado proposto por este trabalho para permitir que o Warped realize a distribuição dos objetos utilizando os escalonadores disponíveis no $A M I G O$.

A seguir são apresentadas as diversas modificações realizadas em classes internas do núcleo do Warped para adequá-lo às necessidades do $A M I G O$, e para que a utilização das duas ferramentas em conjunto pudesse ser possível. Esses aperfeiçoamentos são descritos na seção 4.8 . 


\subsection{Esquema de particionamento}

O esquema de particionamento criado visa balancear a carga das máquinas envolvidas na simulação, distribuindo os objetos de acordo com a capacidade de cada máquina. A capacidade é uma estimativa feita levando em conta alguns fatores, como resultados de benchmarks executados nas máquinas e a carga medida em tempo de execução. Um esquema como esse é especialmente útil quando as máquinas que formam a plataforma são diferentes entre si, no que diz respeito à capacidade de seus recursos.

A política utilizada como base para o esquema foi originalmente desenvolvida e testada no auxílio aos ambientes de passagem de mensagem na execução de aplicações paralelas em plataformas heterogêneas. A heurística criada para essa política baseia-se na contribuição que cada máquina oferece à plataforma, isto é, caso os índices de desempenho mostrem que uma máquina tem o dobro de capacidade que outra, assume-se que a primeira é capaz de receber duas vezes mais processos do que a segunda. Essa idéia foi aproveitada para criar o esquema de balanceamento para as simulações distribuídas. Nesse caso, a política recebe a informação do número total de objetos da simulação e define a quantidade de objetos que os LPs irão conter, utilizando o algoritmo original de distribuição de processos. Essa informação é repassada para o Warped que monta as partições de acordo com o resultado da política.

Conforme as características das aplicações variam, os dispositivos das máquinas que influenciam o desempenho das aplicações também variam. Por exemplo, uma aplicação que utiliza grandes quantidades de memória será mais afetada pela característica da memória das máquinas, como a quantidade disponível e a velocidade de acesso. Por outro lado, uma aplicação que é altamente dependente da comunicação entre os processos tem seu desempenho mais afetado pela velocidade da conexão de rede entre as máquinas. No caso das simulações 
distribuídas, isso não é diferente. Cada modelo de simulação possui características particulares e pode ter seu desempenho afetado por diferentes recursos.

Um dos objetivos do estudo feito neste trabalho é avaliar o impacto do uso de diferentes tipos de informações para estimar a capacidade de cada máquina na execução de um modelo de simulação específico. Essa avaliação foi facilitada por uma característica presente na política utilizada que permite utilizar diferentes informações, tanto estáticas como dinâmicas, para o cálculo da capacidade das máquinas. As informações estáticas são aquelas que estão disponíveis a priori, antes da execução de qualquer modelo, e visam representar quantitativamente características da máquina, como por exemplo, quantidade de memória disponível, velocidade do processador, velocidade da memória e velocidade da conexão de rede. As informações dinâmicas são coletadas durante a execução do modelo e visam representar o estado da carga da plataforma. Essas informações, também conhecidas como índices de carga, são utilizadas para estimar o impacto causado pela simulação nos recursos da máquina.

Os índices de carga, se combinados com as informações estáticas, formam os chamados "índices de desempenho" (Branco, 2004) que podem ser usados em casos onde a plataforma é compartilhada com outras simulações ou aplicações. Em situações onde a carga da plataforma está em níveis baixos, a decisão de particionamento pode ser feita considerando apenas as informações estáticas. Quando várias instâncias de simulações são enviadas à plataforma ao mesmo tempo, é essencial empregar os índices de desempenho. Quando os recursos se aproximam de certos limites, submissões de novas simulações podem sobrecarregar as máquinas e degradar significativamente o desempenho do sistema. As informações dinâmicas são capazes de indicar se as decisões de particionamento anteriores causaram falta de balanceamento, sendo possível tomar decisões futuras melhores e retardar, ou até mesmo evitar, os efeitos maléficos da sobrecarga das máquinas. 


\subsubsection{Avaliação da heterogeneidade}

Medir o desempenho de cada máquina é uma atividade essencial para caracterizar a heterogeneidade da plataforma. Para alimentar a política de particionamento realizou-se uma avaliação para classificar as máquinas de acordo com sua capacidade quando executam certo tipo de operação, seja o processamento de instruções pelo processador, leitura e escritas na memória ou troca de mensagens pela rede. Essas informações correspondem às informações estáticas que juntamente com os índices de carga formam os índices de desempenho.

A fim de representar a capacidade de dispositivos específicos três métricas de desempenho foram definidas: (1) velocidade de processador, (2) capacidade de memória e (3) velocidade da rede. A abordagem empregada para as medições foi a utilização de benchmarks ${ }^{l}$.

Para medir a velocidade de processador foi utilizado o conjunto de programas $S S$ BENCH (SSBench CPU). Esse benchmark consiste em oito testes para a unidade de processamento de inteiros e oito testes para a unidade de ponto-flutuante. Os testes são bastante diversificados. Alguns são algoritmos específicos como cálculos de números primos, resolução de jogos, filtros de imagens, cálculos de fractais e inversão de matrizes, enquanto outros representam aplicações reais formadas de múltiplos algoritmos, como uma aplicação para fotometria astronômica. O resultado do benchmark é um índice que corresponde à média geométrica dos tempos de execução de cada teste. A escolha do SSBENCH foi baseada em algumas razões, como o fato de ele ser gratuito e de código aberto e possuir testes variados e representativos.

O benchmark STREAM (McCalpin(a) ) foi o escolhido para testar a velocidade da memória das máquinas. Esse é um benchmark sintético baseado em quatro operações, aplicadas em vetores:

\footnotetext{
${ }^{1}$ Programas destinados a quantificar a capacidade dos recursos através de testes representativos.
} 
COPY: $a(i) \leftarrow b(i)$;

SCALE: $a(i) \leftarrow q * b(i)$;

ADD: $a(i) \leftarrow b(i)+c(i)$;

TRIAD: $\mathrm{a}(\mathrm{i}) \leftarrow \mathrm{b}(\mathrm{i})+\mathrm{q} * \mathrm{c}(\mathrm{i})$.

Para a avaliação feita nesse estudo o resultado considerado foi apenas o da operação TRIAD, que representa todas as outras. Essa operação corresponde a ler um número em ponto flutuante de uma posição de memória, multiplicá-lo por uma constante, somar o resultado a outro número lido da memória e gravar o resultado final numa terceira posição da memória. A quantidade de dados manipulados em cada iteração é de 24 bytes: cada número em ponto flutuante possui oito bytes (64 bits) e são feitas três operações na memória (2 leituras e 1 escrita).

A justificativa do benchmark STREAM baseia-se na sua capacidade de medir o desempenho da memória em operações conjuntas com o processador, já que são realizadas operações matemáticas. Estudos anteriores mostraram que o resultado da operação TRIAD corresponde a um índice que representa com qualidade a velocidade da memória de sistemas reais (McCalpin(b) ). O resultado fornecido pelo benchmark é a capacidade da memória em $M B / s$. O benchmark foi configurado para utilizar uma grande quantidade de memória, que não excede a capacidade total da memória de cada máquina, mas é suficiente para testar o desempenho do sistema de memória além do alcance dos níveis de cache.

No caso das medições da capacidade da rede, a estratégia adotada foi executar o programa ping entre todos os pares de máquinas disponíveis. O programa ping envia pacotes ICMP (Internet Control Message Protocol) e mede a velocidade da resposta. Utilizando a configuração padrão que define pacotes de 64 bytes, a medição reflete basicamente a latência da rede. Nas simulações com Time Warp a latência causa um impacto significante já que o padrão de comunicação geralmente consiste numa grande quantidade de mensagens de tama- 
nho reduzido. O resultado de cada máquina foi considerado como a média de dois conjuntos de tempos de resposta; o primeiro consiste dos tempos obtidos enviando uma mensagem da máquina $A$ para todas as outras máquinas da rede e o segundo consiste nos tempos de todas as outras para a máquina $A$.

De posse dos resultados de cada teste, adotou-se uma estratégia de ranking para produzir valores de desempenho comparáveis e padronizados. Considerando que tem-se um conjunto de máquinas $C$ que consiste de $n$ máquinas heterogêneas. A potência de uma máquina $m_{i}$ $\in \mathrm{C}$ é $p_{i}$. Os valores dos benchmarks do processador, da memória e da rede são denotados por $b p_{i}, b m_{i}$ e $b r_{i}$, respectivamente. Cada máquina recebe três "notas" referentes ao seu desempenho em cada benchmark, expressas em função do desempenho de uma máquina padrão $m_{p}$. A nota de uma maquina $i$ corresponde à divisão do resultado da máquina $i$ pelo resultado da máquina padrão. Isso é válido para as métricas em que valores medidos maiores significam desempenho melhor, como é o caso do benchmark da memória $(\mathrm{bm})$. No caso das métricas em que valores de medição menores significam desempenho melhor, a nota considerada corresponde ao inverso da divisão, como acontece nos benchmarks do processador ( $b p$ ) e da rede (br). A equação 1 expressa a nota final de uma máquina $i$ :

$$
p_{i}=\frac{b p\left(m_{p}\right)}{b p_{i}} \cdot w b p+\frac{b m_{i}}{b m\left(m_{p}\right)} \cdot w b m+\frac{b r\left(m_{p}\right)}{b r_{i}} \cdot w b r
$$

onde $w b p, w b m$ e $w b r$ correspondem aos pesos de cada métrica na nota final.

Os pesos podem ser ajustados de acordo com as características do modelo a ser simulado. Se há conhecimento sobre o padrão de utilização de recursos do modelo podem ser atribuídos pesos maiores para as métricas que representam os recursos que mais afetam o desempenho da simulação. 
Quando se deseja executar apenas uma instância de uma simulação na plataforma e há garantia que a plataforma é dedicada às simulações, as informações estáticas de heterogeneidade são suficientes para alimentar a política de particionamento. A maior parte dos cenários de avaliação de desempenho foi analisada considerando esse tipo de plataforma.

\subsection{2. Índice de carga}

Uma parte dos estudos deste trabalho foi investigar as vantagens e desvantagens de executar simulações numa plataforma compartilhada. Pode ser útil executar uma simulação ao mesmo tempo em que outras aplicações estão rodando na plataforma, principalmente quando essas aplicações não utilizam completamente os recursos da máquina, deixando-os parcialmente ociosos. Mesmo em simulações mais pesadas pode-se tirar proveito de casos onde o processador pode ficar ocioso quando há muita comunicação a ser feita, possibilitando que outra aplicação aproveite os ciclos que seriam desperdiçados.

Nas plataformas compartilhadas os índices de carga indicam a real situação da plataforma após sucessivas decisões de particionamento, sendo possível alimentar o algoritmo de particionamento com novas informações a serem utilizadas nas decisões subseqüentes.

Para os estudos deste trabalho os índices de carga escolhidos foram a quantidade de processos na fila do processador; e a quantidade de memória livre, que pode indicar com precisão os níveis de saturação da máquina. O excesso de operações de swap que ocorrem quando a memória satura podem diminuir a capacidade das máquinas a níveis mínimos.

A política coleta o índice periodicamente (intervalos de 1 segundo) e calcula uma média móvel exponencial para uma máquina $i$ considerando as $N$ medições mais recentes, de acordo com a equação 2 :

$$
v_{i}=\left(l_{i}-v a_{i}\right) \cdot \frac{2}{1+N}+v a_{i},
$$


onde $v_{i}$ é a média móvel exponencial, $l_{i}$ é a medida atual do índice de carga e $v a_{i}$ é a média do período anterior.

A média móvel exponencial é empregada para suavizar a medição do índice, impedindo que valores de pico de pouca duração afetem a medição. Além disso, por considerar valores passados, esse tipo de média pode representar a carga da máquina $[L S F]$.

O cálculo do índice também depende do estabelecimento de um limiar de carga mínima. Quando o valor medido está abaixo desse limiar considera-se que a carga da máquina não faz diferença em sua capacidade. Quando a carga ultrapassa o limiar a sua capacidade é reduzida proporcionalmente. Nesse caso o valor da capacidade é expressa pela equação 3.

$$
c_{i}=p_{i} \cdot \frac{v_{i}}{t h_{i}}
$$

onde $t h_{i}$ é valor do limiar de carga.

\subsubsection{Algoritmo de particionamento}

O algoritmo de particionamento balanceado baseia-se na estimativa da contribuição que cada máquina oferece à plataforma. A contribuição de uma máquina $i$ é definida como a porcentagem $\left(S h_{i}\right)$ da capacidade de toda a plataforma oferecida pela máquina $i$, como expresso na equação 4. A capacidade total da plataforma é o somatório da capacidade das $n$ máquinas que a compõem.

$$
S h_{i}=\frac{c_{i}}{\sum_{j=0}^{n-1} c_{j}}
$$

A quantidade de objetos $\left(o_{i}\right)$ que compõem o $L P$ atribuído a uma máquina $i$ corresponde à multiplicação do total de objetos $(T o)$ da simulação pela porcentagem de contribuição da máquina $i$, como formalizado na equação 5 . 


$$
o_{i}=T o \cdot S h_{i}
$$

O procedimento de particionamento recebe uma lista de máquinas ordenada pela capacidade e uma lista de objetos organizada pela aplicação. A alocação de objetos inicia pela máquina mais potente e continua até chegar à máquina menos potente ou até o número de objetos não alocados ser igual a zero. A lista de objetos é percorrida seqüencialmente e nenhuma informação sobre a natureza dos objetos é considerada.

Após a alocação é possível que a soma total de objetos alocados seja maior ou menor que o total de objetos da simulação, devido aos arredondamentos necessários. Nesse caso os valores são ajustados de forma que se foram alocados menos objetos que o necessário, os objetos restantes são alocados para as máquinas mais potentes, e caso haja sobra de objetos alocados, a diferença é subtraída das máquinas menos potentes.

O resultado desse esquema de particionamento é que se a capacidade calculada de uma determinada máquina equivale a $x \%$ da capacidade total da plataforma, a partição que formará o $L P$ atribuído àquela máquina conterá $x \%$ do total de objetos da simulação.

\subsection{Integração das ferramentas}

Várias adições foram feitas à arquitetura do núcleo do Warped, para possibilitar o acesso ao AMIGO. Esta seção descreve as classes criadas e o funcionamento da interface. A figura 4.1 apresenta um diagrama contendo as classes criadas e as classes originais do núcleo que com elas interagem. As originais estão representadas na cor branca, enquanto que as classes criadas estão em tom de cinza. 


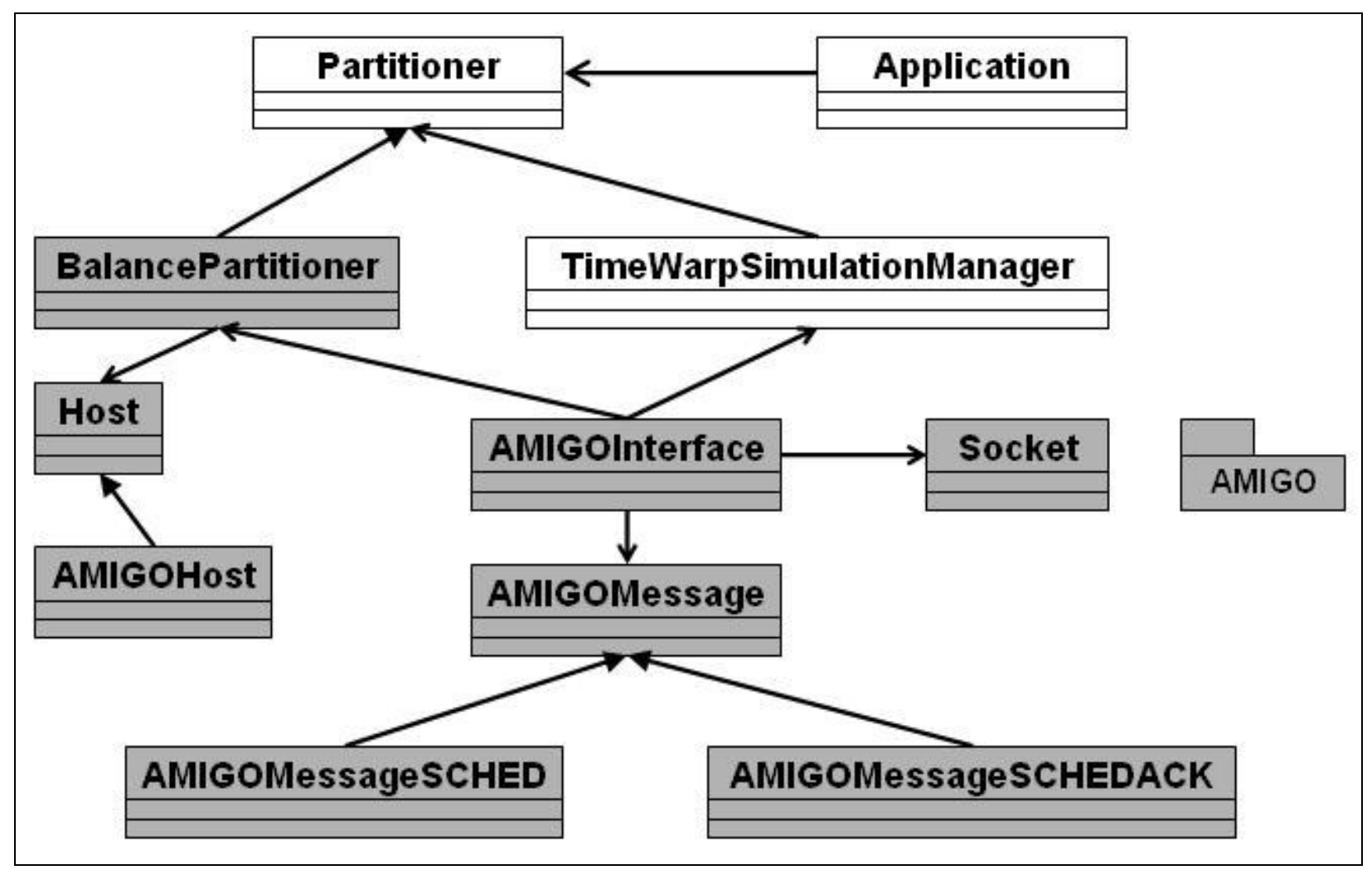

Figura 4.1 Diagrama de classes da interface com o $A M I G O$.

A classe BalancePartitioner, derivada de Partitioner, contém a implementação de um método partition preparado para acessar o mecanismo de particionamento balanceado. Esse método prepara uma lista de identificadores (IDs) dos receptores Time Warp Simulation Manager (TWSMs) que estarão envolvidos no particionamento e repassa essa informação, juntamente com o número total de objetos, para a parte responsável pela interface com o $A M I G O$.

Os mecanismos da interface são implementados primariamente na classe AMIGOInterface. Assim que a instância dessa classe recebe os IDs dos TWSMs e a quantidade de objetos, ela trata de efetuar a conversão dos $I D s$ dos gerenciadores para os endereços $I P$ das máquinas correspondentes. Isso é necessário porque o $A M I G O$ identifica as máquinas pelo seu endereço IP e, por outro lado, o Warped utiliza números inteiros para rotular cada gerenciador. Num sistema com $N$ máquinas, há um TWSM por máquina, sendo que o da máquina mestre recebe o $I D 0$ e as máquinas escravo recebem os $I D s 1,2,3$, até $N-1$.

O mecanismo de conversão de $I D$ para $I P$ e vice-versa, foi implementado dentro da classe TimeWarpSimulationManager. Durante a fase de inicialização todas as máquinas exe- 
cutam um procedimento para descobrir o $I P$ local. Então, cada escravo envia seu $I P$ para o mestre que os armazena numa tabela. Uma pesquisa nessa tabela permite descobrir um IP através do $I D$ e vice-versa. Essa conversão é utilizada em duas situações: (1) quando o método de particionamento faz uma requisição à interface passando uma lista de $I D s$ que devem ser convertidos para IPs antes de enviar ao AMIGO; (2) quando a interface recebe o resultado do particionamento do $A M I G O$, os IPs devem ser convertidos para IDs que são retornados à classe particionadora.

A especificação do $A M I G O$ (Souza, 2000) define um conjunto de mensagens de propósitos específicos que compõe o protocolo de comunicação do $A M I G O$ com outras entidades do sistema. Originalmente, um subconjunto de mensagens é destinado à comunicação entre o $A M I G O$ e o módulo que necessita das informações de escalonamento dos processos. Nesse caso, este módulo é o Warped. Para as necessidades deste trabalho apenas dois tipos de mensagem precisam ser tratados. O primeiro, de código AM_SCHED, é enviado pelo Warped para requisitar um particionamento, e o segundo, de código $A M \_S C H E D A C K$, representa o retorno do $A M I G O$.

Algumas classes foram criadas para representar as mensagens e os mecanismos para manipulá-las. Qualquer implementação é derivada da classe abstrata AMIGOMessage. As informações comuns a todas as classes são: o código da mensagem, o código e o endereço $I P$ do módulo transmissor, e o código e o endereço IP do módulo destino.

O tratamento da mensagem AM_SCHED foi implementado na classe AMIGOMessageSCHED. O conteúdo da mensagem é composto do número de objetos e da lista de possíveis receptores (TWSMs). Essa classe, como representa uma mensagem que deve ser enviada para o $A M I G O$ deve implementar um método pack para empacotar o conteúdo da mensagem num buffer que será transmitido pela rede juntamente com o cabeçalho. 
A classe que representa a mensagem AM_SCHEDACK é a AMIGOMessageSCHE$D A C K$. Uma instância dessa classe é criada quando a interface recebe a mensagem correspondente do $A M I G O$. Ela contém uma lista de pares (IP, quantidade de objetos), que associa a cada máquina a quantidade de objetos que o $L P$ residente nela irá conter, de acordo com a decisão do $A M I G O$. Como essa classe representa uma mensagem que é recebida do $A M I G O$ ela deve implementar um método unpack que recebe um buffer e preenche os membros da classe com as informações de particionamento. Assim as informações podem ser facilmente obtidas, de forma mais amigável, através dos métodos da classe.

A resposta que a interface retorna para a classe particionadora é uma lista de instâncias do tipo Host. A interface preenche os IDs dos objetos, após a conversão, dentro das instâncias de Host e as informações podem ser facilmente obtidas através dos métodos próprios dessa classe. A classe AMIGOHost, derivada de Host, é usada dentro da interface para operações que envolvem o uso do endereço $I P$.

A comunicação física entre o Warped e o $A M I G O$ é feita através de sockets locais TCP. A distribuição original do Warped fornece a classe Socket, que cria um código orientado a objetos para utilizar mais facilmente as primitivas de baixo nível da interface socket.

\subsection{Implementação no núcleo}

No caso das decisões de particionamento baseadas apenas em informações estáticas sobre as máquinas, o AMIGO é dispensável. Nas primeiras implementações realizadas nesse estudo as informações estáticas eram inseridas na política que estava conectada ao AMIGO. As decisões eram tomadas pela política que deixava os índices de carga desativados. Por questões de desempenho, optou-se por reimplementar o algoritmo de particionamento dentro do núcleo do Warped e criar a possibilidade de ativar e desativar o $A M I G O$, conforme a necessidade. 
Esta implementação pode ser vista como uma otimização do método de particionamento balanceado, que dependendo do perfil da plataforma de execução, pode escolher utilizar apenas informações estáticas, ou contar com o AMIGO para fornecer informações dinâmicas. A primeira opção é ideal para uma plataforma heterogênea mas dedicada, enquanto que a segunda opção é útil quando há vários usuários compartilhando a plataforma; ambos são cenários comuns. A possibilidade de ativar e desativar o $A M I G O$ é especialmente útil, já que o perfil da plataforma pode mudar no intervalo entre uma simulação e outra.

A informação sobre a utilização ou não do $A M I G O$ é descrita no arquivo de configuração do Warped (Apêndice A, seção A.4). Essa informação é interpretada pelo método partition, da classe BalancePartitioner, fazendo com que o programa siga caminhos diferentes dependendo da situação. Assim como no caso onde se utiliza a interface com o $A M I G O$, o resultado do particionamento é uma lista de instâncias de Host, preenchidas com as quantidades de objetos a serem alocados para cada $L P$.

O esforço principal feito nesse caso foi reimplementar o código do particionamento e a criação de classe Host, que antes não era necessária. Isso permitiu que o código do particionador se tornasse simples e flexível.

\subsection{Particionamento centralizado e descentralizado}

Alguns conceitos de simulação distribuída são aplicados pelo Warped de maneira que confusões podem ser feitas. O Warped denomina $L P$ um grupo de objetos que serão colocados para executar numa mesma máquina; diferente da literatura que caracteriza $L P$ como um processo lógico que representa uma das $N$ partes da simulação, e que possui alguns atributos (seção 2.3). Na visão Warped há apenas um $L P$ por máquina, formado pelos objetos que executarão nesta máquina, assim a quantidade de LPS é definida de acordo com a quantidade de máquinas que serão utilizadas da plataforma. O que o Warped chama de objeto, é o que se reco- 
nhece como um $L P$ definido pela literatura, ou seja, cada objeto Warped possui um relógio para indicar o progresso da simulação; gera eventos; tem um estado e possui filas de eventos enviados e recebidos. Neste trabalho optou-se por manter a terminologia usada pela ferramenta.

Originalmente no Warped, o particionamento é realizado de forma descentralizada em cada máquina, a figura 4.2 ilustra as fases de um particionamento descentralizado. Isso é possível porque todas as máquinas recebem a lista de todos os objetos da simulação (fase 1), executam o algoritmo de criação de objetos integralmente criando localmente todos os objetos (fase 2). Após executar o algoritmo de particionamento, cada máquina escolhe sua partição e registra seus objetos como objetos locais (fase 3). Depois cada máquina informa a lista dos seus objetos locais para as demais máquinas, quando estas recebem as listas, elas registram estes objetos como objetos remotos, chamados pelo Warped de objetos proxy.

Quando se utilizam apenas informações estáticas ou o particionamento é realizado pelo algoritmo round-robin, pode-se garantir que o particionamento realizado de forma descentralizada terá o mesmo resultado em todas as máquinas. Isso não é verdade quando se utiliza o $A M I G O$ para tomar a decisão de particionamento. Devido aos padrões de atualização das informações adotados pela arquitetura do $A M I G O$ e das políticas, não é garantido que todos os AMIGODs repassarão a mesma informação para todas as instâncias do Warped. 


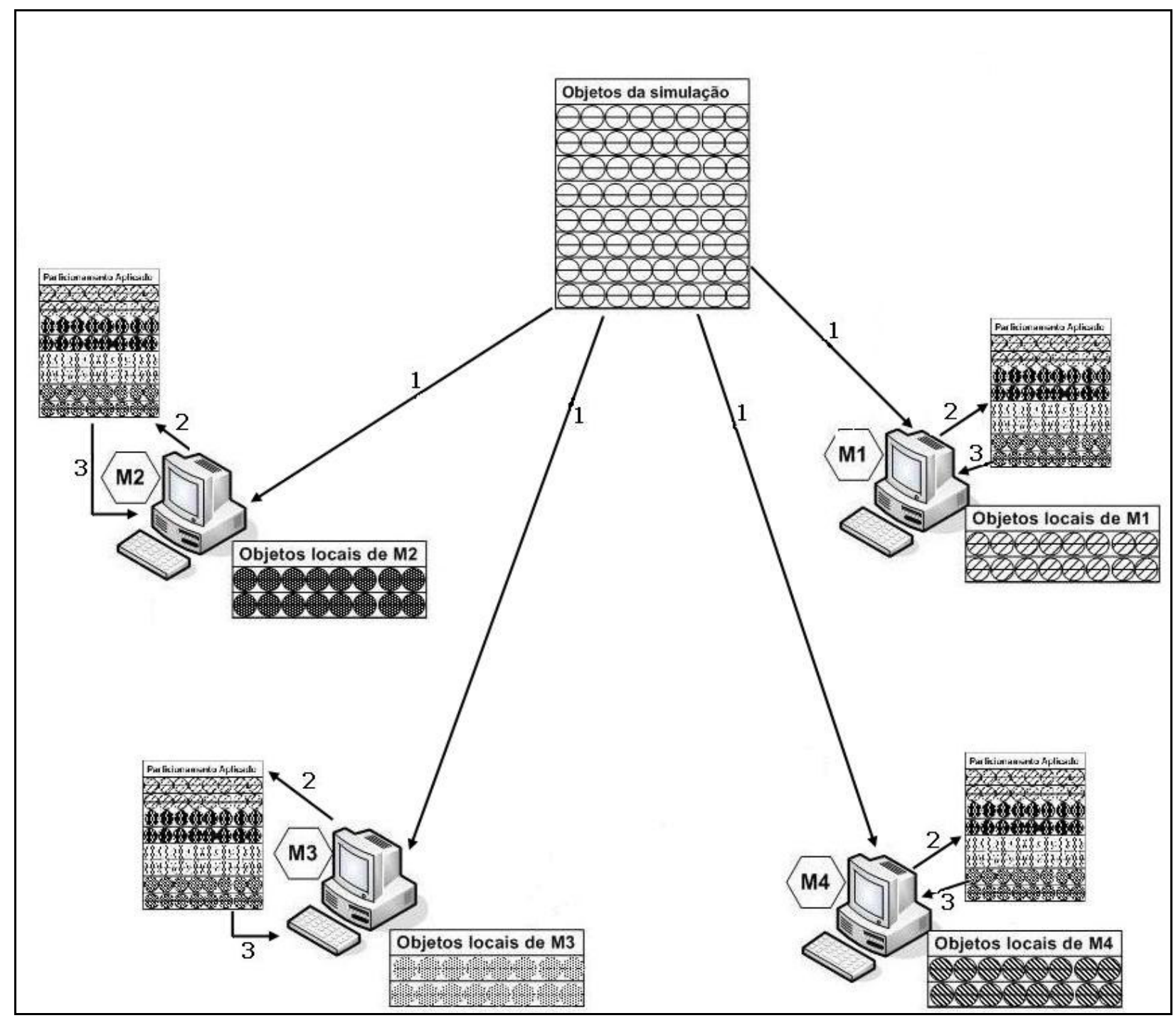

Figura 4.2 Exemplo de um particionamento descentralizado.

Para contornar essa situação optou-se por modificar o esquema de organização do mecanismo de particionamento. Para isso foi criada uma forma de efetuar o particionamento de forma centralizada, ilustrado na figura 4.3. Essa tarefa é deixada por conta da máquina mestre (máquina M1) que efetua o particionamento (fase 2 e 3) e envia para as máquinas uma lista com os nomes dos objetos pertencentes a cada uma (fase 4). 


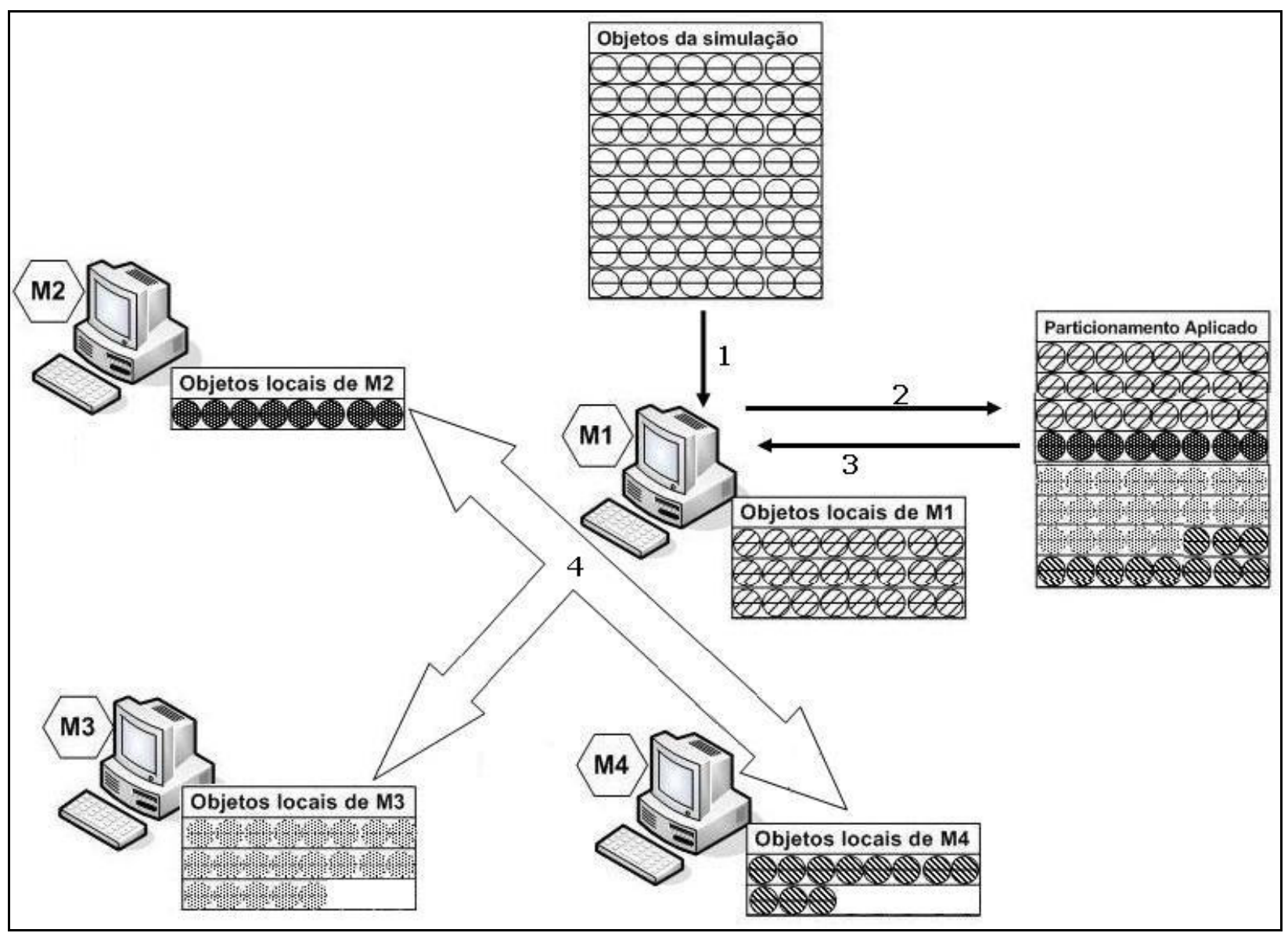

Figura 4.3 Exemplo de um particionamento centralizado.

A mensagem é criada através da instanciação da classe PartitionMessage. A criação dessa classe foi facilitada pelo fato do Warped fornecer a classe abstrata KernelMessage, que descreve uma interface padrão para troca de mensagens entre os $S M S$.

A criação dos objetos ainda é feita de forma descentralizada. Quando uma máquina recebe a lista com os nomes dos seus objetos, ela compara com a lista de objetos criados e retira os seus objetos, registrando-os como locais. Os demais são registrados como proxy. Os procedimentos originais de registro do Warped foram mantidos.

A figura 4.4 ilustra os fluxos de execuções dos particionamentos centralizado e descentralizado. A fase 1 corresponde à criação de todos os objetos da simulação. A fase 2 é a realização do particionamento. No modo centralizado $(a)$ apenas a máquina mestre $(M 1)$ realiza essa fase, enviando em seguida os nomes dos respectivos objetos de cada máquina. No modo descentralizado $(b)$ todas as máquinas aplicam o particionamento definido para saber 
seus objetos locais. Os procedimentos das fases 3 e 4 para o modo centralizado foram mantidos como está na implementação original do Warped. Eles correspondem, respectivamente, à troca de nomes de objetos entre as máquinas, para que todas tenham a informação de onde estão localizados os demais objetos, e o registro destes objetos do tipo proxy.

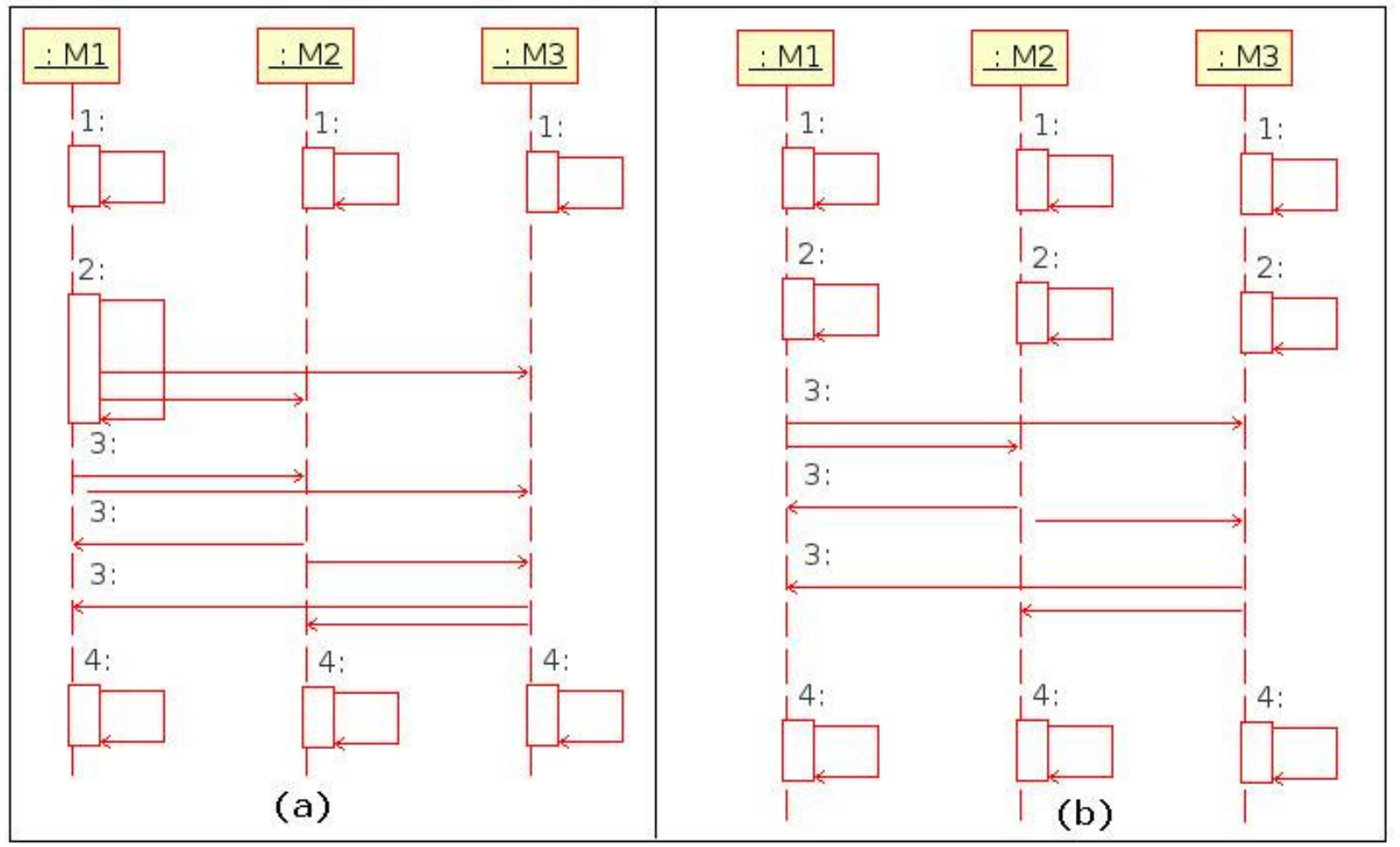

Figura 4.4 Fluxos dos particionamentos centralizado (a) e descentralizado (b).

\subsection{Informações adicionadas ao arquivo de configu- ração}

A arquivo de configuração do Warped foi adaptado para conter mais informações sobre particionamento. Para isso foi criado o escopo Partitioning. A figura 4.5 mostra um exemplo de configuração desse escopo. O arquivo completo de configuração do Warped é apresentado e descrito no apêndice A, seção A.4. 


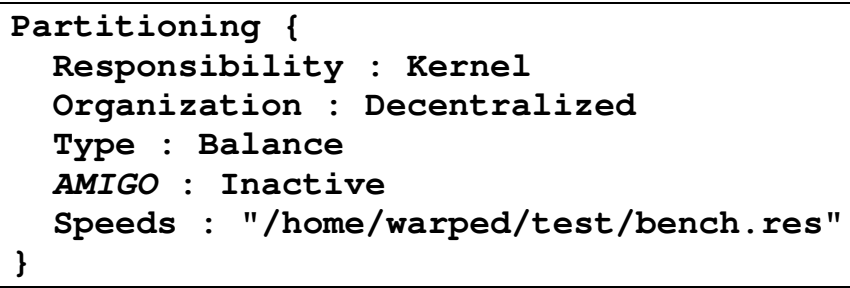

Figura 4.5 Arquivo de configuração: escopo Partititioning.

O parâmetro Responsibility indica a parte responsável pelo particionamento. Os valores possíveis para esse parâmetro são Kernel e Application. No primeiro caso, o núcleo assume a responsabilidade pelo particionamento. No segundo caso a responsabilidade é da aplicação, sendo que cabe ao usuário fornecer os métodos necessários. Os outros parâmetros do escopo Partitioning são ignorados caso o valor de Responsibility seja igual a Application.

O valor de Organization define se o particionamento será centralizado ou descentralizado, como descrito na seção 4.5. Os valores possíveis são Centralized ou Decentralized. Quando o AMIGO está ativo a escolha desse parâmetro deve ser Centralized, caso contrário, a escolha é livre. Contudo, é recomendado que o particionamento seja descentralizado quando se utilizam apenas informações estáticas.

Para o parâmetro Type, os valores possíveis são Balance ou Round-robin. No primeiro caso, o particionamento balanceado é escolhido, enquanto que no segundo caso, o escalonamento é feito pelo algoritmo round-robin que distribui os objetos igualmente entre os LPS.

O parâmetro $A M I G O$, que pode receber os valores Active ou Inactive, indica se o A$M I G O$ será ativado ou não. Esse parâmetro só é reconhecido quando o tipo de particionamento escolhido é Balance.

O parâmetro Speeds indica o caminho completo do arquivo que contém as notas obtidas pelas máquinas na avaliação de heterogeneidade. Ele é usado apenas quando o $A M I G O$ está inativo, situação na qual o Warped utiliza o particionamento balanceado implementado no núcleo. A figura 4.6 ilustra o formato de um arquivo de notas. 


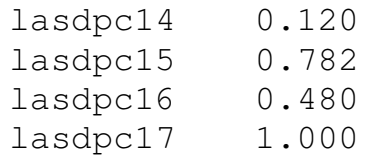

Figura 4.6 Arquivo com notas de benchmarks.

\subsection{PHOLD}

O modelo PHOLD (Parallel HOLD) é uma proposta utilizada para avaliar o desempenho de programas de simulação paralela de eventos discretos. Ele é uma extensão do $H O L D$, um modelo largamente usado para avaliar o desempenho algoritmos de listas de eventos seqüenciais. Seu principal objetivo é ser um modelo de carga sintética capaz de fornecer resultados que possibilitem comparações entre diferentes mecanismos de simulação paralela e distribuída, tanto otimistas como conservativos. (Fujimoto, 1990b).

A simulação consiste de um conjunto de objetos organizados de acordo com alguma topologia. Cada objeto comunica-se com um número fixo de vizinhos. O processamento de uma mensagem consiste em executar alguma computação por certo tempo e então enviar uma nova mensagem para outro objeto.

O modelo pode ser configurado através dos seguintes parâmetros:

1. Número de objetos;

2. População de mensagens: quantidade de mensagens (eventos) que se movem entre os objetos. Para cada mensagem recebida apenas uma mensagem é enviada, por isso o número de mensagens circulando permanece sempre o mesmo;

3. Função de incremento do timestamp: se um objeto recebe um evento no tempo T, ele calcula, de acordo com alguma distribuição, um incremento $I$ e envia um novo evento com tempo de recebimento igual a $T+I$; 
4. Função movimento: usada para definir o destino do próximo evento a ser enviado;

5. Granulosidade computacional: define por quanto tempo (pode ser 0 ) o objeto ficará executando algum trabalho antes de enviar o próximo evento;

6. Configuração inicial: define a localização (no tempo e no espaço) de cada evento inicial antes que a simulação comece.

A implementação do modelo $P H O L D$ criada para os testes deste trabalho possibilita que o modelo seja configurado de acordo com as especificações citadas anteriormente. Cada nova configuração deste modelo genérico deve ser visto como um novo modelo de simulação independente.

Os objetos são organizados numa topologia do tipo torus de duas dimensões. A quantidade total de objetos é definida pelo número de linhas e colunas do torus. Cada objeto pode se comunicar com quatro vizinhos, que são identificados pelas direções: norte $(\mathrm{N})$, sul $(\mathrm{S})$, leste (L) e oeste (O). Além disso, um objeto pode enviar mensagens para si mesmo. Cada objeto recebe uma identificação única utilizada como nome de objeto dentro do sistema Warped. O nome é formado pelos números da linha e coluna na qual o objeto está posicionado, p.ex. $(2,3)$. A figura 4.7 ilustra a organização de objetos numa topologia torus, juntamente com o detalhamento da conexão de um objeto com seus quatro vizinhos. 


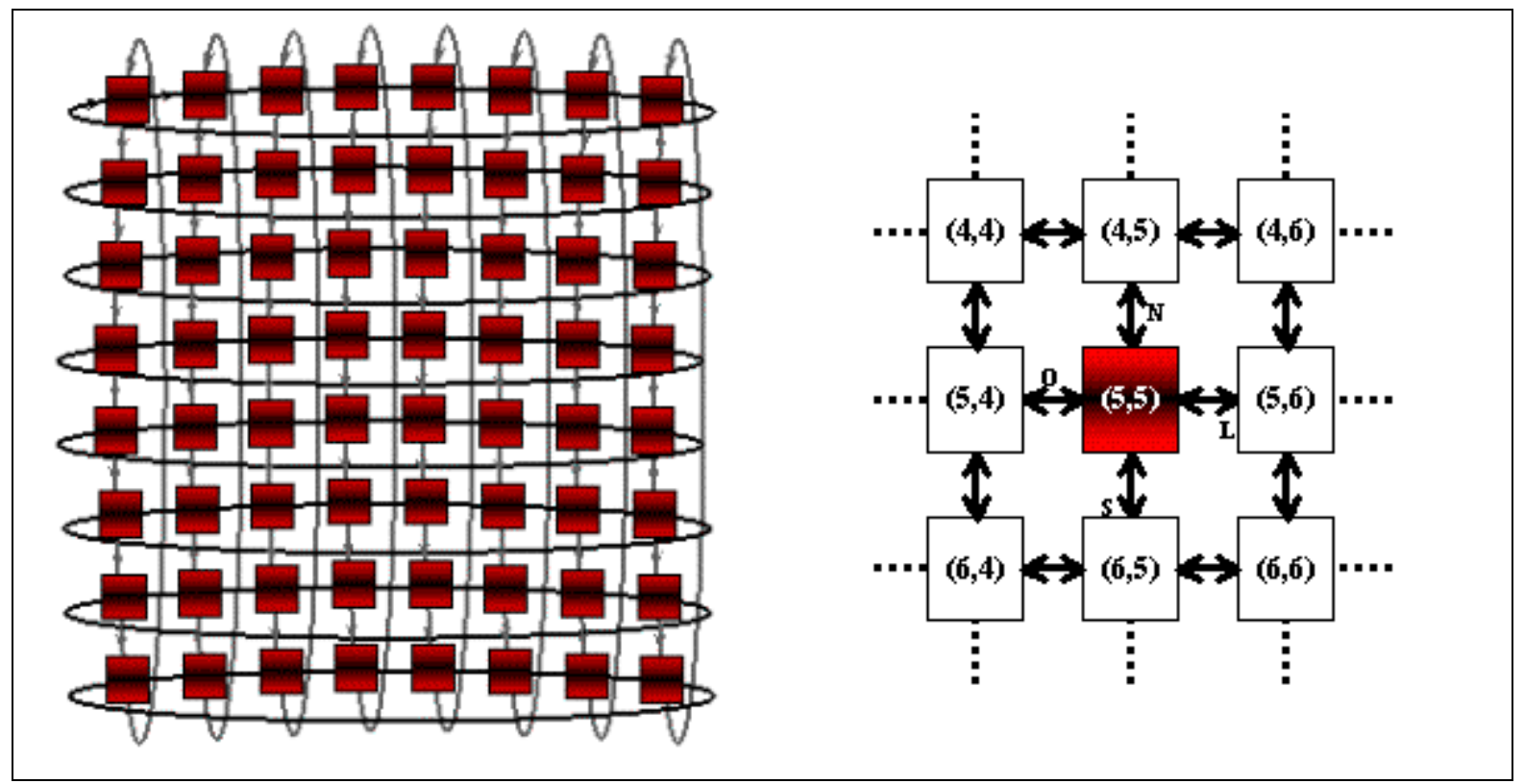

Figura 4.7 Organização dos objetos.

Na função movimento, o destino da próxima mensagem depende da origem da última mensagem recebida. Há cinco opções de movimentação: para frente, para trás, para a direita, para a esquerda e para si mesmo. Uma dessas direções será escolhida de acordo com as probabilidades escolhidas pelo usuário. As probabilidades são definidas em porcentagem e a escolha é feita de acordo com uma distribuição uniforme. Por exemplo, quando um objeto recebe uma mensagem do vizinho oeste e a variável aleatória gerada define que a movimentação deve ser para frente, a próxima mensagem será enviada para o vizinho leste. Para casos onde a última mensagem foi originada pelo próprio objeto, considera-se a localização da última fonte diferente de si mesmo. A tabela 4.1 mostra outras opções de movimentação possíveis.

Tabela 4.1 Tabela de escolha do receptor da próxima mensagem.

\begin{tabular}{|c|c|c|c|c|}
\hline \multicolumn{1}{|c|}{ Fonte } & Sul & Leste & Norte & Oeste \\
\hline Freção & Norte & Oeste & Sul & Leste \\
\hline Trás & Sul & Leste & Norte & Oeste \\
\hline Direita & Leste & Norte & Oeste & Sul \\
\hline Esquerda & Oeste & Sul & Leste & Norte \\
\hline
\end{tabular}


A granulosidade foi simulada através da inserção de um cálculo de multiplicação de matrizes no processamento de um evento. O tamanho do atraso a ser inserido pode ser controlado pelo tamanho das matrizes. Além do parâmetro que define o tamanho médio das matrizes, é possível especificar um desvio padrão que controla a diferença na quantidade de trabalho de um objeto para outro. Esses dois parâmetros são utilizados para gerar números aleatórios de acordo com uma distribuição normal. As quantidades de linhas e colunas das duas matrizes são definidas por esses números aleatórios, que são gerados apenas uma vez, durante a inicialização do objeto. Dessa forma, o tamanho do trabalho (atraso) de um determinado objeto permanece constante durante toda a simulação e não depende dos eventos.

Foi assumido que inicialmente os eventos estão uniformente distribuídos entre os objetos. Para determinar a localização inicial de cada evento do tempo, é calculado um número aleatório distribuído uniformemente no intervalo entre 0 e o tempo virtual máximo de inicialização dos eventos.

A definição do modelo $P H O L D$ não define o tempo máximo de duração da simulação. Nos testes realizados neste trabalho, foi utilizado um mecanismo do Warped que permite definir um tempo virtual máximo de duração para qualquer simulação. Assim que o último GVT calculado é maior ou igual ao valor máximo definido, a simulação é finalizada.

Pelo fato desse modelo ser amplamente empregado nos trabalhos de outros pesquisadores, incluindo alguns dos trabalhos citados no capítulo 3 desta dissertação, optou-se por implementá-lo no Warped e utilizá-lo como base para os testes deste trabalho. Os experimentos com o modelo PHOLD mostraram sua utilidade para avaliar o desempenho do mecanismo Time Warp em diferentes situações. 


\subsection{Correções de bugs e outros aperfeiçoamentos no código do Warped}

Durante o processo de aprendizado e experimentação do Warped, foram encontrados alguns problemas que momentaneamente impediram o avanço dos estudos. Em todos os casos optou-se por investir o tempo necessário para corrigir os erros encontrados ou para aperfeiçoar problemas de desempenho. A seguir são descritos os problemas encontrados e suas soluções.

\subsubsection{Garbage collecting}

O processo de limpeza é feito pelo gerenciador da simulação sempre que o GVT é atualizado. O Warped organiza o processo de limpeza de modo que cada módulo efetua a sua limpeza interna independentemente. Basicamente, os módulos que precisam executar a limpeza são: (1) o gerenciador de salvamento de estados, (2) o gerenciador de saída e (3) o gerenciador das listas de eventos.

O processo 1 apaga os estados armazenados antes do novo $G V T$, que certamente não precisarão ser recuperados, já que a simulação não pode mais voltar para um tempo menor que o GVT. O processo 2 apaga as informações sobre os eventos enviados, que são armazenadas pelo gerenciador de saída caso haja a necessidade de enviar anti-mensagens. No processo de limpeza 3 todos os eventos processados que haviam sido armazenados e que não tenham sido previamente cancelados por anti-mensagens são apagados.

Nesses processos foi encontrado um bug que podia fazer a simulação falhar sem avisar o motivo. O motivo era um erro na ordem de execução dos processos, que estavam organizados da seguinte maneira: os processos 1, 2 e 3, nessa ordem, eram executados para cada objeto da simulação. Havia casos onde um evento E enviado por um objeto A para um objeto B, 
era apagado pelo gerenciadores das listas de eventos de $\mathrm{B}$, supondo que os processos eram executados antes para B. Quando o gerenciador de saída de A (transmissor do evento) fosse consultar o tempo virtual de envio do evento E, para verificar a necessidade de enviar uma antimensagem, um erro ocorria pelo fato da instância do evento E já ter sido apagada.

A solução foi alterar a organização das execuções dos processos de limpeza. A nova implementação garante que o processo 3 só inicia quando o processo 2 estiver concluído para todos os objetos.

\subsubsection{Rollbacks secundários}

Nas primeiras simulações com o modelo PHOLD, foi verificado um problema de desempenho. Após algumas investigações, percebeu-se que o número de eventos que circulavam no sistema aumentava rapidamente e sem limites durante a simulação. Como o modelo PHOLD só envia um único evento para cada evento recebido, o número de eventos circulando deve permanecer sempre constante.

A causa do problema era uma implementação incompleta do mecanismo de rollback, que além de ser um erro também afeta o desempenho do sistema. Os rollbacks secundários ocorrem quando um objeto recebe uma antimensagem que provoca o cancelamento de um evento já processado. Nessa situação o objeto deve reiniciar a simulação a partir do tempo imediatamente anterior ao processamento do evento.

Para permitir o perfeito funcionamento do Warped, investiu-se um esforço significante para implementar completamente o mecanismo de rollbacks secundários. Isso exigiu modificações em várias partes do código, incluindo o gerenciador da simulação e no gerenciamento das listas de eventos.

Originalmente, o código do gerenciador da simulação continha comandos apenas para cancelar os eventos processados pelo próprio objeto que estava sofrendo rollback. Não havia 
uma implementação que se preocupasse em cancelar as mensagens enviadas aos outros objetos. O código adicionado ao Warped executa os passos necessários para garantir que o estado de todos os objetos envolvidos no rollback seja restaurado ao instante de tempo correto.

Para isso foi criada uma implementação através da qual é possível obter uma lista de todos os eventos que foram enviados para outros objetos após o timestamp do rollback. Essa lista é dividida de acordo com a máquina de destino de cada evento. Caso o evento tenha sido enviado para um objeto da mesma máquina, a função de rollback secundário pode ser chamada diretamente. Para cada evento enviado é feito um teste para verificar se o LVT do objeto receptor é maior que o timestamp de recebimento do evento. Caso o teste seja positivo, a função de rollback do gerenciador da simulação é chamada recursivamente para cada objeto com LVT avançado. No caso dos eventos enviados para outras máquinas, são enviadas mensagens com uma lista de identificadores dos eventos que devem ser cancelados. Quando o gerenciador da simulação da máquina receptora recebe a lista, o mesmo código usado para cancelamento de eventos de objetos locais é usado.

\subsubsection{Desempenho do escalonamento dos objetos}

Uma das operações freqüentemente realizadas numa simulação é a de requisitar ao gerenciador de escalonamento uma referência ao próximo evento que deve ser executado. Isso corresponde à execução do algoritmo de escalonamento LTF (Lowest Timestamp First).

Após algumas análises detalhadas de desempenho percebeu-se que, dependendo do número de objetos na simulação, o tempo gasto com a operação de "pegar um evento" poderia corresponder a até $99 \%$ do tempo total de execução.

Para descobrir o motivo de um desempenho tão ruim, foram feitas algumas medições para avaliar o tempo de execução de cada trecho do código envolvido na operação. O motivo principal do problema era o excesso de operações de resolução de nomes de objetos. Esse 
procedimento consiste numa busca em uma tabela de espalhamento passando o nome do objeto e recebendo como resultado um ponteiro para a instância do objeto.

A solução foi reescrever parte do código do gerenciador das listas de eventos para obter acesso direto à lista dos eventos recebidos de cada objeto. Na solução original o próprio objeto não guardava uma referência à sua lista de eventos recebidos, sendo necessária à busca pelo nome do objeto. Como a organização das listas de eventos é descentralizada não houve motivo que impedisse a colocação de uma referência à lista dentro de cada objeto. Essa solução melhorou consideravelmente o desempenho das simulações.

\subsubsection{Estatísticas da simulação}

Para analisar o desempenho dos diferentes tipos de particionamento foi necessário adicionar algumas informações sobre a simulação. Elas correspondem basicamente às estatísticas sobre o desempenho da simulação. O objetivo dessas adições foi permitir que fossem feitas observações mais claras do desempenho durante o ajuste dos algoritmos desenvolvidos.

Ao todo, 14 informações são fornecidas ao usuário assim que a simulação termina, que são:

1. Tempo total da simulação;

2. Quantidade de eventos processados;

3. Quantidade de eventos desfeitos por rollback;

4. Quantidade de eventos consolidados (não desfeitos);

5. Quantidade total de rollbacks;

6. Quantidade de rollbacks primários;

7. Quantidade de rollbacks secundários;

8. Tempo útil (gasto com processamento de eventos consolidados) 


\section{Tempo gasto com rollbacks;}

10. Eventos processados por segundo;

11. Eventos consolidados por segundo do tempo total;

12. Eventos consolidados por segundo do tempo útil;

13. Tempo de espera por mensagens;

14. Rollbacks causados por máquina.

Para cada máquina da simulação é exibido um conjunto de estatísticas. A figura 4.8 mostra um exemplo da saída contendo as estatísticas citadas, considerando uma simulação com quatro máquinas, numeradas de 0 a 3.

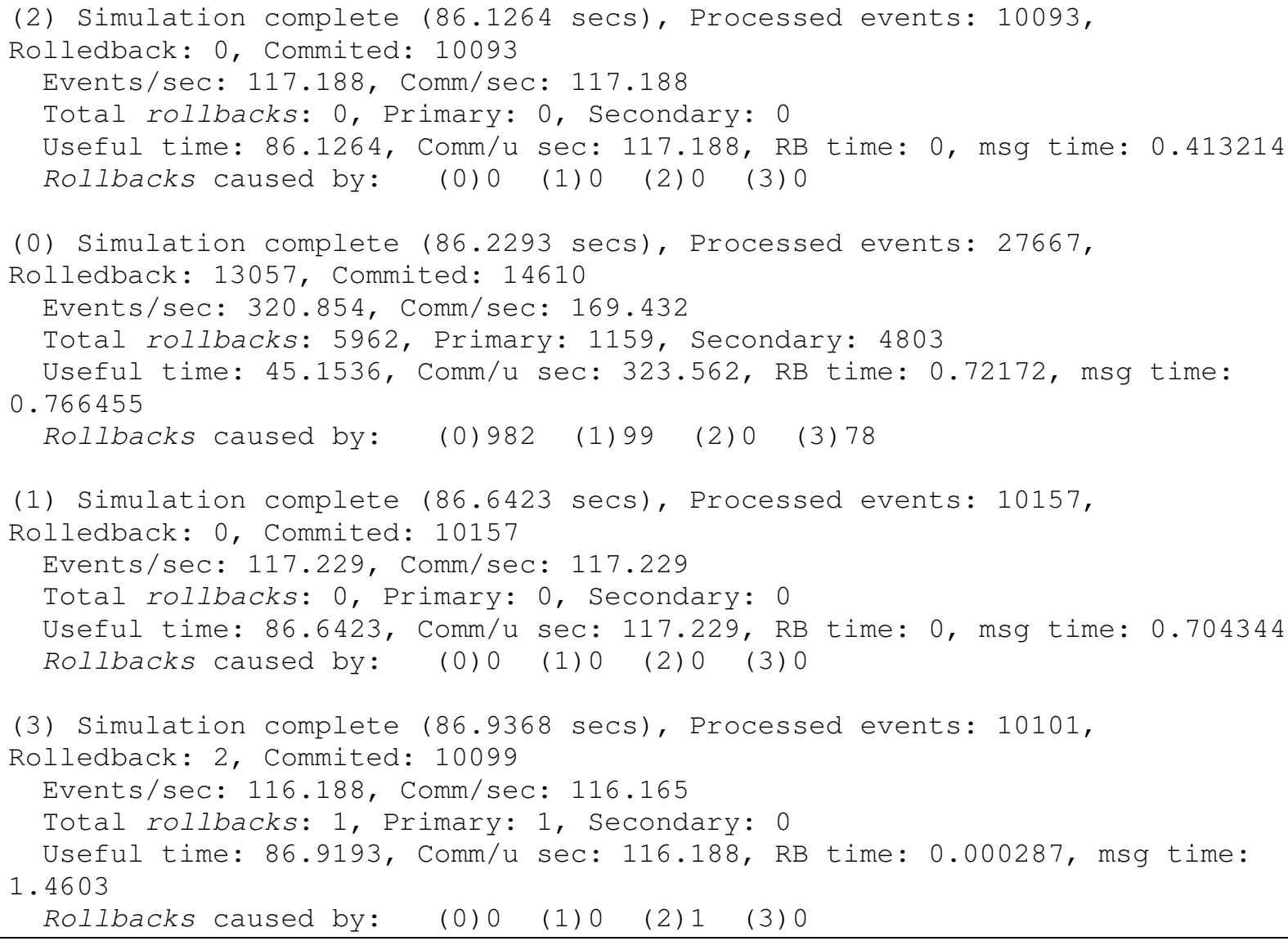

Figura 4.8 Exemplo de uma saída com estatísticas da simulação.

Na figura 4.8, cada bloco de linhas equivale às informações de uma máquina. Como uma máquina pode terminar a simulação um pouco antes do que outras, os blocos não são impressos ordenados pelo número da máquina. Nesse exemplo o gerenciador da máquina 0 
(mestre) obteve um tempo total da simulação igual a 86,2293 segundos. Foram processados 27.667 eventos, dos quais 13.057 foram desfeitos e 14.610 foram consolidados. Nessa máquina, a média de eventos processados por segundo foi de 320.854, e os 169.432 foi a média de eventos consolidados por segundo. O total de rollbacks sofridos foi de 5962, dos quais 1159 foram primários e os 4083 restantes foram rollbacks secundários. O tempo útil foi 45,1536 segundos. A média de eventos consolidados por segundo útil foi de 117,226. O tempo gasto com o processo de rollback foi de 0,72172 segundos. Dos rollbacks sofridos pelos objetos da máquina 0,982 foram causados por objetos da própria máquina, 99 foram causados por objeto da máquina 1; os objetos da máquina 2 não causaram rollbacks e 78 rollbacks foram provenientes da máquina 3.

\subsection{Considerações Finais}

Este capítulo apresentou uma importante parte deste trabalho, que são detalhes da base sobre a qual experimentos foram realizados e análises feitas. Detalhes de como é a realização de um particionamento, como uma plataforma heterogênea é avaliada, e índices de carga foram discutidos. Características de funcionamento e implementação da integração das duas ferramentas, AMIGO e Warped, utilizadas também foram apresentadas. Esta integração contribuiu ampliando as funcionalidades e o leque de usuários de ambas as ferramentas.

Outra contribuição importante apresentada neste capítulo foram as melhorias realizadas na ferramenta de simulação Warped. Esta ferramenta inicialmente se mostrou um software amplo e eficaz para a realização de simulação distribuída, porém, como qualquer software está sujeito a erros. Considerando ainda que o Warped não possui atualmente pesquisadores empenhados em sua manutenção e aperfeiçoamento os erros são mais significativos. Apesar disto, esta ferramenta foi a de mais fácil acesso, e os ajustes realizados a tornaram funcional e muito mais robusta, sendo de fundamental contribuição para a comunidade acadêmica. 
Este trabalho se preocupou em realizar a comunicação entre as ferramentas para que elas possam interagir entre si como uma só. Evoluções futuras e independentes de cada uma estarão sempre contribuindo indiretamente entre elas. E a partir desta união experimentos podem ser realizados com o objetivo de executar simulações distribuídas com um escalonamento convencional e dinâmico. O próximo capítulo apresenta os testes realizados com a utilização destas ferramentas, a primeira parte de testes é realizada apenas com o Warped por se tratar de um ambiente dedicado; na segunda parte, onde o ambiente analisado é compartilhado as ferramentas integradas são utilizadas. 



\section{Capitulo 5 - TESTES E RESULTADOS}

\subsection{Considerações Iniciais}

Objetiva-se com este capítulo demonstrar não somente que é possível a obtenção de ganhos de desempenho com a utilização de políticas convencionais em simulações distribuídas, mas também quando e como essas políticas devem ser aplicadas visando bons resultados. A seguir é descrito o ambiente e as condições em que foram realizados os experimentos práticos e a análise de seus resultados.

\subsection{Estudos de Casos}

Uma vez que o número de fatores envolvidos na avaliação de desempenho é consideravelmente alto, houve a necessidade de estabelecer experimentos que contemplassem alguns objetivos. Nesses experimentos, comparou-se o desempenho das aplicações quando o particionamento é feito utilizando a política round-robin ${ }^{7}$, e quando se beneficia de informações de benchmarks e índices de desempenho tradicionalmente utilizados.

Os experimentos foram realizados inicialmente num ambiente dedicado, onde apenas a simulação é executada na plataforma. Neste ambiente foram utilizados benchmarks das má-

\footnotetext{
${ }^{7}$ A política round-robin não leva em conta nenhuma informação da aplicação e/ou plataforma para realizar o escalonamento.
} 
quinas para auxiliar no particionamento dos objetos. O segundo ambiente de testes é compartilhado, ou seja, simultaneamente com a simulação é executada uma aplicação parasita, que tem como finalidade gerar cargas na plataforma. Para este ambiente serão considerados índices de desempenho, que são baseados em cálculos de benchmarks e índices de carga.

A escolha dos benchmarks e/ou índices de carga é feita baseada no tipo de aplicação que será executada, assim o desempenho obtido com o escalonamento é avaliado em função do tipo da aplicação que o utiliza. Considerando que a avaliação a ser feita é das políticas convencionais, com o intuito de validar e testar a eficiência destas políticas, optou-se por efetuar os experimentos submetendo tipos de simulações de acordo com os diferentes tipos de Índices: CPU-Bound, Network-Bound, Memory-Bound e mistas ${ }^{8}$.

\subsubsection{Dados coletados}

Durante a execução de cada modelo foram coletadas informações da simulação distribuída. Através destas informações é possível estabelecer quadros comparativos sobre o desempenho de cada modelo, quando executados com diferentes políticas de particionamento. As informações coletadas foram:

$\checkmark$ Tempo total: é o tempo total da simulação medido em segundos;

$\checkmark$ Quantidade de eventos processados por segundo: se refere a quantidade total de eventos que são processados por segundo na simulação, independente se estes eventos posteriormente sofrerão ou não rollbacks;

$\checkmark$ Quantidade de eventos realizados por segundo: esta medida se refere a quantidade dos eventos por segundo que foram realmente aproveitados, ou sejá, que não sofreram rollbacks;

\footnotetext{
${ }^{8}$ Entende-se por mista, uma simulação que apresenta um comportamento variado com relação a utilização de recursos.
} 
$\checkmark$ Quantidade total de eventos processados: a quantidade final de eventos que foram processados, ou seja computação feita, mesmo que posteriormente desfeita;

$\checkmark$ Quantidade total de eventos cancelados: é o número de computações que foram desfeitas, ou seja, eventos que sofreram rollbacks; e

$\checkmark$ Quantidade de total de rollbacks: é número total de rollbacks que ocorreu durante a simulação. Sobre este valor total, é possível também que se tenha a informação de quantos destes rollbacks foram primários ou secundários; e ainda saber a quantidade gerada por cada máquina da plataforma.

A partir destas informações coletadas durante a execução da simulação é possível que outras informações possam ser extraídas:

$\checkmark$ Quantidade total de eventos realizados: como já definido, eventos realizados são aqueles eventos que foram processados e não sofreram rollbacks posteriormente. Esse valor equivale à diferença entre a quantidade total de eventos processados e a quantidade total de eventos cancelados; e

Eficiência: é um valor $\leq 1$, calculado através da divisão da quantidade total de eventos realizados pela quantidade total de eventos processados. Desta maneira relaciona-se a eficiência com a quantidade de computação útil que foi processada pela simulação em sua execução.

\subsubsection{Modelos simulados}

De acordo com os objetivos, alguns parâmetros do modelo PHOLD podem ser ajustados de maneira que o modelo final tenha uma configuração específica do que se quer simular. Por exemplo, quando se pretende analisar um modelo de simulação que utiliza muita cpu, basta que os parâmetros sejam formados de maneira que a quantidade de objetos e a população de mensagens não sejam muito grandes, porém o trabalho configurado para ser realizado por cada evento possui um valor alto. 
Com o objetivo de analisar características e ambientes diferentes foram definidas dezessete variações do modelo PHOLD. Cada variação é identificada como “Modelo X”, onde " $X$ " são letras de "A" a "Q" representando as diferentes configurações do modelo PHOLD. Conforme discutido na seção 4.7, cada configuração do modelo PHOLD deve ser tratada como um modelo independente.

Os modelos foram divididos em três grupos, onde para cada grupo, no momento de sua execução, foi utilizado na política de particionamento de objetos um dos benchmarks: rede, memória ou сри. Esses modelos têm seus parâmetros definidos de forma que, a sua simulação requer uma utilização maior ou menor de um determinado recurso (memória, cpu ou rede). As tabelas 5.1, 5.2 e 5.3 apresentam os parâmetros de cada modelo para os grupos de rede, memória e cpu.

A primeira coluna dos parâmetros de cada modelo define a quantidade de objetos que terá cada um. Quanto maior a quantidade de objetos, mais será exigido do recurso de memória. A coluna população de mensagens se refere à quantidade de eventos que o modelo irá possuir, sendo que esta quantidade é constante durante toda a simulação. Uma quantidade grande de mensagens significa que uma maior comunicação irá ocorrer entre os objetos da simulação, utilizando rede.

O trabalho que cada objeto da simulação irá executar ao receber um evento é um cálculo de multiplicação de matrizes (M1 e M2). Quanto maior o tamanho definido para estas matrizes maior será o tempo que o objeto levará para processar o evento. Na coluna trabalho das tabelas 5.1, 5.2 e 5.3 os valores estão definidos no formato " $Y \mathbf{x} Z$ ”, onde $Y$ corresponde a quantidade média de linhas e colunas das matrizes e $Z$ corresponde ao desvio padrão em porcentagem do valor $Y$. Esses dois parâmetros geram, de acordo com uma distribuição normal, três números aleatórios $\boldsymbol{T}, \boldsymbol{U}$ e $\boldsymbol{W}$. Onde $T$ será a quantidade de linhas da $M I, U$ é a quan- 
tidade de colunas de $M 1$ e de linhas de $M 2$, e $W$ será a quantidade de colunas de $M 2$. Assim tem-se uma multiplicação de $M 1_{T, U}$ por $M 2_{U}, W$.

A última coluna das tabelas, 'Propabilidades de Navegação'’ caracteriza as opções de movimentação das mensagens, ou seja, o destino da próxima mensagem (que depende da origem da mensagem anterior). As opções de destino podem ser cinco: para frente, para trás, para a direita, para a esquerda e para si mesmo. Os valores são definidos em porcentagem e a escolha é feita de acordo com uma distribuição uniforme.

Tabela 5.1 Modelos que apresentam uma grande comunicação entre os objetos.

GRUPO REDE

\begin{tabular}{|c|c|c|c|c|}
\hline \multirow{2}{*}{ Modelo } & \multicolumn{3}{|c|}{ Parâmetros } \\
\cline { 2 - 5 } & Objetos & População & Trabalho & Probabilidades de \\
\cline { 4 - 5 } & & Mensagens & Navegação \\
\hline A & 1000 & 2000 & $0 \times 0$ & $20,20,20,20,20$ \\
\hline B & 1000 & 4000 & $0 \times 0$ & $20,20,20,20,20$ \\
\hline C & 5000 & 10000 & $0 \times 0$ & $20,20,20,20,20$ \\
\hline D & 5000 & 20000 & $0 \times 0$ & $20,20,20,20,20$ \\
\hline E & 5000 & 20000 & $0 \times 0$ & $50,10,20,20,0$ \\
\hline
\end{tabular}

Pode-se observar que os modelos do grupo rede possuem uma população de mensagens alta em relação a sua quantidade de objetos. Um parâmetro em comum desses objetos é o trabalho, ou seja, nenhum dos modelos realiza a multiplicação de matrizes. Como o objetivo nesse grupo é testar comunicação, o parâmetro trabalho foi setado como nulo para que não houvesse uma demanda grande por processamento, e conseqüentemente uma utilização significativa de $с р и$. Os modelos $A$ e $B$ apenas diferem na quantidade de sua população de mensagens, onde $B$ possui o dobro que $A$. O mesmo ocorre em relação aos modelos $C$ e $D$. O mode- 
lo $E$ possui quantidade de objetos, população de mensagens e trabalho igual ao modelo $D$ sendo apenas suas probabilidades de navegação diferenciadas. Neste último modelo a probabilidade do destino do evento ser "para frente" é de $50 \%$ e o destino nunca será para o próprio objeto.

Tabela 5.2 Modelos que utilizam principalmente memória.

\begin{tabular}{|c|c|c|c|c|}
\hline \multicolumn{5}{|c|}{ GRUPO MEMÓRIA } \\
\hline \multirow[b]{2}{*}{ Modelo } & \multicolumn{4}{|c|}{ Parâmetros } \\
\hline & Objetos & $\begin{array}{l}\text { População } \\
\text { Mensagens }\end{array}$ & Trabalho & $\begin{array}{c}\text { Probabilidades de } \\
\text { Navegação }\end{array}$ \\
\hline $\mathbf{F}$ & 10000 & 20000 & $0 \times 0$ & $20,20,20,20,20$ \\
\hline $\mathbf{G}$ & 10000 & 40000 & $0 \times 0$ & $20,20,20,20,20$ \\
\hline $\mathbf{H}$ & 15000 & 15000 & $0 \times 0$ & $20,20,20,20,20$ \\
\hline I & 15000 & 15000 & $0 \times 0$ & $5,5,5,5,80$ \\
\hline
\end{tabular}

O grupo de memória é caracterizado por modelos que possuem grandes quantidades de objetos e população de mensagens. Observa-se que as probabilidades de navegação do modelo I são ajustadas de forma que a comunicação entre os objetos ocorra raramente, isto é observado, pois a probabilidade do objeto passar o evento para outro objeto o evento é pequena, já que há uma probabilidade de $80 \%$ do evento ser enviado a ele mesmo. 
Tabela 5.3 Modelos que efetuam muito processamento exigindo mais do recurso CPU. GRUPO CPU

\begin{tabular}{|c|c|c|c|c|}
\hline \multirow[b]{2}{*}{ Modelo } & \multicolumn{4}{|c|}{ Parâmetros } \\
\hline & Objetos & $\begin{array}{l}\text { População } \\
\text { Mensagens }\end{array}$ & Trabalho & $\begin{array}{c}\text { Probabilidades de } \\
\text { Navegação }\end{array}$ \\
\hline $\mathbf{J}$ & 1000 & 2000 & $50 \times 0$ & $20,20,20,20,20$ \\
\hline $\mathbf{K}$ & 1000 & 2000 & $50 \times 50$ & $20,20,20,20,20$ \\
\hline $\mathbf{L}$ & 1000 & 2000 & $50 \times 25$ & $20,20,20,20,20$ \\
\hline $\mathbf{M}$ & 5000 & 10000 & $50 \times 0$ & $20,20,20,20,20$ \\
\hline $\mathbf{N}$ & 5000 & 10000 & $50 \times 50$ & $20,20,20,20,20$ \\
\hline $\mathbf{O}$ & 5000 & 10000 & $50 \times 25$ & $20,20,20,20,20$ \\
\hline $\mathbf{P}$ & 5000 & 20000 & $50 \times 0$ & $20,20,20,20,20$ \\
\hline $\mathbf{Q}$ & 5000 & 20000 & $50 \times 25$ & $20,20,20,20,20$ \\
\hline
\end{tabular}

Os modelos que formam o grupo de $C P U$ são modelos que possuem o parâmetro trabalho diferente de nulo, ao contrário dos grupos anteriores.

\subsection{Plataforma Utilizada}

\subsubsection{Estrutura Física}

O ambiente utilizado para a realização dos testes compreende quatro computadores do tipo PC, formando uma arquitetura MIMD de memória distribuída. Esse ambiente está disposto no Laboratório de Sistemas Distribuídos e Programação Concorrente, do Instituto de Ciências Matemáticas e de Computação da USP, executando o sistema operacional Linux. 
As máquinas possuem características computacionais distintas e estão conectadas por uma rede FastEthernet (100Mbps). A heterogeneidade encontrada no ambiente descrito constitui um fator motivante para o estudo das técnicas de escalonamento de processos quando se deseja aumentar o desempenho de um sistema. A tabela 5.4 descreve a configuração das máquinas utilizadas. A primeira coluna se refere ao nome da máquina na rede do laboratório de sistemas distribuídos do ICMC; a segunda coluna é o id utilizado para identificar a respectiva máquina nos testes e a última coluna apresenta a configuração de hardware da máquina.

Tabela 5.4 Plataforma utilizada nos testes.

\begin{tabular}{|c|c|l|}
\hline Máquina & Id & \multicolumn{1}{|c|}{ Configuração } \\
\hline Lasdpc14 & $\mathbf{3}$ & AMD Duron 1.2 GHz Cache 64Kb 256MB RAM HD \\
\hline Lasdpc15 & $\mathbf{2}$ & Pentium 4 2.0 GHz Cache 256Kb 256MB RAM HD \\
\hline Lasdpc16 & $\mathbf{1}$ & Pentium 3 600MHz Cache 64Kb 256MB RAM HD \\
\hline Lasdpc17 & $\mathbf{0}$ & $\begin{array}{l}\text { AMD Atlon XP 2000+ 1.6 GHz Cache 256Kb 256MB RAM } \\
\end{array}$ \\
& & HD \\
\hline
\end{tabular}

\subsubsection{Avaliação da Plataforma}

Para a realização dos testes, antes das ferramentas Warped e AMIGO serem instaladas e configuradas foi necessária uma avaliação de cada máquina, através de benchmarks, com o objetivo de alimentar as políticas de particionamento utilizadas nas execuções. Os benchmarks utilizados para esta avaliação foram discutidos na seção 4.2.1 deste trabalho. A tabela 5.5 apresenta a nota individual das máquinas em cada benchmark. Quando o particionamento dos objetos considera combinações destes benchmarks, a nota que a máquina receberá é a média aritmética entre os benchmarks considerados. 
Tabela 5.5 Resultados dos Benchmarks.

\begin{tabular}{|c|c|c|c|}
\hline Id Máquina & Rede & CPU & Memória \\
\hline $\mathbf{3}$ & 0,8272 & 0,686 & 0,533 \\
\hline $\mathbf{2}$ & 1 & 0,856 & 1 \\
\hline $\mathbf{1}$ & 0,8220 & 0,384 & 0,319 \\
\hline $\mathbf{0}$ & 0,9354 & 1 & 0,696 \\
\hline
\end{tabular}

\subsubsection{Definição do GVT (Tempo Virtual Global)}

Após a estrutura física estar avaliada e configurada, foi necessário a avaliação de características das simulações. A primeira é a definição do valor do GVT máximo. Como apresentado na seção 4.7 o modelo PHOLD não define qual o término da simulação, assim, caso este parâmetro não seja ajustado o modelo irá executar infinitamente.

Para achar um valor adequado duas questões devem ser analisadas, a primeira diz respeito a se encontrar um valor de GVT que seja aceitável de se executar tanto simulações leves quanto pesadas. Por exemplo, um valor de $G V T$ muito alto para uma simulação simples pode significar alguns minutos de execução, porém uma simulação mais complexa, onde se tenha muita computação e até uma grande comunicação entre os objetos, esse GVT alto pode significar dias para finalizar uma única execução. Este trabalho considera diversos modelos que serão executados diversas vezes, assim o tempo real de cada simulação não deve ser muito alto. O segundo ponto que deve ser considerado diz respeito à definição de um GVT que produza dados suficientes para serem analisados e comparados.

Foi apresentado (seção 4.7) que o modelo PHOLD, é um modelo sintético, onde dependendo das alterações de seus parâmetros pode-se "criar" um modelo com características específicas, ou seja, quando falamos "modelo PHOLD" estamos falando de um modelo "genérico", e cada nova configuração dele é um modelo diferente. 
Para definir o tempo das simulações deste trabalho realizou-se uma análise sobre o comportamento de uma configuração ${ }^{9}$ PHOLD, onde esta configuração (modelo B) ${ }^{10}$ foi executada variando seu GVT máximo. O particionamento dos objetos foi realizado com a política round-robin. A tabela 5.6 apresenta os parâmetros do modelo simulado (definidos na seção 4.7). As variáveis totais de tempo, quantidade de rollbacks ocorridos e eficiência foram coletadas para cada variação do valor do $G V T$. Analisando a tabela observam-se os valores médios de quinze execuções do modelo para cada valor de GVT.

Tabela 5.6 Análise de GVT.

\begin{tabular}{|c|c|c|c|}
\hline Parâmetros: & $\begin{array}{l}\text { Objetos: } 1000 \\
\text { Mensagens: } 4000\end{array}$ & $\begin{array}{l}\text { Trabalho: } 0 \times 0 \\
\text { Probabilidades de navegaçc }\end{array}$ & $20,20,20,20$ \\
\hline$G V T$ & Tempo & Quantidade de Rollbacks & Eficiência \\
\hline 100 & 1,889 & 3844,867 & 0,778 \\
\hline 200 & 3,692 & 9488,533 & 0,707 \\
\hline 300 & 5,560 & 15223,133 & 0,683 \\
\hline 400 & 7,447 & 21324,600 & 0,669 \\
\hline 500 & 9,379 & 27023,467 & 0,660 \\
\hline
\end{tabular}

A primeira análise estatística que pode ser feita é a correlação (tabela 5.7) entre o GVT e as variáveis tempo, quantidade de rollbacks e eficiência. De acordo com a tabela 5.6 podese afirmar que a relação entre estas variáveis é considerável, pois à medida que o GVT aumen-

\footnotetext{
${ }^{9}$ Durante este capítulo cada configuração do modelo PHOLD será tratada como um modelo de simulação independente.

${ }^{10}$ No decorrer deste capítulo para referenciar esta mesma configuração cita-se o "Modelo B".
} 
ta o tempo também tem um crescimento. A eficiência da simulação reduz devido ao crescimento do número de rollbacks.

Tabela 5.7 Correlação entre variáveis - Correlação entre as variáveis GVT e tempo com quantidade de rollbacks e eficiência.

\begin{tabular}{|c|c|c|c|}
\hline CORRELAÇÃO & Tempo & Quantidade de Rollbacks & Eficiência \\
\hline$G V T$ & 0,9991995 & 0,999916974 & $-0,914871371$ \\
\hline TEMPO & - & 0,99992208 & $-0,909875684$ \\
\hline
\end{tabular}

Os gráficos apresentados a seguir ilustram a linha de tendência das variáveis com o aumento do GVT. Duas linhas estão representadas nesses gráficos, onde a linha cheia é referente aos valores apresentados na tabela 5.6 e a linha tracejada é a linha de tendência ${ }^{11}$ dos dados do gráfico.

O gráfico 5.1 apresenta a linha de comportamento do tempo real da simulação quando o seu tempo virtual de execução é aumentado. Utilizando-se do método de regressão linear, que é uma forma de análise estatística para fazer previsões, pode-se afirmar que com $99 \%$ de certeza que a equação linear $y=0,0187 x-0,0268$ faz o ajuste da linha.

\footnotetext{
${ }^{11}$ A linha de tendência pode ser linear, de potência, polinomial, exponencial, média móvel ou logarítmica.
} 


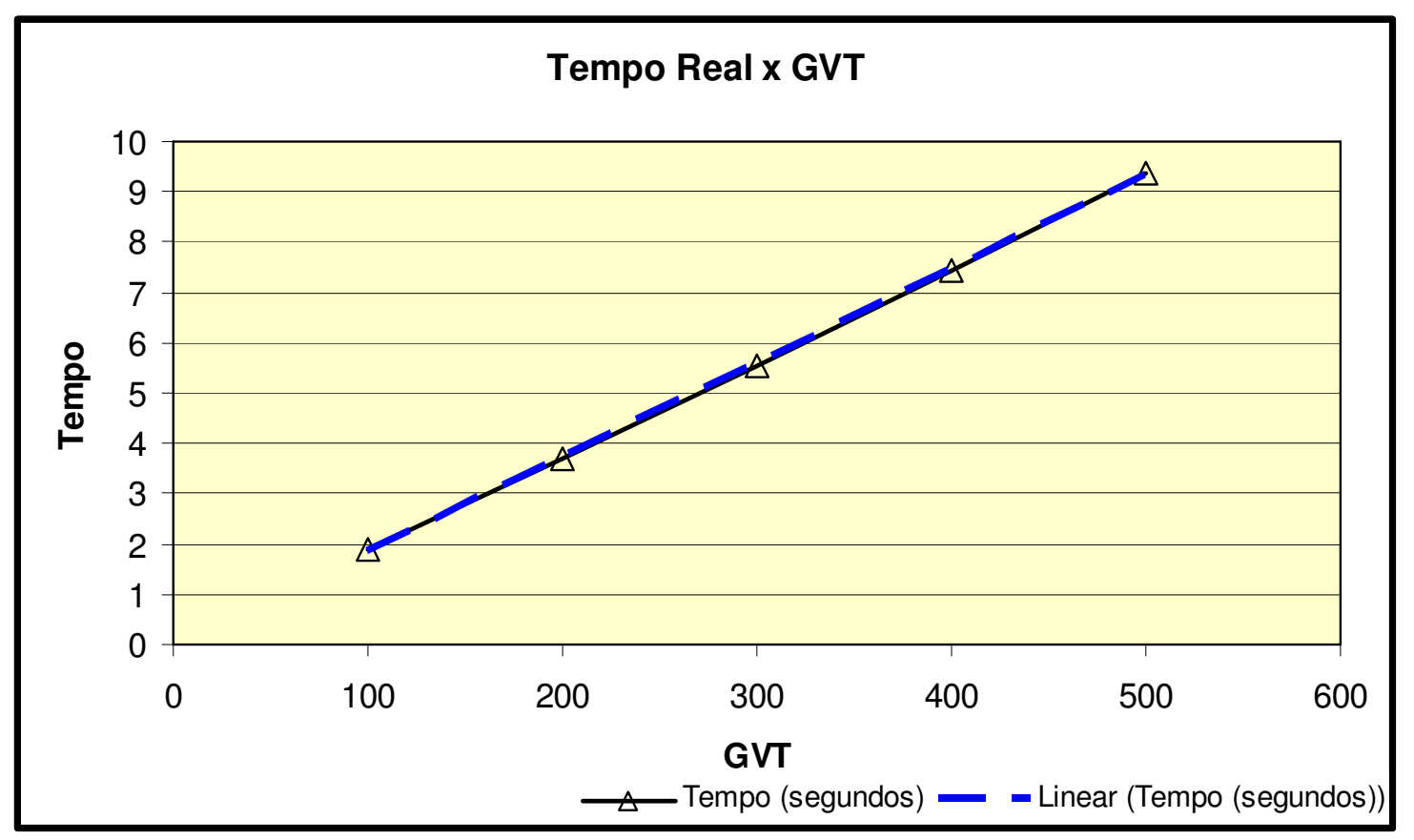

Gráfico 5.1 Comportamento do tempo real com o aumento do GVT.

O gráfico 5.2 apresenta a linha de comportamento da eficiência da simulação quando o seu tempo virtual de execução é aumentado. Através de regressão linear, afirma-se que com $97 \%$ de certeza que a equação de potência $y=1,2361 x^{-0,1027}$ faz o ajuste da linha para estas variáveis. 


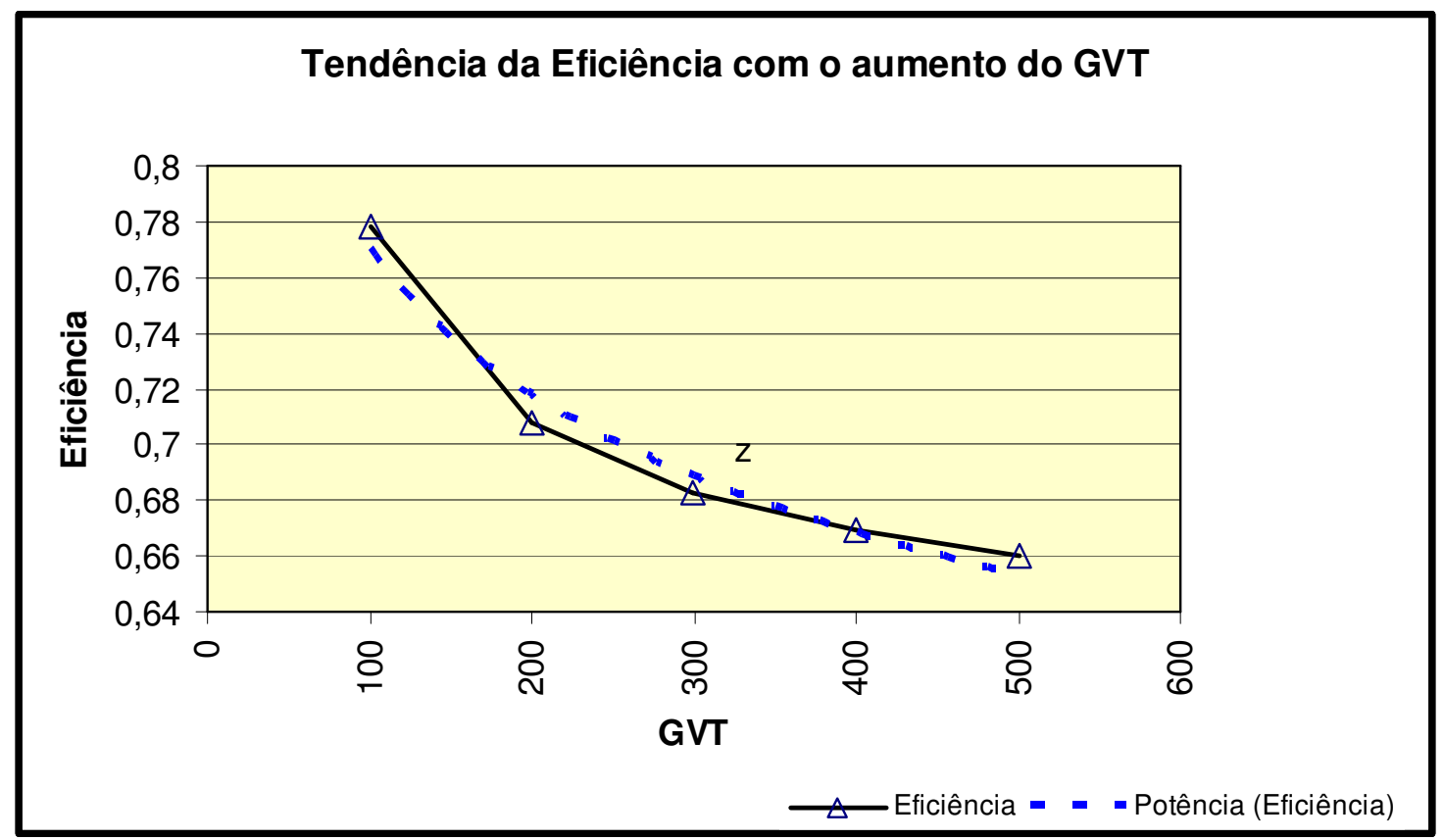

Gráfico 5.2 Comportamento da Eficiência com o aumento do GVT.

O gráfico 5.3 apresenta a linha de comportamento da quantidade de rollbacks que ocorrem quando o GVT aumenta. A equação linear $y=58,193 x-2077,1$ provê uma base ajustada em $99 \%$ de certeza para previsões futuras.

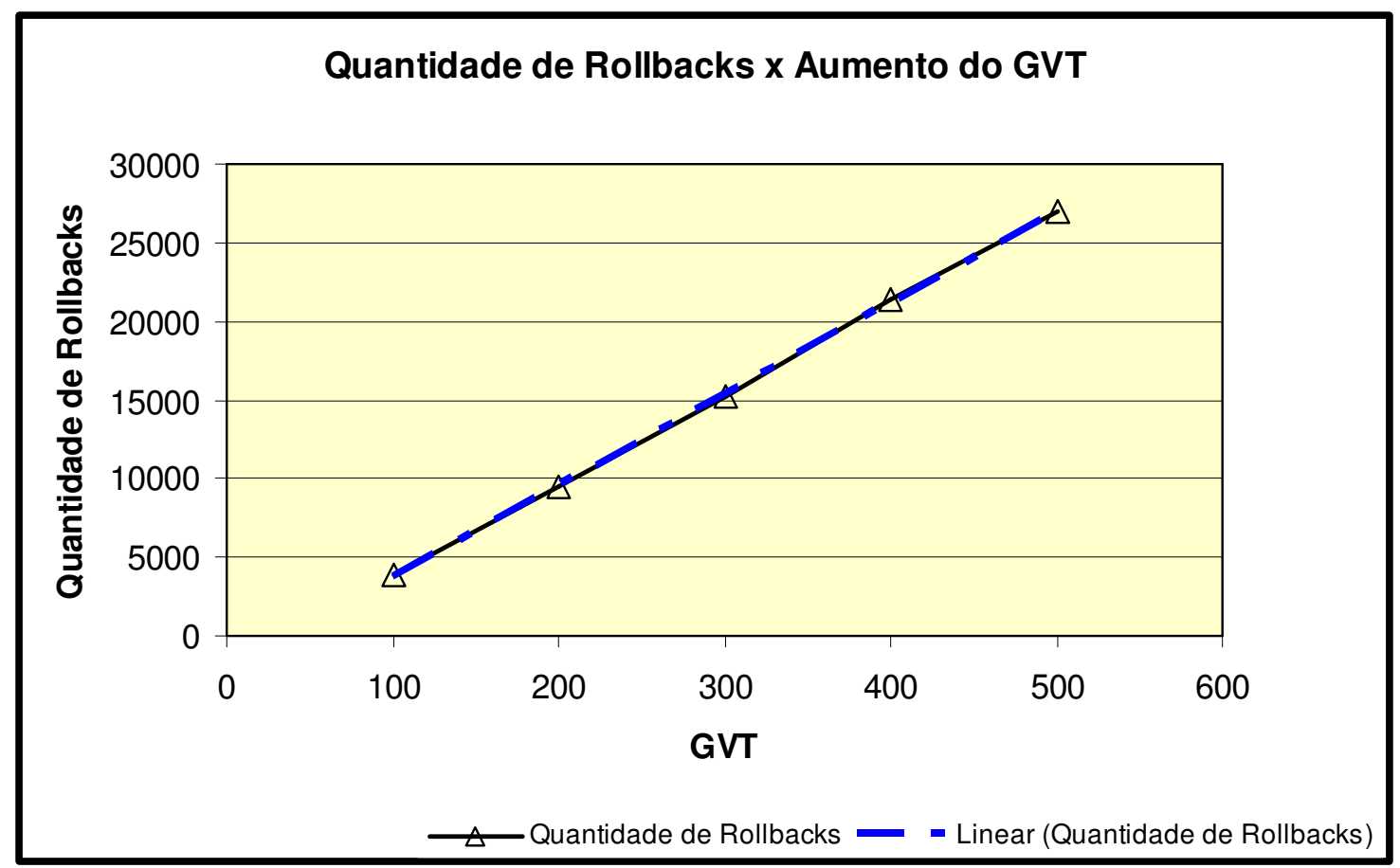

Gráfico 5.3 Quantidade de Rollbacks ocorridas com o aumento do GVT. 
Por meio de uma configuração do modelo PHOLD, pode-se observar o comportamento da simulação desse modelo quando o tempo virtual de execução foi aumentado. Alguns comportamentos já são esperados, mesmo antes da simulação do modelo. O fato da simulação prosseguir por um tempo maior infere que um número maior de rollbacks vai ocorrer em relação a uma simulação que executou por um tempo menor. Assim, cada execução da simulação, com valores de GVT diferentes, deve ser considerada independente. Esse mesmo modelo foi analisado fazendo o particionamento baseado no benchmark de rede, como o comportamento foi semelhante, optou-se por detalhar um deles. Após essa análise o valor do GVT dos estudos de caso deste trabalho foi fixado em 300, por ser um valor que gera um tempo real de simulação aceitável para que possa ser explorado um número grande de modelos.

\subsubsection{Definiçãa das execuções}

Um ponto definido antes da realização dos experimentos é o número de execuções a que cada modelo de simulação será submetido. Essa repetição é necessária para se poder analisar a variabilidade que um mesmo modelo demonstra em suas diversas execuções. De um modo geral, quanto maior o número de repetições, mais precisas serão as estimativas, porém na prática o número de repetições vai depender muito do conhecimento sobre o comportamento da variabilidade dos dados.

Neste trabalho avaliou-se o comportamento da variabilidade dos dados através da comparação de médias de diferentes quantidades de execuções de um modelo de simulação. Coletou-se e comparou-se a média de cinco, dez e quinze execuções do modelo. Optou-se por não continuar as comparações com um número maior de execuções, pois através dos dados coletados observou-se que o comportamento apresentava uma variabilidade quase nula. Observa-se pelos gráficos 5.4, 5.5 e 5.6 o comportamento das variáveis: tempo, eficiência e quantidade de rollbacks, respectivamente. 
O estudo do número de execuções necessárias também foi realizado para diversos valores de GVT. Assim, os gráficos 5.4 a 5.6 mostram que, independente da quantidade de repetições feitas da execução do modelo $B$, a média das variáveis tempo, eficiência e quantidade de rollbacks não demonstram alterações significativas.

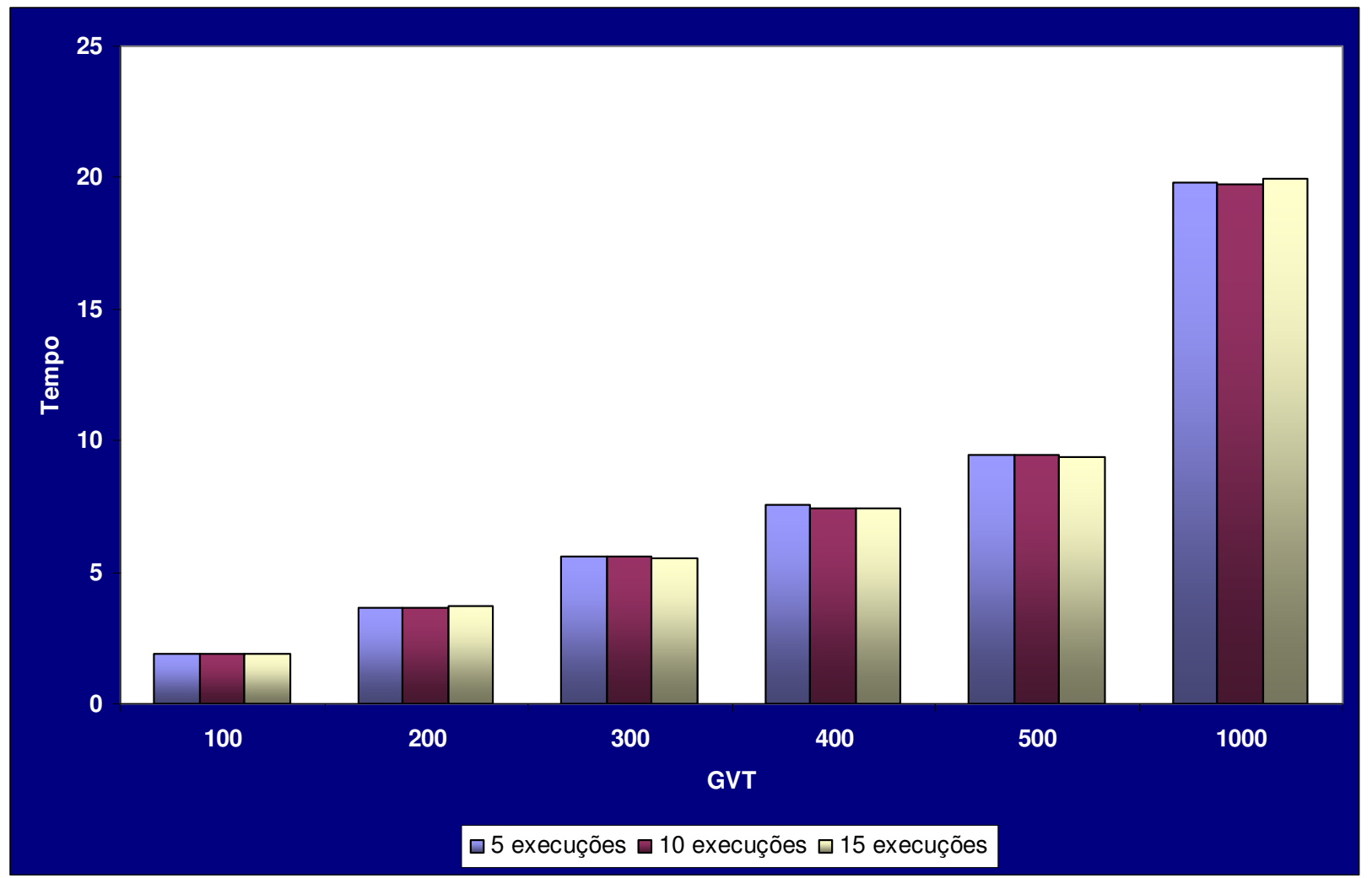

Gráfico 5.4 Comportamento do tempo de 5, 10 e 15 execuções do modelo B. 


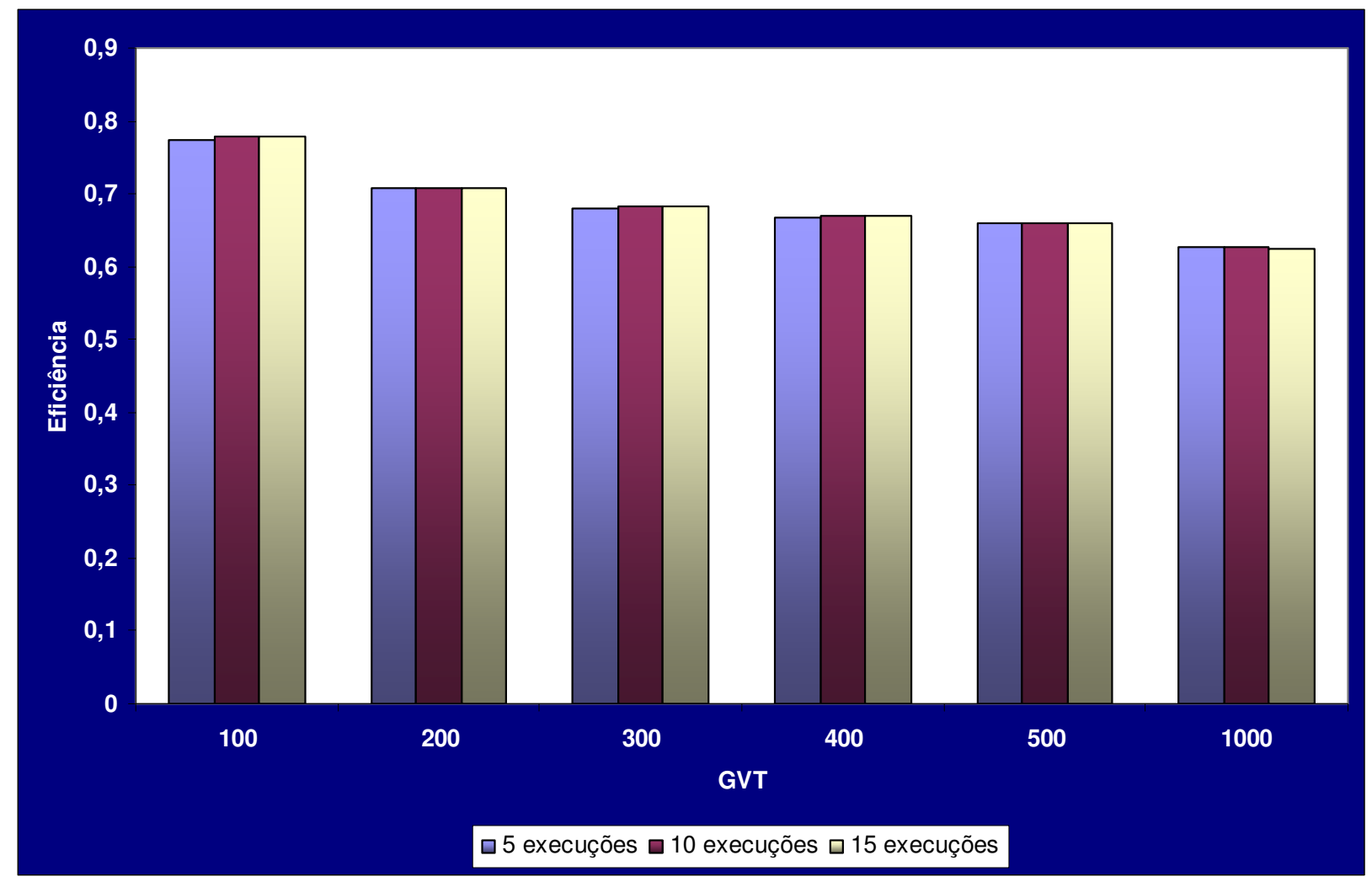

Gráfico 5.5 Comportamento da eficiência de 5,10 e 15 execuções do modelo B.

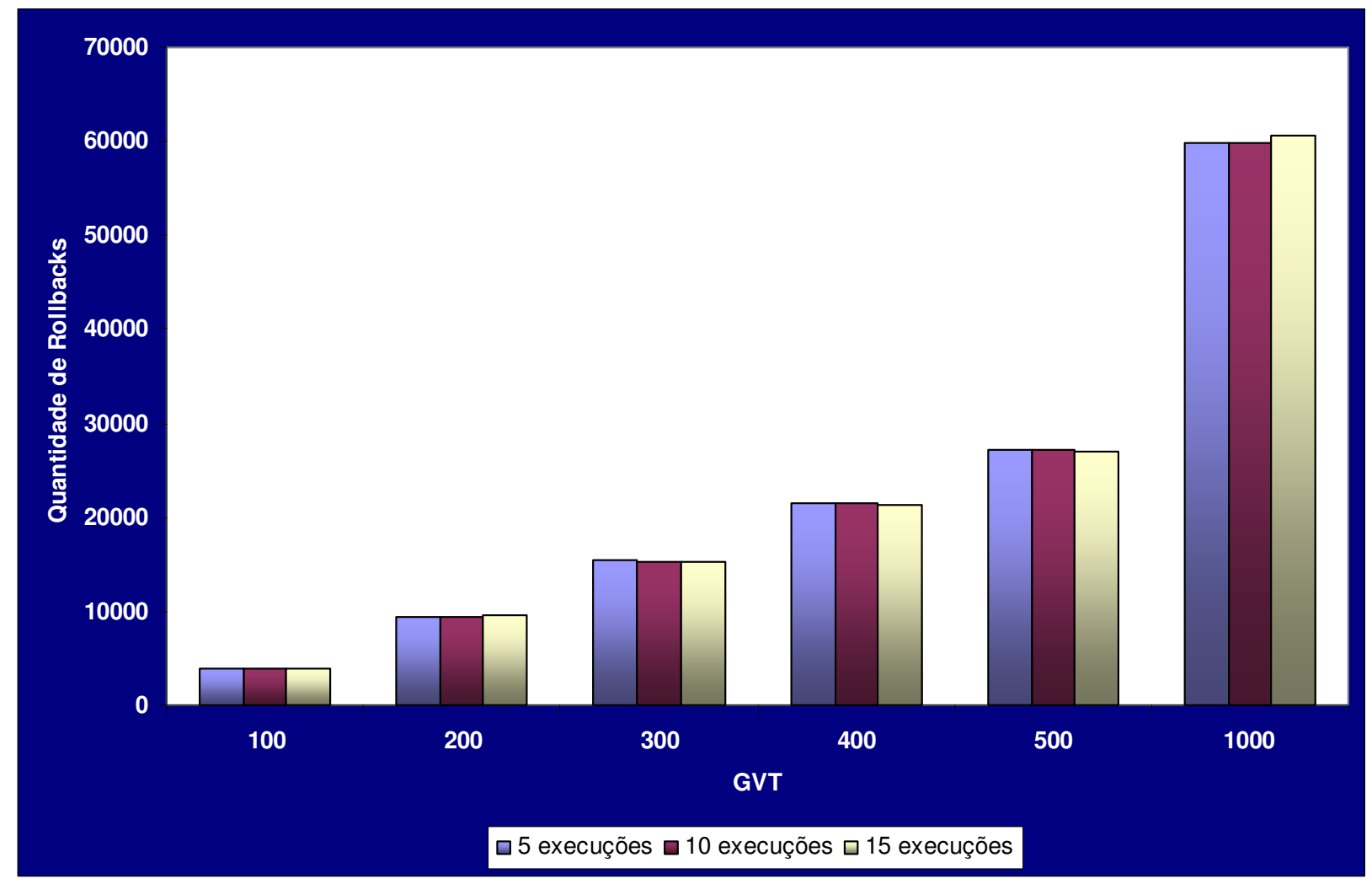

Gráfico 5.6 Comportamento da quantidade de rollbacks ocorridas de 5, 10 e 15 execuções do modelo B. 
Através dos resultados desses gráficos concluiu-se que a média dos dados gera uma diferença pequena quando um número maior de execuções é realizado. E essa diferença não compensaria o tempo total gasto se uma quantidade maior de execuções fosse considerada. A tabela 5.7 apresenta o desvio padrão das médias para o valor do $G V T$ igual a 300 que será o valor fixado em todas as simulações deste trabalho.

Tabela 5.8 Desvio padrão das médias para as execuções do modelo B com GVT 300 .

\begin{tabular}{|c|c|c|c|}
\hline & Número de Execuções & Média & Desvio Padrão \\
\hline \multirow{3}{*}{ Tempo } & 5 & 5,577 & 0,184 \\
\hline & 10 & 5,605 & 0,185 \\
\hline & 15 & 5,560 & 0,169 \\
\hline \multirow{3}{*}{$\begin{array}{l}\text { Quantidade de } \\
\text { Rollbacks }\end{array}$} & 5 & 15357,8 & 798,653 \\
\hline & 10 & 15308,2 & 656,440 \\
\hline & 15 & 15223,133 & 548,663 \\
\hline \multirow{3}{*}{ Eficiência } & 5 & 0,680 & 0,011 \\
\hline & 10 & 0,681 & 0,008 \\
\hline & 15 & 0,683 & 0,007 \\
\hline
\end{tabular}

Analisando-se a tabela 5.8 percebe-se que o aumento do número de execuções causa uma alteração muito pequena na médias das três variáveis observadas. Sendo assim, fixou-se o número de quinze repetições para cada modelo simulado nos testes deste trabalho, por apresentar um tempo de execução aceitável.

\subsection{Resultados obtidos}

Os gráficos desta seção têm por objetivo apresentar e comparar o desempenho de cada modelo de simulação, quando o particionamento dos objetos é realizado com o round-robin; e 
quando uma política convencional de sistemas distribuídos é utilizada. Dentre as informações ${ }^{12}$ obtidas da simulação, foram analisadas três: Tempo, Quantidade de Rollbacks e Eficiência. Com essas informações é possível visualizar o ganho obtido na simulação com políticas não específicas. Os resultados serão apresentados de acordo com os grupos de modelos definidos na seção anterior, sendo que para cada grupo têm-se três gráficos, cada um apresentando uma das três informações analisadas: tempo, quantidade de rollbacks e eficiência.

\subsubsection{Ambiente heterogêneo e dedicado}

Neste ambiente as máquinas estavam disponíveis apenas para os testes, e a rede em que elas se encontram foi isolada. A política de particionamento convencional utilizada baseia-se no benchmark que julgou-se mais adequado para cada tipo de modelo considerado.

\section{GRUPO REDE}

Para a execução dos modelos deste grupo, a política de particionamento convencional utilizada baseou-se no benchmark de rede. Os gráficos 5.7, 5.8 e 5.9 apresentam comparativos de desempenho das simulações dos cinco modelos que caracterizam este grupo: $A, B, C, D$ e E.

Para cada modelo há duas colunas associadas, onde cada coluna representa o tempo de execuções da simulação em situações diferentes de particionamento de objetos. A primeira (coluna preta) corresponde a execução de um modelo no qual o particionamento dos objetos foi feito baseado em informações sobre a plataforma. A segunda coluna (branca) corresponde a execução do mesmo modelo, porém o particionamento dos objetos é feito de maneira igualitária para todas as máquinas (round-robin).

\footnotetext{
${ }^{12}$ As tabelas com todas as informações e valores de cada modelo estão apresentadas no Apêndice B.
} 
A utilização de uma política convencional reduziu o tempo de execução de todos os modelos deste grupo (gráfico 5.7). As reduções mais significativas foram nos modelos A e B, com $18,4 \%$ e $23,7 \%$ respectivamente. Nos modelos C, D e E as reduções foram de 6,5\%, $2,9 \%$, e 3,8\% respectivamente. Analisando os parâmetros de cada modelo (tabela 5.1) observa-se que os modelos $\mathrm{C}$, D e E possuem um número maior de objetos e eventos que $\mathrm{A}$ e $\mathrm{B}$, ou seja, são modelos que além de terem uma comunicação acentuada entre os seus objetos, também utilizam e/ou acessam a memória de maneira que o desempenho final possa ser afetado.

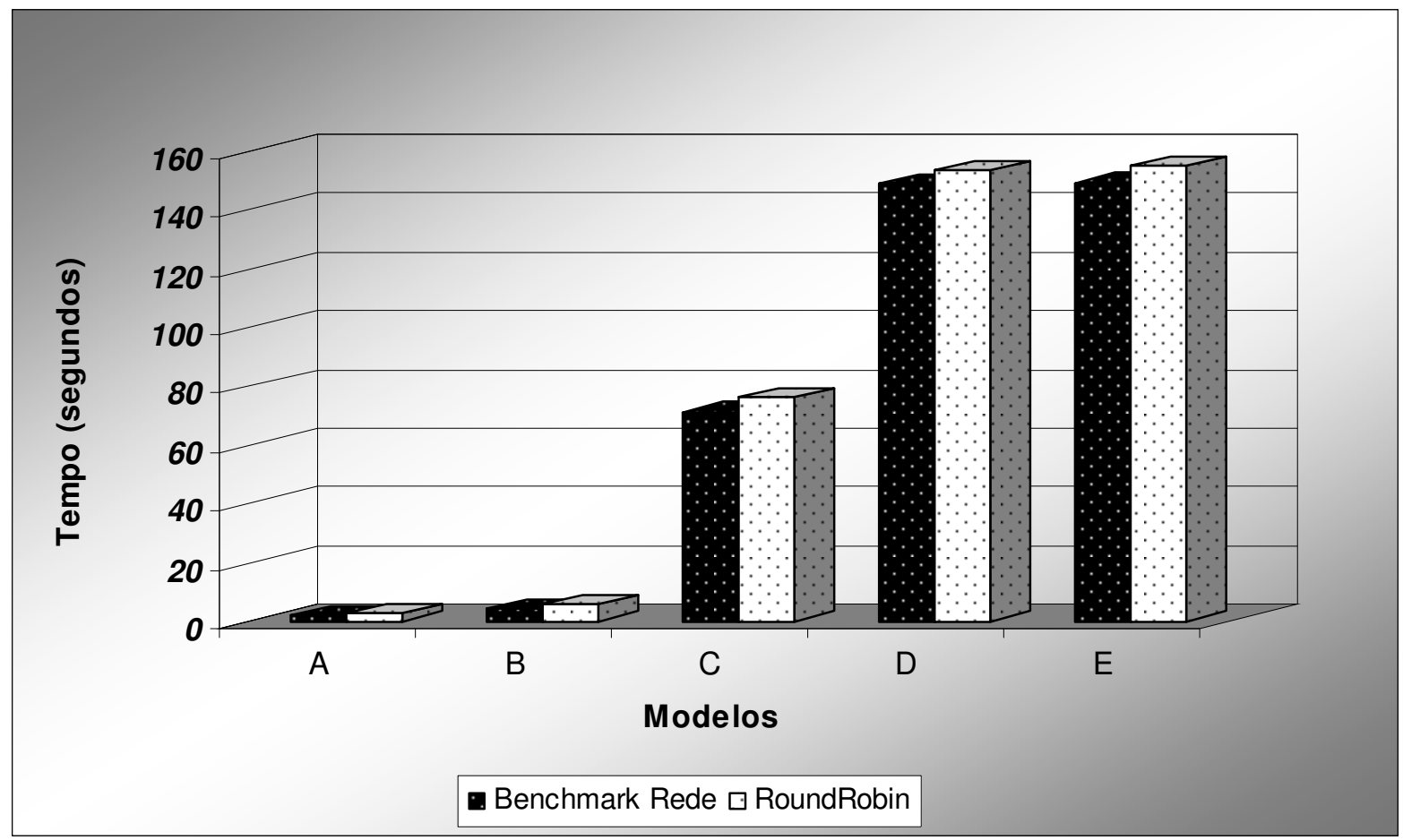

Gráfico 5.7 Comparativo do Tempo total de execução dos modelos do grupo Rede.

O gráfico 5.8 apresenta um comparativo entre a quantidade de rollbacks em cada modelo para as duas situações já abordadas. Pode-se observar que a quantidade de rollbacks que ocorreram com a utilização de round-robin (colunas brancas), foram consideravelmente superior ao caso onde a política foi aplicada (colunas pretas). A redução da quantidade de rollbacks mais significativa foi no modelo $\mathrm{C}$ com 78,9\%; os demais modelos, como o gráfico já demonstra, também obtiveram uma redução considerável de 55,6\% em média. 
Os modelos deste grupo diferem entre si em quantidade de objetos e/ou no tamanho da população de mensagens. Percebe-se que o uso de uma política exerce influencia na redução de rollbacks. Como a política proporcionou um melhor balanceamento de carga, os objetos progrediram de maneira uniforme diminuindo assim a quantidade de rollbacks.

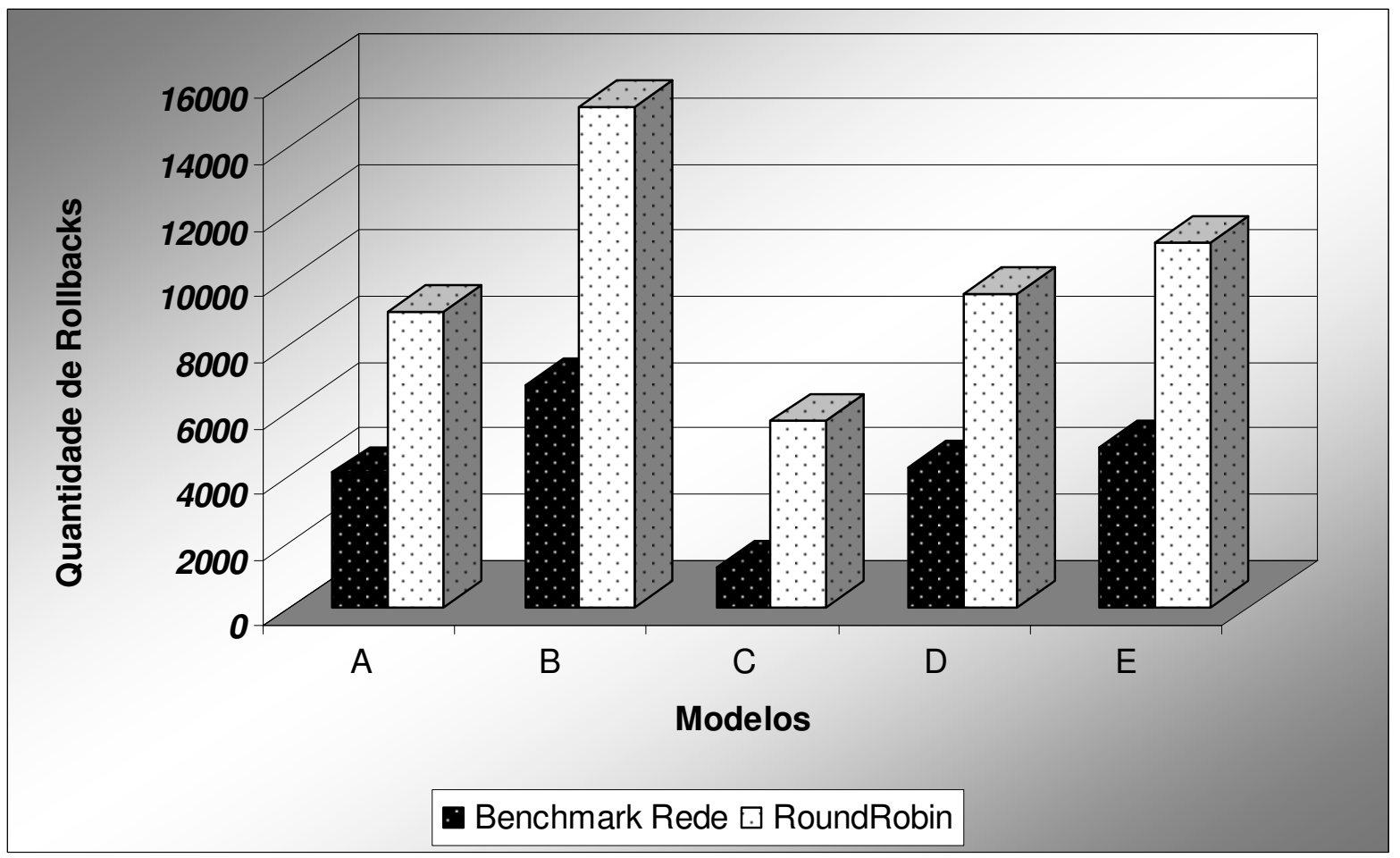

Gráfico 5.8 Comparativo da quantidade de rollbacks ocorridas durante a execução dos modelos do grupo Rede.

A terceira informação avaliada nesse grupo de modelos foi a eficiência das simulações. O gráfico 5.9 apresenta a comparação entre os valores obtidos. As simulações executadas com round-robin apresentaram em todos os modelos uma eficiência inferior. Nos modelos A e B a utilização de round-robin resulta em uma eficiência inferior (19,3\% e 21,9\% respectivamente), comparando as execuções com a política de particionamento utilizando benchmark de rede. As execuções dos modelos C, D e F foram em média 3,8\% inferiores com round-robin. 


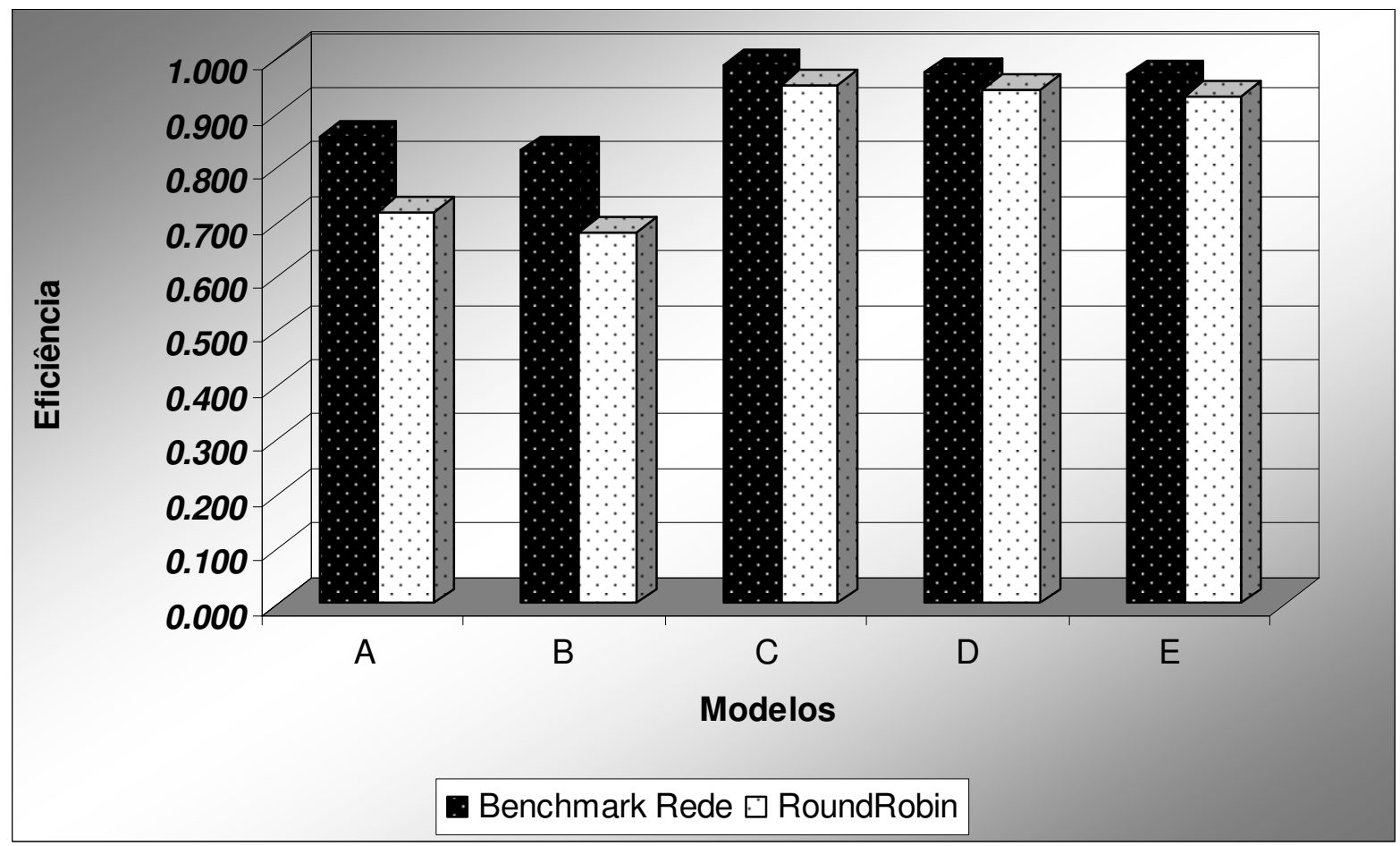

Gráfico 5.9 Comparativo da Eficiência final da execução dos modelos do grupo Rede.

\section{GRUPO MEMÓRIA}

A política de particionamento de objetos, utilizada na execução dos modelos deste grupo, foi realizada de acordo com o benchmark de memória. Os gráficos 5.10, 5.11 e 5.12 apresentam os desempenhos obtidos, em tempo, quantidade de rollbacks e eficiência respectivamente, nas execuções dos modelos deste grupo.

Pode-se observar através dos gráficos que os resultados obtidos com a utilização do benchmark de memória na heurística da política de particionamento dos objetos não foram satisfatórios. Em todas as simulações deste grupo, com a política, o desempenho foi significativamente inferior que ao desempenho obtido quando apenas round-robin foi considerado. 


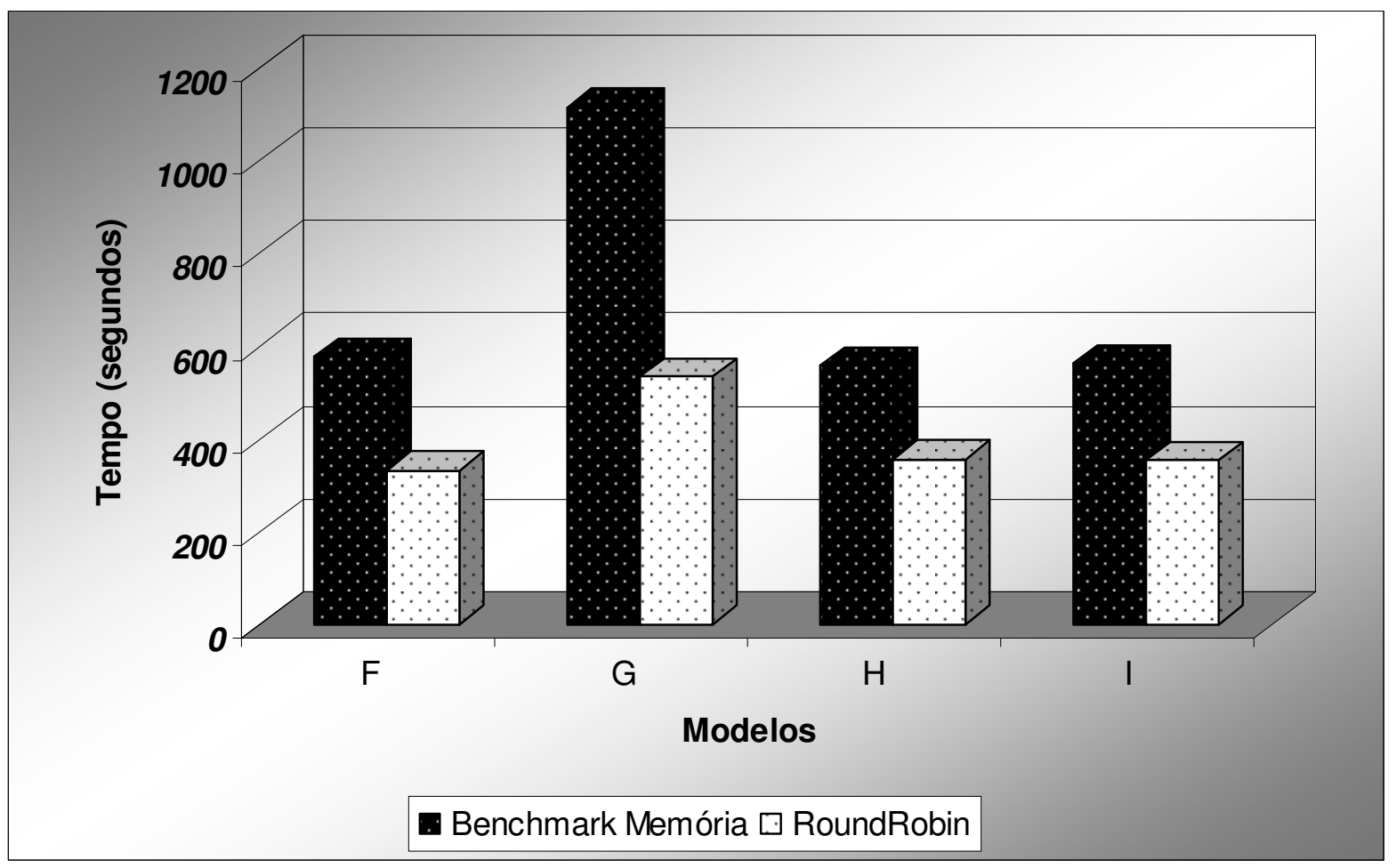

Gráfico 5.10 Comparativo do Tempo total de execução dos modelos do grupo memória.

Pelo gráfico 5.11 é possível observar que a quantidade de rollbacks que ocorreram foi consideravelmente alta, podendo-se afirmar que os resultados do tempo e da eficiência foram afetados diretamente por esta situação. Através de números este impacto fica mais acentuado, por exemplo o "melhor caso", entre as execuções dos modelos (coluna branca) deste grupo, sofreu 45.265 rollbacks a mais que a execução do mesmo modelo com round-robin. No pior caso este número chega em 265.812 rollbacks a mais. 


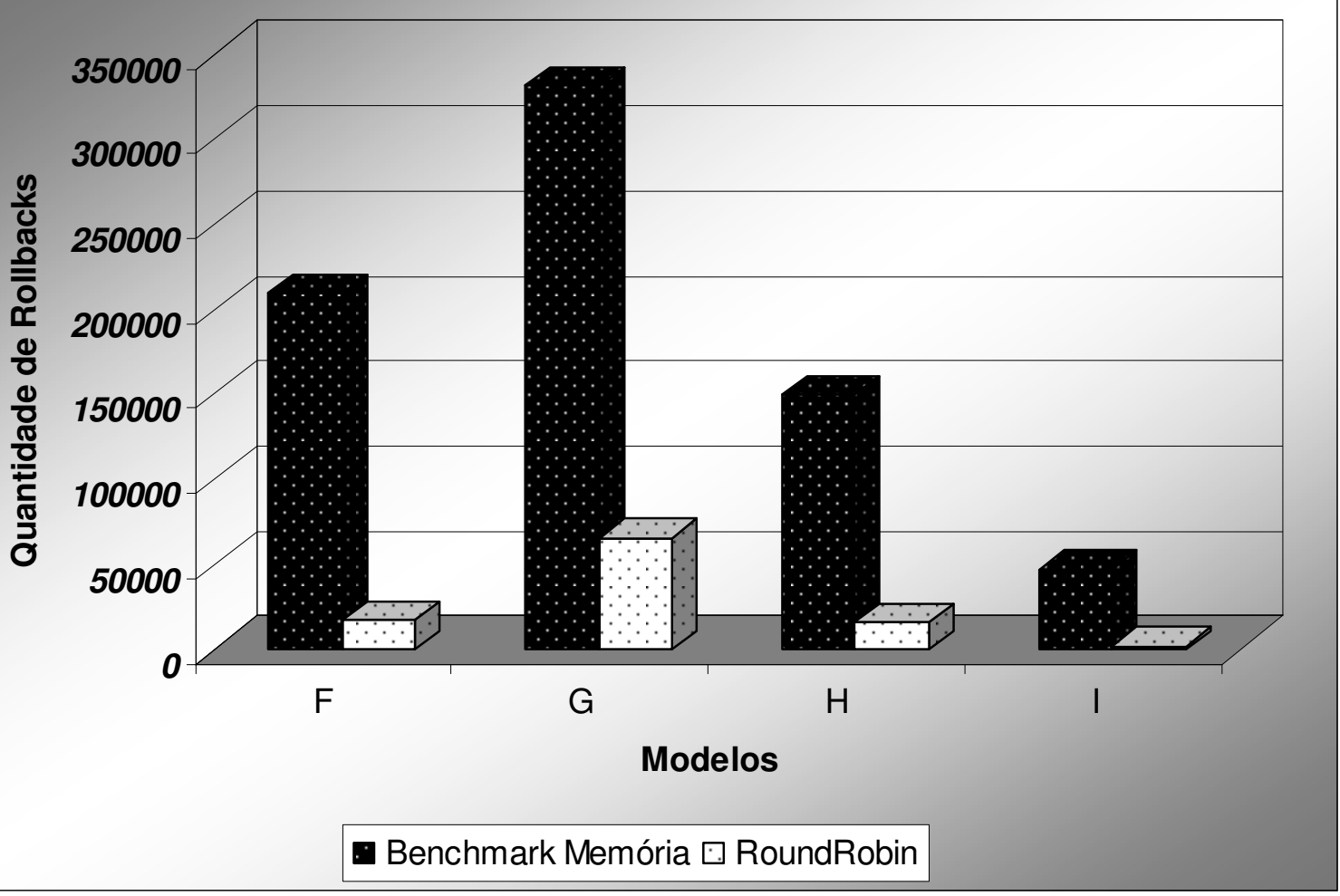

Gráfico 5.11 Comparativo da Quantidade de Rollbacks ocorridas durante a execução do grupo memória.

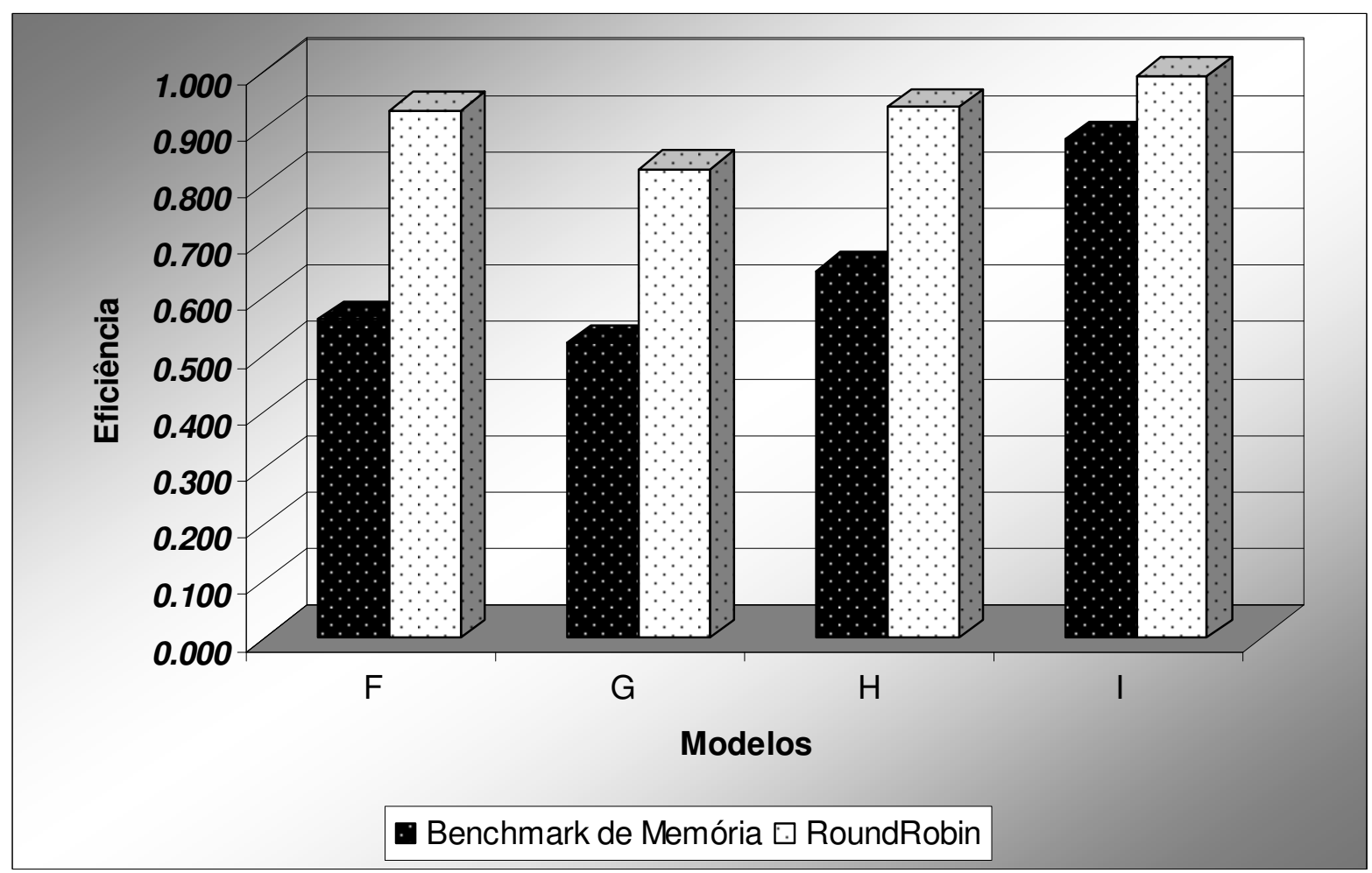

Gráfico 5.12 Comparativo da Eficiência final da execução do grupo memória.

Por meio desses resultados observados pode-se afirmar que o benchmark de memória utilizado não reflete o desempenho que a simulação irá apresentar na máquina. Pois, a simula- 
ção pode depender também de outros fatores que tem mais influência em seu desempenho do que a velocidade de acesso à memória.

Para comprovar que o benchmark de memória utilizado não foi adequado para prover um bom particionamento, selecionou-se um dos modelos deste grupo para ser executado com diferentes políticas de particionamento. $\mathrm{O}$ modelo $\mathrm{G}$ foi selecionado e executado com a política de particionamento baseada em diferentes informações, utilizando-se da combinação dos benchmarks:

$\checkmark$ de $c p u$ e rede;

$\checkmark$ de memória e rede;

$\checkmark$ de $c p u$, rede e memória;

apenas rede;

$\checkmark$ apenas memória; e

$\checkmark$ round-robin.

Conforme definido na tabela 5.2, o modelo $\mathrm{G}$ apresenta as seguintes características:

$\checkmark$ Muita comunicação, uma população com 40.000 mensagens sendo apenas $20 \%$ de chances da mensagem ser enviada para o próprio objeto;

$\checkmark$ Composto por 10.000 objetos, o que exige maior quantidade de memória para armazená-los; e

$\checkmark$ Não possui trabalho adicional, o processamento executado equivale ao repasse de uma mensagem.

O gráfico 5.13 apresenta o tempo de execução do modelo G quando simulado para cada um dos conjuntos de benchmarks, utilizados na política de particionamento. Pode-se observar que na execução em que o particionamento foi baseado nos benchmarks de $C P U$ e re- 
de, o tempo da simulação foi reduzido em $18 \%$ em relação à execução com round-robin. Os resultados também mostram que a utilização do índice de velocidade de acesso a memória isoladamente não oferece um bom balanceamento. Esse comportamento pode ser explicado pela existência de uma grande quantidade de comunicação desse modelo, o que torna o índice de rede mais atrativo. Como para a execução de qualquer modelo observa-se a utilização de $C P U$, a associação de índices de $C P U$ e rede proporcionou um melhor resultado. Os resultados obtidos indicaram que a memória disponível na plataforma utilizada supre adequadamente as necessidades do modelo, mesmo quando um grande número de objetos é considerado.

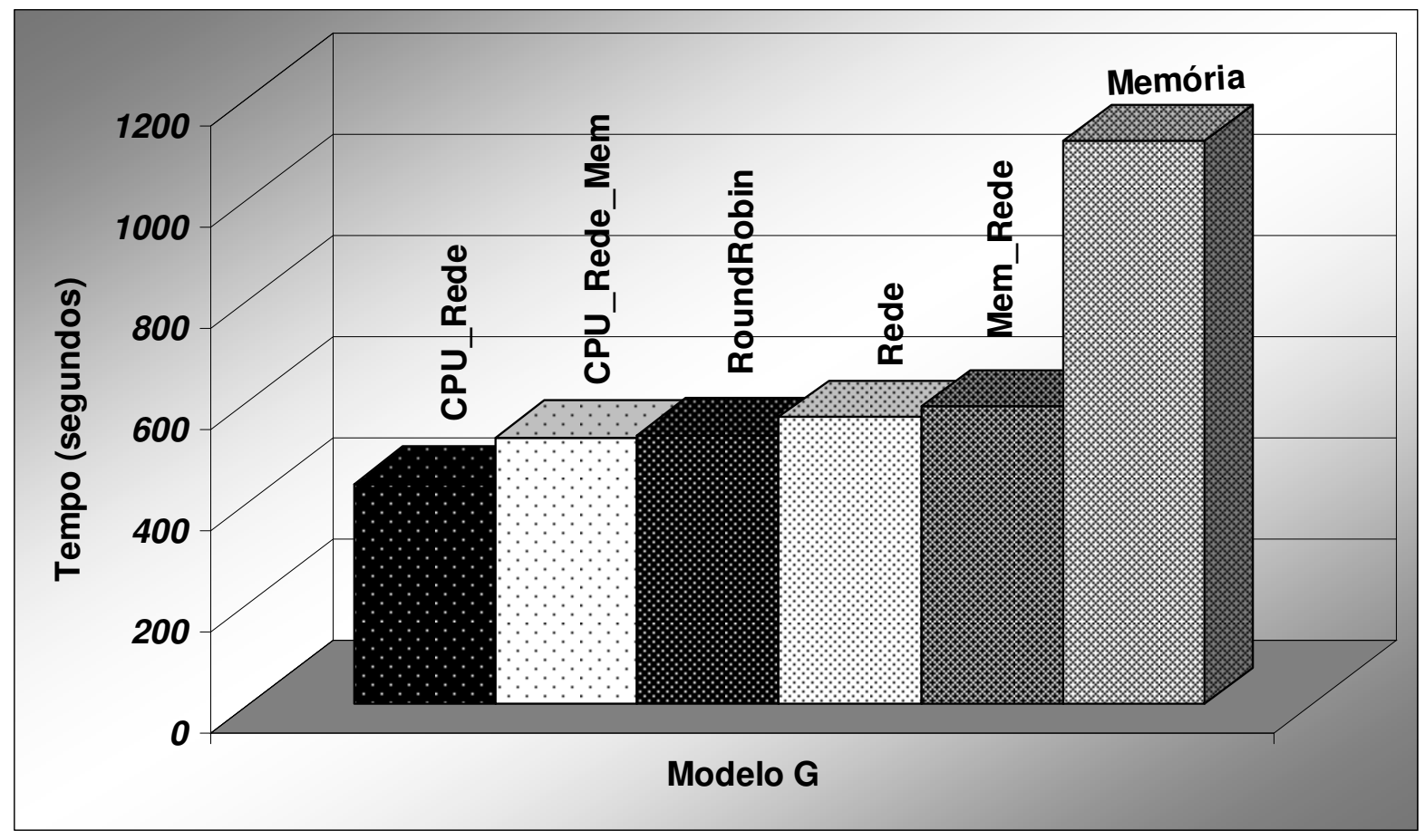

Gráfico 5.13 Tempo de execução de cada execução do "Modelo G".

A quantidade de rollbacks em cada situação de execução do modelo G é apresentada no gráfico 5.14. Neste gráfico há duas situações em que a quantidade de rollbacks foi inferior a do round-robin. A primeira é quando o benchmark de rede foi utilizado para o particionamento dos objetos, a diferença foi de $93,6 \%$ de rollbacks a menos. O segundo caso é quando o benchmark de сри foi considerado juntamente com o de rede, a diferença foi de $92,7 \%$ menos 
rollbacks. Para estes mesmos casos é observado no gráfico 5.15, que a eficiência foi superior ao round-robin em $16,3 \%$ na média.

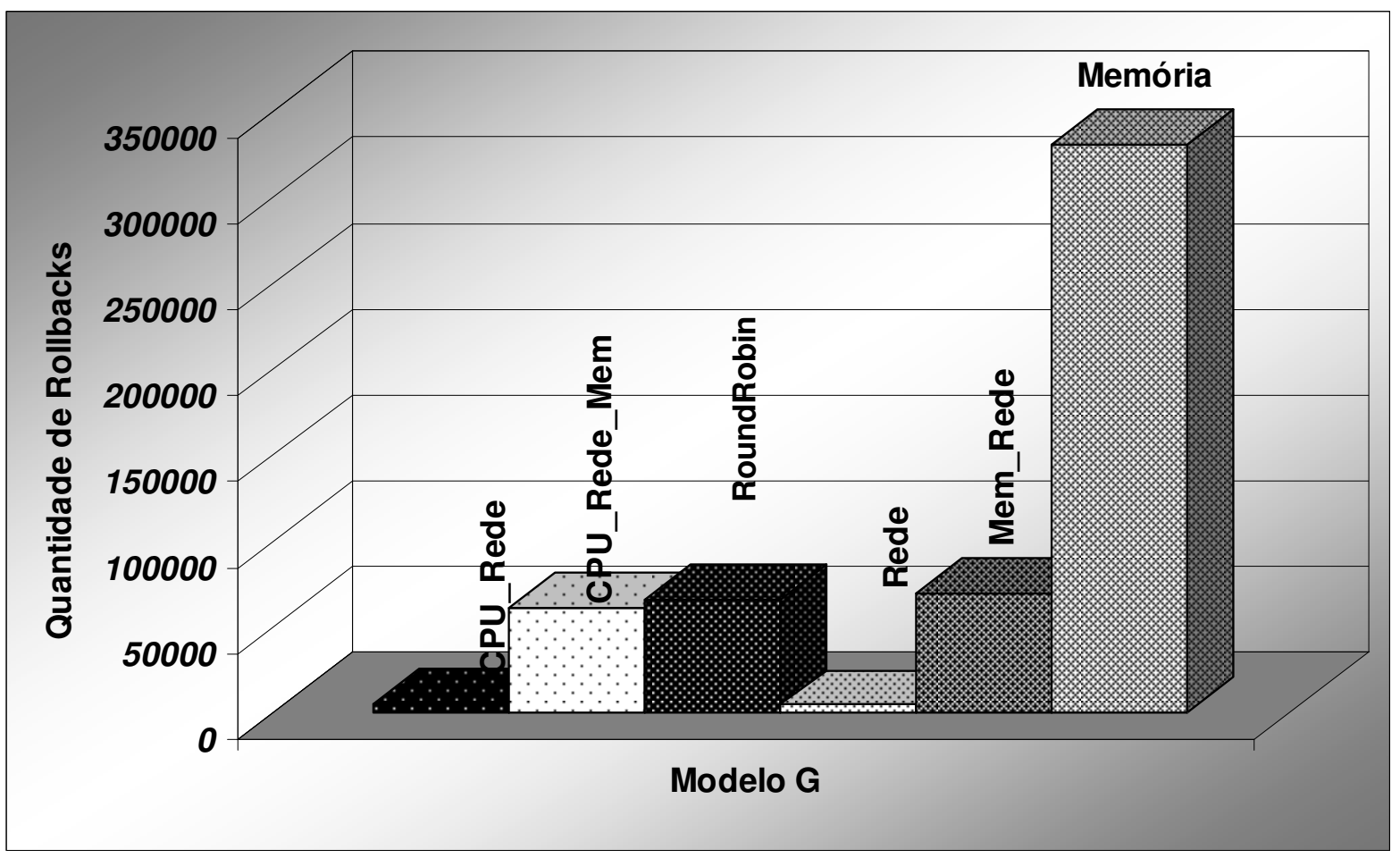

Gráfico 5.14 Quantidade de rollbacks de cada execução do "Modelo G".

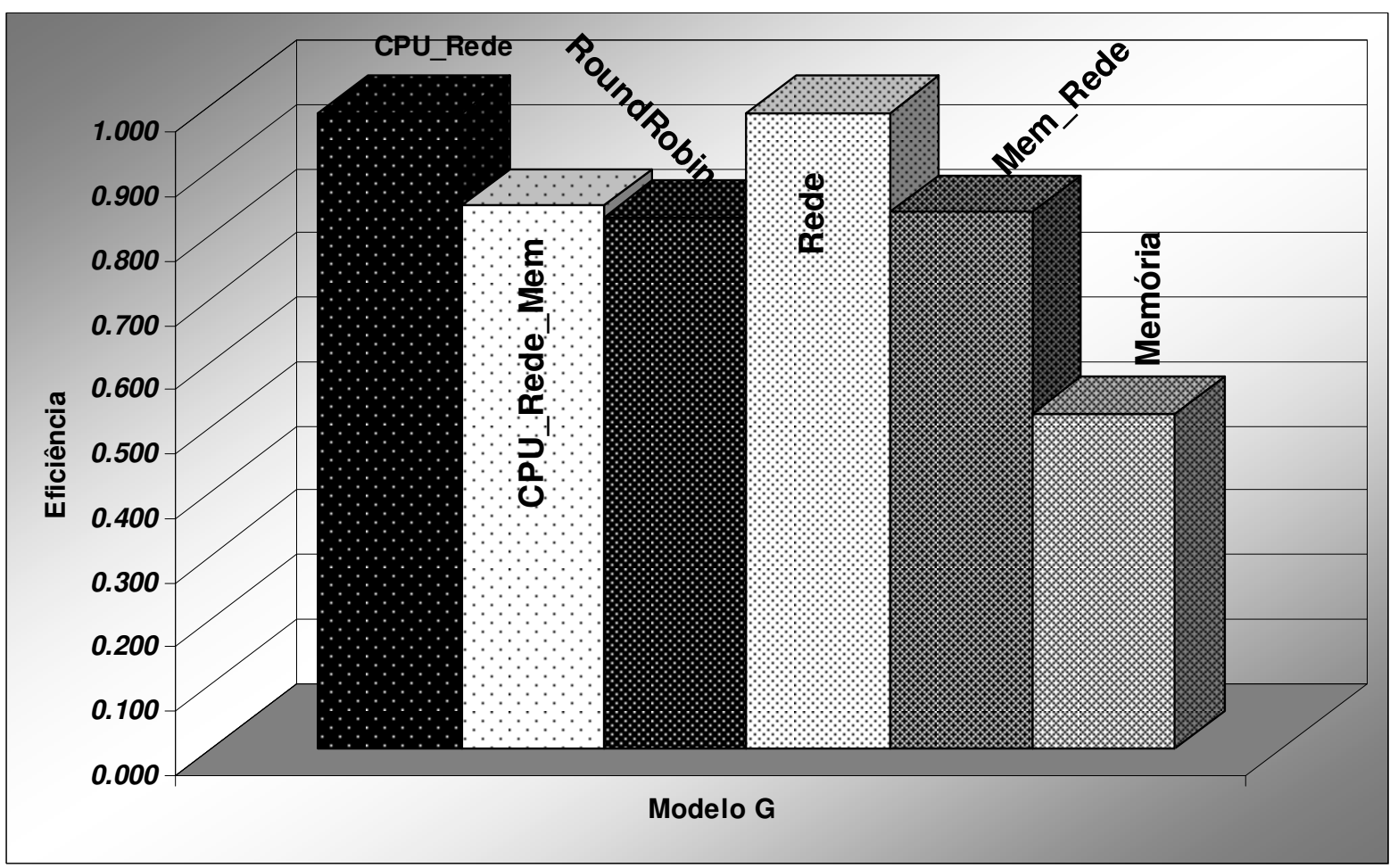




\section{GRUPO CPU}

Este grupo teve seu particionamento realizado através de informações do benchmark de $C P U$. Os modelos deste grupo (tabela 5.3) têm por principal característica o parâmetro "trabalho" diferente de nulo. Este trabalho corresponde a uma multiplicação de matrizes, sendo que a dimensão das matrizes leva à diferenciação do trabalho realizado pela $C P U$ em cada modelo.

Os gráficos de 5.16 a 5.18 apresentam uma comparação dos resultados obtidos com os modelos $\mathrm{J}$ a Q que apresentam uma carga de processamento elevada. O gráfico 5.16 mostra os tempos de execução dos modelos. Observa-se que quando o modelo simulado é particionado de acordo com o benchmark de cpu há uma redução do tempo final de execução. Com exceção dos modelos $\mathrm{P}$ e Q, os demais modelos apresentaram uma redução média de 22,8\% no tempo total comparado ao obtido quando os modelos foram executados com round-robin.

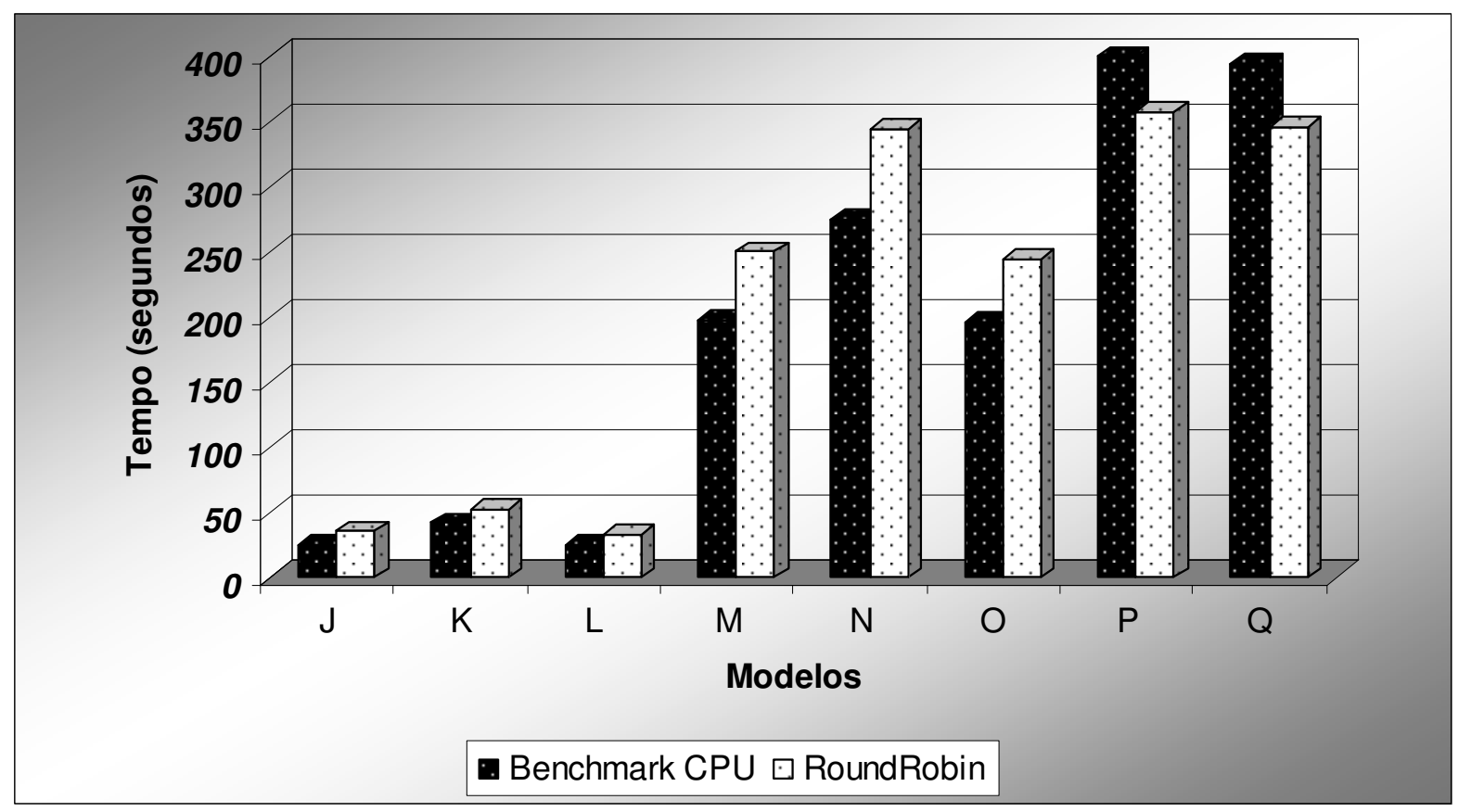

Gráfico 5.16 Comparativo do Tempo total de execução do grupo cpu.

O gráfico 5.17 apresenta o comparativo da quantidade de rollbacks. Para este grupo os resultados foram expressivos, no melhor caso houve uma redução de $88 \%$ (modelo J). O caso 
com menor ganho foi de $25 \%$ de redução (modelo P). O valor médio de redução dos rollbacks para este grupo de modelos foi de 53,4\%, em relação às execuções com o round-robin.

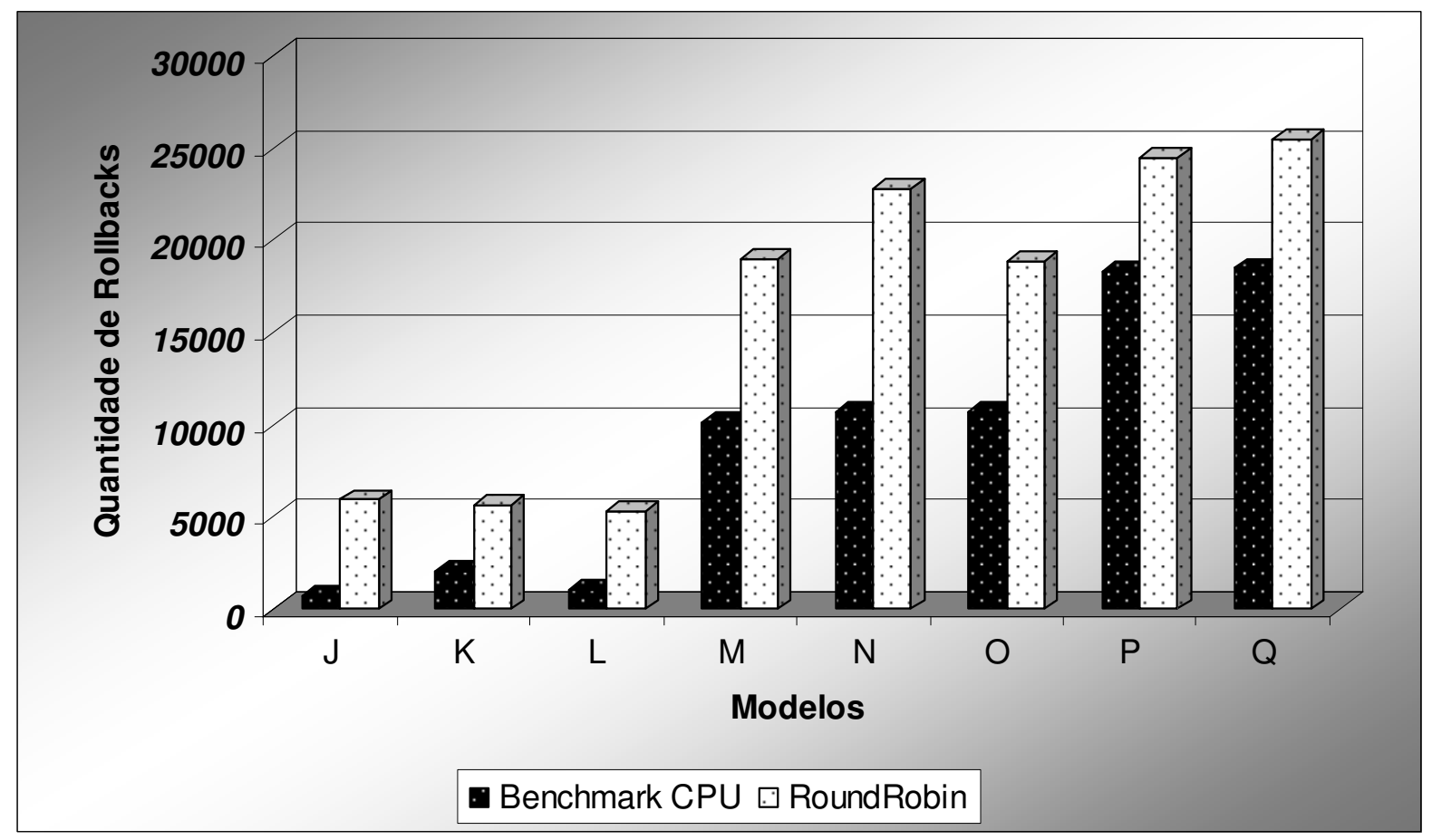

Gráfico 5.17 Quantidade de rollbacks ocorridas no do grupo cpu.

O gráfico 5.18 apresenta o comparativo das eficiências obtidas na simulação dos modelos. A execução desses modelos utilizando-se de round-robin causa uma queda na eficiência de até $20 \%$. Os modelos analisados neste grupo obtiveram sempre ganhos em suas execuções com o benchmark de cpu. 


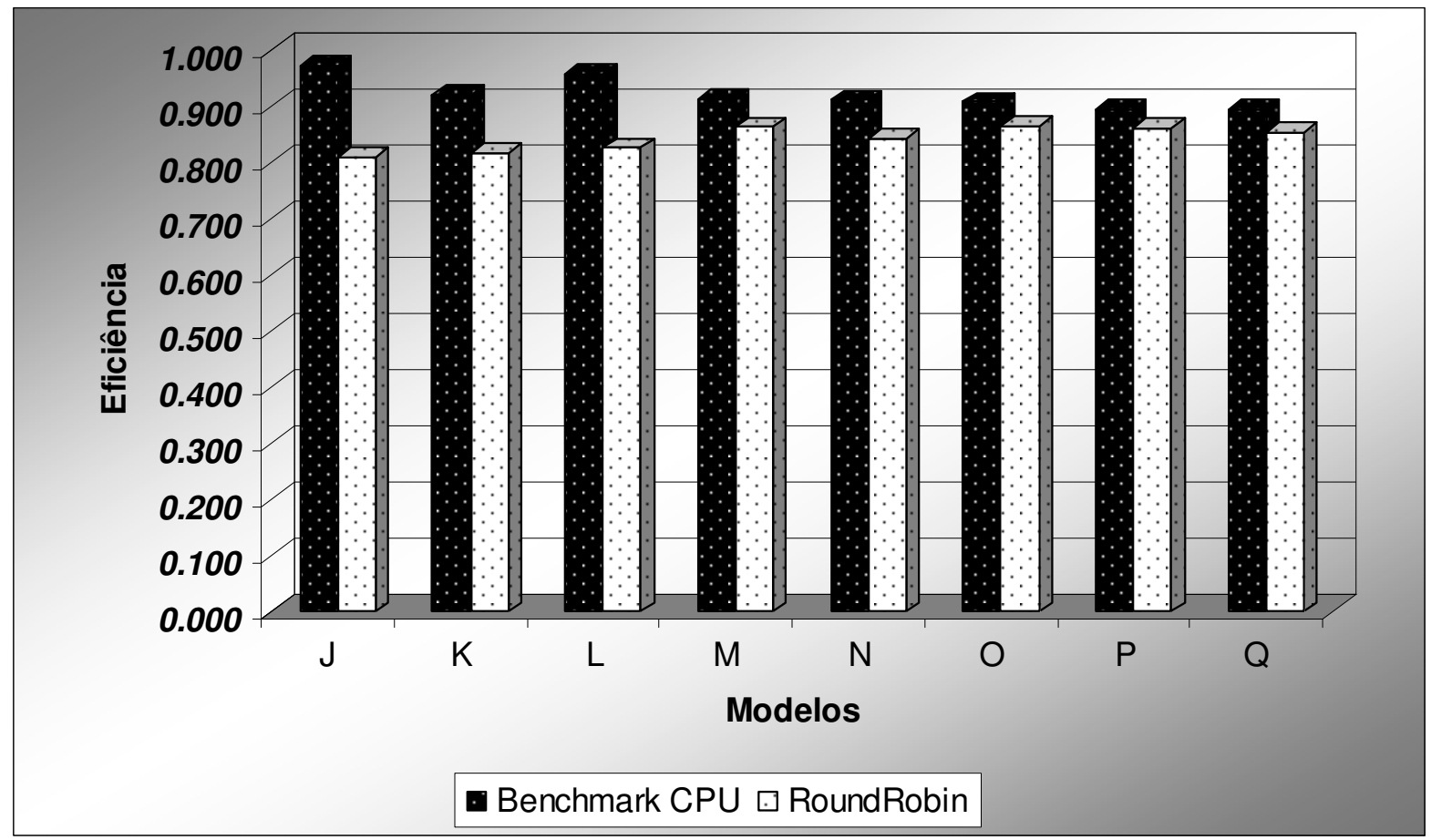

Gráfico 5.18 Eficiência de execuções de cada modelo do grupo de CPU.

Observa-se nesse grupo que os modelos $\mathrm{P}$ e $\mathrm{Q}$, executados com o benchmark de cpu, apresentaram o tempo final da execução superior a execução com round-robin. Porém, a quantidade de rollbacks observados foi menor e a eficiência final da simulação foi superior. O aumento do tempo total de execução dos modelos $\mathrm{P}$ e $\mathrm{Q}$ pode ser atribuído à elevada população de mensagens presentes nesses modelos. Nos dois casos tem-se 20.000 mensagens, sendo apenas $20 \%$ de chances de o destino da mensagem ser o próprio objeto. Para esse nível de comunicação seria interessante considerar, além do índice de $C P U$, também um benchmark de rede.

A utilização de um valor de benchmark que não reflete as características da aplicação influenciou a quantidade de rollbacks na eficiência da simulação. Com relação aos rollbacks, pode-se observar que a queda detectada nos modelos P e Q $(25.12 \%$ e $27.44 \%$ respectivamente) quando o índice de $C P U$ foi utilizado, foi menor que a queda observada nos outros modelos (62.37\% em média). O gráfico 5.18, que representa a eficiência da simulação, apresenta o mesmo comportamento. 
A queda menos significativa dos rollbacks, se comparado ao tempo de processamento, pode ser creditada a falta de balanceamento tanto em relação ao índice de rede quanto em relação ao processamento, como pode ser verificado na análise a seguir. Por meio da análise das tabelas de dados pôde-se constatar que, das quatro máquinas da plataforma, as duas máquinas (0 e 2) com maior potência computacional não sofreram rollbacks. Isto significa que a política de particionamento superestimou estas duas máquinas, sobrecarregando-as com um maior número de objetos que as outras duas.

É interessante analisar algumas informações da simulação do modelo P, com utilização da política de particionamento baseada no benchmark de cpu, para analisar o seu comportamento. A tabela 5.9 apresenta valores de três execuções ${ }^{13}$ do modelo $\mathrm{P}$, das quais se podem tirar algumas conclusões.

A primeira coluna refere-se a uma das execuções que cada modelo é submetido; a segunda coluna identifica as máquinas da plataforma utilizada. Para cada execução as quatro linhas das próximas colunas apresentam dados da execução por máquina. A coluna tempo informa quantos segundos cada máquina levou para alcançar o GVT (igual a 300) da simulação. As demais colunas trazem informações sobre os rollbacks que ocorreram durante a simulação.

\footnotetext{
${ }^{13}$ A tabela completa está disponível no apêndice C.
} 
Tabela 5.9 Informações de três execuções de modelo $P$.

\begin{tabular}{|c|c|c|c|c|c|c|c|}
\hline \multirow{3}{*}{ 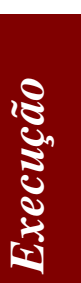 } & \multirow{3}{*}{$\begin{array}{l}\text { Máquina } \\
\text { (Tabela 5.1) }\end{array}$} & \multirow{3}{*}{ Tempo Total } & \multicolumn{5}{|c|}{ Rollbacks } \\
\hline & & & \multicolumn{4}{|c|}{ Primários (causados por:) } & \multirow[b]{2}{*}{ Secundários } \\
\hline & & & 0 & 1 & 2 & 3 & \\
\hline \multirow{4}{*}{1} & 0 & 400,704 & 0 & 0 & 0 & 0 & 0 \\
\hline & 1 & 400,195 & 747 & 2965 & 700 & 0 & 8998 \\
\hline & 2 & 401,089 & 0 & 0 & 0 & 0 & 0 \\
\hline & 3 & 400,186 & 530 & 0 & 611 & 1073 & 2755 \\
\hline \multirow{4}{*}{2} & 0 & 402,259 & 0 & 0 & 0 & 0 & 0 \\
\hline & 1 & 402,099 & 744 & 2987 & 715 & 0 & 9206 \\
\hline & 2 & 401,883 & 0 & 0 & 0 & 0 & 0 \\
\hline & 3 & 402,284 & 464 & 0 & 591 & 1076 & 2884 \\
\hline \multirow{4}{*}{3} & 0 & 397,348 & 0 & 0 & 0 & 0 & 0 \\
\hline & 1 & 396,585 & 778 & 2964 & 712 & 0 & 8768 \\
\hline & 2 & 397,128 & 0 & 0 & 0 & 0 & 0 \\
\hline & 3 & 397,442 & 531 & 0 & 612 & 1057 & 2771 \\
\hline
\end{tabular}

Os rollbacks ocorridos podem ser primários, ou secundários que são rollbacks que ocorreram decorrentes de outro rollback, devido a anti-mensagens. Verifica-se pela tabela que as máquinas com ids 0 e 2, nunca sofrem rollbacks. A coluna "rollbacks primários" está dividida em quatro colunas, onde cada coluna corresponde ao número de rollbacks causado por 
determinada máquina em outra. Por exemplo, vê-se que a máquina de id 0 provocou 747 e 530 rollbacks respectivamente nas máquinas de id 1 e 3, na primeira execução do modelo $\mathrm{P}$. Pode-se perceber ainda que as únicas máquinas que sofreram rollbacks (1 e 3), tiveram a maior parte de seus rollbacks primários ocasionados por ela mesma. Isto se explica pelo fato de que os objetos apenas estão executando numa mesma máquina, o rollback de um deles não necessariamente implica num rollback imediato dos outros objetos. Porém na evolução da simulação um objeto pode causar rollbacks em outros objetos da mesma máquina.

De acordo com informações da tabela 5.4 verifica-se que as máquinas 0 e 2 são as que possuem maior potência computacional da plataforma. Uma simulação distribuída em plataformas heterogêneas tem a necessidade de manter balanceada a carga das máquinas, de forma que máquinas com potência computacional maior não avancem mais rapidamente no seu processamento em relação a máquinas com potência inferior. Caso esta situação não seja evitada as melhores máquinas sofrerão rollbacks provocados pelas máquinas mais lentas e computações serão desfeitas.

Porém, nesse modelo simulado observa-se a situação oposta, as máquinas com maior potência computacional não sofrem rollbacks, mas causam nas máquinas inferiores. Esse comportamento ocorre devido a política de particionamento usada que baseou-se em informações do benchmark de cpu. De acordo com a tabela 5.5, as máquinas de id 0 e 2, são as que receberam as maiores notas do benchmark e conseqüentemente, receberam um maior número de objetos a serem processados. Assim, pode-se afirmar que, a heurística da política de particionamento superestimou a potência computacional dessas máquinas, sobrecarregando-as com uma grande quantidade de objetos e deixando-as mais lentas que as outras máquinas.

De acordo com a heurística da política de particionamento com benchmark de cpu, a máquina de id 1 recebe $34,2 \%$ dos objetos, e a máquina de id 2 receberá $29,3 \%$. Ou seja, as duas são responsáveis pelo processamento de aproximadamente 3175 dos 5000 objetos deste 
modelo. Sendo assim, o tempo de simulação foi maior devido à concentração de objetos em um número menor de máquinas. Esse comportamento permite concluir que quando a sobrecarga de execução de um modelo é muito alta, o benchmark proposto para o cálculo da potência computacional das máquinas pode não apresentar o resultado esperado. Apesar disso, é importante salientar que mesmo nesses casos, a eficiência da simulação melhorou em relação à utilização do round-robin.

O modelo P, como definido na tabela 5.3, possui as seguintes características:

$\checkmark$ Muita comunicação, uma população com 20.000 mensagens sendo $20 \%$ para o próprio objeto. Valor considerado alto devido a quantidade de objetos definida.

$\checkmark$ Compostos por 5.000 objetos, exigindo pouca quantidade de memória para armazená-los; e

$\checkmark$ Como diferencial realiza uma multiplicação de matrizes de tamanho 50x50, antes de repassar a mensagem.

Este modelo foi executado também com as seguintes combinações de benchmarks:

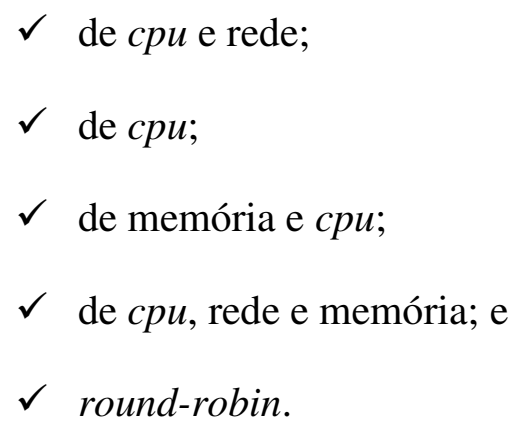

Como já discutido anteriormente a utilização apenas do benchmark de cpu não foi suficiente para melhorar o tempo do modelo. Observa-se no gráfico 5.19 que a adição de outros benchmarks na política trouxe ganhos para a simulação. 


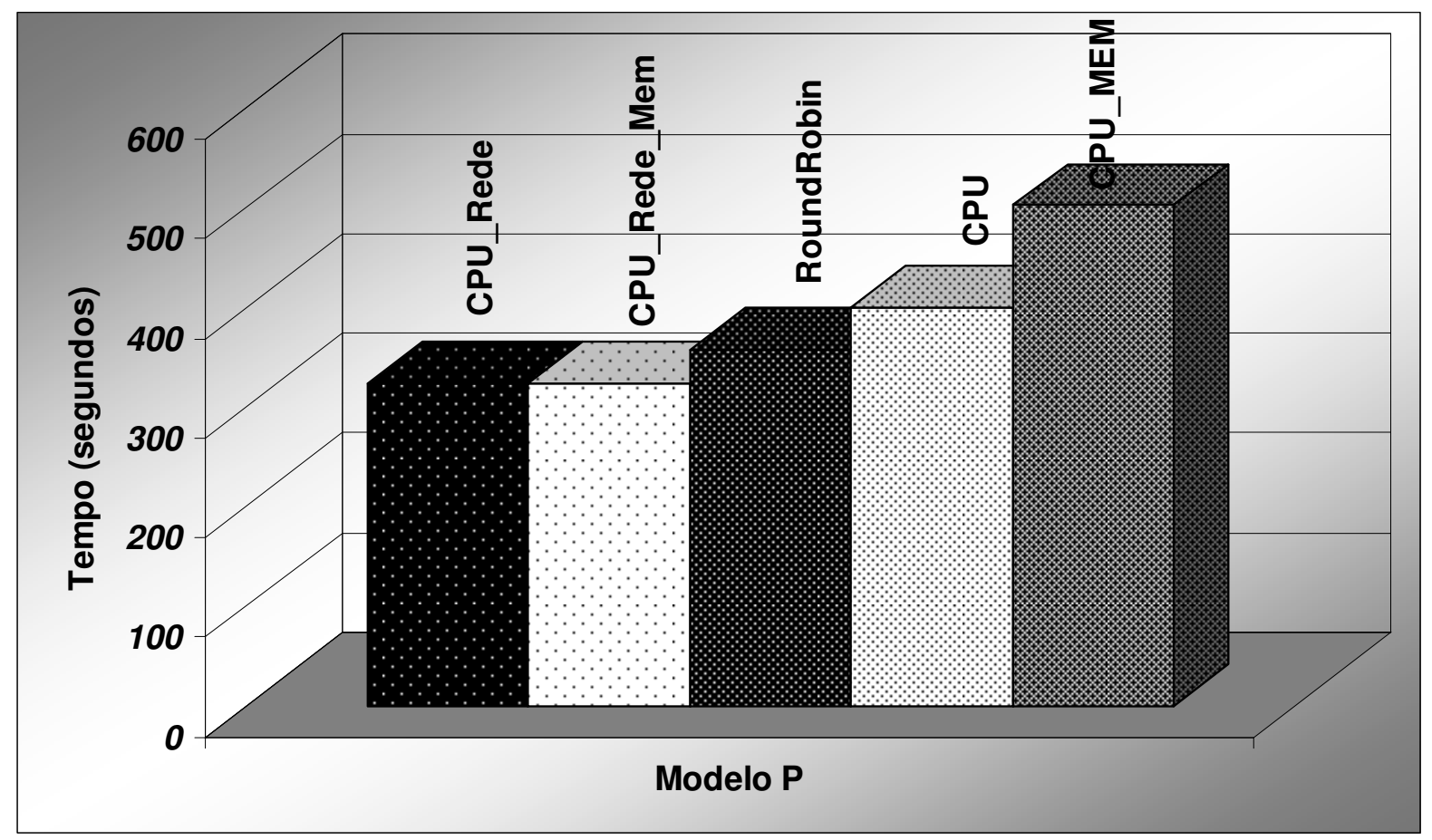

Gráfico 5.19 Tempo de execução do modelo P com diferentes benchmarks.

Usando-se apenas o benchmark de cpu o tempo de execução da simulação foi $12 \%$ superior que quando executada com round-robin, com adição do benchmark de memória este tempo foi 40,7\% maior. Porém, quando se usa a combinação de cpu e rede este tempo é reduzido em 9,7\%. Executando com os três benchmarks: cpu, rede e memória, a redução do tempo é de 9,5\%. Percebe-se aqui também que o benchmark de memória não traz ganhos para o desempenho da simulação.

No gráfico 5.20 pode-se analisar a quantidade de rollbacks do modelo $\mathrm{P}$ executado com as diferentes combinações de benchmarks. A quantidade de rollbacks foi reduzida em 73\% quando utilizados os benchmarks de cpu e rede. Porém, verificou-se que quando o benchmark de memória é considerado, em quaisquer combinações, o desempenho da simulação sempre é degradado. O caso de maior impacto é o ilustrado nesse gráfico onde, com o bechmark de cpu, a quantidade de rollbacks foi $25.12 \%$ inferior que o round-robin. Mas quando adicionado o benchmark de memória, junto com o de cpu, a quantidade de rollbacks aumenta 
em $288.29 \%$. Assim, pode-se concluir que o benchmark de memória não é útil nos estudos de casos realizados.

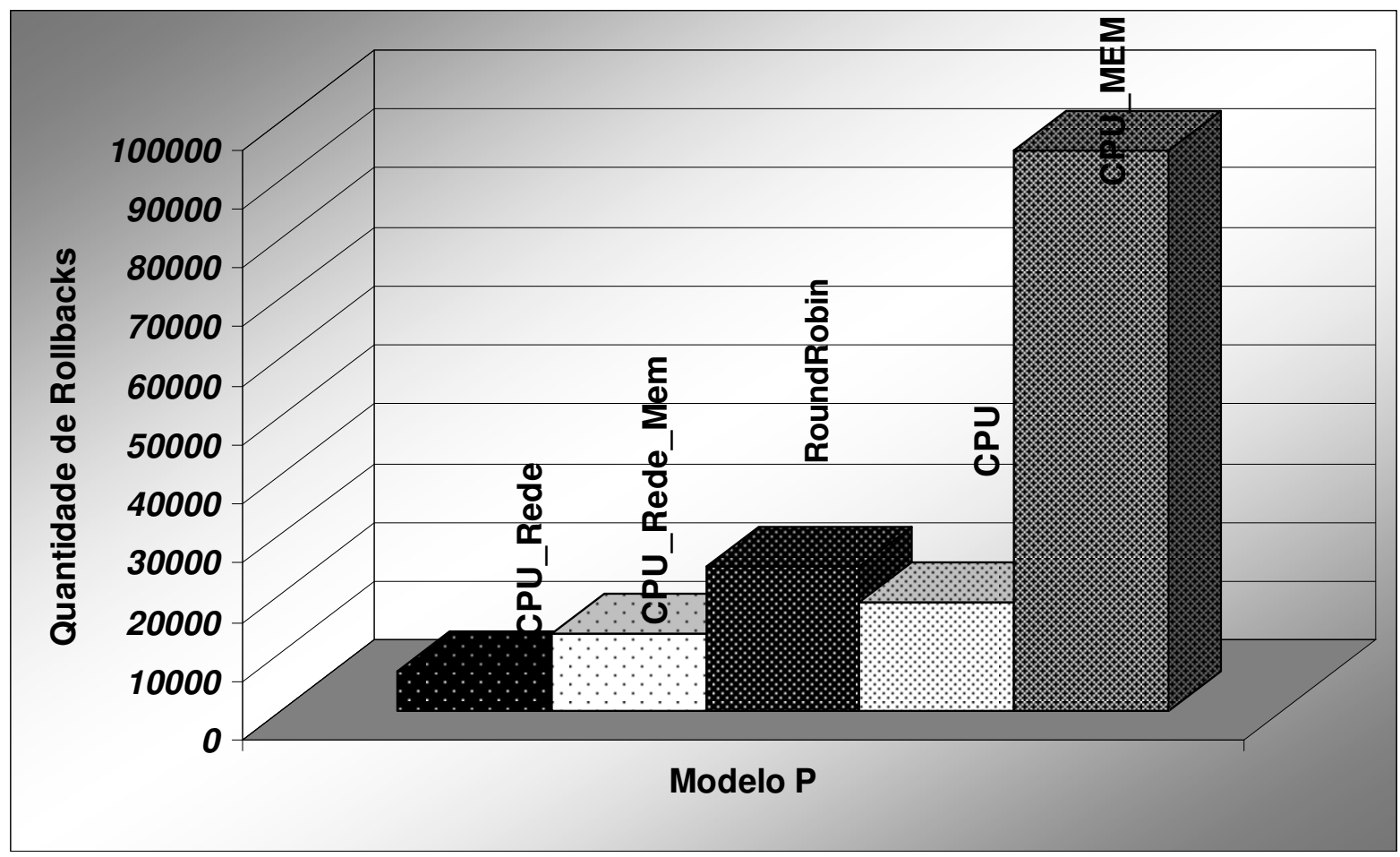

Gráfico 5.20 Quantidade de rollbacks ocorridos na execução do modelo P com diferentes benchmarks.

O gráfico 5.21 apresenta a eficiência obtida em cada execução do modelo P com as variações dos benchmarks considerados. Nesse gráfico a mesma análise anteriormente feita para quantidade de rollbacks é válida. Ou seja, quando adicionado o índice de memória a eficiência da simulação é afetada. 


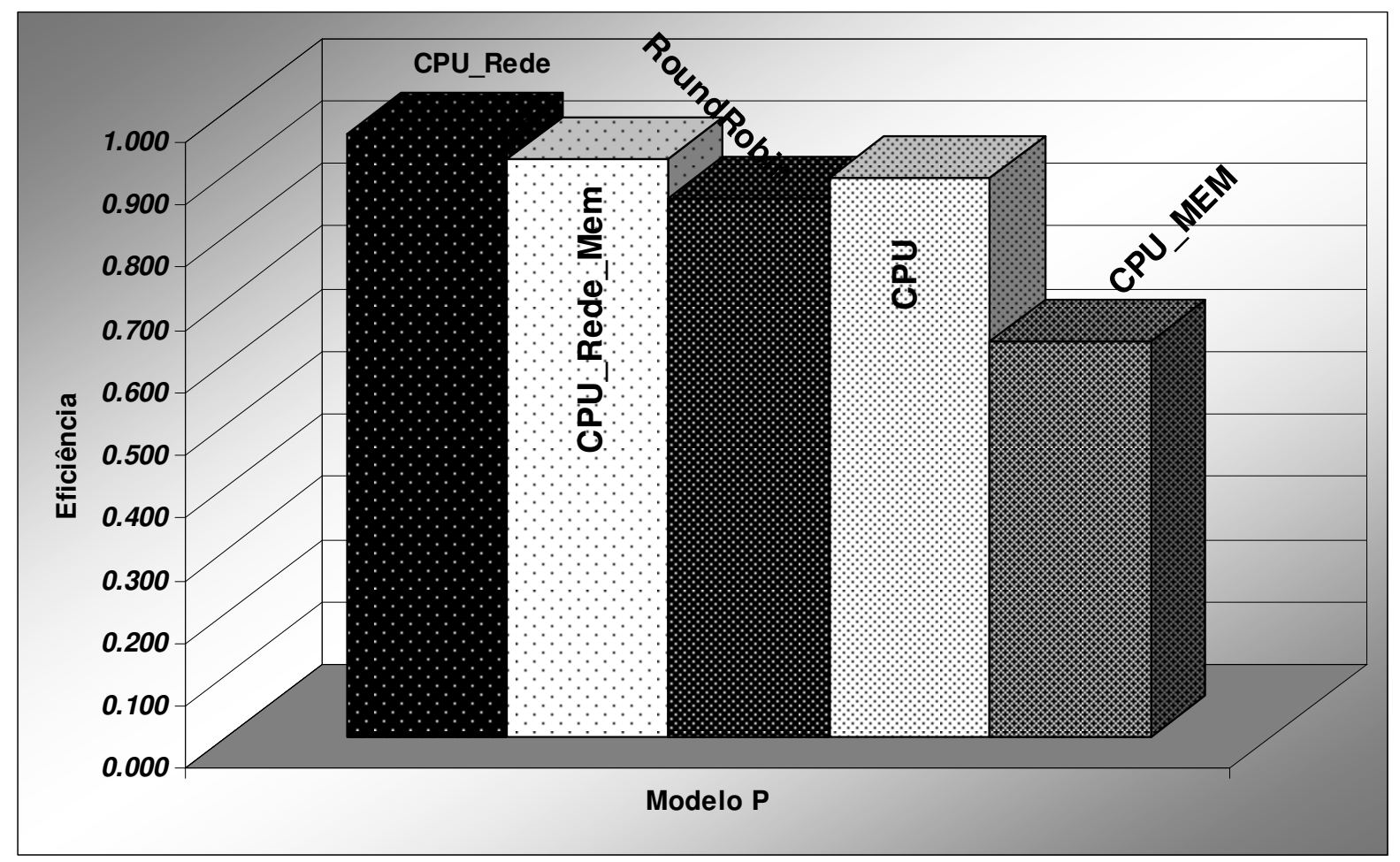

Gráfico 5.21 Eficiência obtida com a execução do modelo P com diferentes benchmarks

Com a utilização dos benchmarks de cpu e rede a eficiência foi $11.7 \%$ superior que o round-robin. Para as execuções considerando os três benchmarks, e somente com o de cpu o ganho foi de $7 \%$ e $3.8 \%$, respectivamente. Já a execução apenas com os benchmarks de cpu e memória a eficiência foi $26.7 \%$ inferior. Pode-se perceber que neste modelo, apesar de realizar um trabalho grande, o fator impactante para melhorar a sua performance foi a rede. Quando este benchmark foi considerado em suas execuções os ganhos obtidos foram consideravelmente superiores.

\subsubsection{Ambiente heterogêneo e compartilhado}

Os resultados da seção anterior mostraram testes em ambiente dedicado a uma única simulação, onde se analisou o impacto da heterogeneidade da plataforma no desempenho da simulação. Os resultados obtidos demonstram que a utilização de um índice que represente a capacidade de trabalho de cada máquina, em relação aos recursos necessários para a execução de uma aplicação, pode causar um impacto grande no sentido de melhorar o desempenho da 
simulação. Os testes realizados na seção anterior consideram um índice estático para cada máquina, sem considerar a carga adicional em execução no momento da alocação dos objetos. O objetivo desta seção é integrar o Warped e o $A M I G O$ de forma a permitir que índices de desempenho sejam considerados durante a alocação de objetos nos processadores. Para demonstrar o funcionamento conjunto desses sistemas, realizou-se alguns testes e verificou-se o impacto no desempenho de uma simulação devido à concorrência na utilização dos recursos com aplicações de outros usuários.

\subsubsection{Caracterização do ambiente}

Com o intuito de caracterizar um ambiente compartilhado desenvolveu-se uma aplicação que fica em execução durante todo o tempo da simulação. Esta aplicação, denominada de "parasita", foi criada para inserir carga na plataforma simulando a presença de aplicações de outros usuários. O parasita corresponde à execução de uma seqüência de processos que provoca variações no nível de carga das máquinas.

Os processos são execuções da versão seqüencial da aplicação $P H O L D$, sendo que para cada máquina uma configuração específica foi definida. Assim máquinas com maior potência computacional receberam processos com um número maior de objetos, em comparação com máquinas inferiores.

A variação de carga durante a execução foi obtida alterando-se o número de processos, que estão executando concorrentemente, de acordo com a seguinte seqüência: $0 ; 1 ; 2 ; 4 ; 2 ; 1$ e 0 processos. Essa seqüência é repetida durante todo o tempo do experimento.

Foi definido um intervalo de tempo durante o qual era mantido cada estado de carga (sequiência de processos executando). Porém, duas formas distintas de geração desta carga foram criadas, diferenciando os experimentos em dois grupos: (1) com carga determinística e (2) com carga aleatória. No primeiro tipo, o intervalo foi definido como um valor fixo de 180 segundos. No outro caso o valor do intervalo era sorteado aleatoriamente de acordo com uma 
distribuição uniforme variando entre 1 e 360 segundos; nesse caso, para cada mudança de estado de carga era sorteado um novo valor do intervalo.

O objetivo das variações no número de processos executando concorrentemente e do intervalo de duração dos diferentes estados de carga, foi tornar a carga parasita menos previsível e consequentemente mais realista.

\subsubsection{Estudo de Caso}

Considerando que a plataforma não está mais dedicada para execução da simulação, esses testes se tornam mais demorados. Assim, apenas o modelo $\mathrm{G}$ foi selecionado para ser executado e analisado neste ambiente. O tempo de execução deste modelo, em média, no ambiente dedicado foi de 570 segundos, enquanto que no ambiente compartilhado o tempo de execução chegou a 2678 segundos.

A quantidade de rollbacks ocorridos e a eficiência da simulação também foram afetadas com a mudança do ambiente de execução. No ambiente dedicado os valores da execução deste modelo foi de 0,99 em eficiência e 4208 rollbacks ocorridos. Já na plataforma compartilhada esses valores foram no melhor caso 0,90 de eficiência e 29.133,667 rollbacks ocorridos. As próximas seções apresentam os resultados obtidos com os testes dessa plataforma.

Conforme apresentado na tabela 5.2 o modelo $\mathrm{G}$ apresenta as seguintes características:

$\checkmark$ Compostos por 10.000 objetos, exigindo considerável quantidade de memória para armazená-los;

$\checkmark$ Muita comunicação, com uma população de 40.000 mensagens sendo apenas $20 \%$ para o próprio objeto.

$\checkmark$ O único custo de processamento para cada objeto é a definição do destino das mensagens que serão enviadas. 


\subsubsection{3. Índices de carga}

Quando plataformas compartilhadas são consideradas outras informações, além das informações estáticas (benchmarks), podem ser analisadas para a realização do particionamento dos objetos. Os índices de carga são utilizados para indicar a real situação da plataforma, sendo assim possível adicionar à política de particionamento novas informações para serem utilizadas nas decisões subsequentes. Os benchmarks utilizados foram os de cpu e rede. A nota obtida para cada máquina da plataforma (tabela 5.5) destes benchmarks é a informação estática utilizada pelo particionamento, que será a nota inicial referente a cada máquina.

A seção 4.2.2 apresentou os índices de carga que foram estudados para este trabalho: a quantidade de processos na fila do processador e a quantidade de memória livre, que podem indicar com precisão os níveis de saturação da máquina. Os testes realizados no ambiente compartilhado foram divididos inicialmente em dois grupos: ambiente onde a carga parasita é determinística e outro onde esta carga é aleatória. O desempenho desses testes foi comparado também com o desempenho da simulação utilizando o round-robin.

Dentro dos grupos citados anteriormente executou-se os testes com quatro configurações distintas de informações para o particionamento, considerando:

$\checkmark$ Apenas informações estáticas, ou seja, a nota inicial de cada máquina obtida com os benchmarks de cpu e rede;

$\checkmark$ As notas iniciais, e o índice de memória;

$\checkmark$ As notas iniciais e o índice da fila do processador;

$\checkmark$ A combinação das três informações: notas iniciais, índice de memória e índice da fila do processador.

\subsubsection{Ambiente com carga determinística}

A carga determinística gerada nessa plataforma de testes, ocorria colocando-se processos para executarem concorrentemente com a simulação. A cada 180 segundos a quantidade 
de processos gerados por essa carga parasita é alterada, de forma que há até quatro processos executando.

A tabela 5.10 apresenta os valores de tempo, eficiência e quantidade de rollbacks obtidos para cada execução do modelo G. Para cada execução diferentes informações foram utilizadas para auxiliar no particionamento dos objetos do modelo. No primeiro caso (NI) apenas informações estáticas sobre a plataforma foram utilizadas. Nos próximos três casos, além da informação estática, também se utilizam informações dinâmicas da plataforma. No último caso apenas o round-robin é utilizado.

Tabela 5.10 Informações de execuções do modelo G em plataforma compartilhada/carga determinística.

\section{Informações utilizadas no particionamento \\ Tempo (seg) Eficiência \\ Rollbacks}

$\begin{array}{llll}\text { Notas Iniciais (NI) } & 909.045 & 0.90 & 36865.133\end{array}$

\begin{tabular}{llll}
\hline NI + índice de fila de processos (IndFila) & 1545.458 & 0.61 & 315888.067
\end{tabular}

\begin{tabular}{lccc}
\hline NI + índice de memória (IndMem) & 1925.162 & 0.43 & 561227.5 \\
\hline NI + IndMem + IndFila & 1069.683 & 0.79 & 89866 \\
\hline Round-robin $(\mathbf{R R})$ & 1276.849 & 0.76 & 111416.2 \\
& & & \\
\hline
\end{tabular}

Observa-se que o tempo de execução (gráfico 5.22) do modelo no melhor caso foi $28.8 \%$ menor que quando apenas o round-robin é utilizado. Porém, este melhor tempo encontrado foi utilizando-se apenas de informações estáticas da plataforma. Quando os dois índices estudados foram adicionados às notas iniciais, o ganho apesar de menor, ainda foi $16.22 \% \mathrm{em}$ relação ao round-robin, mas quando utilizados separadamente o tempo foi afetado, sendo $21 \%$ maior no caso onde apenas o índice de fila de processos foi utilizado, e chegando a $50.8 \%$ com o índice de memória. 


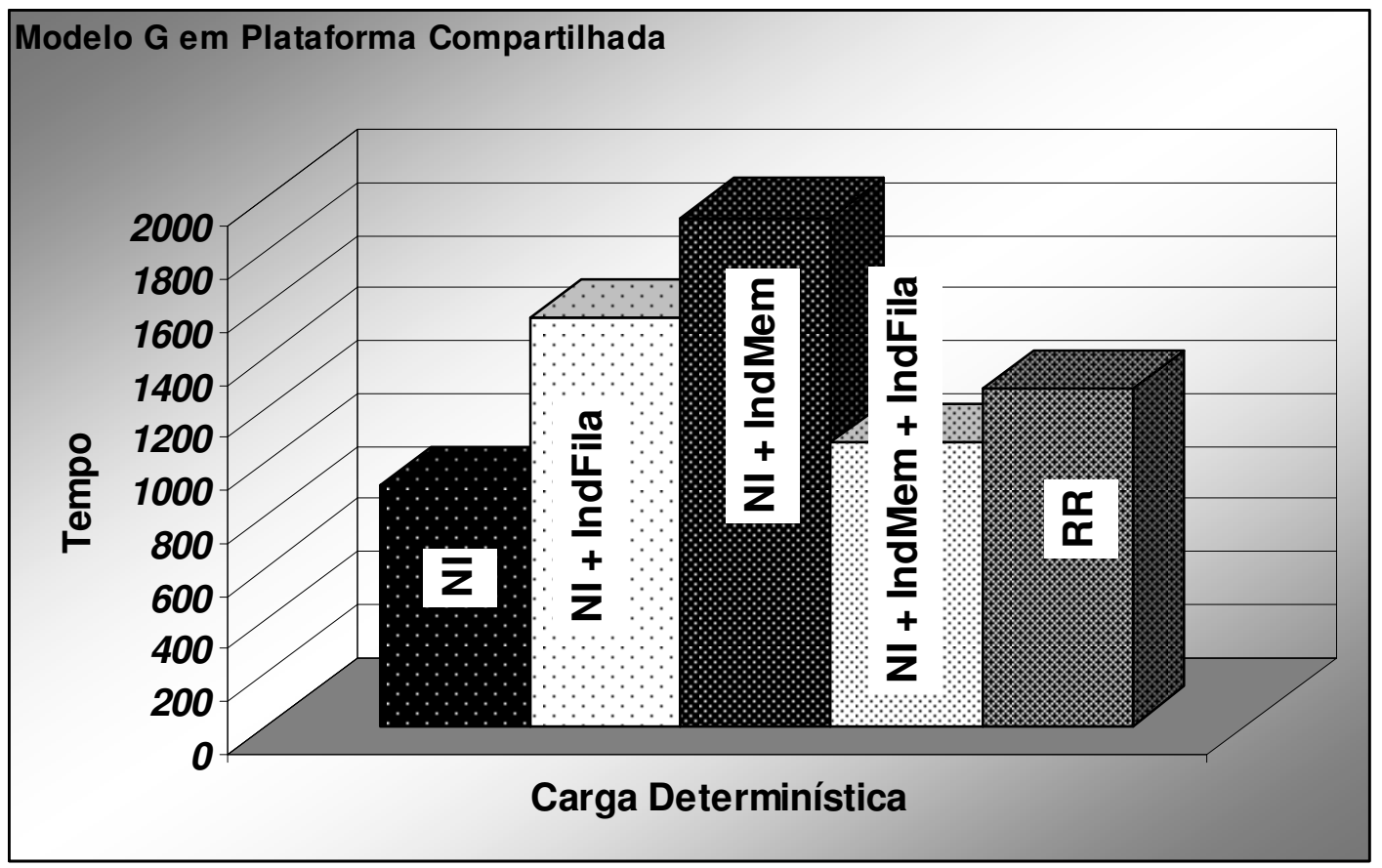

Gráfico 5.22 Tempo de execução numa plataforma compartilhada com carga determinística.

O gráfico 5.23 apresenta a eficiência obtida nas simulações, que chegou a ser $18.8 \%$ superior em relação ao round-robin, quando apenas as notas iniciais foram consideradas. Um ganho de $4.7 \%$ foi obtido com a combinação das informações estáticas e os dois índices de carga estudados. E como no caso da variável tempo, quando os índices foram utilizados separadamente, a eficiência foi reduzida em $19.8 \%$ com índice de fila e $43 \%$ com o índice de memória. 


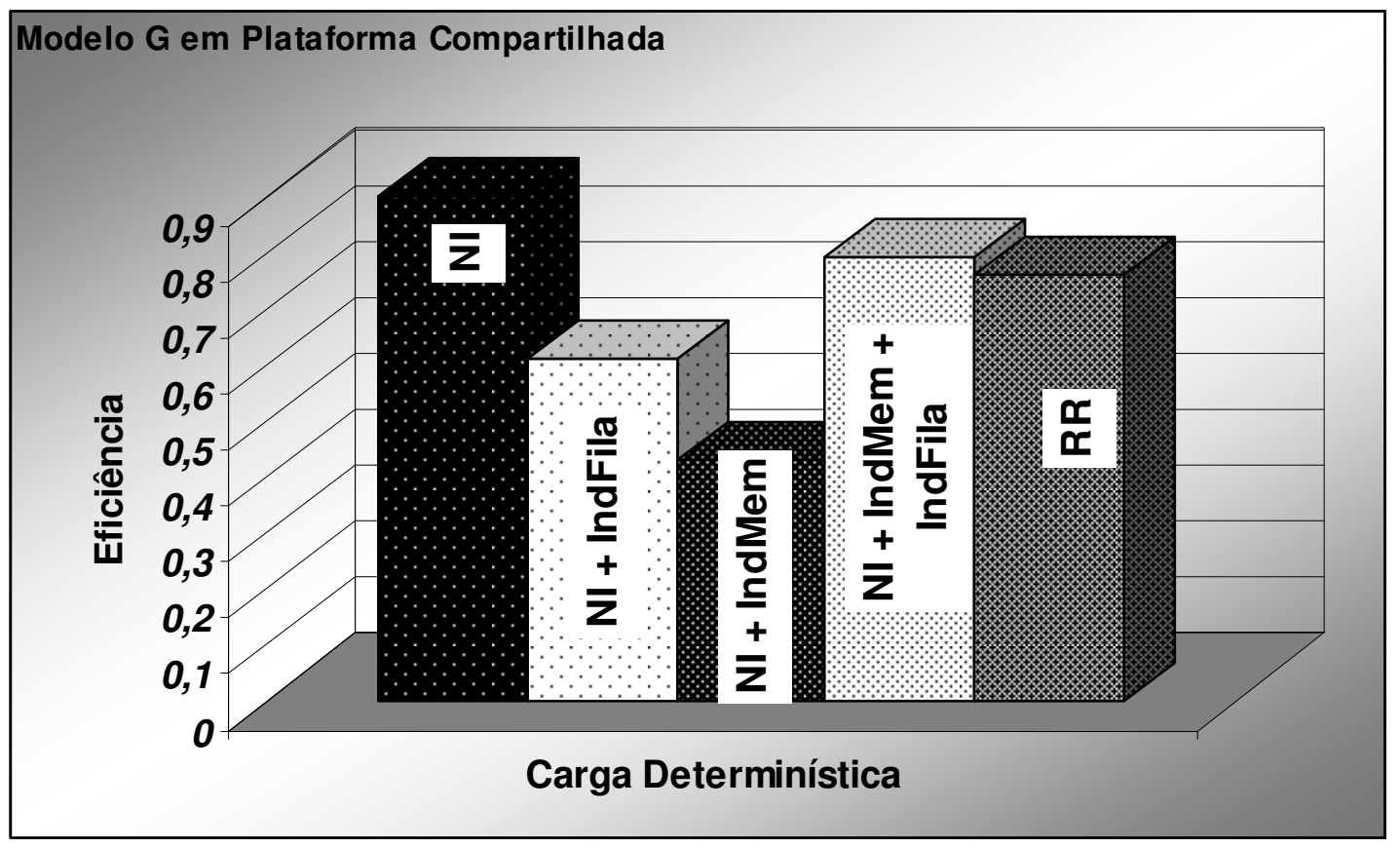

Gráfico 5.23 Eficiência obtida numa plataforma compartilhada com carga determinística.

O gráfico 5.24 apresenta a quantidade de rollbacks ocorridos. A redução mais significativa foi de $67 \%$ usando apenas informações estáticas. O pior caso de desempenho foi com o índice de memória, adicionado as notas iniciais, com $403.7 \%$ rollbacks a mais que o roundrobin.

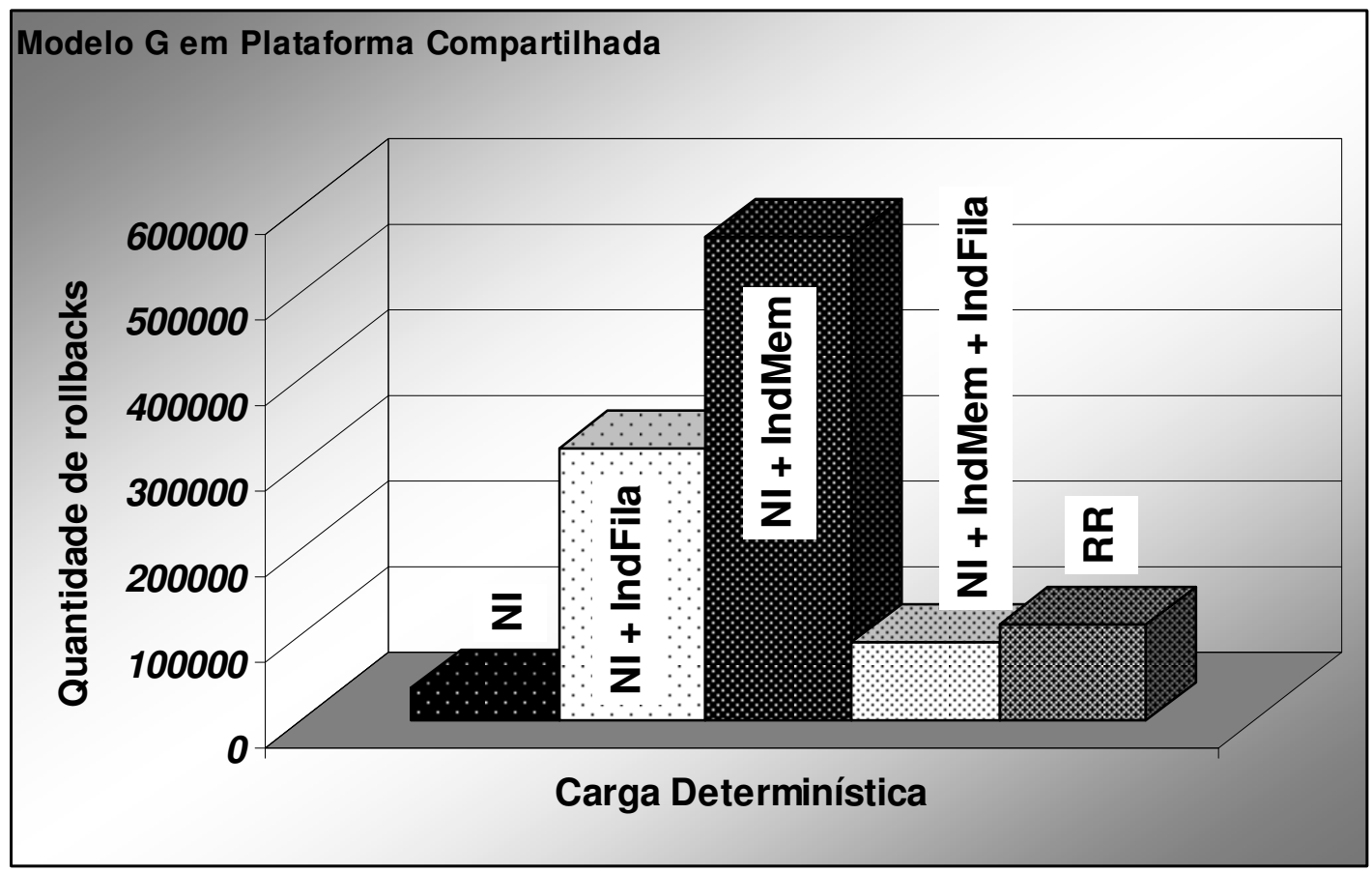

Gráfico 5.24 Quantidade de rollbacks ocorridos em plataforma compartilhada e com carga determinística. 
Percebe-se que nesse estudo de caso as informações dinâmicas não trouxeram ganhos consideráveis quando adicionadas com as informações estáticas. Quando utilizadas independentemente acabaram degradando o desempenho. A combinação das duas informações elevou o desempenho, porém o maior ganho foi obtido somente com a utilização das informações estáticas.

Isso mostra que a carga gerada pela aplicação parasita não causou grande impacto na plataforma, e apenas as informações estáticas foram suficientes para balancear a carga da simulação.

\subsubsection{Ambiente com carga aleatória}

Nesse ambiente, a carga parasita também gera processos para serem executados concorrentemente com a simulação. A diferença é que em vez do intervalo em que o número de processos ativos é alterado ser fixo em 180 segundos, ele foi calculado de forma aleatória, podendo ser 1 a 360 segundos. A tabela 5.11 apresenta os dados obtidos nesse ambiente.

Tabela 5.11 Informações das execuções do modelo $G$ na plataforma compartilhada com carga aleatória.

Informações utilizadas no particionamento Tempo(seg) Eficiência Rollbacks

$\begin{array}{llll}\text { Notas Iniciais (NI) } & 2677.711 & 0.55 & 315636.933\end{array}$

\begin{tabular}{llll}
\hline NI + índice de fila de processos (IndFila) & 1214.118 & 0.69 & 158642.267
\end{tabular}

\begin{tabular}{llll}
\hline $\mathbf{N I}+$ índice de memória (IndMem) & 1804.833 & 0.60 & 268347.133
\end{tabular}

\begin{tabular}{llll}
\hline NI + IndMem + IndFila & 1156.571 & 0.68 & 183080.333 \\
& & & \\
\hline Round-robin $(\mathbf{R R})$ & 1358.145 & 0.71 & 149678.200 \\
& & & \\
\hline
\end{tabular}

Os gráficos 5.25, 5.26 e 5.27 apresentam respectivamente as variáveis tempo, eficiência e quantidade de rollbacks obtidas nas execuções deste ambiente. Percebe-se que, diferentemente do ambiente anterior, onde a carga parasita era determinística, nesse ambiente, a utilização apenas das informações estáticas para a realização do particionamento, foi o pior caso 
de todas as simulações. Em relação ao round-robin, o uso apenas das notas iniciais teve o seu tempo de execução $97 \%$ pior, a eficiência $22 \%$ menor e a quantidade de rollbacks ocorridos 110.9\% superior. Isso mostra que o fator aleatoriedade da carga imposta na plataforma teve um considerável impacto na tomada de decisão do particionamento dos objetos. Apenas as informações estáticas não foram suficientes para expressar a carga da plataforma.

Percebe-se também nesses estudos que o índice de carga de memória, quando utilizado como única informação dinâmica, não contribui significativamente para o aumento do desempenho da simulação. A adição desse índice junto com as informações estáticas trouxe pequenos ganhos nos resultados. Comparando com o resultado anterior, que considera apenas as notas iniciais, a eficiência aumentou em torno de 5\%, a quantidade de rollbacks foi aproximadamente $30 \%$ menor. Apesar dessas pequenas melhoras, o uso destas combinações de informações sobre a plataforma não se mostram úteis, pois ainda apresentam um desempenho inferior ao round-robin.

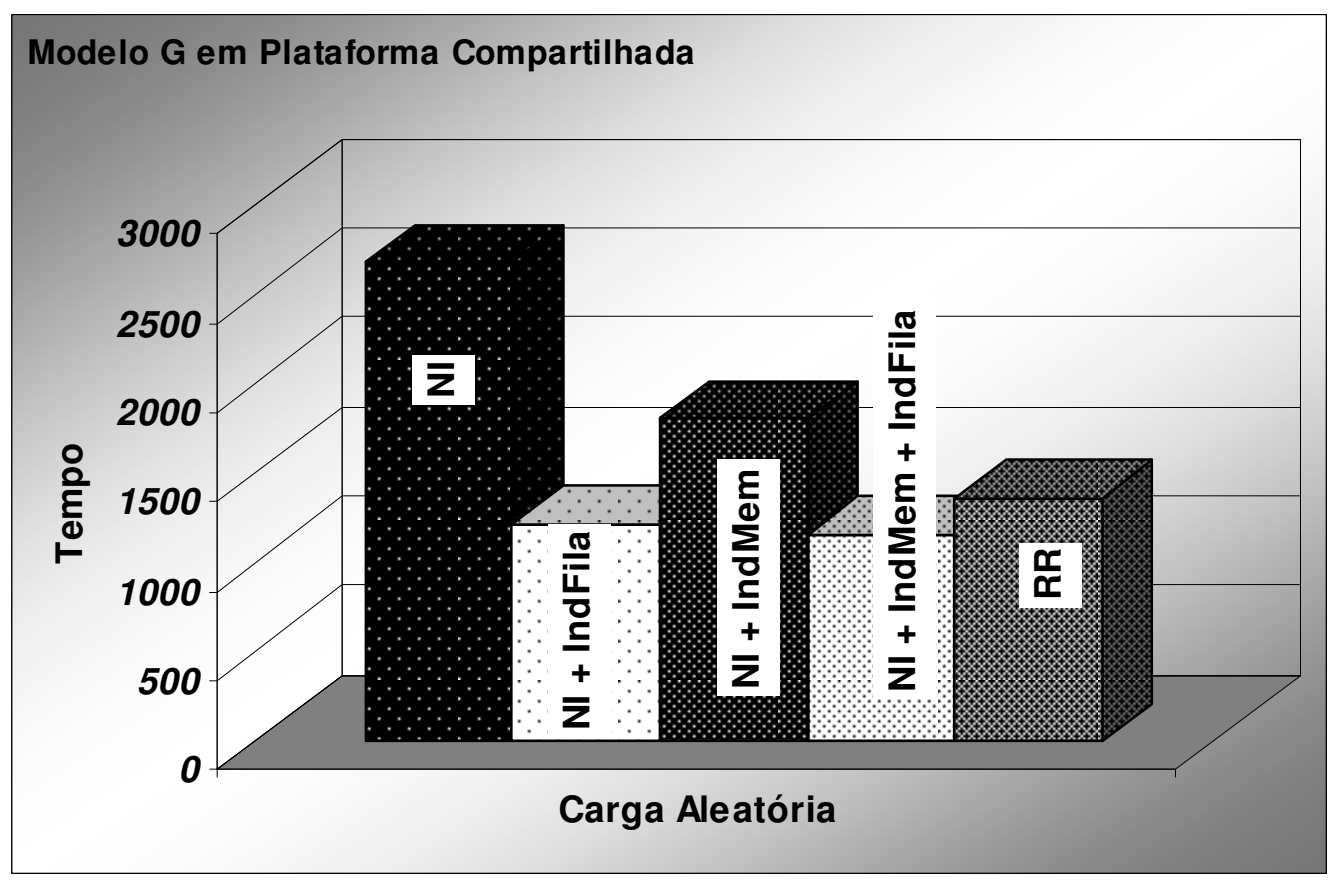

Gráfico 5.25 Tempo de execução numa plataforma compartilhada com carga aleatória.

O tempo da simulação foi reduzido quando, junto com as informações estáticas, as duas informações dinâmicas foram utilizadas. $\mathrm{O}$ uso do índice de fila de processos reduziu o 
tempo em 10.6\%; já a combinação com o índice de memória o ganho foi de um tempo 14,8\% menor que o round-robin.

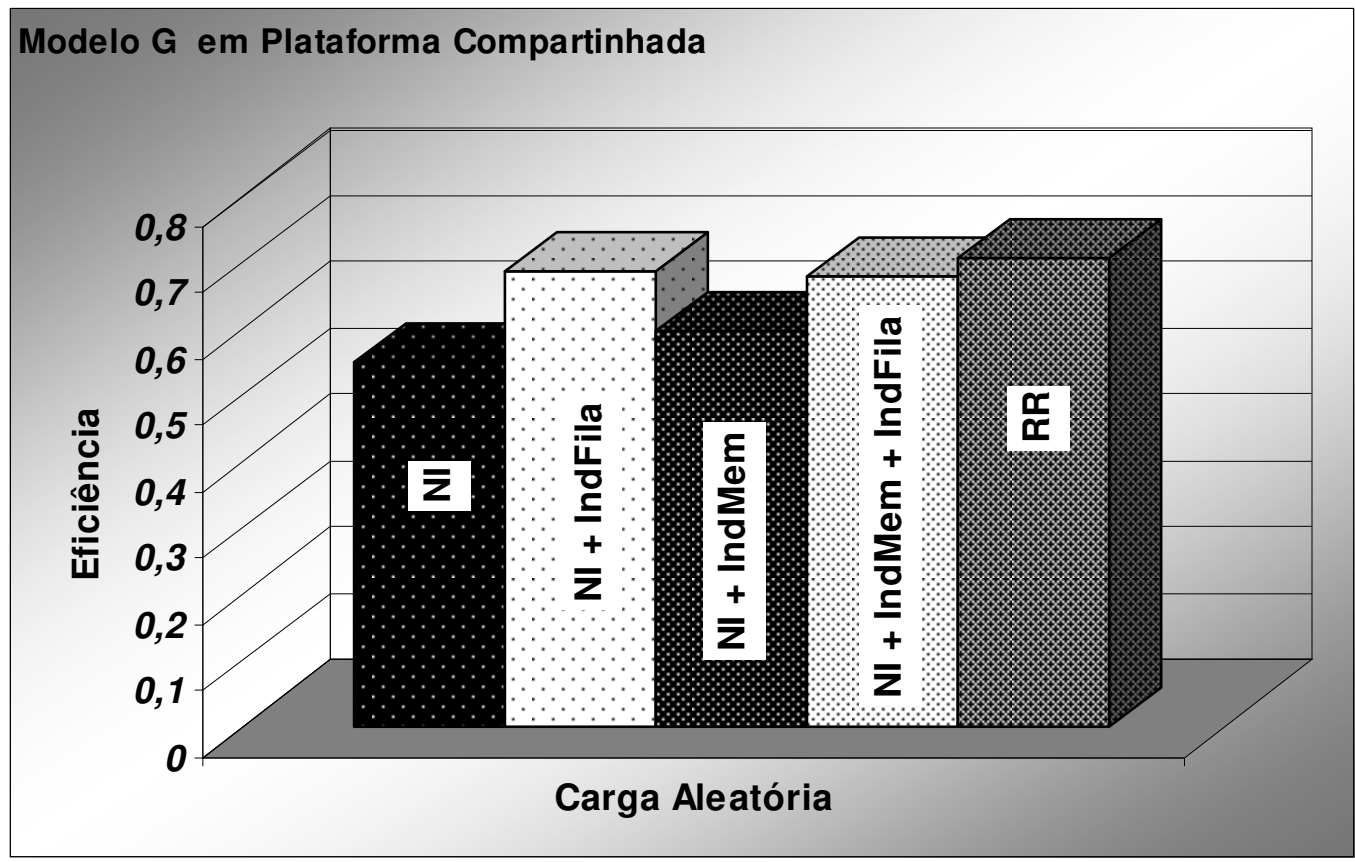

Gráfico 5.26 Eficiência obtida numa plataforma compartilhada com carga aleatória.

Apesar dessa combinação ter reduzido o tempo da simulação, a sua eficiência final acabou sendo 4,5\% inferior ao round-robin. Essa diferença ocorre pelo fato da eficiência estar relacionada com a quantidade de eventos, realizados por processados, durante toda a simulação. Observou-se que apesar desse cenário, executar num tempo menor, a quantidade de rollbacks ocorridos foi $22 \%$ superior. Já, o cenário que considera apenas as notas iniciais com o índice de fila de processos teve uma eficiência $2,3 \%$ inferior ao round-robin e gerou $6 \%$ rollbacks a mais. 


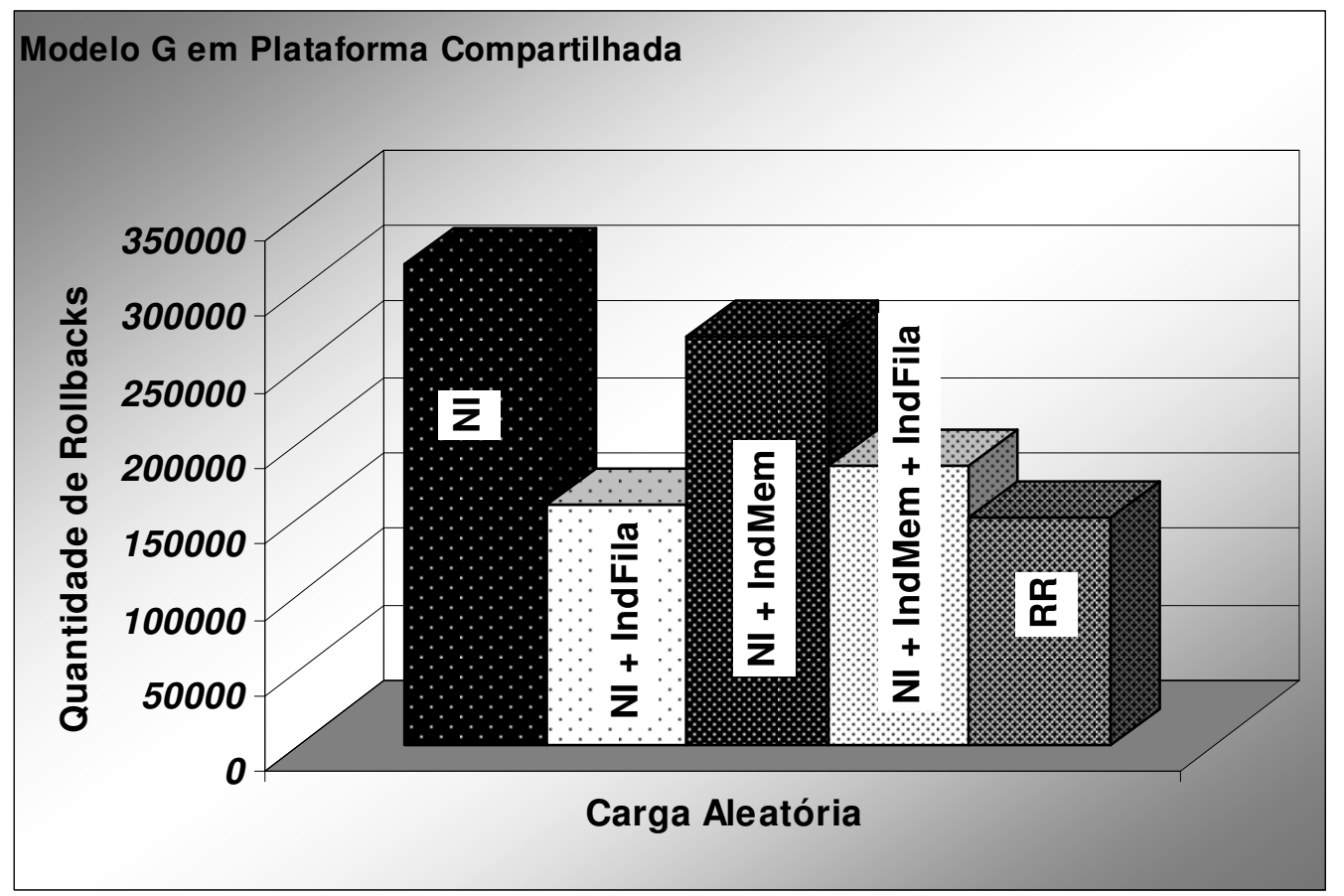

Gráfico 5.27 Quantidade de rollbacks ocorridos numa plataforma compartilhada e com carga aleatória.

\subsection{Considerações Finais}

O ambiente de testes utilizado neste trabalho é formado por uma quantidade grande de características específicas, desde as máquinas utilizadas até a definição dos modelos simulados. Os modelos foram divididos em três grupos de análise, de acordo com os benchmarks aplicados: rede, $c p u$, memória ou combinações deles.

Os parâmetros dos modelos foram ajustados de forma que a sua simulação requeira uma utilização maior ou menor de um determinado recurso (memória, сри ou rede). Os modelos do grupo de rede possuem uma população alta em relação à quantidade de objetos e também uma probabilidade maior de propagar mensagens para seus vizinhos. Para caracterizar os modelos do grupo cpu, o parâmetro ajustado foi referente ao trabalho realizado por cada objeto (multiplicação de matrizes), de maneira que um uso significativo de cpu fosse necessário. Já os modelos de memória são caracterizados por ter grandes quantidades de objetos e mensagens. 
Informações sobre a plataforma foram coletadas visando alimentar a política de particionamento. A avaliação dos recursos utilizados foi feita através de benchmarks e as informações sobre o desempenho de cada recurso são conhecidas antes do início das simulações. Os testes executados na plataforma dedicada fazem uso apenas dessas informações, que são estáticas. Já em ambientes compartilhados utilizam-se também informações dinâmicas, que são os índices de carga. Estes índices informam o estado de carga da plataforma.

Os desempenhos dos modelos executados com as políticas de particionamento balanceado foram comparados com os resultados utilizando a política round-robin. Dessa forma, foi possível avaliar o impacto de políticas de particionamento convencionais na execução de simulações distribuídas. As métricas de desempenho utilizadas nas comparações forma: Tempo de execução, quantidade de rollbacks e eficiência.

Os resultados obtidos no ambiente dedicado mostram que a utilização dos benchmarks de rede e сри resultou em tempos de execução das simulações significativamente menores e portanto, em um melhor desempenho. O tempo de execução foi reduzido em até $24 \%$, a eficiência teve um aumento de até $22 \%$ e houve uma redução de $79 \%$ no número de rollbacks. Nesse mesmo ambiente, o uso do benchmark de memória não foi eficiente por provocar um desbalanceamento na simulação causando perda de desempenho.

Os resultados do ambiente compartilhado, também apresentaram ganhos com o uso de políticas convencionais. O tempo de execução teve redução de até $28,8 \%$, a eficiência foi em torno de $18.8 \%$ superior e a quantidade de rollbacks foi reduzida em $66 \%$. Nesses casos o índice de carga que mede a quantidade de memória livre também se mostrou incapaz de melhorar o particionamento.

O próximo capítulo apresenta as principais contribuições geradas para a área de Simulação Distribuída e propostas de trabalho futuros. 


\section{Capítulo 6 - CONCLUSÕES}

\subsection{Considerações Iniciais}

Este trabalho tem por objetivo principal a investigação da qualidade das decisões oferecidas por políticas de escalonamento convencionais na execução de simulações distribuídas. Neste capítulo estão descritas as contribuições desta pesquisa, uma análise do desenvolvimento do trabalho, que resultou em outras importantes contribuições à área e as propostas de trabalhos futuros, concluindo desta forma, esta dissertação.

\subsection{Ponderações finais desta dissertação}

O objetivo deste trabalho foi avaliar o efeito da aplicação de políticas de particionamento convencionais na execução de simulação distribuída. Essas políticas geralmente já estão disponíveis para uso sem que sejam necessárias adaptações na aplicação. Ao contrário das políticas de particionamento específicas, que não estão facilmente disponíveis, normalmente demandam mais pesquisa e tempo de implementação, e ainda são construídas e avaliadas para um modelo pré-determinado.

As políticas convencionais baseiam suas decisões normalmente em informações sobre as características e o estado da plataforma. Uma forma de extrair essas características é a uti- 
lização de benchmarks que medem a potência dos recursos. Essa foi a abordagem adotada neste trabalho, com benchmarks para avaliar a capacidade de memória, rede e $c p u$ das máquinas. O estado da plataforma foi avaliado através da utilização de índices de carga. Os dois índices empregados foram a quantidade de processos na fila do processador e a quantidade de memória livre.

Foram realizados testes em dois tipos de ambiente: dedicado e compartilhado. No primeiro caso as simulações submetidas ao sistema não competiam pelos recursos com outras aplicações. Nesse ambiente, apenas informações estáticas sobre a potência dos recursos foram utilizadas pela política de particionamento. No segundo caso, as simulações compartilharam os recursos com uma aplicação "parasita", que tem como objetivo simular a presença de outros usuários. Nessa situação a política de particionamento também utilizou informações dinâmicas, fornecidas pelos índices de carga.

Diferentes tipos de simulações foram executadas e avaliadas. Essas simulações foram configuradas de forma que apresentassem diferentes comportamentos com relação a utilização de recursos, ou seja, foram caracterizadas de maneira que demandassem por mais memória, processamento, comunicação ou combinações destes.

Os resultados obtidos demonstram ganhos na maioria dos cenários avaliados. No ambiente dedicado, aplicando os resultados do benchmark de rede no particionamento, foram obtidos ganhos de até $24 \%$ na redução do tempo de execução, a quantidade de rollbacks foi reduzida em até $79 \%$ e a eficiência foi melhorada em até $22 \%$, em comparação à execução dos mesmos modelos utilizando a política round-robin. Com o benchmark de cpu, ganhos expressivos também foram obtidos, com redução de tempo de execução em até $23 \%$, redução dos rollbacks em $88 \%$ e aumento da eficiência em $20 \%$.

A execução de modelos nesse mesmo ambiente, porém com resultados do benchmark de memória, não apresentou ganhos. Em todos os casos, a política round-robin proporcionou 
desempenhos superiores aos obtidos com o uso desse benchmark. Percebeu-se que o benchmark de memória não é capaz de avaliar corretamente a potência dos recursos, quando se deseja balancear a carga de uma simulação distribuída. Por exemplo, um mesmo modelo executado com outros benchmarks, apresentou ganhos expressivos comparados ao round-robin, com redução do tempo em até $18 \%$, aumento da eficiência em $16 \%$ e uma redução na quantidade de rollbacks ocorridos em até $94 \%$.

No ambiente compartilhado, as informações dinâmicas utilizadas trouxeram ganhos quando a carga imposta à plataforma não era previsível. Apesar das métricas que representam a eficiência e a quantidade de rollbacks indicarem resultados inferiores, o tempo de execução foi reduzido em $15 \%$. Isso ainda indica um resultado positivo, já que a redução da métrica "tempo" é desejável pelo usuário. Nesses casos, os resultados também foram comparados com a política round-robin.

Conclui-se que a execução de simulações em ambientes dedicados proporciona benefícios consideralmente melhores aos usuários. A execução de um mesmo modelo num ambiente compartilhado pode aumentar o tempo em até 5 vezes, em comparação ao resultado obtido no ambiente dedicado.

A utilização de políticas convencionais no particionamento de simulações distribuídas se mostrou vantajosa, pois são políticas de fácil acesso para utilização. Além disso, apenas o conhecimento sobre a plataforma demostrou trazer ganhos de desempenho para as simulações. Portanto, ignorar as informações inerentes desse tipo de aplicação é aceitável quando se dispõe de pouco tempo para definir a melhor política a ser aplicada ao modelo simulado.

\subsection{Contribuições deste Trabalho}

As principais contribuições deste trabalho foram: 
Estudo e documentação de uma ferramenta de simulação distribuída. Dentre todas as ferramentas pesquisadas o Warped foi a que melhor se adequou às necessidades desta pesquisa, principalmente por ser uma ferramenta disponível livremente. Porém uma dificuldade encontrada de início é que a ferramenta não possuía documentações sobre a utilização, e nem uma visão geral sobre o funcionamento do sistema. Para gerar esta documentação, mostrando desde como é a interface do Warped, passando por como modelar uma simulação na sua linguagem e indo até a sua execução, foram dispensados muitos estudos sobre o código da ferramenta e os comentários de implementação contidos nele.

Contribuições no desenvolvimento da ferramenta de simulação. O objetivo de uma ferramenta ser disponível livremente, é que qualquer pessoa possa adquiri-la e adaptá-la segundo as suas necessidades. Porém neste trabalho, as adaptações foram além dos objetivos próprios. Alguns erros, de fundamental importância para a correta execução da simulação, foram diagnosticados e corrigidos. A maioria dos erros foi difícil de ser diagnosticada, o que exigiu considerável tempo de dedicação.

Uma contribuição importante adicionada à ferramenta foi a possibilidade de extração de um número maior de informações sobre a execução de uma simulação, por exemplo, informações sobre a quantidade de rollbacks ocasionados por cada máquina da plataforma, a quantidade de eventos processados e cancelados, e quantidade de eventos processados por segundo. Além de informações sobre as decisões tomadas pelo AMIGO no momento dos particionamentos.

Implementação do modelo PHOLD. Outra contribuição para este trabalho e também para o desenvolvimento do Warped foi a implementação do modelo sintético PHOLD. Esse modelo é um dos mais usados pelo meio acadêmico em testes de ferramentas que implementam o protocolo Time Warp. A adição de uma implementação do PHOLD ao Warped será de 
grande importância a outros usuários que necessitarem da ferramenta para validar novas idéias de mecanismos para simulação distribuída.

Interface entre o WARPED e o AMIGO. A interface entre uma ferramenta de simulação distribuída e um ambiente de escalonamento trás uma grande facilidade para futuras pesquisas em simulação distribuída e escalonamento de processos. Essa interface adicionou novos recursos para os usuários de ambas as ferramentas. Embora esta não seja a primeira contribuição para o projeto $A M I G O$, pode-se considerar que é a primeira vez em que um projeto o aborda em conjunto com aspectos de simulação distribuída. Nessa interface foi implementada a opção de particionamento centralizado, ou seja, uma única máquina realiza o particionamento. $\mathrm{O}$ Warped apenas oferecia o particionamento descentralizado.

Políticas de Escalonamento Convencionais x Simulação Distribuída. O objeto de estudo deste trabalho era a análise do desempenho de uma simulação distribuída, quando políticas de escalonamento convencionais são consideradas no particionamento. Percebeu-se através dos testes realizados que é possível se obter ganho no desempenho de uma simulação com essas políticas, que ignoram informações inerentes da simulação e apenas informações sobre a plataforma são consideradas.

Utilizar índices de benchmarks para se conhecer a plataforma e a partir disto fazer o particionamento dos objetos da simulação, trouxe ganhos no desempenho final da simulação se comparado com uma execução que não leva em conta nenhuma informação (round-robin).

As simulações são aplicações que exigem muito dos recursos da plataforma, assim quando executadas numa plataforma dedicada apresentam resultados consideravelmente melhores que quando executadas em plataformas compartilhadas. 


\subsection{Propostas para Trabalhos Futuros}

O trabalho desenvolvido nesta dissertação de mestrado está inserido em dois grandes projetos acadêmicos. O AMIGO que é um projeto desenvolvido no Grupo de Sistemas Distribuídos e Programação Concorrente do ICMC/USP. E o WARPED que é um projeto desenvolvido pelo Laboratório de Computação Experimental da University of Cincinnati (EUA).

Outras pesquisas podem ser sugeridas com o objetivo de aprimorar o estudo aqui realizado. São elas:

Interface gráfica. $\mathrm{O}$ desenvolvimento de uma interface gráfica para as ferramentas utilizadas tornaria a sua utilização mais atrativa e simplificada para usuários leigos na área. Com tal interface um usuário poderia facilmente instalar e configurar seu ambiente de simulação, definir seu modelo de simulação e executar de forma facilitada.

Migração de objetos. Durante a execução de uma simulação é natural que algumas máquinas passem a ser mais sobrecarregadas que outras. Em alguns casos essas máquinas sobrecarregadas passam a deixar as outras ociosas. Dentro dessa situação, percebe-se que uma migração de objetos entre as máquinas pode balancear a execução da simulação, permitindo um melhor aproveitamento dos recursos disponíveis e principalmente um ganho no desempenho final da simulação. A implementação dessa migração no Warped seria de fundamental importância para estudos de escalonamento em simulação distribuída.

Processos lógicos. O Warped foi implementado de maneira que considera um único processo lógico por máquina da plataforma. Ou seja, todos os objetos que forem escalonados para uma mesma máquina estarão num mesmo LP. Como já discutido, essa característica dificulta a extração de informações dinâmicas da plataforma. Propõe-se que esta característica seja reformulada. 
Strong Groups. Dentro do contexto proposto anteriormente, é interessante também adicionar o conceito proposto por Som e Sargent (2000) de Strong Groups, que são grupos formados por objetos que exercem forte influência uns nos outros. Esses grupos podem ser identificados a partir da análise do modelo de simulação e para tanto é necessário certo nível de conhecimento sobre o comportamento do modelo.

Outros Testes. Os testes do ambiente compartilhado podem ser expandidos através de um estudo maior sobre outros índices de carga, que possam apresentar valores mais significativos para a simulação. A avaliação de modelos com outras características também é sugerida.

Pretende-se também realizar um estudo mais abrangente com o objetivo de aplicar outras pesquisas em simulação, criadas em trabalhos do grupo LASDPC, de escalonamento de processos em sistemas distribuídos. As aplicações destas pesquisas, já relacionadas com o $A M I G O$, poderão contribuir com a riqueza de novas funcionalidades que estarão sendo embutidas na ferramenta. Como a interface entre $A M I G O$ e Warped já está implementada, a validação de qualquer funcionalidade adicionada ao $A M I G O$ pode ser realizada sem muito esforço.

\subsection{Considerações Finais}

Esta pesquisa preenche uma das lacunas abertas nos estudos de escalonamento de processos em simulação distribuída. Através dos testes realizados pode-se dizer que em algumas situações, principalmente em plataformas dedicadas, um serviço de qualidade pode ser alcançado, mesmo que características inerentes e importantes da simulação sejam ignoradas, dependendo dos objetivos e do tempo que o usuário dispõe para a execução de sua simulação.

Aconselha-se o uso de políticas convencionais quando não se dispõe de tempo para desenvolvimento de uma nova política e nem de conhecimentos suficientes para a implementação desta. 


\section{Referências}

(Akyildiz et al., 1992)

(Almasi, 1994)

(Araújo et al., 1999)

(Bagrodia, 1994)

(Bagrodia, 1996)

(Bagrodia et al., 1998)

(Banks, 1998)

(Boukerche, 2002)
AKYILDIZ, L. F.; CHEN, L.; DAS, S. R.; FUJIMOTO, R. M.; SERFOZO, R. F., Performance analysis of Time Warp with Limited Memory. In: Proceedings of the 1992 ACM Sigmetrics Conference on Measurement and Modeling Computer Systems, p. 213-224, 1992.

ALMASI, G.S. and GOTTLIEB, A.. Highly Parallel Computing, $2^{\mathrm{a}}$ ed., The Benjamin/Cummings Publishing Company, 1994.

ARAÚJO, A.P.F., SANTANA, M.J., SANTANA, R.H.C., SOUZA, P.S.L., DPWP - A New Load Balancing Algorithm. $5^{\text {th }}$ International Conference on Information Systems Analysis and Synthesis - ISAS'99, agosto, 1999.

BAGRODIA, R. L. Language Support for Parallel DiscreteEvent Simulations. Proceedings of the 1994 Winter Simulation Conference - WSC'94, pp. 1324-1331, 1994.

BAGRODIA, R. L. Perils and Pitfals of Parallel DiscreteEvent Simulations. Proceedings of the 1996 Winter Simulation Conference - WSC'96, pp. 136-146, 1996.

BAGRODIA, R.; MEYER, R.; TAKAI, M.; CHEN, Y.; ZENG, X.; MARTIN, J.; SONG, H. PARSEC: A Parallel Simulation Environment for Complex Systems. IEEE Computer, v.3, n.10, p.77-85, 1998.

BANKS, J., Handbook of Simulation: Principles, Methodology, Advances, Applications, and Practice. New York: John Wiley \& Sons, Inc., 1998.

BOUKERCHE, A. An Adaptive Partitioning Algorithm for Distributed Discrete Event Simulation Systems. Journal of Parallel and Distributed Computing, $\mathrm{n}^{\circ}$ 62, 1454-1475, 2002. 
(Boukerche \& Das, 1997)

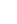

BOUKERCHE, A.; DAS, S. K. Dynamic Load Balancing Strategies for Conservative Parallel Simulations. In: Proceedings of the $11^{\text {th }}$ workshop on Parallel and distributed simulation. p.20-28, 1997.

(Boukerche \& Das, 1999)

BOUKERCHE, A.; DAS, S. K. Load Balancing Strategies Parallel Simulation on a Multiprocessor machine. In: ZOBRIST, C.; BAGCHI, J.; WALRAND, J. (Eds.), State-ofthe-Art in Performance Modeling and Simulation, Gordon and Breach, Londres, 1999.

(Boukerche \& Das, 2004)

BOUKERCHE, A.; DAS, S. K. Reducing null messages overhead through load balancing in conservative distributed simulation systems. Journal of parallel an distributed Computting. V. 4, p. 330-344, march 2004.

(Branco, 2000)

BRANCO, K.R.L.J.C. Índice de Carga e Desempenho em Ambientes Paralelos/Distribuídos - Modelos e Métricas. Trabalho de doutorado em andamento no ICMC-USP, São Carlos, 2000.

(Branco, 2004)

(Bratley, 1987)

(Brown, 1988)

(Bruschi, 2002)

(Bryant, 1977)
BRATLEY, P. A guide to Simulation. Second Edition. New York: Springer-Verlag, 1987. p.31-45.

BROWN, R. Calendar Queues: A fast O(1) Priority Queue Implementation for the Simulation Event Set Problem. Communications of the ACM. v. 31, $\mathrm{n}^{\mathrm{o}} 10$, p. 1220-1227, October-1988.

BRUSCHI, S. M., ASDA - Um Ambiente de Simulação Distribuída Automático. Tese (Doutorado em Ciências da Computação). ICMC-USP, São Carlos, 2002.

BRANCO, K.R.L.J.C. Índice de Carga e Desempenho em Ambientes Paralelos/Distribuídos: Modelagem e Métricas. Tese (Doutorado em Ciências da Computação). ICMCUSP, São Carlos, 2004.

BRYANT, R. E., Simulation of Packet Communications Architecture Computer Systems. Massachusetts Institute of Technology, 1977. (Relatório Técnico 188 - MIT-LCS). 
(Burdorf \& Marti, 1993)

BURDORF, C.; MARTI J. Load Balancing Strategies for Time Warp on Multiuser Workstations. The Computer Journal, v. $36, \mathrm{n}^{\circ} .2$, p. 168-176, 1993.

(Carothers et al., 2002)

CAROTHERS, C. D.; BAUER, D.; PEARCE, S. ROSS: A high-performance, low-memory, modular Time Warp System. Journal of Parallel and Distributed Computing, $\mathrm{n}^{\circ} 62$, p. 1648-1669, 2002.

(Carothers \& Fujimoto, 2000)

CAROTHERS, C. D.; FUJIMOTO, R. M. Efficient Execution of Time Warp Programs on Heterogeneous, NOW Platforms. IEEE Transactions on Parallel and Distributed Systems, v. 11, n 3 , março, 2000.

(Casavant \& Kuhl, 1988)

CASAVANT; T. L.; KUHL, J. G., A Taxonomy of scheduling in General-Purpose Distributed Computing Systems. IEEE Transactions on Software Engineering, p. 141-154, fevereiro, 1988.

(Chandy \& Misra, 1979)

CHANDY, K. M., MISRA, J., Distributed Simulation: A Case Study in Design and Verification of Distributed Programs. IEEE Transactions on Software Engineering. SE-5, n.5, p. 440-452, 1979.

(Chandy \& Misra, 1981)

CHANDY, K. M., MISRA, J. Asynchronous Distributed Simulation via a sequence of parallel computations. Communications of ACM, v.24, n.4, p. 11-14; 198-205, mar. 1981.

(Chen \& Szymanski, 2005) CHEN, G.; SZYMANSKI, B. K. DSIM: Scaling Time Warp to 1,033 processors. In: Proceedings of the 2005 Winter Simulation Conference. 2005.

(Chiola \& Ferscha, 1993)

CHIOLA, G.; FERSCHA, A. Performance Comprable Implementation Desing of Synchronization Protocols for Distributed Simulation. Technical Report Series of the Austrian Center for Parallel Computation, ACPC/TR 93-23, December 1993.

(Choe \& Tropper, 1999)

CHOE, M.; TROPPER, C. On Learning Algorithms an Balancing Loads in Time Warp. In: Proceedings of the $13^{\text {th }}$ Workshop on Parallel and Distributed Simulation (PADS '99), Atlanta, GA, USA, p. 101-108, May 1-4, 1999. 
(Clark et al., 1995)

(Cota \& Sargent, 1989)

(Dantas \& Zaluska, 1998)

(Das \& Fujimoto, 1993)

(Das et al., 1994)

(Deelman \& Szymanski, 1998)

(Djemame et al., 1996)

(Ewing et al., 1999)
CLARK, D.L.; CASAS, J.; OTTO, S.W.; PROUTY, R.M.; WALPOLE, J. Scheduling of Parallel Jobs on Dynamic, Heterogeneous Networks. janeiro, 1995. Disponível em: http://www.cse.ogi.edu/DISC/projects/cpe/ Acesso em 12 janeiro 2004.

COTA, B. A., SARGENT, R. G., A Framework for Automatic Lookahead Computation in Conservative Distributed Simulations. In: Proceedings of the SCS Multiconference on Distributed Simulation, p. 56-59. The Society for Computer Simulation International, 1989.

DANTAS, M.A.R.; ZALUSKA, E.J. Efficient Scheduling of MPI applications on Networks of Workstations. Future Generation Computer Systems - FGCS, v.13, p.489-499, 1998.

DAS, R. S.; FUJIMOTO, R. M., A performance Study of the Cancellback Protocol for Time Warp. In: Proceedings of the $7^{\text {th }}$ Workshop on Parallel and Distributed Simulation, p. 135-142, 1993.

DAS, S.; FUJIMOTO, R. M.; PANESAR, K.; ALLISON, D.; HYBINETE, M. GTW: A Time Warp System for Shared Memory Multiprocessors. Proceedings of the 1994 Winter Simulation Conference, p. 1332-1339, 1994.

DEELMAN, E.; SZYMANSKI, B. K. Dynamic Load Balancing in Parallel Discrete Event Simulation for Spatially Explicit Problems. In: Proceedings of the $12^{\text {th }}$ Workshop on PADS, Banff, Alberta, Canada, p. 46-53, May 1998.

DJEMAME, K.; BETTAZ, M.; GILLES, D. C.; MACKENZIE, L. M. Performance Comparison of High Level Algebraic Nets Distributed Simulation Protocols. Proceedings of the 1996 Winter Simulation Conference (WSC'96), p.621-628,1996.

EWING, G.C.; PAWLIKOWSKI, K.; MCNICKLE, D. Akaroa-2: Exploiting Network Computing by Distributing Stochastic Simulation. In: Proceeding of European Simulation Multiconference (ESM'99), Warson - Poland, p.175181, 1999. 
(Feitelson \& Rudolph, 1995)

(Ferrari \& Zhou, 1987)

(Fujimoto, 1990)

(Fujimoto, 1990b)

(Fujimoto \& Nicol, 1992)

(Fujimoto, 1993)

(Fujimoto, 2000)

(Fujimoto, 2003)

(Gan et al., 2000)
FEITELSON, D. G.; RUDOLPH, L., Parallel Job Scheduling: Issues and Aproaches. In: IPPS'95 Workshop on Job Scheduling Strategies for Parallel Processing, Lecture Notes in Computer Science v.949, Santa Barbara, CA, USA, abril, 1995.

FERRARI, D.; ZHOU, S. An Empirical Investigation of Load Indices for Load Balancing Applications. Proceedings of the $12^{\text {th }}$ Int'l Symposium on Computer Performance Modeling, Measurement, and Evaluation (Performance'87), p.515-528, 1987.

FUJIMOTO, R. M., Parallel Discrete Event Simulation. Communications of the ACM, v. 33, $\mathrm{n}^{\circ} 10$, p. 31-53, 1990.

FUJIMOTO, R. M., Performance of Time Warp under Synthetic Workloads. Proceedings of the SCS Multiconference on Distributed Simulation, p.23-28,1990.

FUJIMOTO, R. M., NICOL, D., State of the Art in Parallel Simulation. In: Proceedings of the 1992 Winter Simulation Conference, p. 246-254, 1992.

FUJIMOTO, R. M. Parallel and distributed discrete event Simulation: Algorithms and applications. In: Proceedings of the 1993 Winter Simulation Conference, December 1993.

FUJIMOTO, R. M., Parallel and Distributed Simulation Systems. John Wiley \& Sons, Inc., 2000.

FUJIMOTO, R. M., Distributed Simulation Systems. In: Proceedings of the 2003 Winter Simulation Conference, p. 124134, 2003.

GAN, B. P; LOW, Y. H.; JAIN, S.; TURNER, S. J.; CAI, W.; HSU, W. J.; HUANG, S. Y. Load Balancing for Conservative Simulation on Shared Memory Multiprocessor Systems. In: Proceedings of the 14th Workshop on Parallel and Distributed Simulation (PADS 2000), p. 139-146, May 28-312000. 
(Ghosh et al., 1994)

(Glazer \& Tropper, 1993)

(Gogf \& Mott, 1995)

(Hagenauer, 1999)

(Heidelberger, 1988)

(Hoover \& Perry, 1990)

(Ishii, 2004)

(Jefferson, 1985)

(Jones \& Das, 2000)

(Knop et al., 1996)
GHOSH, K.; PANESAR, K; FUJIMOTO, R. M.; SCHWAN, K., PORTS: A Parallel, Optimistic, Real-Time Simulator. Proceedings of the $8^{\text {th }}$ Workshop on Parallel and Distributed Simulation (PADS'94), 1994.

GLAZER, D. W.; TROPPER, C. On Process Migration and Load Balancing in Time Warp. IEEE Transactions on Parallel and Distributed Systems. v. 4, n 3, March 1993.

GOGF, T. J.; MOTT, J. A., Improve Quality \& Productivity With Simulation. JMI Consulting Group, 1995.

HAGENAUER, H., Global Virtual Time Approximation for Split Queue Time Warp. $4^{\text {th }}$ International ACPC Conference. In: Lecture Notes on Computer Science, $\mathrm{n}^{\circ} 1557, \mathrm{p}$. 540-548, 1999.

HEIDELBERGER, P. Discrete Event Simulation and Parallel Processing: Statistical Properties. SIAM J. Stat. Comput, v.9, n.6, p.1114-1132, 1988.

HOOVER, S.V., PERRY, R.F., A Problem Simulation - Solving Approach, Addison - Wesley Publishing Company, 1990.

ISHII, R. P. NBSP: uma política de escalonamento networkbound para aplicações paralelas distribuídas. Dissertação de mestrado. ICMC-USP, São Carlos, 2004.

JEFFERSON, D. R., Virtual Time. IEEE Transactions on Programming Languages and Systems, v.7, n.3, p. 404-425, 1985.

JONES, K. G.; DAS, S., Parallel Execution of a Sequential Network Simulator. In: Proceeding of the 2000 Winter Simulation Conference (WSC'2000), p. 418-424, 2000.

KNOP, F.; MASCARENHAS, E.; REGO, V., A Parallel GPSS Based on the Parasol Simulation System. Proceedings of the 1996 Winter Simulation Conference (WSC'96), p. 801-808, 1996. 
(Kunz, 1991)

(Lobato et al., 2004)

(Low et al., 1999)

(MacDougall, 1987)

(Madiseti et al., 1992)

(Majumdar \& Parsons, 2000)

(Maryansky, 1980)

(Martin \& Bagrodia,1995)

(Martin et al., 2003)
KUNZ, T. The Influence of Different Workload Descriptions on a Heuristic Load Balancing Scheme. IEEE Transactions on Software Engineering, v.17, n.7, p.725-730, julho, 1991.

LOBATO, R. S., SANTANA, M. J., SANTANA, R. H. C., ULSON, R. S., Uma hierarquia para classificação de protocolos otimistas de sincronização em simulação distribuída. CLEI - Conferência Latino Americana em Informática: Arequipa : 2004.

LOW, Y.; LIM, C.; CAI, W.; HUANG, S.; HSU, W.; JAIN, S.; TURNER, S. J., Survey of Languages and Runtime Libraries for Parallel Discrete Event Simulation. Technica article Simulation, v.72, n.3, p. 170-186, 1999.

MACDOUGALL, M. H., Simulating Computing Systems Techniques and Tools. The MIT Press, 1987.

MADISETI, V. K.; HARDAKER, D. A.; FUJIMOTO, R. M.; et al., The MIMDIX Operating Systems for Parallel Simulation. In: Proceedings of the SCS Multiconference on Parallel and Distributed Simulation, v. 24, n. 3, p. 65-74. The Society for Computer Simulation International, 1992.

MAJUMDAR, S.; PARSONS, E. W. Parallel job scheduling: A performance perspective. In: Performance Evaluation: Origins and directions. Berlim: Springer, 2000, (Lecture Notes in Computer Science, v. 1769). p. 233-252.

MARYANSKI, F. J., Digital Computer Simulation. Hayden Book Company, 1980.

MARTIN, J. M.; BAGRODIA, R. L. COMPOSE: An ObjectOriented Environment for Parallel Discrete-Event Simulations. Proceedings of the 1995 Winter Simulation Conference (WSC'95), 1995.

MARTIN, D. E.; WILSEY, P. A.; HOEKSTRA, R. J.; KEITER, E. R.; HUTCHINSON, T. V. R.; WATERS, L. J. Redesigning the WARPED Simulation Kernel fo Analysis and Application Development. Proceedings of the $36^{\text {th }} \mathrm{An}$ nual Simulation Symposium (ANSS’03), 2003. 
(Mascarenhas et al., 1996)

(Mattern, 1993)

(McCalpin (a))

(McCalpin (b))

(Mchaney, 1991)

(Mehra \& Wah, 1993);

(Meyer \& Bagrodia, 1999)

(Misra, 1986)

(Muniz, 1994)

(Naim, 1995 )

(Nicol \& Fujimoto, 1994)
MASCARENHAS, E.; KNOP, F.; REGO, V. Parasol: A Multithreaded System for Parallel Simulation based on Mobile threads. Proceeding of the 1996 Winter Simulation Conference (WSC'96), 1996.

MATTERN, F. Efficient Algoritms for Distributed Snapshots and Global Virtual Time Approximation. Journal of Parallel and Distributed Computing. v.18, nº 1993.

MCCALPIN, J.D. STREAM: Sustainable Memory Bandwidth in High Performance Computers. Disponível em: http://www.cs.virginia.edu/stream . Acesso em janeiro de 2004.

MCCALPIN, J.D. A Survey of Memory Bandwidth and Machine Balance in Current High Performance Computers. Disponivel em http://home.austin.rr.com/mccalpin/papers/balance/ . Acesso em janeiro de 2004.

MCHANEY, R. Computer Simulation: a practical perspective. Academic Press, San Diego: California, 1991.

MEHRA, P.; WAH, B.W. Automated Learning of LoadBalancing Strategies for a Distributed Computer System. University of Illinois at Urbana-Champaign, 1993.

MEYER, R. A.; Bagrodia, R. L., Path Lookahead: a Data Flow View of PDES Models. In: Proceedings of the $13^{\text {th }}$ Worshop on Parallel and Distributed Simulation (PADS'99), 1999.

MISRA, J. Distributed Discrete-event Simulation. ACM Computing Surveys, v.18, n.1, p. 39-65, 1986.

MUNIZ, F.J. Parallel Load-Balancing on Message Passing Architectures. Tese (Doutorado), Faculdade de Engenharia da Universidade de Southampton, março, 1994.

NAIM, A. K. Systems Modeling and Computer Simulation. Second Edition. New York: Marcel Dekker, 1995.

NICOL, D. M.; FUJIMOTO, R. M., Parallel Simulation To- 
day. Annals of Operations Research, vol. 53, p. 279-286, 1994.

(Overeinder et al., 1991)

Overeinder, B.; HERTZBERGER, B.; SLOOT, P., Parallel Discret Event Simulation, 1991. Disponível em: http://www.fwi.uva.nl/research/pwrs/papers/archieve/Overe inder91.htm. Acesso em 27 novembro 2003.

(Pegden et al., 1991)

PEGDEN, C.D., SHANNON, R.E., SADOWSKI, R.P., Introduction to Simulation Using SIMAN, McGraw-Hill International Editions, 1991.

(Poplawski \& Nicol, 1998)

POPLAWSKI, A.; NICOL, D. M. Nops: A conservative parallel simulation engine for Ted. In Proceedings of the $12^{\text {th }}$ Workshop on Parallel and Distributed Simulation (PADS'98), p. 180-187, 1998.

(Prakash \& Subramarian, 1991)

PRAKASH, A.; SUBRAMARIAN, R., Optimistic Distributed Simulation. In: Proceedings of the $24^{\text {th }}$ annual Simulation Symposium, p. 123-132, 1991.

(Preiss \& Loucks, 1990)

PREISS, B. R.; LOUCKS, W. M., The Impact of Lookahead on the Performance of Conservative Distributed Simulation. In: Proceeding of 1990 European Multiconference - Simulation Methodologies, Languages and Architectures, p. 204-209, Nuremberg, FRG, June 1990.

(Reiher \& Jefferson, 1990)

REIHER, P.L.; JEFFERSON, D. Dynamic Load Management in the Time Warp Operating System. Trans. Society for Computer Simulation, vol. 7, n . 2, p. 91-120, June 1990.

(Santana \& Zaluska, 1988)

SANTANA, M.J.; ZALUSKA, E.J. Load Balancing in a Session-based Distributes File-Store Architecture. Software Practice and Experience, v. 18(11), p. 1091-1107, novembro, 1988.

(Schlagenhaft et al., 1995)

SCHLAGENHAFT, R.; RUHWANDL, M; SPORRER, C.; BAUER, H. Dynamic Load Balancing of a Multi-Cluster Simulator on a Network of Workstations. In: Proceedings of the $9^{\text {th }}$ Workshop on Parallel and Distributed Simulation, p. 175-180, June 1995. 
(Schnor et al., 1996)

(Schof, 1998)

(Shannon, 1975)

(Shirazi et al., 1995 (a))

(Shirazi et al., 1995 (b))

(Shivaratri et al., 1992)

(Sleator \& Tarjan, 1985)

(Simmonds, 2000)
SCHNOR, B.; PETRI, S.; LANGENDÖRFER, H. Load Management for Load Balancing on Heterogeneous Platforms: A Comparison of Traditional and Neural Network Based Approaches. Lecture Notes in Computer Science, v.1124, pp. 611-614, agosto, 1996.

SCHOF, S., Efficient Data Structures for Time Warp Simulation Queue. Journal of Systems Architecture, n. 44, p. 497517, 1998.

SHANNON, R. E. Systems Simulation, the Art and Science. New Jersey: Prentice Hall, p. 67-98, 1975.

SHIRAZI, B.A.; HURSON, A.R.; KAVI, K.M. Introduction to Scheduling and Load Balancing. Introdução do Primeiro Capítulo do Livro Scheduling and Load Balancing in Parallel and Distributed Systems, IEEE Computer Society Press, Los Alamitos, CA, p.2-6, USA, 1995.

SHIRAZI, B.A.; HURSON, A.R.; KAVI, K. M. Mechanisms for Process Migration. Introdução do Sexto Capítulo do Livro Scheduling and Load Balancing in Parallel and Distributed Systems, IEEE Computer Society Press, Los Alamitos, CA, USA, p.411-413, 1995.

SHIVARATRI, N.G.; KRUEGER, P.; SINGHAL, M. Load Distributing for Locally Distributed Systems. IEEE Computer Society Press, dezembro, 1992.

SLEATOR, D. D.; TARJAN, R. E. Self-Adjusting Binary search Trees. Journal of the Association for Computing Machinery, v. 32, nº 3, p. 652-686, July, 1985.

SIMMONDS, R.; BRADFORD, R.; UNGER, B., Applying Discrete Event Simulation to Network Emulation. In: Proceeding of the $14^{\text {th }}$ Workshop on Parallel and Distributed Simulation (PADS 2000), p. 15-22, 2000.

SOARES, L.F.G., Modelagem e Simulação Discreta de Sistemas, VII Escola de Computação, IME-USP, São Paulo, 1990. 
(Soares, 1992)

(Som \& Sargent, 1993)

(Som \& Sargent, 1998)

(Som \& Sargent, 2000)

(Song et al., 1997)

(Souza, 2000)

(Souza et al., 2000)

(SPEEDES)

(Srinivasan \& Reynolds, 1995)
SOARES, L. F. G., Modelagem e Simulação Discreta de Sistemas. Editora Campus Ltda, 1992.

SOM, T. K.; SARGENT, R. G. A New Process to Processor Assignment Criterion for Reducing Rollbacks in Optimistic Simulation. Journal of Parallel and Distributed Computing, $\mathrm{n}^{\circ} 18$, p. 509-515, 1993.

SOM, T. K.; SARGENT, R. G. A Probabilistic Event Scheduling Policy for Optimistic Parallel Discrete Event Simulation. In: Proceeding of the 12th Workshop on Parallel and Distributed Simulation, p. 56-63, May 26-29, 1998.

SOM, T. K.; SARGENT, R. G. Model Structure and Load Balancing in Optimistic Parallel Discrete Event Simulation. In: Proceeding of the 14th Workshop on Parallel and Distributed Simulation, p. 147-154, May 28-31, 2000.

SONG, J.; CHOO, H.K.; LEE, K.M. Application-level load migration and its implementation on top of PVM. Concurrency: Practice and Experience, v.9(1), p.1-19, janeiro, 1997.

SOUZA, P. S. L., AMIGO: Uma Contribuição para a Convergência na Área de Escalonamento de Processos. Tese (Doutorado). IFSC-USP, São Carlos, Junho de 2000.

SOUZA, P. S. L., SANTANA, M. J., SANTANA, R. H. C., Escalonamento de Processos: Uma contribuição para a Convergência da Área, Notas, Instituto de Ciências Matemáticas e de Computação, Universidade de São Paulo (ICMC/USP), 2000.

SPEEDES Disponível em http://www.speedes.com . Acesso em novembro de 2003.

SRINIVASAN, S.; REYNOLDS JR, P., NPSI Adaptative Synchronization Algorithms for PDES. In: Proceedings of the 1995 Winter Simulation Conference, p. 658-665. The Society for Computer Simulation International, USA, 1995. 
(SSBENCH)

(Tanenbaum, 1995)

(Tatsumi, 2002)

(Turner \& Xu, 1992)

(Turner, 1998)

(Ulson et al., 1997)

(Vries, 1990)

(Xu \& Chung, 2004)

(Zhang et al., 2000)
SSBENCH CPU benchmark test. Disponivel em http://www.spaennare.se/ssbench.html Acesso em janeiro de 2004.

TANENBAUM, A.S. Modern Operating Systems. Prentice Hall, New Jersey, 1995.

TATSUMI, S. E., Análise e Avaliação do Uso da Ferramenta ParSMPL em um Ambiente de Simulação Distribuída Automático (ASDA). Monografia de qualificação (Mestrado), ICMC - USP, abril 2002.

TURNER, S. J.; XU, M. Q. A Portable Parallel Discrete Event Simulation System. Proceedings os ESPRIT Workshop on Parallel Computing, p. 284-287, March 1992.

TURNER, S. J., Models of Computation for Parallel Discrete Event Simulation. Journal of Systems Architecture, n. 44, p. 395-409, 1998.

ULSON, R. S.; SANTANA, R. H. C.; SANTANA, M. J. Distributed Simulation Environment for Computing Systems Performance Evaluation. The proceeding of the 1997 Summer Computer Simulation Conference - Symposium of Performance Evaluation of Computer and Telecommunication Systems (SPECTS'97), P. 85-90. The Society for Computer Simulation International, July 1997.

VRIES, R. C. Reducing Null Messages in Misra's Distributed Discrete Event Simulation Method. IEEE Transactions on Software Engineering, v. 16, n. 1, p. 82-91, January, 1990.

XU, J.; CHUNG, M. J. Predicting the Performance of Synchronous Discrete Event Simulation. IEEE Transactions on Parallel and Distributed Systems. V.15, no 12, p. 11301137, December 2004.

ZHANG, Y.; CAI, W.; TURNER, S. J., Parallel Discrete Event Simulation of Manufacturing Systems Using Parsec. In: Proceedings of the $14^{\text {th }}$ European Simulation Multiconference (ESM'2000), p. 296-301, 2000. 
(Zhou te al., 1993)

ZHOU, S.; ZHENG, X.; WANG, J.; DELISLE, P. Utopia: a Load Sharing Facility for Large, Heterogeneous Distributed Computer Systems. Software: Practice and Experience, v.23(12), p.1305-1336, dezembro,1993. 



\section{APÊNDICE A-Warped}

Este apêndice descreve a interface fornecida pelo Warped para definir a estrutura de uma aplicação de simulação, com seus objetos, estados e eventos. Além disso, apresenta os principais mecanismos internos empregados pelo Warped para implementar o protocolo Time Warp. O particionamento de objetos para formar os LPS representa uma das tarefas mais importantes para garantir o bom desempenho da simulação distribuída. Diversas implementações relacionadas ao particionamento foram efetuadas nesse trabalho. Os detalhes foram descritos no capítulo 4, que descreveu a integração do Warped com a ferramenta $A M I G O$.

\section{A1 - Interface com a aplicação (API)}

A API (Application Programming Interface) do Warped é baseada nos conceitos do artigo original de Jefferson sobre o Time Warp (1985). Os objetos são modelados como entidades que enviam e recebem eventos entre si e trabalham esses eventos fazendo com que o estado do objeto seja alterado. Para isto, o sistema fornece funções básicas para enviar e receber eventos e a habilidade de especificar diferentes tipos de objetos, cada um com um tipo único de estado.

No Warped, os objetos são organizados em grupos chamados de Processos Lógicos (LPs - Logical Processes). Os objetos de um mesmo LP comunicam-se entre si sem a neces-

sidade da rede de comunicação. É tarefa do algoritmo de particionamento agrupar os objetos em processos lógicos. Idealmente os objetos que se comunicam com mais freqüência devem ser colocados no mesmo $L P$, tarefa esta, que pode não ser fácil, por envolver conhecimento sobre os padrões de comunicação entre os objetos da simulação. O escalonamento dos objetos 
é uma tarefa atribuída ao processo lógico que, em cada passo da simulação, deve escolher qual objeto será o próximo a ser executado. Um objeto dentro de um $L P$ age como um processo Time Warp, seguindo os conceitos da definição de Jefferson. Isso significa que, mesmo estando agrupados, a sincronização dos objetos não é forçada, dependendo do algoritmo de escalonamento. Isso ainda implica que os objetos sofrem rollback individualmente, o que significa que o regresso de um objeto a um estado anterior não implica regresso de todos os objetos do $L P$.

A interação entre o núcleo e a aplicação é feita toda através de invocação de métodos e ambos compartilham a mesma thread. Para que a simulação funcione corretamente o usuário deve fornecer ao núcleo diversas funções, sobrecarregando os métodos apropriados. Essas funções fornecem ao núcleo informações do tipo: como inicializar a aplicação e o que cada objeto faz durante um ciclo da simulação.

Nas seções seguintes, será apresentada uma descrição detalhada das principais classes da interface com a aplicação. Essas classes formam a base da implementação que deve ser derivada e especificada com as classes do usuário.

Há quatro classes abstratas básicas que devem ser especificadas em qualquer simulação que tenha algum significado. São elas: Application, SimulationObject, State e Event.

\section{A1.1 - Classe Application}

Das classes da API, a classe derivada de Application é a primeira a ser criada. Ela possui basicamente as tarefas de receber os parâmetros de linha de comando destinados à aplicação e criar os objetos. O particionamento do conjunto de objetos em LPs também pode ser uma tarefa de Application caso o usuário deseje utilizar um modo de particionamento diferente dos que existem no núcleo. Os principais métodos que devem ser definidos são:

\section{initialize e finalize}


O método initialize recebe como parâmetro a lista dos argumentos passados à aplicação na linha de comando. É recomendado que qualquer validação de parâmetros ou outros testes necessários sejam realizados nesse método. O finalize permite que a aplicação imprima as saídas necessárias quando a simulação termina.

\section{$>$ getSimulationObjects}

Os objetos da simulação devem ser criados na implementação desse método. Os objetos devem receber nomes, que serão gerenciados pelo núcleo e usados como referência aos objetos. Qualquer tarefa que exija passar informações aos objetos para que eles possam iniciar corretamente deve ser feita nesse método. Exemplos dessas tarefas incluem: definir a topologia de comunicação entre os objetos, passando a cada um os nomes dos seus vizinhos e definir alguma regra sobre como os objetos irão enviar os eventos iniciais.

\section{$>$ getPartitionInfo}

Caso defina-se que o particionamento dos objetos é responsabilidade da aplicação, a tarefa deve ser feita por esse método. Nesse caso, uma instância de uma classe de particionamento (derivada da classe Partitioner), deve ser criada. A lista dos objetos é passada para a classe de particionamento que retorna um objeto do tipo PartitionInfo, que contém as partições, e é retornado para o núcleo.

\section{A1.2 - Classe SimulationObject}

A classe SimulationObject define os dados e os métodos que cada objeto precisa para funcionar. O usuário pode definir vários tipos de objetos, contanto que sejam derivados desta classe. O conjunto de métodos definido nesta classe forma a interface vista pela aplicação. Os principais métodos que devem ser definidos são: 


\section{initialize e finalize}

O método initialize é chamado pelo núcleo, para todos os objetos, antes que a simulação inicie. A ação mais comum executada nesse método é o envio de eventos iniciais. É natural que pelo menos um objeto envie um evento antes que a simulação comece para que um outro objeto tenha algo para fazer; caso contrário, a simulação terminaria mesmo antes de começar. O método finalize é chamado quando a simulação termina. Ele permite que os objetos coletem estatísticas, fechem arquivos, produzam saída, etc. O objetivo principal é permitir uma finalização "limpa".

\section{$>$ executeProcess}

O núcleo chama esse método quando o objeto tem pelo menos um evento para executar. O código do método corresponde a todas as tarefas que o objeto deve executar em um ciclo da simulação. Comumente, em um ciclo o objeto recebe os eventos destinados a ele naquele instante do tempo virtual, processa os eventos, atualiza o seu estado e se necessário, envia novos eventos.

\section{allocateState e deallocateState}

Esses métodos são responsáveis por alocar e desalocar instâncias do estado do objeto. O método allocateState é chamado antes que a simulação inicie e sempre que um estado deve ser salvo. O método deallocateState é chamado quando as cópias de estados armazenadas não são mais necessárias. Isso acontece durante o processo de limpeza (garbage collecting), executado sempre que o GVT é atualizado. No momento da chamada desse método o objeto pode tanto apagar a instância do estado como pode armazená-la e reutilizá-la em uma chamada à allocateState. 


\section{getEvent}

Retorna o próximo evento que deve ser tratado pelo objeto. Normalmente as chamadas a esse método devem ser controladas com chamadas a haveMoreEvents(), como no exemplo a seguir:

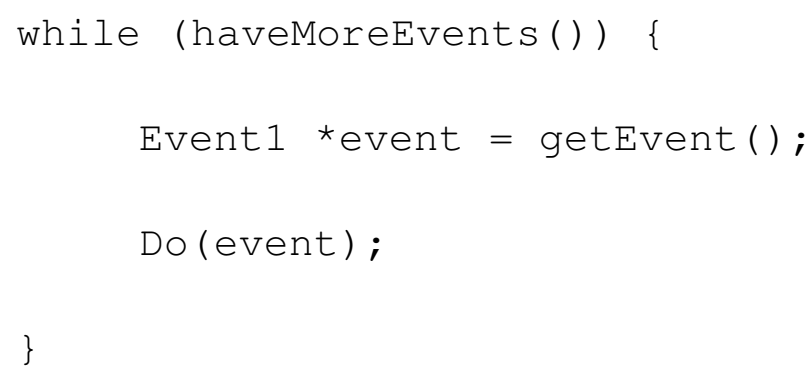

Um código como esse deve residir no método executeProcess e irá garantir o tratamento de todos os eventos recebidos pelo objeto no tempo virtual atual.

\section{A1.3 - Classe State}

No Warped o estado de um objeto é definido utilizando os recursos da classe abstrata State. Os estados são gerenciados pelo núcleo, que salva instâncias dessa classe de acordo com o algoritmo de salvamento de estados escolhido. A criação e a destruição de instâncias de estados são tarefas do objeto.

Além o construtor e o destruidor as classes derivadas de State devem fornecer apenas um método obrigatório: copyState.

\section{copyState}

Quando o núcleo precisa salvar um estado ele executa dois passos básicos: (1) requisita que o objeto aloque uma nova instância do estado através da chamada à SimulationObject::allocateState e (2) invoca o método copyState para que ele copie corretamente o conteúdo do estado a ser salvo para a nova instância. A tarefa de copiar o estado é deixada a cargo da aplicação porque a instância do estado pode conter ponteiros para outros objetos ou outros objetos podem conter ponteiros para o estado. Todos os ponteiros devem ser acertados pela 
aplicação. Caso esse tipo de situação não aconteça numa aplicação é possível definir o estado como uma subclasse de FlatState em vez de State. Nesse caso, uma implementação padrão de copyState é fornecida e a aplicação do usuário deve apenas definir o método FlatState::getSize que informa ao núcleo o tamanho da instância do estado.

\section{A1.4 - Classe DefaultEvent}

Os eventos representam a comunicação entre os objetos. É comum as simulações possuírem diversos tipos de eventos. Um novo tipo de evento é criado a partir da derivação da classe DefaultEvent que, por sua vez, é derivada da classe abstrata Event. Contudo, é possível que uma simulação não necessite especificar nenhum novo tipo de evento, sendo possível criar instâncias diretamente a partir da classe DefaultEvent. Nesse caso o evento enviado carrega apenas as informações básicas definidas na classe Event, que são: tempo virtual em que o evento foi enviado, tempo virtual em que o evento será recebido, nome do objeto transmissor, nome do objeto receptor e um número identificador.

Se, além das informações básicas, os eventos necessitam carregar mais informações, novas variáveis devem ser incluídas na parte de dados da nova classe. Nesse caso, os seguintes métodos adicionais devem ser redefinidos pela classe derivada:

\section{serialize e deserialize}

As instâncias das classes que definem tipos de evento são transmitidas através de mensagens. Esses dois métodos executam a tarefa de empacotar e desempacotar os dados das instâncias para que eles possam ser inseridos nas mensagens. Essas tarefas também são conhecidas como serialização e deserialização.

\section{eventCompare}

O Warped exige que seja fornecido um método para comparar dois eventos para conferir se eles são idênticos ou não. O núcleo fornece o método compareEvents que testa a i- 
gualdade das informações básicas, ficando a critério da aplicação definir quais são as informações adicionais que garantem a igualdade de dois eventos.

\section{$>$ new e delete}

Em casos onde se deseja reaproveitar a memória utilizada por uma instância de um evento é comum que os operadores new e delete sejam sobrecarregados. A biblioteca clutils, que faz parte da distribuição do Warped, fornece um contêiner para facilitar o reaproveitamento de instâncias. Ele possui o funcionamento de uma pilha onde as referências para os objetos são inseridas e retiradas e memória ocupada não é desalocada. Numa simulação, o número de eventos circulando pode ser extremamente grande fazendo com o volume de novas instanciações degrade o desempenho da simulação. Na maioria dos casos uma nova instanciação é uma operação mais lenta do que um reaproveitamento de memória através da pilha.

\section{A2 - Arquitetura do núcleo}

Esta seção apresenta a estrutura interna do núcleo de simulação do Warped. Será apresentada uma descrição dos mecanismos que o núcleo emprega para implementar uma simulação Time Warp.

\section{A2.1 - Gerenciadores de simulação}

Os principais mecanismos utilizados pelo núcleo são controlados pelo gerenciador de simulação (Simulation Manager ou SM). Há dois tipos de SM implementados no Warped: um para simulação seqüencial e outro para simulação com o protocolo Time Warp.

Um $S M$ fornece uma interface para que um objeto da simulação possa desempenhar tarefas como: comunicar-se com outros objetos, receber eventos e informar-se sobre o tempo da simulação, etc. Essa interface é definida na classe abstrata SimulationManager e implementa- 
da nas classes SequentialSimulationManager e TimeWarpSimulationManager (TWSM). Esse projeto de gerenciamento permite que uma mesma aplicação seja executada em modo seqüencial ou distribuído sem que nenhuma de suas classes tenha o código modificado.

A escolha do gerenciador é feita em tempo de execução, portanto, a aplicação não precisa sequer ser recompilada. A própria estrutura interna do código do Warped foi feita de forma flexível com relação ao $S M$ já que muitas classes internas comunicam-se apenas com a interface SimulationManager. Isso permitiria adicionar um novo tipo de $S M$, por exemplo, para implementar um protocolo de sincronização conservativo, sem muitas modificações na estrutura do núcleo. A figura A.1 exibe um diagrama de classe composto das classes que interagem com os SMs.

O $S M$ gerencia toda a estrutura da simulação, por isso está conectado às principais classes que implementam diversos mecanismos, como: gerenciamento dos objetos, gerenciamento da lista de eventos, escalonamento de objetos e gerenciamento do tempo virtual. No caso do TWSM, o gerenciador do TimeWarp, alguns mecanismos adicionais são gerenciados, como: salvamento de estados, cálculo do tempo global virtual $(G V T)$, particionamento dos objetos e comunicação externa.

As discussões que se seguem serão focadas no funcionamento dos mecanismos para simulação distribuída com TimeWarp. A partir desse ponto a sigla $S M$ será utilizada como sinônimo de TWSM (TimeWarpSimulationManager) . 


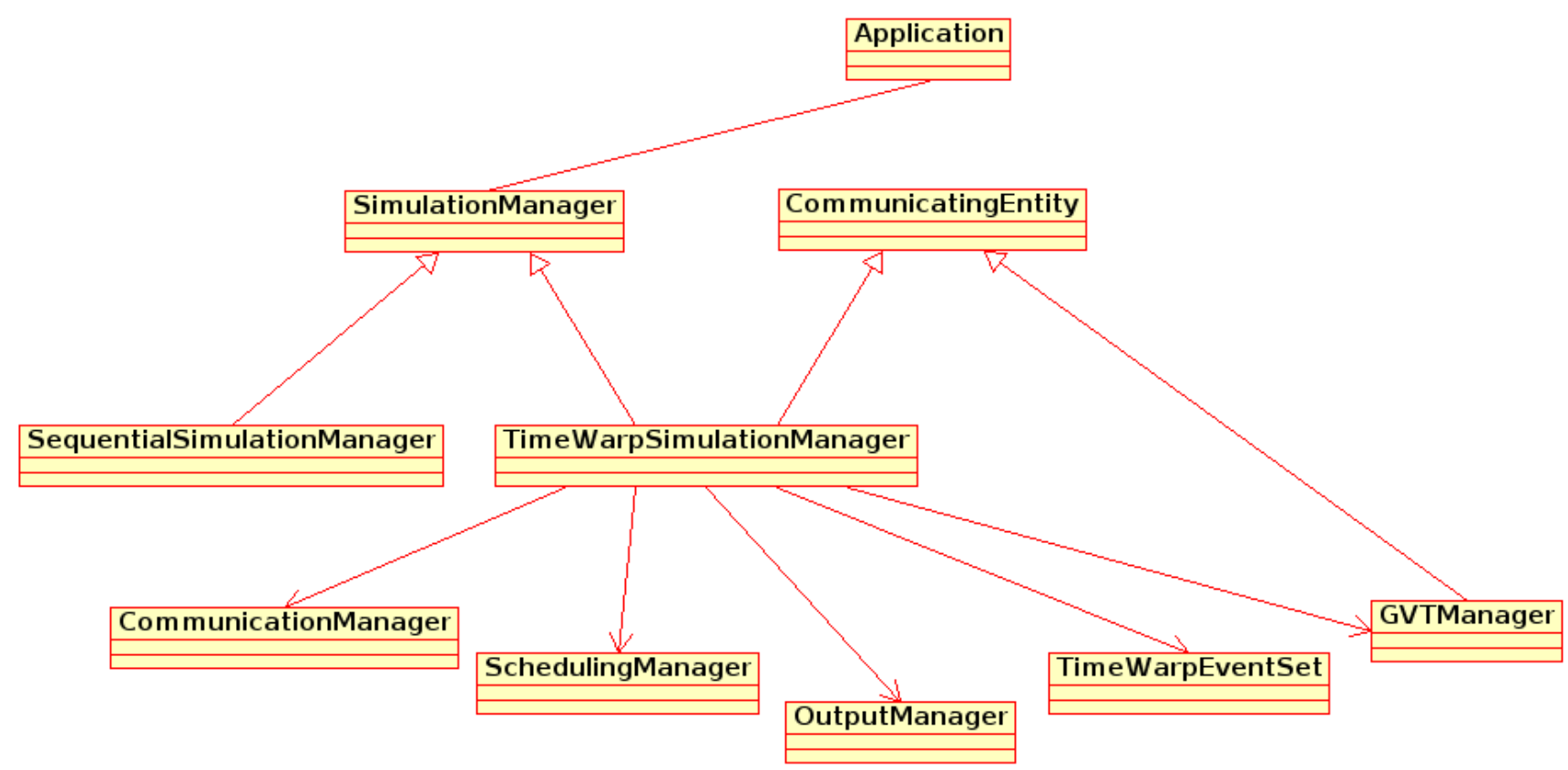

Figura A.1 Diagrama de classes relacionadas ao SM.

\section{A2.2 - Gerenciamento dos objetos}

No Warped, os objetos são identificados por um nome definido pelo usuário. Numa simulação, qualquer referência a um objeto deve ser feita pelo nome. Isso é obtido através de uma chamada ao método SimulationManager::getObjectHandle, que recebe como parâmetro uma string com o nome e retorna uma referência para um SimulationObject. No caso das simulações distribuídas, a referência ainda pode ser do tipo SimulationObjectProxy, que provê acesso ao mecanismo de comunicação externa. Isso ocorre quando o objeto requisitado não reside no mesmo $L P$ do objeto que pediu a referência. Mesmo assim, o envio de eventos pode ser feito utilizando as mesmas chamadas de métodos, já que o proxy é um tipo de objeto.

Internamente o SM mantém um Mapa de Dispersão (Hash Map), construído no momento da criação dos objetos, que mantém as relações de nomes e referências para todos os objetos da simulação. Os mapas de dispersão são estruturas de dados eficientes e representam uma boa opção quando se trata de buscas utilizando strings como chave. Isso proporciona ao Warped flexibilidade e facilidade de uso sem penalizar o desempenho. 


\section{A2.3 - Escalonamento e listas de eventos}

O escalonador é um mecanismo presente nos $L P$ s que tem a responsabilidade de selecionar o próximo objeto a ser executado. A escolha é dependente de alguma regra que normalmente é relacionada ao tempo virtual dos eventos recebidos pelos objetos. Atualmente, no Warped, o único algoritmo de escalonamento de objetos implementado é o LTF (Lowest Timestamp First ou Menor Timestamp Primeiro). No LTF o próximo objeto a ser executado é sempre o receptor do evento com menor timestamp, presente na lista de eventos não processados. A atividade de escalonamento está diretamente ligada com o tipo de armazenamento das listas de eventos.

O núcleo do Warped está preparado para utilizar duas formas de gerenciamento de listas de eventos: centralizada e descentralizada. Na primeira abordagem, todos os eventos recebidos pelos objetos de um $L P$ são armazenados em uma mesma estrutura de dados, enquanto que na abordagem descentralizada, uma estrutura separada é mantida para cada objeto. Na versão utilizada neste trabalho, a única implementação que estava funcionando corretamente era uma versão simples do gerenciamento descentralizado utilizando listas ordenadas.

O escalonamento é deixado a cargo da classe SchedulingManager, que em cada instante do tempo virtual de simulação recebe uma chamada do $S M$ requisitando uma referência ao próximo evento a ser tratado. No escalonamento padrão do Warped, o escalonador percorre a lista de objetos do $L P$ acessando a lista de eventos de cada um, em busca do evento com menor timestamp, cuja referência é retornado ao $S M$. Utilizado o nome do objeto receptor, que está contido na instância do evento, o $S M$ obtém uma referência ao próximo objeto a ser executado. Em seguida, o método executeProcess do objeto receptor é invocado. 
Cada objeto mantém duas listas de eventos: uma com os eventos processados e outra com os eventos não processados. A lista dos eventos processados é ordenada sob-demanda, isto é, ela pode ficar desordenada após uma ou mais modificações e é reordenada apenas quando o evento de menor timestamp deve ser retirado. Um evento processado permanece armazenado em sua lista enquanto há a possibilidade de ocorrer um rollback que faça a simulação voltar a um ponto anterior ao seu tempo de recebimento. Caso isso ocorra, os eventos processados com tempos virtuais menores ou iguais ao tempo do rollback e que não tenham sido cancelados por antimensagens, são movidos de volta para a lista dos não-processados.

As listas ordenadas possuem baixa complexidade e são fáceis de implementar, contudo podem apresentar desempenho insatisfatório frente a grandes quantidades de eventos, devido à complexidade dos algoritmos de ordenação. Estruturas de dados mais eficientes são freqüentemente empregadas no gerenciamento de listas de eventos, tanto em simulações distribuídas como seqüenciais. Alguns exemplos dessas estruturas incluem: splay trees (Sleator \& Tarjan, 1985) e calendar queues (Brown, 1988).

\section{A2.4 - Tempo virtual}

O Warped define a noção de tempo virtual através da classe abstrata VTime. A única classe derivada presente no núcleo é IntVTime, na qual cada instante de tempo virtual é representado por um número inteiro. Caso haja necessidade de representar o tempo virtual com outros tipos de dados, basta criar uma classe derivada de VTime e implementar os métodos necessários. É comum alguns tipos de simulações utilizarem tipos de dados mais complexos para representar o tempo virtual, como vetores ou números reais.

A classe VTime e suas derivações são usadas tanto para representar o tempo virtual local de cada objeto como o tempo virtual global $(G V T)$. O gerenciamento do $G V T$ é uma tarefa que influencia significativamente o desempenho de uma simulação Time Warp. A principal 
influência é no gerenciamento dos dados que devem ser salvos para posteriormente serem recuperados em caso de rollback. Esses dados incluem os estados dos objetos e as cópias das mensagens enviadas e recebidas. O GVT define o instante do tempo virtual no qual todos os objetos chegaram. Seguramente não ocorrerá rollback para trás desse tempo. A atualização do GVT indica o momento em que um procedimento de limpeza (garbage collecting) pode ser disparado para excluir os que foram salvos e não são mais necessários.

A classe abstrata GVTManager define as funcionalidades básicas de um esquema de gerenciamento de GVT. No núcleo existe apenas um esquema implementado, que é o algoritmo de Mattern (Mattern, 1993). Esse método funciona através da passagem de duas rodadas de mensagens de controle para criar dois cortes que dividem a simulação entre passado e futuro. Os cortes são feitos de forma a evitar o problema das mensagens transientes que podem causar erros no cálculo do GVT. O primeiro corte indica o início da fase de cálculo, onde cada objeto registra o tempo do evento enviado com menor timestamp. O segundo corte garante que todas as mensagens enviadas antes do primeiro corte foram recebidas.

A frequiência com que o processo de cálculo do $G V T$ é disparado é definida por um parâmetro chamado "período". Esse parâmetro baseia-se na quantidade de eventos executados. Cada vez que um ou mais eventos são processados por um objeto em um instante da simulação a variável de controle do período é incrementada. Quando essa variável atinge o valor do período uma fase de cálculo do GVT é disparada. Um valor do período menor aumenta a freqüência de atualização do $G V T$ e da execução do processo de limpeza. Períodos curtos podem causar excesso de comunicação e afetar negativamente o desempenho. Períodos mais longos fazem com que a influência no desempenho da simulação seja menor, mais em contrapartida, o espaço de memória necessário para armazenar estados e mensagens aumenta significativamente. 


\section{A2.5 - Salvamento de estados}

No núcleo, há um gerenciador responsável por tratar das tarefas relativas ao salvamento de estados. A classe abstrata StateManager define a interface básica dos gerenciadores de estados. O salvamento de estado periódico é o único que está implementado atualmente no Warped. A classe PeriodicStateManager implementa a lógica necessária. Nesse tipo de salvamento os estados são copiados para uma lista periodicamente.

A freqüência do salvamento depende de um período que deve ser definido pelo usuário. Se o período for igual a 0 , o estado é copiado sempre que alterado. Isso é equivalente à definição do esquema Copy State Saving.

Um período maior que 0 define de quanto em quanto tempo a cópia será feita, como definido pelo esquema Sparse State Saving. Nesse caso, quando ocorre um rollback, o objeto deve voltar para o último estado salvo antes do tempo do rollback. Isso pode implicar num retorno mais longo ao que seria necessário caso os estados fossem salvos mais freqüentemente.

Na versão utilizada neste trabalho o gerenciador de salvamento não funcionava caso o período fosse maior que 0 .

\section{A2.6 - Particionamento dos objetos}

O particionamento dos objetos para formar os $L P$ s é uma das tarefas mais importantes quando se trata de garantir o bom desempenho da simulação. Uma porção significativa do esforço deste trabalho foi empregada no estudo dessa tarefa. O objetivo do particionamento é dividir os objetos em grupos de acordo com alguma regra. Cada grupo de objetos torna-se um $L P$. O Warped só permite que se tenha um $L P$ por máquina. 
O particionamento pode ser feito pelo núcleo ou pode ser deixado a cargo da aplicação. Em ambos os casos, a lógica do particionamento deve ser definida numa classe derivada de Partitioner. Essa classe abstrata define apenas o método partition, dentro do qual deve ser implementada a heurística. Originalmente o núcleo implementa apenas um tipo de particionamento, através da classe RoundRobinPartitioner. A Round-robin é uma das heurísticas mais simples possíveis; ela divide os objetos igualmente entre os $L P$ s e não utiliza qualquer tipo de conhecimento sobre o modelo de simulação ou sobre a plataforma. Apesar de simples, essa heurística é opção mais indicada quando não se pode basear as decisões de particionamento em informações mais detalhadas.

A implementação do método partition deve preparar um objeto do tipo PartitionInfo e usá-lo como valor de retorno. Após a execução da heurística de particionamento esse objeto deve conter um número de partições equivalente ao número de $L P$ s. Cada partição é uma lista de ponteiros para objetos.

\section{A2.7 - Comunicação Externa}

O sistema de comunicação do Warped foi projetado para proporcionar principalmente uma boa flexibilidade. Isso é obtido com alguns níveis de abstração que isolam a implementação da comunicação física do gerenciador da simulação.

O gerenciador da simulação distribuída (TimeWarpSimulationManager) é ligado à classe abstrata CommunicationManager. Essa classe provê os métodos necessários para enviar e receber mensagens através da rede. Atualmente há duas classes concretas derivadas de CommunicationManager, que implementam diferentes estratégias para gerenciar as mensagens. A classe DefaultCommunicationManager implementa o mecanismo padrão no qual as mensagens são enviadas imediatamente após a requisição do $S M$, ao contrário do que acontece na implementação do gerenciador de comunicação com agregação de mensagens. Essa 
otimização, implementada pela classe MessageAgreggatingCommunicationManager, procura diminuir o impacto da latência da rede atrasando o envio de algumas mensagens por certo tempo, agrupando-as e enviando-as de uma só vez. O mecanismo de comunicação padrão sem agregação de mensagens foi adotado nos testes realizados nesse estudo.

A classe CommunicationManager não implementa a comunicação física. Isso é deixado para o segundo nível de abstração, definido na classe PhysicalCommunicationLayer. Essa é uma classe abstrata que define os métodos que devem ser implementados pelos sistemas específicos de comunicação física. O Warped suporta atualmente três tipos de comunicação fornecidos pela biblioteca eclmpl: $M P I, T C P$ ou $U D P$. No primeiro caso a distribuição dos processos e a comunicação entre os LPs são feitos através da biblioteca MPI (Message Pas-

sing Interface). Nas outras opções a comunicação é feita diretamente através de sockets TCP ou $U D P$, dependendo da escolha do usuário. A biblioteca eclmpl faz parte da distribuição do Warped.

Nas execuções feitas para este trabalho, o modo de comunicação utilizado foi com o auxílio da biblioteca MPI. Atualmente a implementação $M P I C H$ é a única suportada pelo Warped.

\section{A3 - Configuração automática do sistema}

As funcionalidades do Warped são configuradas automaticamente na fase de inicialização da simulação. Diversos mecanismos podem ser personalizados sem que o programa precise ser recompilado. Esta seção descreve o significado dos parâmetros mais relevantes. O tópico A.4 apresenta um arquivo de configuração completo para ser usado em uma simulação Time Warp.

Cada parâmetro é descrito em uma linha no formato: 
Os parâmetros relacionados são agrupados em escopos, que podem ser aninhados, como pode ser observado no exemplo a seguir.

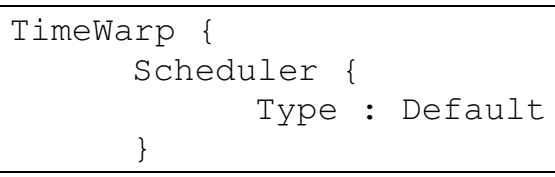

O parâmetro Simulation pode receber os valores "Time Warp" ou "Sequential". No primeiro caso uma simulação distribuída é realizada. No segundo caso adota-se uma simulação seqüencial.

O escopo Time Warp, contém vários escopos internos que definem as escolhas de mecanismos que serão usados na simulação e suas configurações.

O escopo Scheduler foi criado para permitir a configuração do mecanismo de escalonamento de objetos. A versão do Warped utilizada neste trabalho contém apenas uma opção de escalonamento (valor Default). O algoritmo dessa versão corresponde ao escalonamento LTF (Lowest Timestamp First).

Através do escopo EventList é possível configurar o mecanismo de gerenciamento das listas de eventos. O parâmetro Type define a estrutura de dado utilizada, podendo assumir os valores Default e Multiset no caso de simulação paralela e Default, SplayTree e SingleLinkedList para a simulação seqüencial. O parâmetro Organization define se será mantida uma lista conjunta de eventos para todos os objetos de cada LP (valor Centralized) ou se uma lista de eventos separada será criada para cada objeto (valor Decentralized).

O mecanismo de monitoramento e instrumentação de simulação pode ser ativado ou desativado através do arquivo de configuração. A opção Type, do escopo ControlManager pode receber os valores Active (mecanismo ativo) ou Inactive (mecanismo inativo).

O escopo CommunicationManager contém os parâmetros necessários para configurar o gerenciador de comunicação. O parâmetro PhysicalLayer define o protocolo de comunica- 
ção utilizado para troca de mensagens entre diferentes gerenciadores de simulação. Os valores possíveis para esse parâmetro são MPI, UDPSelect e TCPSelect. O parâmetro Type define se haverá agregação de mensagens (valor MessageAggregating) ou não (valor Default). O parâmetro Nodes é usado para definir os nomes das máquinas participantes da simulação. Os nomes das máquinas participantes, com exceção da máquina de onde a simulação será iniciada, devem escritos separados por vírgulas.

O comportamento do gerenciador de salvamento de estados pode ser ajustado através do escopo StateManager. O parâmetro Type pode assumir dois valores: Periodic ou Adaptive. No primeiro caso, é feito um salvamento de estados do tipo Copy State Saving, sendo que o intervalo de salvamento é controlado pelo parâmetro Period. No segundo caso seria usado um salvamento de estados adaptativo, contudo, o Warped não inclui nenhuma implementação desse tipo de salvamento.

O escopo OutputManager contém um parâmetro (Type) para definir como será feito o cancelamento dos eventos enviados na ocorrência de rollback. As opções disponíveis são $A g$ gressive e Lazy. No primeiro caso, usa-se o método de cancelamento agressivo (seção 2.5.2) enquanto que no segundo caso usa-se o método preguiçoso.

O último escopo de configuração disponível no arquivo de configuração do Warped é o escopo GvtManager. Ele é usado para configurar o mecanismo de controle do GVT, através dos parâmetros Type e Period. O parâmetro Type pode receber apenas o valor Mattern (Mattern, 1993), que corresponde ao único tipo de cálculo de GVT implementado no Warped. O parâmetro Period controla a freqüência em que o cálculo do GVT é chamado. Quanto menor o valor do período, mais frequentemente o cálculo será disparado. 


\section{A4 - Exemplo de um arquivo de configuração do warped}

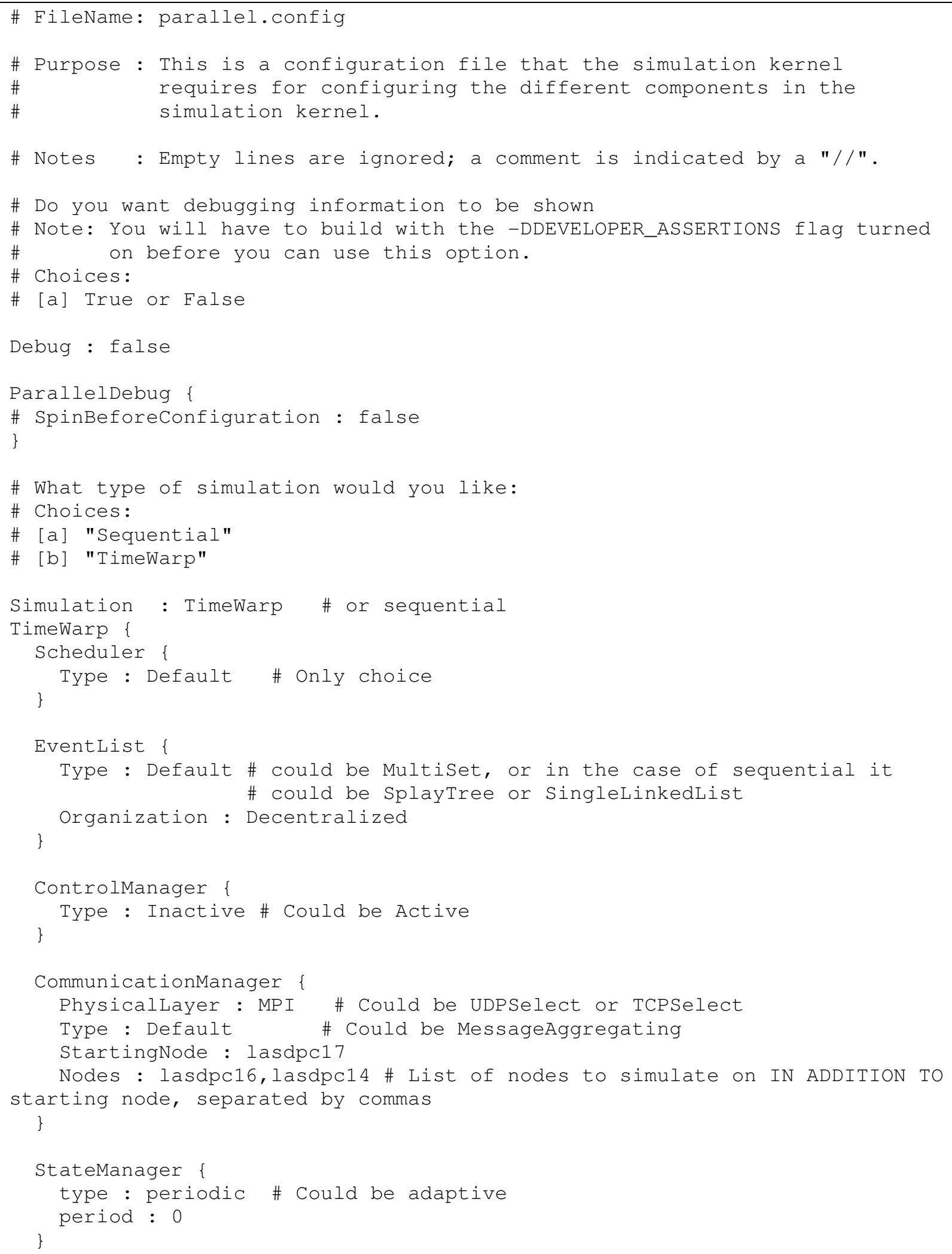




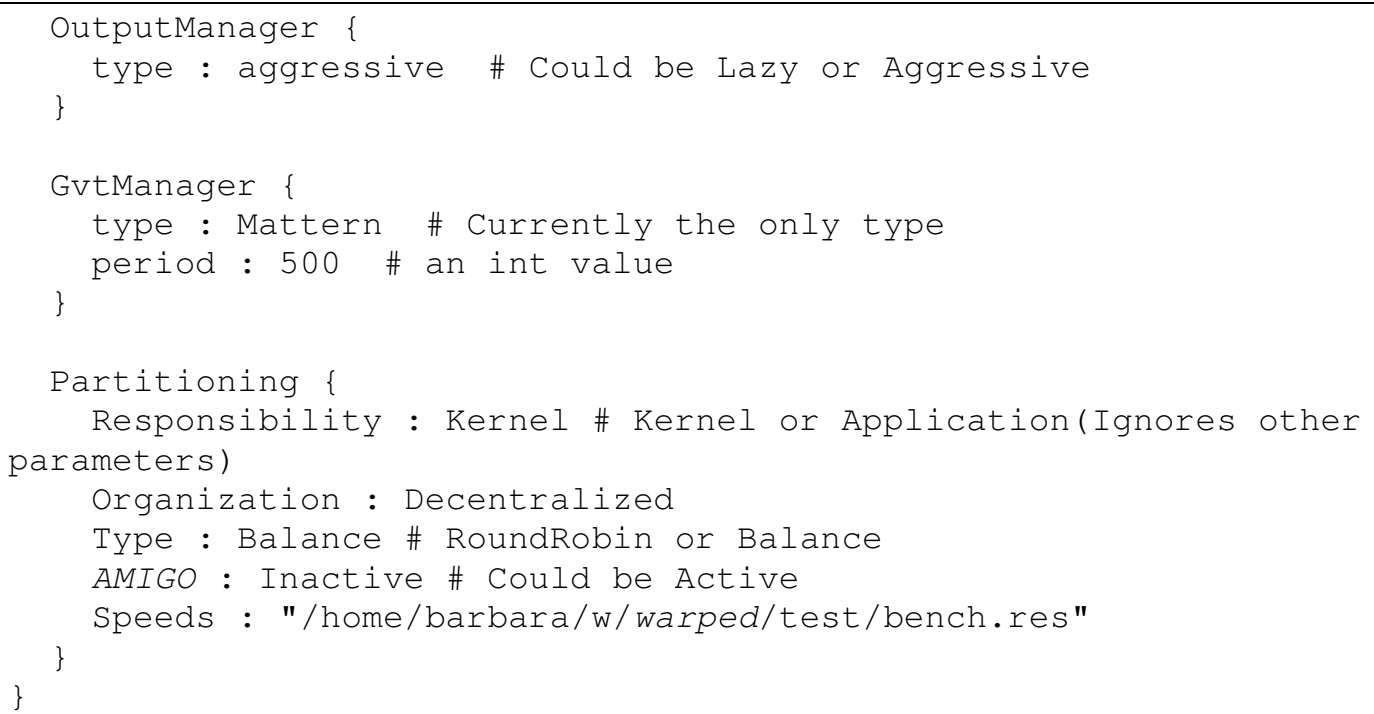





\section{APÊNDICE B - Tabelas de dados}

\section{B.1. Ambiente Dedicado}

\section{B.1.1. Modelos executados com benchmark de CPU}

\begin{tabular}{|c|c|c|c|c|c|c|c|c|c|c|c|c|c|c|}
\hline \multirow[b]{2}{*}{ Execução } & \multicolumn{3}{|c|}{ Eventos } & \multirow[b]{2}{*}{$\begin{array}{l}\text { Total Pro- } \\
\text { cessados }\end{array}$} & \multirow[b]{2}{*}{$\begin{array}{l}\text { Total Can- } \\
\text { celados }\end{array}$} & \multirow[b]{2}{*}{$\begin{array}{c}\text { Total Rea- } \\
\text { lizados }\end{array}$} & \multicolumn{3}{|c|}{ Rollbacks } & \multirow[b]{2}{*}{ Secundários } & \multicolumn{3}{|c|}{ Causados por: } & \multirow[b]{2}{*}{3} \\
\hline & $\begin{array}{c}\text { Tempo } \\
\text { Total }\end{array}$ & $\begin{array}{c}\text { Processados } \\
\text { p/ segundo }\end{array}$ & $\begin{array}{l}\text { Realizados } \\
\text { p/ segundo }\end{array}$ & & & & Eficiência & Total & Primários & & 0 & 1 & 2 & \\
\hline 1 & 24,885 & 1957,843 & 1917,247 & 47941 & 1001 & 46940 & 0,979 & 505 & 224 & 281 & 8 & 59 & 105 & 52 \\
\hline 2 & 25,411 & 1949,994 & 1879,793 & 48994 & 1762 & 47232 & 0,964 & 902 & 361 & 541 & 14 & 132 & 130 & 115 \\
\hline 3 & 25,387 & 1950,822 & 1893,970 & 48891 & 1430 & 47461 & 0,971 & 749 & 331 & 418 & 19 & 91 & 140 & 81 \\
\hline 4 & 25,395 & 1955,405 & 1911,679 & 48937 & 1098 & 47839 & $\mathbf{0 , 9 7 8}$ & 564 & 259 & 305 & 13 & 74 & 106 & 66 \\
\hline 5 & 25,353 & 1953,175 & 1893,643 & 48991 & 1496 & 47495 & 0,969 & 781 & 297 & 484 & 15 & 90 & 126 & 66 \\
\hline 6 & 26,859 & 1939,208 & 1869,423 & 50112 & 1832 & 48280 & 0,963 & 897 & 347 & 550 & 27 & 112 & 117 & 91 \\
\hline 7 & 24,981 & 1962,099 & 1917,192 & 48404 & 1115 & 47289 & $\mathbf{0 , 9 7 7}$ & 580 & 264 & 316 & 17 & 78 & 110 & 59 \\
\hline 8 & 25,297 & 1954,728 & 1885,187 & 48972 & 1746 & 47226 & 0,964 & 859 & 334 & 525 & 11 & 115 & 144 & 64 \\
\hline 9 & 25,055 & 1960,241 & 1910,110 & 48485 & 1246 & 47239 & 0,974 & 619 & 297 & 322 & 22 & 100 & 120 & 55 \\
\hline 10 & 25,416 & 1946,612 & 1893,528 & 48970 & 1336 & 47634 & $\mathbf{0 , 9 7 3}$ & 704 & 294 & 410 & 16 & 92 & 112 & 74 \\
\hline 11 & 25,598 & 1955,956 & 1897,499 & 49462 & 1464 & 47998 & 0,970 & 811 & 365 & 446 & 28 & 119 & 149 & 69 \\
\hline 12 & 25,429 & 1952,548 & 1895,579 & 49008 & 1436 & 47572 & 0,971 & 728 & 299 & 429 & 15 & 90 & 120 & 74 \\
\hline 13 & 25,506 & 1951,062 & 1886,727 & 48997 & 1617 & 47380 & 0,967 & 809 & 330 & 479 & 25 & 90 & 125 & 90 \\
\hline 14 & 25,002 & 1957,408 & 1911,851 & 47976 & 1127 & 46849 & $\mathbf{0 , 9 7 7}$ & 577 & 284 & 293 & 10 & 83 & 135 & 56 \\
\hline 15 & 24,995 & 1960,031 & 1914,589 & 47945 & 1125 & 46820 & 0,977 & 574 & 243 & 331 & 7 & 84 & 112 & 40 \\
\hline Média & 25,371 & & & & & & 0,972 & 711 & & & & & & \\
\hline
\end{tabular}

Tabela B. 1 - Dados da execução do Modelo J com benchmark de cpu. 


\begin{tabular}{|c|c|c|c|c|c|c|c|c|c|c|c|c|c|c|}
\hline \multirow[b]{2}{*}{ Execução } & \multicolumn{3}{|c|}{ Eventos } & \multirow[b]{2}{*}{$\begin{array}{l}\text { Total Pro- } \\
\text { cessados }\end{array}$} & \multirow[b]{2}{*}{$\begin{array}{l}\text { Total Cance- } \\
\text { lados }\end{array}$} & \multirow[b]{2}{*}{$\begin{array}{c}\text { Total Reali- } \\
\text { zados }\end{array}$} & \multicolumn{4}{|c|}{ Rollbacks } & \multicolumn{4}{|c|}{ Causados por: } \\
\hline & $\begin{array}{l}\text { Tempo } \\
\text { Total }\end{array}$ & $\begin{array}{l}\text { Processados } \\
\text { p/ segundo }\end{array}$ & $\begin{array}{l}\text { Realizados } \\
\text { p/ segundo }\end{array}$ & & & & Eficiência & Total & Primários & Secundários & 0 & 1 & 2 & 3 \\
\hline 1 & 40,043 & 1303,793 & 1209,781 & 51579 & 3724 & 47855 & 0,928 & 1759 & 566 & 1193 & 146 & 219 & 116 & 85 \\
\hline 2 & 44,136 & 1291,055 & 1168,724 & 55889 & 5287 & 50602 & 0,905 & 2532 & 750 & 1782 & 178 & 291 & 141 & 140 \\
\hline 3 & 41,759 & 1295,678 & 1212,770 & 53148 & 3444 & 49704 & 0,935 & 1711 & 546 & 1165 & 120 & 208 & 128 & 90 \\
\hline 4 & 41,474 & 1293,459 & 1206,045 & 53209 & 3599 & 49610 & 0,932 & 1798 & 582 & 1216 & 140 & 231 & 128 & 83 \\
\hline 5 & 40,848 & 1301,010 & 1194,625 & 52694 & 4302 & 48392 & 0,918 & 2063 & 660 & 1403 & 162 & 232 & 144 & 122 \\
\hline 6 & 42,985 & 1333,118 & 1197,654 & 56440 & 5672 & 50768 & 0,900 & 2731 & 800 & 1931 & 188 & 338 & 152 & 122 \\
\hline 7 & 41,158 & 1290,664 & 1204,486 & 52706 & 3539 & 49167 & $\mathbf{0 , 9 3 3}$ & 1742 & 506 & 1236 & 124 & 211 & 93 & 78 \\
\hline 8 & 41,758 & 1300,551 & 1205,670 & 53242 & 3914 & 49328 & 0,926 & 1922 & 673 & 1249 & 171 & 231 & 148 & 123 \\
\hline 9 & 42,156 & 1301,168 & 1203,951 & 53756 & 4065 & 49691 & 0,924 & 1953 & 647 & 1306 & 159 & 257 & 138 & 93 \\
\hline 10 & 41,778 & 1286,165 & 1180,062 & 53255 & 4393 & 48862 & 0,918 & 2229 & 693 & 1536 & 215 & 233 & 132 & 113 \\
\hline 11 & 42,139 & 1303,664 & 1197,078 & 54309 & 4445 & 49864 & 0,918 & 2194 & 662 & 1532 & 158 & 245 & 153 & 106 \\
\hline 12 & 42,636 & 1291,302 & 1190,544 & 54275 & 4271 & 50004 & 0,921 & 2174 & 644 & 1530 & 146 & 255 & 144 & 99 \\
\hline 13 & 42,978 & 1280,910 & 1185,562 & 54372 & 3983 & 50389 & $\mathbf{0 , 9 2 7}$ & 1941 & 612 & 1329 & 132 & 253 & 134 & 93 \\
\hline 14 & 42,421 & 1304,010 & 1197,473 & 54786 & 4490 & 50296 & 0,918 & 2169 & 608 & 1561 & 126 & 232 & 128 & 122 \\
\hline 15 & 42,774 & 1313,052 & 1197,055 & 55351 & 4922 & 50429 & 0,911 & 2425 & 696 & 1729 & 136 & 299 & 162 & 99 \\
\hline Média & 42,069 & & & & & & 0,921 & 2090 & & & & & & \\
\hline
\end{tabular}

Tabela B.2 - Dados da execução do Modelo K com benchmark de cpu. 


\begin{tabular}{|c|c|c|c|c|c|c|c|c|c|c|c|c|c|c|}
\hline \multirow[b]{2}{*}{ Execução } & \multicolumn{3}{|c|}{ Eventos } & \multirow[b]{2}{*}{$\begin{array}{l}\text { Total Pro- } \\
\text { cessados }\end{array}$} & \multirow[b]{2}{*}{\begin{tabular}{|c|}
$\begin{array}{c}\text { Total Cance- } \\
\text { lados }\end{array}$ \\
\end{tabular}} & \multirow[b]{2}{*}{$\begin{array}{c}\text { Total Reali- } \\
\text { zados }\end{array}$} & \multicolumn{4}{|c|}{ Rollbacks } & \multicolumn{4}{|c|}{ Causados por: } \\
\hline & $\begin{array}{c}\text { Tempo } \\
\text { Total }\end{array}$ & $\begin{array}{c}\text { Processados } \\
\text { p/ segundo }\end{array}$ & $\begin{array}{l}\text { Realizados } \\
\text { p/ segundo }\end{array}$ & & & & Eficiência & Total & Primários & Secundários & 0 & 1 & 2 & 3 \\
\hline 1 & 24,558 & 2017,993 & 1930,072 & 48380 & 2144 & 46236 & 0,956 & 1058 & 352 & 706 & 84 & 141 & 77 & 50 \\
\hline 2 & 23,934 & 2024,323 & 1945,847 & 47888 & 1850 & 46038 & 0,961 & 930 & 346 & 584 & 55 & 149 & 102 & 40 \\
\hline 3 & 25,027 & 2031,100 & 1947,879 & 49461 & 2065 & 47396 & 0,958 & 1058 & 377 & 681 & 81 & 138 & 100 & 58 \\
\hline 4 & 25,316 & 2031,487 & 1940,340 & 50508 & 2254 & 48254 & 0,955 & 1146 & 390 & 756 & 98 & 112 & 107 & 73 \\
\hline 5 & 24,661 & 1998,409 & 1916,926 & 48445 & 1943 & 46502 & 0,960 & 995 & 373 & 622 & 60 & 153 & 114 & 46 \\
\hline 6 & 24,278 & 2062,342 & 1990,591 & 48479 & 1724 & 46755 & 0,964 & 840 & 320 & 520 & 70 & 120 & 73 & 57 \\
\hline 7 & 25,388 & 2062,742 & 1962,089 & 51042 & 2534 & 48508 & 0,950 & 1271 & 420 & 851 & 85 & 160 & 111 & 64 \\
\hline 8 & 24,577 & 2013,984 & 1936,882 & 48973 & 1886 & 47087 & 0,961 & 947 & 368 & 579 & 60 & 147 & 116 & 45 \\
\hline 9 & 24,782 & 2022,490 & 1922,913 & 50045 & 2458 & 47587 & 0,951 & 1226 & 449 & 777 & 88 & 165 & 128 & 68 \\
\hline 10 & 25,062 & 2039,463 & 1944,947 & 50585 & 2318 & 48267 & 0,954 & 1179 & 412 & 767 & 72 & 183 & 104 & 53 \\
\hline 11 & 24,116 & 2065,465 & 1983,784 & 48534 & 1957 & 46577 & 0,960 & 958 & 388 & 570 & 64 & 155 & 121 & 48 \\
\hline 12 & 24,818 & 2022,637 & 1944,471 & 49002 & 1926 & 47076 & 0,961 & 986 & 385 & 601 & 59 & 146 & 112 & 68 \\
\hline 13 & 24,498 & 2021,796 & 1922,236 & 48429 & 2351 & 46078 & $\mathbf{0 , 9 5 1}$ & 1142 & 418 & 724 & 84 & 165 & 116 & 53 \\
\hline 14 & 24,608 & 2026,568 & 1940,033 & 48370 & 2114 & 46256 & 0,956 & 1052 & 417 & 635 & 96 & 162 & 99 & 60 \\
\hline 15 & 24,908 & 1999,920 & 1892,704 & 49491 & 2627 & 46864 & 0,947 & 1295 & 466 & 829 & 109 & 168 & 121 & 68 \\
\hline Média & 24,702 & & & & & & 0,956 & 1072 & & & & & & \\
\hline
\end{tabular}




\begin{tabular}{|c|c|c|c|c|c|c|c|c|c|c|c|c|c|c|}
\hline \multirow[b]{2}{*}{ Execução } & \multicolumn{3}{|c|}{ Eventos } & \multirow[b]{2}{*}{$\begin{array}{l}\text { Total Pro- } \\
\text { cessados }\end{array}$} & \multirow[b]{2}{*}{$\begin{array}{l}\text { Total Cance- } \\
\text { lados }\end{array}$} & \multirow[b]{2}{*}{$\begin{array}{l}\text { Total Reali- } \\
\text { zados }\end{array}$} & \multicolumn{4}{|c|}{ Rollbacks } & \multicolumn{4}{|c|}{ Causados por: } \\
\hline & $\begin{array}{l}\text { Tempo } \\
\text { Total } \\
\end{array}$ & $\begin{array}{l}\text { Processados } \\
\text { p/ segundo }\end{array}$ & $\begin{array}{l}\text { Realizados } \\
\text { p/ segundo }\end{array}$ & & & & Eficiência & Total & Primários & Secundários & 0 & 1 & 2 & 3 \\
\hline 1 & 197,258 & 1196,823 & 1091,885 & 235669 & 20692 & 214977 & 0,912 & 10105 & 3234 & 6871 & 616 & 1555 & 562 & 501 \\
\hline 2 & 197,157 & 1198,441 & 1093,422 & 235410 & 20617 & 214793 & 0,912 & 9972 & 3315 & 6657 & 615 & 1550 & 642 & 508 \\
\hline 3 & 199,759 & 1194,953 & 1089,831 & 238464 & 20990 & 217474 & 0,912 & 10231 & 3371 & 6860 & 606 & 1548 & 641 & 576 \\
\hline 4 & 197,298 & 1199,091 & 1095,272 & 235414 & 20451 & 214963 & 0,913 & 9883 & 3288 & 6595 & 648 & 1574 & 583 & 483 \\
\hline 5 & 200,422 & 1193,575 & 1080,128 & 238371 & 22605 & 215766 & 0,905 & 10998 & 3612 & 7386 & 681 & 1676 & 653 & 602 \\
\hline 6 & 196,925 & 1199,412 & 1096,321 & 235551 & 20273 & 215278 & 0,914 & 9763 & 3209 & 6554 & 559 & 1592 & 566 & 492 \\
\hline 7 & 197,156 & 1197,489 & 1092,278 & 235217 & 20715 & 214502 & 0,912 & 9912 & 3408 & 6504 & 618 & 1640 & 660 & 490 \\
\hline 8 & 196,400 & 1200,316 & 1091,731 & 235438 & 21302 & 214136 & 0,910 & 10293 & 3312 & 6981 & 603 & 1548 & 631 & 530 \\
\hline 9 & 198,118 & 1199,136 & 1089,568 & 236792 & 21577 & 215215 & 0,909 & 10338 & 3436 & 6902 & 636 & 1624 & 662 & 514 \\
\hline 10 & 196,745 & 1200,504 & 1097,366 & 235871 & 20265 & 215606 & 0,914 & 9685 & 3287 & 6398 & 616 & 1530 & 639 & 502 \\
\hline 11 & 195,203 & 1199,930 & 1098,817 & 233618 & 19629 & 213989 & 0,916 & 9397 & 3049 & 6348 & 570 & 1475 & 589 & 415 \\
\hline 12 & 197,978 & 1198,932 & 1093,502 & 236931 & 20755 & 216176 & 0,912 & 10022 & 3300 & 6722 & 626 & 1547 & 632 & 495 \\
\hline 13 & 196,949 & 1198,563 & 1090,838 & 235255 & 21109 & 214146 & 0,910 & 10019 & 3253 & 6766 & 638 & 1545 & 601 & 469 \\
\hline 14 & 199,723 & 1195,992 & 1089,145 & 238453 & 21272 & 217181 & 0,911 & 10323 & 3404 & 6919 & 600 & 1647 & 648 & 509 \\
\hline 15 & 198,318 & 1198,415 & 1088,890 & 237263 & 21693 & 215570 & 0,909 & 10479 & 3460 & 7019 & 593 & 1660 & 668 & 539 \\
\hline Média & 197,694 & & & & & & 0,911 & 10095 & & & & & & \\
\hline
\end{tabular}

Tabela B. 4- Dados da execução do Modelo M com benchmark de cpu. 


\begin{tabular}{|c|c|c|c|c|c|c|c|c|c|c|c|c|c|c|}
\hline \multirow[b]{2}{*}{ Execução } & \multirow[b]{2}{*}{$\begin{array}{c}\text { Tempo } \\
\text { Total }\end{array}$} & \multirow{2}{*}{$\begin{array}{l}\text { Eventos } \\
\text { Processados } \\
\text { p/ segundo }\end{array}$} & \multirow[b]{2}{*}{$\begin{array}{l}\text { Realizados } \\
\text { p/ segundo }\end{array}$} & \multirow[b]{2}{*}{$\begin{array}{l}\text { Total Pro- } \\
\text { cessados }\end{array}$} & \multirow[b]{2}{*}{$\begin{array}{c}\text { Total Can- } \\
\text { celados }\end{array}$} & \multirow[b]{2}{*}{$\begin{array}{c}\text { Total Reali- } \\
\text { zados }\end{array}$} & \multicolumn{3}{|c|}{ Rollbacks } & \multicolumn{5}{|c|}{ Causados por: } \\
\hline & & & & & & & Eficiência & Total & Primários & Secundários & 0 & 1 & 2 & 3 \\
\hline 1 & 272,518 & 915,258 & 837,483 & 248494 & 21076 & 227418 & 0,915 & 10512 & 3477 & 7035 & 660 & 1413 & 651 & 753 \\
\hline 2 & 273,261 & 918,097 & 834,184 & 250535 & 22902 & 227633 & 0,909 & 11049 & 3689 & 7360 & 758 & 1385 & 664 & 882 \\
\hline 3 & 273,090 & 910,634 & 830,685 & 248437 & 21804 & 226633 & 0,912 & 10581 & 3474 & 7107 & 709 & 1239 & 665 & 861 \\
\hline 4 & 275,036 & 910,240 & 828,139 & 249744 & 22516 & 227228 & 0,910 & 10726 & 3424 & 7302 & 654 & 1182 & 648 & 940 \\
\hline 5 & 271,533 & 914,365 & 835,485 & 247458 & 21366 & 226092 & 0,914 & 10363 & 3487 & 6876 & 661 & 1325 & 684 & 817 \\
\hline 6 & 279,186 & 907,567 & 827,524 & 252108 & 22277 & 229831 & 0,912 & 10870 & 3509 & 7361 & 636 & 1387 & 617 & 869 \\
\hline 7 & $\mathbf{2 7 0 , 1 5 7}$ & 912,902 & 835,269 & 245770 & 20835 & 224935 & 0,915 & 9839 & 3331 & 6508 & 658 & 1245 & 661 & 767 \\
\hline 8 & 272,501 & 914,756 & 835,310 & 248531 & 21559 & 226972 & 0,913 & 10625 & 3588 & 7037 & 693 & 1397 & 652 & 846 \\
\hline 9 & 295,563 & 894,503 & 800,600 & 263673 & 27690 & 235983 & $\mathbf{0 , 8 9 5}$ & 13091 & 3971 & 9120 & 614 & 1451 & 709 & 1197 \\
\hline 10 & 270,752 & 909,329 & 834,242 & 245776 & 20289 & 225487 & 0,917 & 9947 & 3404 & 6543 & 697 & 1262 & 657 & 788 \\
\hline 11 & 270,406 & 915,209 & 834,426 & 247023 & 21769 & 225254 & 0,912 & 10328 & 3505 & 6823 & 659 & 1294 & 676 & 876 \\
\hline 12 & 271,412 & 907,986 & 830,666 & 245893 & 20924 & 224969 & 0,915 & 10131 & 3421 & 6710 & 608 & 1252 & 714 & 847 \\
\hline 13 & $\mathbf{2 7 8 , 8 5 7}$ & 916,750 & 826,579 & 255304 & 25111 & 230193 & $\mathbf{0 , 9 0 2}$ & 11991 & 3817 & 8174 & 691 & 1425 & 725 & 976 \\
\hline 14 & 274,575 & 908,280 & 830,184 & 249070 & 21397 & 227673 & 0,914 & 10099 & 3342 & 6757 & 599 & 1247 & 641 & 855 \\
\hline 15 & 274,580 & 912,259 & 831,771 & 249973 & 22005 & 227968 & 0,912 & 10677 & 3467 & 7210 & 673 & 1242 & 645 & 907 \\
\hline Média & 5 & & & & & & 0,911 & 10722 & & & & & & \\
\hline
\end{tabular}

Tabela B. 5- Dados da execução do Modelo N com benchmark de cpu. 


\begin{tabular}{|c|c|c|c|c|c|c|c|c|c|c|c|c|c|c|}
\hline \multirow[b]{2}{*}{ Execução } & \multirow[b]{2}{*}{$\begin{array}{c}\text { Tempo } \\
\text { Total }\end{array}$} & \multirow{2}{*}{$\begin{array}{l}\text { Eventos } \\
\text { Processados } \\
\text { p/ segundo }\end{array}$} & \multirow[b]{2}{*}{$\begin{array}{l}\text { Realizados } \\
\text { p/ segundo }\end{array}$} & \multirow[b]{2}{*}{$\begin{array}{l}\text { Total Pro- } \\
\text { cessados }\end{array}$} & \multirow[b]{2}{*}{$\begin{array}{c}\text { Total Can- } \\
\text { celados }\end{array}$} & \multirow[b]{2}{*}{$\begin{array}{c}\text { Total Reali- } \\
\text { zados }\end{array}$} & \multicolumn{3}{|c|}{ Rollbacks } & \multicolumn{5}{|c|}{ Causados por: } \\
\hline & & & & & & & Eficiência & Total & Primários & Secundários & 0 & 1 & 2 & 3 \\
\hline 1 & 198,520 & 1221,223 & 1104,621 & 241605 & 23112 & 218493 & 0,904 & 11331 & 3544 & 7787 & 665 & 1686 & 579 & 614 \\
\hline 2 & 196,419 & 1227,149 & 1113,218 & 240184 & 22358 & 217826 & $\mathbf{0 , 9 0 7}$ & 10818 & 3561 & 7257 & 656 & 1638 & 634 & 633 \\
\hline 3 & 194,865 & 1221,215 & 1112,066 & 237432 & 21245 & 216187 & 0,911 & 10316 & 3330 & 6986 & 596 & 1497 & 647 & 590 \\
\hline 4 & 195,191 & 1221,116 & 1108,800 & 237902 & 21875 & 216027 & 0,908 & 10654 & 3439 & 7215 & 650 & 1606 & 615 & 568 \\
\hline 5 & 194,875 & 1229,704 & 1111,613 & 238553 & 22892 & 215661 & 0,904 & 11057 & 3563 & 7494 & 630 & 1680 & 626 & 627 \\
\hline 6 & 195,841 & 1221,372 & 1107,112 & 238258 & 22258 & 216000 & $\mathbf{0 , 9 0 7}$ & 10780 & 3534 & 7246 & 586 & 1708 & 637 & 603 \\
\hline 7 & 197,500 & 1223,005 & 1104,403 & 240907 & 23378 & 217529 & 0,903 & 11293 & 3563 & 7730 & 672 & 1639 & 603 & 649 \\
\hline 8 & 194,674 & 1223,926 & 1114,822 & 237398 & 21148 & 216250 & 0,911 & 10187 & 3299 & 6888 & 616 & 1541 & 589 & 553 \\
\hline 9 & 194,657 & 1221,246 & 1109,171 & 237405 & 21815 & 215590 & 0,908 & 10504 & 3475 & 7029 & 631 & 1517 & 683 & 644 \\
\hline 10 & 197,773 & 1219,819 & 1105,547 & 240486 & 22555 & 217931 & 0,906 & 10741 & 3522 & 7219 & 645 & 1571 & 660 & 646 \\
\hline 11 & 195,180 & 1222,479 & 1109,735 & 238088 & 21960 & 216128 & 0,908 & 10563 & 3439 & 7124 & 626 & 1538 & 646 & 629 \\
\hline 12 & 194,939 & 1227,430 & 1115,555 & 238477 & 21785 & 216692 & 0,909 & 10581 & 3531 & 7050 & 580 & 1646 & 673 & 632 \\
\hline 13 & 195,180 & 1221,502 & 1111,969 & 237918 & 21356 & 216562 & 0,910 & 10158 & 3396 & 6762 & 616 & 1541 & 648 & 591 \\
\hline 14 & 194,125 & 1230,432 & 1116,927 & 237904 & 21886 & 216018 & 0,908 & 10559 & 3613 & 6946 & 681 & 1677 & 620 & 635 \\
\hline 15 & 192,938 & 1228,796 & 1112,938 & 236294 & 22301 & 213993 & 0,906 & 10578 & 3410 & 7168 & 609 & 1571 & 611 & 619 \\
\hline Média & 195,512 & & & & & & 0,907 & 10675 & & & & & & \\
\hline
\end{tabular}

Tabela B. 6- Dados da execução do Modelo O com benchmark de cpu. 


\begin{tabular}{|c|c|c|c|c|c|c|c|c|c|c|c|c|c|c|}
\hline \multirow[b]{2}{*}{ Execução } & \multirow[b]{2}{*}{$\begin{array}{c}\text { Tempo } \\
\text { Total }\end{array}$} & \multicolumn{5}{|l|}{ Eventos } & \multicolumn{4}{|c|}{ Rollbacks } & \multicolumn{4}{|c|}{ Causados por: } \\
\hline & & $\begin{array}{c}\text { Processados } \\
\text { p/ segundo }\end{array}$ & $\begin{array}{l}\text { Realizados } \\
\text { p/ segundo }\end{array}$ & \begin{tabular}{|c} 
Total Pro- \\
cessados
\end{tabular} & \begin{tabular}{|c|} 
Total Can- \\
celados
\end{tabular} & $\begin{array}{c}\text { Total Rea- } \\
\text { lizados }\end{array}$ & Eficiência & Total & $\begin{array}{l}\text { Primá- } \\
\text { rios }\end{array}$ & Secundários & 0 & 1 & 2 & 3 \\
\hline 1 & 401,089 & 1185,582 & 1059,982 & 474898 & 50264 & 424634 & $\mathbf{0 , 8 9 4}$ & 18379 & 6626 & 11753 & 1277 & 2965 & 1311 & 1073 \\
\hline 2 & 402,284 & 1181,363 & 1055,380 & 475074 & 50664 & 424410 & $\mathbf{0 , 8 9 3}$ & 18667 & 6577 & 12090 & 1208 & 2987 & 1306 & 1076 \\
\hline 3 & 397,442 & 1186,267 & 1060,231 & 471137 & 50013 & 421124 & $\mathbf{0 , 8 9 4}$ & 18193 & 6654 & 11539 & 1309 & 2964 & 1324 & 1057 \\
\hline 4 & 397,989 & 1185,731 & 1058,720 & 471200 & 50462 & 420738 & $\mathbf{0 , 8 9 3}$ & 18379 & 6620 & 11759 & 1320 & 2929 & 1308 & 1063 \\
\hline 5 & 402,440 & 1183,898 & 1055,746 & 476201 & 51555 & 424646 & $\mathbf{0 , 8 9 2}$ & 18557 & 6625 & 11932 & 1330 & 2889 & 1289 & 1117 \\
\hline 6 & 395,923 & 1186,712 & 1063,558 & 469417 & 48638 & 420779 & 0,896 & 17607 & 6414 & 11193 & 1312 & 2839 & 1269 & 994 \\
\hline 7 & 401,014 & 1183,157 & 1057,026 & 473697 & 50425 & 423272 & $\mathbf{0 , 8 9 4}$ & 18199 & 6528 & 11671 & 1253 & 2845 & 1313 & 1117 \\
\hline 8 & 397,573 & 1186,885 & 1063,550 & 471285 & 49014 & 422271 & 0,896 & 17821 & 6471 & 11350 & 1245 & 2873 & 1303 & 1050 \\
\hline 9 & 400,502 & 1184,810 & 1057,375 & 474161 & 50964 & 423197 & $\mathbf{0 , 8 9 3}$ & 18590 & 6604 & 11986 & 1275 & 2889 & 1321 & 1119 \\
\hline 10 & 401,459 & 1182,958 & 1056,737 & 474324 & 50536 & 423788 & $\mathbf{0 , 8 9 3}$ & 18237 & 6589 & 11648 & 1220 & 2956 & 1307 & 1106 \\
\hline 11 & 403,683 & 1180,125 & 1051,797 & 475801 & 51744 & 424057 & $\mathbf{0 , 8 9 1}$ & 19089 & 6840 & 12249 & 1290 & 3053 & 1361 & 1136 \\
\hline 12 & 400,341 & 1185,668 & 1061,217 & 474104 & 49663 & 424441 & $\mathbf{0 , 8 9 5}$ & 18049 & 6384 & 11665 & 1262 & 2802 & 1255 & 1065 \\
\hline 13 & $\mathbf{3 9 8 , 8 3 3}$ & 1185,208 & 1060,571 & 471830 & 49512 & 422318 & $\mathbf{0 , 8 9 5}$ & 17927 & 6472 & 11455 & 1263 & 2859 & 1294 & 1056 \\
\hline 14 & 398,233 & 1186,291 & 1059,568 & 471383 & 50297 & 421086 & $\mathbf{0 , 8 9 3}$ & 18318 & 6530 & 11788 & 1245 & 2923 & 1287 & 1075 \\
\hline 15 & 399,928 & 1183,618 & 1054,976 & 472824 & 51366 & 421458 & 0,891 & 18483 & 6594 & 11889 & 1239 & 2885 & 1311 & 1159 \\
\hline Média & 399,916 & & & & & & 0,894 & 18300 & & & & & & \\
\hline
\end{tabular}

Tabela B. 7- Dados da execução do Modelo P com benchmark de cpu. 


\begin{tabular}{|c|c|c|c|c|c|c|c|c|c|c|c|c|c|c|}
\hline \multirow[b]{2}{*}{ Execução } & \multirow[b]{2}{*}{$\begin{array}{c}\text { Tempo } \\
\text { Total }\end{array}$} & \multirow{2}{*}{$\begin{array}{l}\text { Eventos } \\
\text { Processados } \\
\text { p/ segundo }\end{array}$} & \multirow[b]{2}{*}{$\begin{array}{l}\text { Realizados } \\
\text { p/ segundo }\end{array}$} & \multirow[b]{2}{*}{$\begin{array}{l}\text { Total Pro- } \\
\text { cessados }\end{array}$} & \multirow[b]{2}{*}{$\begin{array}{c}\text { Total Can- } \\
\text { celados }\end{array}$} & \multirow[b]{2}{*}{$\begin{array}{c}\text { Total Rea- } \\
\text { lizados }\end{array}$} & \multicolumn{3}{|c|}{ Rollbacks } & \multicolumn{5}{|c|}{ Causados por: } \\
\hline & & & & & & & Eficiência & Total & $\begin{array}{l}\text { Primá- } \\
\text { rios }\end{array}$ & Secundários & 0 & 1 & 2 & 3 \\
\hline 1 & 394,490 & 1210,819 & 1080,137 & 477241 & 51478 & 425763 & 0,892 & 18773 & 6806 & 11967 & 1370 & 2913 & 1302 & 1221 \\
\hline 2 & 397,862 & 1216,002 & 1076,558 & 483373 & 55450 & 427923 & $\mathbf{0 , 8 8 5}$ & 20299 & 7002 & 13297 & 1257 & 3184 & 1273 & 1288 \\
\hline 3 & 394,734 & 1212,290 & 1079,482 & 478021 & 52325 & 425696 & $\mathbf{0 , 8 9 1}$ & 18954 & 6742 & 12212 & 1274 & 2961 & 1325 & 1182 \\
\hline 4 & 396,389 & 1211,755 & 1077,545 & 480065 & 53113 & 426952 & $\mathbf{0 , 8 8 9}$ & 19386 & 6954 & 12432 & 1356 & 3015 & 1343 & 1240 \\
\hline 5 & 393,205 & 1212,186 & 1079,637 & 476192 & 52049 & 424143 & 0,891 & 18802 & 6766 & 12036 & 1314 & 2992 & 1370 & 1090 \\
\hline 6 & 395,354 & 1197,914 & 1076,356 & 473047 & 48048 & 424999 & $\mathbf{0 , 8 9 8}$ & 17398 & 6412 & 10986 & 1304 & 2545 & 1384 & 1179 \\
\hline 7 & 395,202 & 1194,789 & 1073,675 & 471469 & 47699 & 423770 & 0,899 & 17495 & 6498 & 10997 & 1280 & 2569 & 1318 & 1331 \\
\hline 8 & 396,197 & 1199,548 & 1075,780 & 474348 & 48963 & 425385 & $\mathbf{0 , 8 9 7}$ & 17979 & 6455 & 11524 & 1245 & 2690 & 1276 & 1244 \\
\hline 9 & $\mathbf{3 9 3 , 7 5 4}$ & 1198,794 & 1079,259 & 471292 & 47012 & 424280 & 0,900 & 17097 & 6395 & 10702 & 1243 & 2615 & 1263 & 1274 \\
\hline 10 & 393,799 & 1193,267 & 1075,547 & 469622 & 46334 & 423288 & 0,901 & 17008 & 6297 & 10711 & 1272 & 2469 & 1312 & 1244 \\
\hline 11 & $\mathbf{3 9 0 , 5 5 7}$ & 1208,901 & 1084,254 & 471313 & 48590 & 422723 & $\mathbf{0 , 8 9 7}$ & 17682 & 6467 & 11215 & 1245 & 2762 & 1261 & 1199 \\
\hline 12 & 395,276 & 1214,298 & 1076,410 & 479344 & 54468 & 424876 & 0,886 & 19965 & 6965 & 13000 & 1356 & 3055 & 1286 & 1268 \\
\hline 13 & $\mathbf{3 9 5 , 0 7 1}$ & 1207,642 & 1073,437 & 476546 & 52923 & 423623 & $\mathbf{0 , 8 8 9}$ & 19021 & 6815 & 12206 & 1334 & 2953 & 1318 & 1210 \\
\hline 14 & $\mathbf{3 9 3 , 5 4 5}$ & 1215,780 & 1078,828 & 477826 & 53770 & 424056 & $\mathbf{0 , 8 8 7}$ & 19599 & 6814 & 12785 & 1271 & 3036 & 1291 & 1216 \\
\hline 15 & 389,258 & 1213,574 & 1088,194 & 471540 & 48670 & 422870 & $\mathbf{0 , 8 9 7}$ & 17605 & 6333 & 11272 & 1241 & 2965 & 1306 & 821 \\
\hline Média & 394,313 & & & & & & 0,893 & 18471 & & & & & & \\
\hline
\end{tabular}

Tabela B. 8 - Dados da execução do Modelo Q com benchmark de cpu. 


\section{B.1.2. Modelos executados com benchmark de Memória}

\begin{tabular}{|c|c|c|c|c|c|c|c|c|c|c|c|c|c|c|}
\hline \multirow[b]{2}{*}{ Execução } & \multirow[b]{2}{*}{$\begin{array}{c}\text { Tempo } \\
\text { Total }\end{array}$} & \multicolumn{5}{|l|}{ Eventos } & \multicolumn{3}{|c|}{ Rollbacks } & \multicolumn{5}{|c|}{ Causados por: } \\
\hline & & $\begin{array}{l}\text { Processados } \\
\text { p/ segundo }\end{array}$ & $\begin{array}{l}\text { Realizados } \\
\text { p/ segundo }\end{array}$ & $\begin{array}{c}\text { Total Pro- } \\
\text { cessados }\end{array}$ & $\begin{array}{l}\text { Total Can- } \\
\text { celados }\end{array}$ & $\begin{array}{c}\text { Total Rea- } \\
\text { lizados }\end{array}$ & Eficiência & Total & $\begin{array}{c}\text { Primá- } \\
\text { rios }\end{array}$ & Secundários & 0 & 1 & 2 & 3 \\
\hline 1 & 557,130 & 1817,815 & 1039,746 & 1011724 & 432810 & 578914 & 0,572 & 197785 & 27505 & 170280 & 3464 & 16100 & 1463 & 6478 \\
\hline 2 & 564,003 & 1798,328 & 1009,212 & 1012269 & 443885 & 568384 & 0,561 & 203199 & 27744 & 175455 & 3791 & 16138 & 1514 & 6301 \\
\hline 3 & 557,486 & 1747,227 & 1012,881 & 972538 & 408522 & 564016 & 0,580 & 186781 & 26600 & 160181 & 3677 & 16654 & 1558 & 4711 \\
\hline 4 & 556,126 & 1789,893 & 1039,900 & 994098 & 416326 & 577772 & 0,581 & 189952 & 27054 & 162898 & 3482 & 16415 & 1550 & 5607 \\
\hline 5 & $\mathbf{5 5 7 , 8 7 5}$ & 1833,352 & 1036,974 & 1021320 & 443474 & 577846 & 0,566 & 202824 & 28379 & 174445 & 3693 & 16685 & 1531 & 6470 \\
\hline 6 & 558,151 & 1824,495 & 1047,508 & 1016920 & 432750 & 584170 & 0,574 & 198914 & 26913 & 172001 & 3169 & 15694 & 1431 & 6619 \\
\hline 7 & $\mathbf{5 5 6 , 8 7 7}$ & 1826,562 & 1032,880 & 1015948 & 441274 & 574674 & 0,566 & 202354 & 28176 & 174178 & 3672 & 16394 & 1532 & 6578 \\
\hline 8 & 560,542 & 1817,908 & 1032,929 & 1018010 & 439430 & 578580 & 0,568 & 201929 & 28420 & 173509 & 3694 & 16477 & 1545 & 6704 \\
\hline 9 & 561,123 & 1828,416 & 1039,606 & 1024647 & 441854 & 582793 & 0,569 & 202417 & 28485 & 173932 & 3682 & 16595 & 1573 & 6635 \\
\hline 10 & 555,843 & 1832,540 & 1040,490 & 1017124 & 439481 & 577643 & 0,568 & 201851 & 27863 & 173988 & 3469 & 16298 & 1513 & 6583 \\
\hline 11 & $\mathbf{5 5 8 , 5 1 5}$ & 1827,448 & 1037,780 & 1019182 & 440162 & 579020 & 0,568 & 200425 & 28030 & 172395 & 3469 & 16419 & 1562 & 6580 \\
\hline 12 & $\mathbf{5 5 9 , 4 5 2}$ & 1828,296 & 1035,518 & 1021826 & 442845 & 578981 & 0,567 & 202469 & 28277 & 174192 & 3726 & 16454 & 1595 & 6502 \\
\hline 13 & $\mathbf{5 5 7 , 0 4 5}$ & 1819,871 & 1032,054 & 1013041 & 438363 & 574678 & 0,567 & 200044 & 28378 & 171666 & 3862 & 16487 & 1563 & 6466 \\
\hline 14 & 558,486 & 1823,298 & 1034,462 & 1017516 & 440025 & 577491 & 0,568 & 202236 & 27743 & 174493 & 3534 & 16140 & 1530 & 6539 \\
\hline 15 & 812,657 & 1723,194 & 774,142 & 1399513 & 770592 & 628921 & 0,449 & 353555 & 42158 & 311397 & 8660 & 21650 & 1547 & 10301 \\
\hline Média & 575,421 & & & & & & 0,562 & 209782 & & & & & & \\
\hline
\end{tabular}




\begin{tabular}{|c|c|c|c|c|c|c|c|c|c|c|c|c|c|c|}
\hline \multirow[b]{2}{*}{ Execução } & \multirow[b]{2}{*}{$\begin{array}{c}\text { Tempo } \\
\text { Total }\end{array}$} & \multirow{2}{*}{$\begin{array}{l}\text { Eventos } \\
\text { Processados } \\
\text { p/ segundo }\end{array}$} & \multirow[b]{2}{*}{$\begin{array}{l}\text { Realizados } \\
\text { p/ segundo }\end{array}$} & \multirow[b]{2}{*}{$\begin{array}{l}\text { Total Pro- } \\
\text { cessados }\end{array}$} & \multirow[b]{2}{*}{$\begin{array}{c}\text { Total Can- } \\
\text { celados }\end{array}$} & \multirow[b]{2}{*}{$\begin{array}{c}\text { Total Rea- } \\
\text { lizados }\end{array}$} & \multicolumn{3}{|c|}{ Rollbacks } & \multicolumn{5}{|c|}{ Causados por: } \\
\hline & & & & & & & Eficiência & Total & $\begin{array}{l}\text { Primá- } \\
\text { rios }\end{array}$ & Secundários & 0 & 1 & 2 & 3 \\
\hline 1 & 1118,510 & 1794,838 & 930,755 & 2005951 & 965490 & 1040461 & 0,519 & 332247 & 51659 & 280588 & 8445 & 28263 & 2968 & 11983 \\
\hline 2 & 1117,160 & 1796,245 & 933,487 & 2005328 & 963143 & 1042185 & 0,520 & 330573 & 50998 & 279575 & 8273 & 27790 & 3069 & 11866 \\
\hline 3 & 1114,550 & 1792,256 & 933,159 & 1996192 & 956747 & 1039445 & 0,521 & 329150 & 51582 & 277568 & 8246 & 28306 & 2928 & 12102 \\
\hline 4 & 1112,920 & 1797,491 & 931,015 & 1999136 & 963547 & 1035589 & 0,518 & 330668 & 51676 & 278992 & 8374 & 28281 & 3050 & 11971 \\
\hline 5 & 1115,490 & 1796,744 & 931,859 & 2002724 & 963712 & 1039012 & 0,519 & 332975 & 51619 & 281356 & 8630 & 28085 & 2904 & 12000 \\
\hline 6 & 1113,390 & 1798,529 & 934,845 & 2000926 & 960616 & 1040310 & 0,520 & 329260 & 52098 & 277162 & 8504 & 28509 & 3084 & 12001 \\
\hline 7 & 1117,020 & 1792,533 & 926,021 & 2000882 & 967148 & 1033734 & $\mathbf{0 , 5 1 7}$ & 335184 & 52569 & 282615 & 8508 & 28762 & 3149 & 12150 \\
\hline 8 & $\mathbf{1 1 1 8 , 5 3 0}$ & 1794,240 & 931,063 & 2005697 & 964688 & 1041009 & 0,519 & 334146 & 51780 & 282366 & 8400 & 28194 & 3002 & 12184 \\
\hline 9 & 1114,760 & 1789,146 & 930,416 & 1992793 & 956370 & 1036423 & 0,520 & 329685 & 51993 & 277692 & 8421 & 28230 & 3071 & 12271 \\
\hline 10 & 1118,220 & 1795,757 & 929,823 & 2006487 & 967400 & 1039087 & 0,518 & 331388 & 51985 & 279403 & 8394 & 28120 & 3129 & 12342 \\
\hline 11 & 1112,090 & 1794,072 & 934,471 & 1993734 & 955040 & 1038694 & 0,521 & 328755 & 51076 & 277679 & 8371 & 27726 & 2988 & 11991 \\
\hline 12 & 1112,450 & 1797,018 & 933,304 & 1997653 & 959916 & 1037737 & 0,519 & 331821 & 51969 & 279852 & 8330 & 28386 & 3032 & 12221 \\
\hline 13 & 1120,640 & 1794,009 & 930,222 & 2008700 & 966804 & 1041896 & 0,519 & 333686 & 52042 & 281644 & 8067 & 28722 & 3128 & 12125 \\
\hline 14 & 1115,400 & 1796,012 & 929,067 & 2001844 & 966246 & 1035598 & 0,517 & 332689 & 52259 & 280430 & 8575 & 28529 & 2984 & 12171 \\
\hline 15 & 1116,670 & 1792,143 & 929,201 & 1999741 & 962817 & 1036924 & 0,519 & 332737 & 52281 & 280456 & 8307 & 28591 & 3115 & 12268 \\
\hline Média & 1115,853 & & & & & & 0,519 & 331664 & & & & & & \\
\hline
\end{tabular}

Tabela B. 10 - Dados da execução do Modelo G com benchmark de memória. 


\begin{tabular}{|c|c|c|c|c|c|c|c|c|c|c|c|c|c|c|}
\hline \multirow[b]{2}{*}{ Execução } & \multirow[b]{2}{*}{$\begin{array}{c}\text { Tempo } \\
\text { Total }\end{array}$} & \multicolumn{5}{|l|}{ Eventos } & \multicolumn{4}{|c|}{ Rollbacks } & \multicolumn{4}{|c|}{ Causados por: } \\
\hline & & $\begin{array}{c}\text { Processados } \\
\text { p/ segundo }\end{array}$ & $\begin{array}{l}\text { Realizados } \\
\text { p/ segundo }\end{array}$ & \begin{tabular}{|c} 
Total Pro- \\
cessados
\end{tabular} & \begin{tabular}{|c|} 
Total Can- \\
celados
\end{tabular} & $\begin{array}{c}\text { Total Rea- } \\
\text { lizados }\end{array}$ & Eficiência & Total & $\begin{array}{l}\text { Primá- } \\
\text { rios }\end{array}$ & Secundários & 0 & 1 & 2 & 3 \\
\hline 1 & 555,298 & 1330,759 & 858,317 & 738449 & 262058 & 476391 & 0,645 & 150969 & 19407 & 131562 & 1694 & 11705 & 1161 & 4847 \\
\hline 2 & 564,159 & 1328,602 & 854,553 & 749161 & 267218 & 481943 & 0,643 & 153478 & 19334 & 134144 & 1694 & 11696 & 1118 & 4826 \\
\hline 3 & 554,643 & 1334,575 & 861,442 & 739601 & 262152 & 477449 & 0,646 & 148982 & 18812 & 130170 & 1624 & 11267 & 1123 & 4798 \\
\hline 4 & 561,974 & 1325,793 & 851,301 & 744395 & 266331 & 478064 & 0,642 & 151633 & 19532 & 132101 & 1872 & 11622 & 1117 & 4921 \\
\hline 5 & $\mathbf{5 5 8 , 3 1 7}$ & 1325,303 & 855,758 & 738977 & 261713 & 477264 & 0,646 & 149413 & 19475 & 129938 & 1809 & 11538 & 1101 & 5027 \\
\hline 6 & $\mathbf{5 5 5 , 7 2 5}$ & 1320,074 & 856,615 & 732862 & 257094 & 475768 & 0,649 & 146377 & 19313 & 127064 & 1660 & 11645 & 1115 & 4893 \\
\hline 7 & 556,718 & 1326,268 & 863,621 & 737601 & 257157 & 480444 & 0,651 & 147184 & 18658 & 128526 & 1673 & 11087 & 1070 & 4828 \\
\hline 8 & 562,741 & 1324,564 & 847,713 & 743794 & 267616 & 476178 & 0,640 & 153166 & 19770 & 133396 & 1744 & 11736 & 1185 & 5105 \\
\hline 9 & 559,749 & 1325,788 & 858,350 & 741030 & 261166 & 479864 & 0,648 & 150166 & 19219 & 130947 & 1601 & 11715 & 1114 & 4789 \\
\hline 10 & 556,254 & 1324,757 & 857,005 & 736137 & 259844 & 476293 & 0,647 & 149014 & 19094 & 129920 & 1731 & 11514 & 1106 & 4743 \\
\hline 11 & $\mathbf{5 5 8 , 0 7 8}$ & 1327,403 & 861,024 & 739004 & 259493 & 479511 & 0,649 & 148605 & 19269 & 129336 & 1790 & 11516 & 1122 & 4841 \\
\hline 12 & 556,500 & 1327,091 & 863,184 & 737196 & 257472 & 479724 & 0,651 & 147360 & 18992 & 128368 & 1807 & 11395 & 1082 & 4708 \\
\hline 13 & 562,903 & 1320,286 & 854,263 & 742538 & 261970 & 480568 & 0,647 & 149756 & 19033 & 130723 & 1687 & 11329 & 1086 & 4931 \\
\hline 14 & 556,492 & 1325,593 & 859,369 & 735882 & 258573 & 477309 & 0,649 & 148316 & 18887 & 129429 & 1711 & 11192 & 1135 & 4849 \\
\hline 15 & 555,146 & 1326,039 & 858,261 & 735566 & 259386 & 476180 & 0,647 & 147973 & 18532 & 129441 & 1617 & 11197 & 1065 & 4653 \\
\hline Média & 558,313 & & & & & & 0,647 & 149493 & & & & & & \\
\hline
\end{tabular}




\begin{tabular}{|c|c|c|c|c|c|c|c|c|c|c|c|c|c|c|}
\hline \multirow[b]{2}{*}{ Execução } & \multirow[b]{2}{*}{$\begin{array}{c}\text { Tempo } \\
\text { Total }\end{array}$} & \multirow{2}{*}{$\begin{array}{l}\text { Eventos } \\
\text { Processados } \\
\text { p/ segundo }\end{array}$} & \multirow[b]{2}{*}{$\begin{array}{l}\text { Realizados } \\
\text { p/ segundo }\end{array}$} & \multirow[b]{2}{*}{$\begin{array}{l}\text { Total Pro- } \\
\text { cessados }\end{array}$} & \multirow[b]{2}{*}{$\begin{array}{c}\text { Total Can- } \\
\text { celados }\end{array}$} & \multirow[b]{2}{*}{$\begin{array}{c}\text { Total Rea- } \\
\text { lizados }\end{array}$} & \multicolumn{3}{|c|}{ Rollbacks } & \multicolumn{5}{|c|}{ Causados por: } \\
\hline & & & & & & & Eficiência & Total & $\begin{array}{l}\text { Primá- } \\
\text { rios }\end{array}$ & Secundários & 0 & 1 & 2 & 3 \\
\hline 1 & $\mathbf{5 5 5 , 5 8 6}$ & 1344,461 & 1178,517 & 745870 & 91994 & 653876 & $\mathbf{0 , 8 7 7}$ & 46798 & 5965 & 40833 & 537 & 4374 & 288 & 766 \\
\hline 2 & 560,370 & 1335,076 & 1177,069 & 747128 & 88324 & 658804 & $\mathbf{0 , 8 8 2}$ & 45712 & 5954 & 39758 & 505 & 4381 & 291 & 777 \\
\hline 3 & 564,909 & 1345,213 & 1188,287 & 758767 & 88416 & 670351 & $\mathbf{0 , 8 8 3}$ & 45496 & 5667 & 39829 & 507 & 4194 & 260 & 706 \\
\hline 4 & $\mathbf{5 6 5 , 0 3 5}$ & 1345,498 & 1176,917 & 759410 & 95138 & 664272 & $\mathbf{0 , 8 7 5}$ & 48883 & 6103 & 42780 & 513 & 4536 & 282 & 772 \\
\hline 5 & 563,371 & 1340,308 & 1173,624 & 754371 & 93743 & 660628 & 0,876 & 48309 & 6095 & 42214 & 557 & 4458 & 276 & 804 \\
\hline 6 & 566,675 & 1343,490 & 1177,997 & 759904 & 93513 & 666391 & $\mathbf{0 , 8 7 7}$ & 48169 & 6111 & 42058 & 564 & 4577 & 267 & 703 \\
\hline 7 & 563,185 & 1335,955 & 1174,134 & 751278 & 90933 & 660345 & 0,879 & 46835 & 6002 & 40833 & 526 & 4539 & 273 & 664 \\
\hline 8 & 561,370 & 1342,946 & 1176,225 & 753015 & 93423 & 659592 & 0,876 & 47508 & 6158 & 41350 & 545 & 4543 & 286 & 784 \\
\hline 9 & $\mathbf{5 5 9 , 4 1 7}$ & 1346,491 & 1181,703 & 752469 & 92053 & 660416 & 0,878 & 47518 & 6107 & 41411 & 532 & 4551 & 277 & 747 \\
\hline 10 & 560,788 & 1341,002 & 1180,630 & 751043 & 89742 & 661301 & $\mathbf{0 , 8 8 1}$ & 46486 & 5821 & 40665 & 532 & 4277 & 258 & 754 \\
\hline 11 & $\mathbf{5 6 0 , 5 3 7}$ & 1346,192 & 1178,567 & 753831 & 93836 & 659995 & 0,876 & 47582 & 5998 & 41584 & 476 & 4313 & 311 & 898 \\
\hline 12 & 560,942 & 1343,189 & 1178,791 & 751803 & 91954 & 659849 & 0,878 & 47224 & 5998 & 41226 & 527 & 4500 & 261 & 710 \\
\hline 13 & 562,418 & 1343,712 & 1184,065 & 755035 & 89640 & 665395 & 0,881 & 46166 & 5702 & 40464 & 489 & 4327 & 257 & 629 \\
\hline 14 & 570,174 & 1335,409 & 1175,159 & 760666 & 91240 & 669426 & $\mathbf{0 , 8 8 0}$ & 46931 & 6059 & 40872 & 553 & 4435 & 274 & 797 \\
\hline 15 & 559,253 & 1346,099 & 1181,937 & 751987 & 91613 & 660374 & 0,878 & 47242 & 6075 & 41167 & 543 & 4427 & 266 & 839 \\
\hline Média & 562,269 & & & & & & 0,878 & 47124 & & & & & & \\
\hline
\end{tabular}

Tabela B. 12 - Dados da execução do Modelo I com benchmark de memória. 


\section{B.1.3. Modelos executados com benchmark de Rede}

\begin{tabular}{|c|c|c|c|c|c|c|c|c|c|c|c|c|c|c|}
\hline \multirow[b]{2}{*}{ Execução } & \multirow[b]{2}{*}{$\begin{array}{c}\text { Tempo } \\
\text { Total }\end{array}$} & \multicolumn{5}{|l|}{ Eventos } & \multicolumn{3}{|c|}{ Rollbacks } & \multicolumn{5}{|c|}{ Causados por: } \\
\hline & & $\begin{array}{c}\text { Processados } \\
\text { p/ segundo }\end{array}$ & $\begin{array}{l}\text { Realizados } \\
\text { p/ segundo }\end{array}$ & $\begin{array}{c}\text { Total Pro- } \\
\text { cessados }\end{array}$ & $\begin{array}{c}\text { Total Can- } \\
\text { celados }\end{array}$ & $\begin{array}{c}\text { Total Rea- } \\
\text { lizados }\end{array}$ & Eficiência & Total & $\begin{array}{l}\text { Primá- } \\
\text { rios }\end{array}$ & Secundários & 0 & 1 & 2 & 3 \\
\hline 1 & 2,190 & 27971,380 & 23754,690 & 60221 & 9040 & 51181 & $\mathbf{0 , 8 5 0}$ & 4359 & 1105 & 3254 & 507 & 137 & 344 & 117 \\
\hline 2 & 2,191 & 27570,380 & 23424,160 & 59523 & 8909 & 50614 & $\mathbf{0 , 8 5 0}$ & 4313 & 1005 & 3308 & 464 & 107 & 316 & 118 \\
\hline 3 & 2,156 & 27889,380 & 24219,110 & 59117 & 7748 & 51369 & 0,869 & 3665 & 997 & 2668 & 476 & 125 & 306 & 90 \\
\hline 4 & 2,145 & 28018,400 & 23874,680 & 59643 & 8803 & 50840 & $\mathbf{0 , 8 5 2}$ & 4087 & 997 & 3090 & 434 & 116 & 335 & 112 \\
\hline 5 & 2,214 & 27815,730 & 23646,070 & 60106 & 8957 & 51149 & $\mathbf{0 , 8 5 1}$ & 4352 & 1055 & 3297 & 489 & 131 & 321 & 114 \\
\hline 6 & 2,188 & 27645,270 & 23383,250 & 59584 & 9176 & 50408 & 0,846 & 4399 & 1066 & 3333 & 467 & 126 & 373 & 100 \\
\hline 7 & 2,109 & 27614,490 & 24187,350 & 57337 & 7097 & 50240 & 0,876 & 3441 & 835 & 2606 & 423 & 101 & 220 & 91 \\
\hline 8 & 2,143 & 27431,860 & 23728,390 & 57990 & 7793 & 50197 & 0,866 & 3910 & 1024 & 2886 & 500 & 128 & 283 & 113 \\
\hline 9 & 2,175 & 27795,050 & 23875,800 & 59554 & 8335 & 51219 & 0,860 & 3939 & 1032 & 2907 & 458 & 125 & 353 & 96 \\
\hline 10 & 2,238 & 27664,320 & 23475,359 & 60586 & 9170 & 51416 & 0,849 & 4480 & 1108 & 3372 & 534 & 119 & 348 & 107 \\
\hline 11 & 2,142 & 27965,640 & 23872,780 & 59037 & 8588 & 50449 & $\mathbf{0 , 8 5 5}$ & 4091 & 984 & 3107 & 431 & 126 & 320 & 107 \\
\hline 12 & 2,120 & 28019,190 & 24252,580 & 58517 & 7831 & 50686 & 0,866 & 3832 & 932 & 2900 & 432 & 111 & 285 & 104 \\
\hline 13 & 2,133 & 27788,690 & 24125,490 & 58098 & 7633 & 50465 & 0,869 & 3628 & 1005 & 2623 & 491 & 123 & 279 & 112 \\
\hline 14 & 2,222 & 27611,370 & 23507,140 & 60751 & 8994 & 51757 & $\mathbf{0 , 8 5 2}$ & 4244 & 1025 & 3219 & 464 & 130 & 318 & 113 \\
\hline 15 & 2,136 & 28118,500 & 24071,670 & 59000 & 8465 & 50535 & $\mathbf{0 , 8 5 7}$ & 4049 & 995 & 3054 & 445 & 107 & 359 & 84 \\
\hline Média & 2,167 & & & & & & 0,858 & 4053 & & & & & & \\
\hline
\end{tabular}

Tabela B. 13 - Dados da execução do Modelo A com benchmark de rede. 


\begin{tabular}{|c|c|c|c|c|c|c|c|c|c|c|c|c|c|c|}
\hline \multirow[b]{2}{*}{ Execução } & \multirow[b]{2}{*}{$\begin{array}{c}\text { Tempo } \\
\text { Total }\end{array}$} & \multirow{2}{*}{$\begin{array}{l}\text { Eventos } \\
\text { Processados } \\
\text { p/ segundo }\end{array}$} & \multirow[b]{2}{*}{$\begin{array}{l}\text { Realizados } \\
\text { p/ segundo }\end{array}$} & \multirow[b]{2}{*}{$\begin{array}{l}\text { Total Pro- } \\
\text { cessados }\end{array}$} & \multirow[b]{2}{*}{\begin{tabular}{|} 
Total Can- \\
celados
\end{tabular}} & \multirow[b]{2}{*}{$\begin{array}{c}\text { Total Rea- } \\
\text { lizados }\end{array}$} & \multicolumn{3}{|c|}{ Rollbacks } & \multicolumn{5}{|c|}{ Causados por: } \\
\hline & & & & & & & Eficiência & Total & $\begin{array}{l}\text { Primá- } \\
\text { rios }\end{array}$ & Secundários & 0 & 1 & 2 & 3 \\
\hline 1 & 4,217 & 26602,860 & 21782,550 & 111582 & 20215 & 91367 & 0,819 & 7098 & 1751 & 5347 & 869 & 169 & 552 & 161 \\
\hline 2 & 4,221 & 26753,350 & 22065,021 & 112080 & 19589 & 92491 & $\mathbf{0 , 8 2 5}$ & 7096 & 1866 & 5230 & 892 & 206 & 616 & 152 \\
\hline 3 & 4,280 & 26476,300 & 22051,740 & 113008 & 18910 & 94098 & $\mathbf{0 , 8 3 3}$ & 6863 & 1732 & 5131 & 772 & 213 & 588 & 159 \\
\hline 4 & 4,174 & 26914,170 & 22363,390 & 111526 & 18775 & 92751 & $\mathbf{0 , 8 3 2}$ & 6613 & 1611 & 5002 & 758 & 161 & 562 & 130 \\
\hline 5 & 4,139 & 26737,090 & 22524,840 & 109905 & 17335 & 92570 & $\mathbf{0 , 8 4 2}$ & 6046 & 1663 & 4383 & 811 & 163 & 542 & 147 \\
\hline 6 & 4,123 & 26877,050 & 22841,310 & 110262 & 16584 & 93678 & $\mathbf{0 , 8 5 0}$ & 6098 & 1692 & 4406 & 814 & 159 & 575 & 144 \\
\hline 7 & 4,234 & 26611,810 & 22351,670 & 111638 & 17820 & 93818 & 0,840 & 6411 & 1776 & 4635 & 811 & 205 & 592 & 168 \\
\hline 8 & 4,086 & 26744,730 & 22256,220 & 108431 & 18120 & 90311 & $\mathbf{0 , 8 3 3}$ & 6401 & 1609 & 4792 & 854 & 147 & 443 & 165 \\
\hline 9 & 4,264 & 26719,390 & 21721,150 & 113398 & 21234 & 92164 & 0,813 & 7458 & 1827 & 5631 & 841 & 181 & 644 & 161 \\
\hline 10 & 4,213 & 26670,459 & 22170,050 & 111481 & 18804 & 92677 & $\mathbf{0 , 8 3 1}$ & 6797 & 1709 & 5088 & 780 & 190 & 597 & 142 \\
\hline 11 & 4,202 & 26574,860 & 22346,710 & 110989 & 17646 & 93343 & $\mathbf{0 , 8 4 1}$ & 6407 & 1800 & 4607 & 869 & 225 & 554 & 152 \\
\hline 12 & 4,194 & 26705,520 & 22305,250 & 111804 & 18452 & 93352 & $\mathbf{0 , 8 3 5}$ & 6866 & 1760 & 5106 & 818 & 183 & 607 & 152 \\
\hline 13 & 4,182 & 26831,360 & 22501,960 & 111084 & 17906 & 93178 & $\mathbf{0 , 8 3 9}$ & 6270 & 1656 & 4614 & 776 & 182 & 561 & 137 \\
\hline 14 & 4,356 & 26567,860 & 21810,510 & 114856 & 20573 & 94283 & 0,821 & 7404 & 1912 & 5492 & 871 & 232 & 642 & 167 \\
\hline 15 & 4,252 & 26682,450 & 21948,450 & 112829 & 19956 & 92873 & 0,823 & 6885 & 1806 & 5079 & 803 & 235 & 628 & 140 \\
\hline Média & 4,209 & & & & & & 0,832 & 6714 & & & & & & \\
\hline
\end{tabular}

Tabela B. 14 - Dados da execução do Modelo B com benchmark de rede. 


\begin{tabular}{|c|c|c|c|c|c|c|c|c|c|c|c|c|c|c|}
\hline \multirow[b]{2}{*}{ Execução } & \multicolumn{6}{|c|}{ Eventos } & \multicolumn{4}{|c|}{ Rollbacks } & \multicolumn{4}{|c|}{ Causados por: } \\
\hline & $\begin{array}{c}\text { Tempo } \\
\text { Total }\end{array}$ & $\begin{array}{c}\text { Processados } \\
\text { p/ segundo }\end{array}$ & $\begin{array}{l}\text { Realizados } \\
\text { p/ segundo }\end{array}$ & \begin{tabular}{|c|} 
Total Pro- \\
cessados
\end{tabular} & \begin{tabular}{|c|} 
Total Can- \\
celados
\end{tabular} & $\begin{array}{c}\text { Total Rea- } \\
\text { lizados }\end{array}$ & Eficiência & Total & $\begin{array}{l}\text { Primá- } \\
\text { rios }\end{array}$ & Secundários & 0 & 1 & 2 & 3 \\
\hline 1 & 71,933 & 3071,876 & 3032,048 & 220339 & 2851 & 217488 & 0,987 & 1494 & 813 & 681 & 131 & 135 & 341 & 206 \\
\hline 2 & 71,239 & 3065,302 & 3040,412 & 217662 & 1770 & 215892 & 0,992 & 963 & 594 & 369 & 93 & 65 & 296 & 140 \\
\hline 3 & 70,680 & 3085,925 & 3055,508 & 217352 & 2144 & 215208 & 0,990 & 1153 & 718 & 435 & 132 & 77 & 339 & 170 \\
\hline 4 & 71,178 & 3076,339 & 3044,426 & 218145 & 2263 & 215882 & 0,990 & 1180 & 736 & 444 & 107 & 124 & 330 & 175 \\
\hline 5 & 71,045 & 3075,291 & 3046,308 & 218228 & 2058 & 216170 & 0,991 & 1085 & 663 & 422 & 89 & 98 & 345 & 131 \\
\hline 6 & 70,606 & 3077,432 & 3049,650 & 216849 & 1961 & 214888 & 0,991 & 1012 & 621 & 391 & 68 & 107 & 298 & 148 \\
\hline 7 & 71,043 & 3070,266 & 3043,026 & 217490 & 1928 & 215562 & 0,991 & 1031 & 650 & 381 & 70 & 97 & 326 & 157 \\
\hline 8 & 71,094 & 3071,120 & 3040,178 & 217693 & 2195 & 215498 & 0,990 & 1194 & 736 & 458 & 111 & 112 & 341 & 172 \\
\hline 9 & 71,114 & 3077,215 & 3042,756 & 218197 & 2444 & 215753 & 0,989 & 1289 & 753 & 536 & 119 & 85 & 332 & 217 \\
\hline 10 & 71,050 & 3070,259 & 3035,543 & 217542 & 2459 & 215083 & 0,989 & 1307 & 795 & 512 & 129 & 122 & 318 & 226 \\
\hline 11 & 70,876 & 3090,461 & 3062,409 & 218579 & 1982 & 216597 & 0,991 & 1100 & 646 & 454 & 94 & 89 & 270 & 193 \\
\hline 12 & 71,064 & 3074,091 & 3045,134 & 218016 & 2049 & 215967 & 0,991 & 1153 & 722 & 431 & 90 & 124 & 306 & 202 \\
\hline 13 & 71,754 & 3069,993 & 3041,656 & 219772 & 2027 & 217745 & 0,991 & 1086 & 674 & 412 & 97 & 86 & 344 & 147 \\
\hline 14 & 72,043 & 3077,074 & 3036,159 & 221208 & 2945 & 218263 & 0,987 & 1547 & 896 & 651 & 157 & 129 & 345 & 265 \\
\hline 15 & 71,460 & 3073,858 & 3043,560 & 219162 & 2163 & 216999 & 0,990 & 1170 & 742 & 428 & 100 & 110 & 357 & 175 \\
\hline Média & 71,212 & & & & & & 0,990 & 1184 & & & & & & \\
\hline
\end{tabular}




\begin{tabular}{|c|c|c|c|c|c|c|c|c|c|c|c|c|c|c|}
\hline \multirow[b]{2}{*}{ Execução } & \multirow[b]{2}{*}{$\begin{array}{c}\text { Tempo } \\
\text { Total }\end{array}$} & \multirow{2}{*}{$\begin{array}{l}\text { Eventos } \\
\text { Processados } \\
\text { p/ segundo }\end{array}$} & \multirow[b]{2}{*}{$\begin{array}{l}\text { Realizados } \\
\text { p/ segundo }\end{array}$} & \multirow[b]{2}{*}{$\begin{array}{l}\text { Total Pro- } \\
\text { cessados }\end{array}$} & \multirow[b]{2}{*}{\begin{tabular}{|} 
Total Can- \\
celados
\end{tabular}} & \multirow[b]{2}{*}{$\begin{array}{c}\text { Total Rea- } \\
\text { lizados }\end{array}$} & \multicolumn{3}{|c|}{ Rollbacks } & \multicolumn{5}{|c|}{ Causados por: } \\
\hline & & & & & & & Eficiência & Total & $\begin{array}{c}\text { Primá- } \\
\text { rios }\end{array}$ & Secundários & 0 & 1 & 2 & 3 \\
\hline 1 & 148,194 & 2974,238 & 2902,967 & 440355 & 10558 & 429797 & 0,976 & 3948 & 1968 & 1980 & 337 & 436 & 931 & 264 \\
\hline 2 & 149,610 & 2972,011 & 2898,630 & 443998 & 10962 & 433036 & $\mathbf{0 , 9 7 5}$ & 4173 & 2061 & 2112 & 398 & 447 & 886 & 330 \\
\hline 3 & 148,078 & 2977,917 & 2911,952 & 440534 & 9755 & 430779 & 0,978 & 3830 & 1973 & 1857 & 379 & 391 & 875 & 328 \\
\hline 4 & 148,453 & 2979,188 & 2911,452 & 441747 & 10044 & 431703 & $\mathbf{0 , 9 7 7}$ & 3908 & 1941 & 1967 & 408 & 392 & 867 & 274 \\
\hline 5 & 150,634 & 2968,276 & 2879,315 & 446790 & 13398 & 433392 & 0,970 & 5049 & 2362 & 2687 & 491 & 530 & 1005 & 336 \\
\hline 6 & 148,352 & 2982,333 & 2910,129 & 441853 & 10711 & 431142 & 0,976 & 4121 & 2071 & 2050 & 365 & 445 & 861 & 400 \\
\hline 7 & 148,147 & 2971,643 & 2903,020 & 439334 & 10161 & 429173 & $\mathbf{0 , 9 7 7}$ & 3886 & 2012 & 1874 & 409 & 376 & 899 & 328 \\
\hline 8 & 148,223 & 2982,026 & 2914,917 & 440949 & 9940 & 431009 & $\mathbf{0 , 9 7 7}$ & 3849 & 1974 & 1875 & 391 & 402 & 815 & 366 \\
\hline 9 & 149,988 & 2966,750 & 2892,567 & 444105 & 11110 & 432995 & 0,975 & 4296 & 2026 & 2270 & 423 & 438 & 867 & 298 \\
\hline 10 & 148,991 & 2979,895 & 2903,255 & 443131 & 11403 & 431728 & $\mathbf{0 , 9 7 4}$ & 4275 & 2127 & 2148 & 432 & 430 & 907 & 358 \\
\hline 11 & $\mathbf{1 5 0 , 5 3 5}$ & 2972,496 & 2891,902 & 446120 & 12106 & 434014 & 0,973 & 4672 & 2241 & 2431 & 480 & 470 & 903 & 388 \\
\hline 12 & 148,694 & 2978,950 & 2907,058 & 442355 & 10681 & 431674 & 0,976 & 4108 & 2007 & 2101 & 416 & 407 & 886 & 298 \\
\hline 13 & 149,791 & 2972,858 & 2893,786 & 444853 & 11838 & 433015 & 0,973 & 4578 & 2199 & 2379 & 453 & 474 & 921 & 351 \\
\hline 14 & 148,842 & 2978,051 & 2903,719 & 442621 & 11031 & 431590 & 0,975 & 4190 & 2070 & 2120 & 369 & 467 & 905 & 329 \\
\hline 15 & 149,698 & 2977,901 & 2902,588 & 445606 & 11268 & 434338 & 0,975 & 4291 & 2126 & 2165 & 442 & 458 & 915 & 311 \\
\hline Média & 149,082 & & & & & & 0,975 & 4212 & & & & & & \\
\hline
\end{tabular}

Tabela B. 16 - Dados da execução do Modelo D com benchmark de rede. 


\begin{tabular}{|c|c|c|c|c|c|c|c|c|c|c|c|c|c|c|}
\hline \multirow[b]{2}{*}{ Execução } & \multirow[b]{2}{*}{$\begin{array}{c}\text { Tempo } \\
\text { Total }\end{array}$} & \multicolumn{5}{|l|}{ Eventos } & \multicolumn{4}{|c|}{ Rollbacks } & \multicolumn{4}{|c|}{ Causados por: } \\
\hline & & $\begin{array}{c}\text { Processados } \\
\text { p/ segundo }\end{array}$ & $\begin{array}{l}\text { Realizados } \\
\text { p/ segundo }\end{array}$ & \begin{tabular}{|c} 
Total Pro- \\
cessados
\end{tabular} & \begin{tabular}{|c|} 
Total Can- \\
celados
\end{tabular} & $\begin{array}{c}\text { Total Rea- } \\
\text { lizados }\end{array}$ & Eficiência & Total & $\begin{array}{l}\text { Primá- } \\
\text { rios }\end{array}$ & Secundários & 0 & 1 & 2 & 3 \\
\hline 1 & 149,197 & 2969,896 & 2887,657 & 441792 & 12243 & 429549 & 0,972 & 4582 & 2546 & 2036 & 560 & 551 & 1022 & 413 \\
\hline 2 & 149,573 & 2966,669 & 2875,828 & 442980 & 13579 & 429401 & 0,969 & 4980 & 2637 & 2343 & 598 & 649 & 1056 & 334 \\
\hline 3 & 148,843 & 2964,972 & 2891,317 & 440740 & 10963 & 429777 & 0,975 & 4094 & 2260 & 1834 & 532 & 469 & 1043 & 216 \\
\hline 4 & 149,666 & 2970,367 & 2876,819 & 443598 & 13993 & 429605 & 0,968 & 5170 & 2717 & 2453 & 583 & 686 & 1133 & 315 \\
\hline 5 & 149,503 & 2968,710 & 2880,197 & 442529 & 13211 & 429318 & 0,970 & 5024 & 2620 & 2404 & 540 & 682 & 998 & 400 \\
\hline 6 & 149,939 & 2970,853 & 2874,113 & 444748 & 14484 & 430264 & 0,967 & 5392 & 2816 & 2576 & 620 & 697 & 1133 & 366 \\
\hline 7 & 149,098 & 2972,608 & 2886,055 & 442977 & 12904 & 430073 & $\mathbf{0 , 9 7 1}$ & 4825 & 2520 & 2305 & 599 & 554 & 1052 & 315 \\
\hline 8 & 149,260 & 2961,994 & 2879,665 & 441412 & 12264 & 429148 & $\mathbf{0 , 9 7 2}$ & 4561 & 2483 & 2078 & 548 & 541 & 1072 & 322 \\
\hline 9 & 148,776 & 2969,446 & 2881,453 & 440809 & 13068 & 427741 & 0,970 & 4801 & 2599 & 2202 & 602 & 568 & 1097 & 332 \\
\hline 10 & 148,989 & 2971,308 & 2889,483 & 441562 & 12175 & 429387 & 0,972 & 4562 & 2532 & 2030 & 545 & 524 & 1126 & 337 \\
\hline 11 & 149,770 & 2966,854 & 2880,863 & 443749 & 12875 & 430874 & 0,971 & 4857 & 2609 & 2248 & 561 & 569 & 1098 & 381 \\
\hline 12 & 150,487 & 2956,481 & 2867,455 & 444115 & 13370 & 430745 & $\mathbf{0 , 9 7 0}$ & 4949 & 2544 & 2405 & 624 & 544 & 1037 & 339 \\
\hline 13 & 148,449 & 2969,643 & 2887,466 & 440256 & 12172 & 428084 & 0,972 & 4519 & 2512 & 2007 & 588 & 517 & 1064 & 343 \\
\hline 14 & 150,441 & 2963,605 & 2864,746 & 444815 & 14843 & 429972 & 0,967 & 5481 & 2884 & 2597 & 627 & 662 & 1155 & 440 \\
\hline 15 & 148,803 & 2972,409 & 2887,265 & 441201 & 12650 & 428551 & 0,971 & 4672 & 2491 & 2181 & 528 & 540 & 1048 & 375 \\
\hline Média & 149,386 & & & & & & 0,971 & 4831 & & & & & & \\
\hline
\end{tabular}

Tabela B. 17 - Dados da execução do Modelo E com benchmark de rede. 


\begin{tabular}{|c|c|c|c|c|c|c|c|c|c|c|c|c|c|c|}
\hline \multirow[b]{2}{*}{ Execução } & \multirow[b]{2}{*}{$\begin{array}{c}\text { Tempo } \\
\text { Total }\end{array}$} & \multirow{2}{*}{$\begin{array}{l}\text { Eventos } \\
\text { Processados } \\
\text { p/ segundo }\end{array}$} & \multirow[b]{2}{*}{$\begin{array}{l}\text { Realizados } \\
\text { p/ segundo }\end{array}$} & \multirow[b]{2}{*}{$\begin{array}{l}\text { Total Pro- } \\
\text { cessados }\end{array}$} & \multirow[b]{2}{*}{$\begin{array}{c}\text { Total Can- } \\
\text { celados }\end{array}$} & \multirow[b]{2}{*}{$\begin{array}{c}\text { Total Rea- } \\
\text { lizados }\end{array}$} & \multicolumn{3}{|c|}{ Rollbacks } & \multicolumn{5}{|c|}{ Causados por: } \\
\hline & & & & & & & Eficiência & Total & $\begin{array}{l}\text { Primá- } \\
\text { rios }\end{array}$ & Secundários & 0 & 1 & 2 & 3 \\
\hline 1 & $\mathbf{5 7 0 , 8 8 5}$ & 1508,555 & 1489,415 & 860622 & 10925 & 849697 & 0,987 & 4229 & 2226 & 2003 & 754 & 293 & 1058 & 121 \\
\hline 2 & 569,163 & 1510,659 & 1492,564 & 859262 & 10298 & 848964 & $\mathbf{0 , 9 8 8}$ & 4058 & 2217 & 1841 & 708 & 250 & 1114 & 145 \\
\hline 3 & $\mathbf{5 6 8 , 8 9 3}$ & 1509,249 & 1488,733 & 858391 & 11669 & 846722 & $\mathbf{0 , 9 8 6}$ & 4525 & 2392 & 2133 & 810 & 349 & 1063 & 170 \\
\hline 4 & $\mathbf{5 7 1 , 7 9 3}$ & 1508,695 & 1490,032 & 862116 & 10670 & 851446 & $\mathbf{0 , 9 8 8}$ & 4127 & 2205 & 1922 & 707 & 302 & 1045 & 151 \\
\hline 5 & $\mathbf{5 7 1 , 7 2 8}$ & 1512,348 & 1491,876 & 863584 & 11702 & 851882 & $\mathbf{0 , 9 8 6}$ & 4458 & 2289 & 2169 & 800 & 249 & 1134 & 106 \\
\hline 6 & 571,231 & 1514,601 & 1493,050 & 864495 & 12309 & 852186 & 0,986 & 4739 & 2401 & 2338 & 833 & 267 & 1191 & 110 \\
\hline 7 & 571,361 & 1512,473 & 1493,965 & 863505 & 10574 & 852931 & 0,988 & 4186 & 2247 & 1939 & 695 & 297 & 1142 & 113 \\
\hline 8 & 567,469 & 1510,991 & 1493,820 & 856730 & 9743 & 846987 & 0,989 & 3810 & 2057 & 1753 & 644 & 272 & 1040 & 101 \\
\hline 9 & 568,700 & 1510,584 & 1492,885 & 858517 & 10064 & 848453 & 0,988 & 4020 & 2111 & 1909 & 673 & 277 & 1033 & 128 \\
\hline 10 & 569,824 & 1508,779 & 1489,855 & 858621 & 10781 & 847840 & $\mathbf{0 , 9 8 7}$ & 4215 & 2245 & 1970 & 731 & 299 & 1104 & 111 \\
\hline 11 & 566,996 & 1515,242 & 1496,444 & 858606 & 10658 & 847948 & $\mathbf{0 , 9 8 8}$ & 4138 & 2171 & 1967 & 744 & 238 & 1074 & 115 \\
\hline 12 & 571,169 & 1513,857 & 1494,891 & 864026 & 10831 & 853195 & 0,987 & 4316 & 2267 & 2049 & 757 & 276 & 1104 & 130 \\
\hline 13 & $\mathbf{5 6 8 , 3 7 6}$ & 1509,163 & 1492,696 & 857013 & 9358 & 847655 & 0,989 & 3686 & 2081 & 1605 & 650 & 259 & 1058 & 114 \\
\hline 14 & 569,000 & 1511,929 & 1492,586 & 860152 & 11004 & 849148 & 0,987 & 4263 & 2276 & 1987 & 751 & 244 & 1107 & 174 \\
\hline 15 & 570,604 & 1510,884 & 1491,674 & 861543 & 10958 & 850585 & 0,987 & 4353 & 2326 & 2027 & 754 & 258 & 1164 & 150 \\
\hline Média & 569,813 & & & & & & 0,987 & 4208 & & & & & & \\
\hline
\end{tabular}

Tabela B. 18 - Dados da execução do Modelo G com benchmark de rede. 


\section{B.1.4. Modelos executados com Round Robin}

\begin{tabular}{|c|c|c|c|c|c|c|c|c|c|c|c|c|c|c|}
\hline \multirow[b]{2}{*}{ Execução } & \multirow[b]{2}{*}{$\begin{array}{c}\text { Tempo } \\
\text { Total }\end{array}$} & \multicolumn{5}{|l|}{ Eventos } & \multicolumn{4}{|c|}{ Rollbacks } & \multicolumn{4}{|c|}{ Causados por: } \\
\hline & & $\begin{array}{c}\text { Processados } \\
\text { p/ segundo }\end{array}$ & $\begin{array}{l}\text { Realizados } \\
\text { p/ segundo }\end{array}$ & \begin{tabular}{|c|} 
Total Pro- \\
cessados
\end{tabular} & $\begin{array}{l}\text { Total Can- } \\
\text { celados }\end{array}$ & $\begin{array}{l}\text { Total Rea- } \\
\text { lizados }\end{array}$ & Eficiência & Total & $\begin{array}{l}\text { Primá- } \\
\text { rios }\end{array}$ & Secundários & 0 & 1 & 2 & 3 \\
\hline 1 & 2,738 & 25767,901 & 18582,410 & 69580 & 19315 & 50265 & 0,722 & 9150 & 1866 & 7284 & 914 & 159 & 615 & 178 \\
\hline 2 & 2,586 & 26227,830 & 18930,050 & 67449 & 18772 & 48677 & 0,722 & 8856 & 1722 & 7134 & 902 & 151 & 537 & 132 \\
\hline 3 & 2,644 & 26054,910 & 18956,660 & 67985 & 18447 & 49538 & 0,729 & 8752 & 1701 & 7051 & 861 & 139 & 534 & 167 \\
\hline 4 & 2,612 & 25796,939 & 18470,320 & 67166 & 19099 & 48067 & 0,716 & 8735 & 1717 & 7018 & 838 & 147 & 569 & 163 \\
\hline 5 & 2,674 & 25899,610 & 18773,100 & 67632 & 18555 & 49077 & 0,726 & 8554 & 1688 & 6866 & 817 & 159 & 578 & 134 \\
\hline 6 & 2,583 & 25833,610 & 18683,390 & 66411 & 18384 & 48027 & 0,723 & 8500 & 1749 & 6751 & 873 & 152 & 558 & 166 \\
\hline 7 & 2,605 & 25704,040 & 18385,410 & 66568 & 18956 & 47612 & 0,715 & 8742 & 1744 & 6998 & 941 & 152 & 495 & 156 \\
\hline 8 & 2,588 & 26095,560 & 18630,140 & 67026 & 19217 & 47809 & 0,713 & 9108 & 1812 & 7296 & 949 & 146 & 565 & 152 \\
\hline 9 & 2,659 & 25945,360 & 18511,690 & 68744 & 19695 & 49049 & 0,714 & 9176 & 1855 & 7321 & 931 & 182 & 602 & 140 \\
\hline 10 & 2,606 & 25797,200 & 18521,600 & 66812 & 18826 & 47986 & 0,718 & 8886 & 1803 & 7083 & 931 & 156 & 560 & 156 \\
\hline 11 & 2,840 & 25702,220 & 18200,300 & 71793 & 20829 & 50964 & 0,710 & 9808 & 1872 & 7936 & 965 & 167 & 570 & 170 \\
\hline 12 & 2,702 & 25693,400 & 18383,230 & 69049 & 19684 & 49365 & 0,715 & 9376 & 1905 & 7471 & 930 & 148 & 658 & 169 \\
\hline 13 & 2,675 & 25785,750 & 18718,720 & 68508 & 18828 & 49680 & 0,725 & 8965 & 1723 & 7242 & 901 & 156 & 526 & 140 \\
\hline 14 & 2,624 & 26409,720 & 18987,140 & 68011 & 19051 & 48960 & 0,720 & 8789 & 1748 & 7041 & 872 & 137 & 590 & 149 \\
\hline 15 & 2,718 & 25879,130 & 18574,100 & 69722 & 19711 & 50011 & 0,717 & 9112 & 1864 & 7248 & 918 & 161 & 603 & 182 \\
\hline Média & 2,657 & & & & & & 0,719 & 8967 & & & & & & \\
\hline
\end{tabular}

Tabela B. 19 - Dados da execução do Modelo A com Round Robin. 


\begin{tabular}{|c|c|c|c|c|c|c|c|c|c|c|c|c|c|c|}
\hline \multirow[b]{2}{*}{ Execução } & \multirow[b]{2}{*}{$\begin{array}{c}\text { Tempo } \\
\text { Total }\end{array}$} & \multirow{2}{*}{$\begin{array}{l}\text { Eventos } \\
\text { Processados } \\
\text { p/ segundo }\end{array}$} & \multirow[b]{2}{*}{$\begin{array}{l}\text { Realizados } \\
\text { p/ segundo }\end{array}$} & \multirow[b]{2}{*}{$\begin{array}{l}\text { Total Pro- } \\
\text { cessados }\end{array}$} & \multirow[b]{2}{*}{\begin{tabular}{|c} 
Total Can- \\
celados
\end{tabular}} & \multirow[b]{2}{*}{$\begin{array}{c}\text { Total Rea- } \\
\text { lizados }\end{array}$} & \multicolumn{3}{|c|}{ Rollbacks } & \multicolumn{5}{|c|}{ Causados por: } \\
\hline & & & & & & & Eficiência & Total & $\begin{array}{l}\text { Primá- } \\
\text { rios }\end{array}$ & Secundários & 0 & 1 & 2 & 3 \\
\hline 1 & $\mathbf{5 , 5 4 1}$ & 25254,500 & 17117,720 & 138609 & 44645 & 93964 & 0,678 & 15570 & 3438 & 12132 & 1694 & 321 & 1149 & 274 \\
\hline 2 & 5,640 & 24954,720 & 16870,590 & 140230 & 45382 & 94848 & 0,676 & 15803 & 3404 & 12399 & 1689 & 320 & 1112 & 283 \\
\hline 3 & 5,655 & 24750,040 & 16593,950 & 139505 & 45947 & 93558 & 0,671 & 15965 & 3444 & 12521 & 1699 & 330 & 1118 & 297 \\
\hline 4 & 5,396 & 24791,050 & 17115,560 & 133119 & 41213 & 91906 & $\mathbf{0 , 6 9 0}$ & 14623 & 3158 & 11465 & 1589 & 283 & 1013 & 273 \\
\hline 5 & 5,498 & 24709,010 & 17172,660 & 135289 & 41298 & 93991 & 0,695 & 14216 & 3152 & 11064 & 1525 & 310 & 1034 & 283 \\
\hline 6 & $\mathbf{5 , 5 8 2}$ & 24820,530 & 16884,820 & 138020 & 44153 & 93867 & 0,680 & 15537 & 3442 & 12095 & 1708 & 329 & 1115 & 290 \\
\hline 7 & 5,430 & 25162,860 & 17292,990 & 136341 & 42637 & 93704 & 0,687 & 14834 & 3313 & 11521 & 1649 & 298 & 1065 & 301 \\
\hline 8 & 5,434 & 25103,811 & 52062,750 & 135509 & 42601 & 92908 & 0,686 & 14842 & 3313 & 11529 & 1580 & 320 & 1132 & 281 \\
\hline 9 & 5,825 & 24631,970 & 16641,600 & 142844 & 46297 & 96547 & 0,676 & 16124 & 3600 & 12524 & 1725 & 359 & 1160 & 356 \\
\hline 10 & 5,420 & 25003,200 & 17072,780 & 135221 & 42877 & 92344 & 0,683 & 15052 & 3417 & 11635 & 1660 & 340 & 1117 & 300 \\
\hline 11 & 5,310 & 24462,850 & 17159,690 & 129584 & 38699 & 90885 & 0,701 & 13495 & 3114 & 10381 & 1595 & 297 & 926 & 296 \\
\hline 12 & 5,504 & 25226,759 & 17410,760 & 137438 & 42441 & 94997 & 0,691 & 14704 & 3272 & 11432 & 1575 & 314 & 1081 & 302 \\
\hline 13 & $\mathbf{5 , 5 4 8}$ & 24922,200 & 16778,100 & 137708 & 44973 & 92735 & 0,673 & 15611 & 3470 & 12141 & 1616 & 332 & 1199 & 323 \\
\hline 14 & 5,539 & 59474,000 & 16832,180 & 137284 & 44362 & 92922 & 0,677 & 15638 & 3372 & 12266 & 1624 & 307 & 1130 & 311 \\
\hline 15 & 5,473 & 25055,370 & 16770,020 & 136359 & 44989 & 91370 & 0,670 & 15711 & 3424 & 12287 & 1672 & 304 & 1144 & 304 \\
\hline Média & 5,520 & & & & & & 0,682 & 15182 & & & & & & \\
\hline
\end{tabular}

Tabela B. 20 - Dados da execução do Modelo B com Round Robin. 


\begin{tabular}{|c|c|c|c|c|c|c|c|c|c|c|c|c|c|c|}
\hline \multirow[b]{2}{*}{ Execução } & \multirow[b]{2}{*}{$\begin{array}{c}\text { Tempo } \\
\text { Total }\end{array}$} & \multicolumn{3}{|l|}{ Eventos } & \multirow[b]{2}{*}{$\begin{array}{c}\text { Total Can- } \\
\text { celados }\end{array}$} & \multirow[b]{2}{*}{$\begin{array}{c}\text { Total Rea- } \\
\text { lizados }\end{array}$} & \multicolumn{3}{|c|}{ Rollbacks } & \multicolumn{5}{|c|}{ Causados por: } \\
\hline & & $\begin{array}{c}\text { Processados } \\
\text { p/ segundo }\end{array}$ & \begin{tabular}{|l|} 
Realizados \\
p/ segundo
\end{tabular} & $\begin{array}{l}\text { Total Pro- } \\
\text { cessados }\end{array}$ & & & Eficiência & Total & $\begin{array}{l}\text { Primá- } \\
\text { rios }\end{array}$ & Secundários & 0 & 1 & 2 & 3 \\
\hline 1 & 75,421 & 3035,671 & 2895,099 & 228634 & 10602 & 218032 & 0,954 & 5317 & 2257 & 3060 & 627 & 598 & 508 & 524 \\
\hline 2 & 76,036 & 3018,204 & 2873,072 & 229201 & 11020 & 218181 & 0,952 & 5397 & 2276 & 3121 & 738 & 585 & 410 & 543 \\
\hline 3 & 76,762 & 3031,275 & 2872,310 & 232192 & 12170 & 220022 & 0,948 & 6140 & 2459 & 3681 & 751 & 563 & 594 & 551 \\
\hline 4 & 76,080 & 3023,519 & 2881,457 & 229384 & 10779 & 218605 & $\mathbf{0 , 9 5 3}$ & 5381 & 2229 & 3152 & 652 & 603 & 460 & 514 \\
\hline 5 & 76,087 & 3031,483 & 2879,336 & 230303 & 11554 & 218749 & $\mathbf{0 , 9 5 0}$ & 5746 & 2455 & 3291 & 734 & 633 & 537 & 551 \\
\hline 6 & 76,010 & 3014,373 & 2881,004 & 228058 & 10093 & 217965 & 0,956 & 5090 & 2178 & 2912 & 673 & 569 & 416 & 520 \\
\hline 7 & 76,135 & 3021,135 & 2868,889 & 229357 & 11560 & 217797 & 0,950 & 5730 & 2333 & 3397 & 699 & 552 & 512 & 570 \\
\hline 8 & 76,239 & 3017,452 & 2867,770 & 229691 & 11390 & 218301 & 0,950 & 5734 & 2340 & 3394 & 772 & 572 & 440 & 556 \\
\hline 9 & 76,055 & 3018,330 & 2872,807 & 228662 & 11031 & 217631 & 0,952 & 5452 & 2293 & 3159 & 630 & 591 & 530 & 542 \\
\hline 10 & 76,259 & 3024,032 & 2876,876 & 230265 & 11211 & 219054 & 0,951 & 5626 & 2361 & 3265 & 746 & 579 & 499 & 537 \\
\hline 11 & 75,885 & 3013,483 & 2867,710 & 228059 & 11014 & 217045 & 0,952 & 5498 & 2313 & 3185 & 675 & 609 & 515 & 514 \\
\hline 12 & 76,205 & 3029,466 & 2876,164 & 230458 & 11648 & 218810 & 0,949 & 5793 & 2351 & 3442 & 778 & 559 & 461 & 553 \\
\hline 13 & 76,895 & 3023,042 & 2860,366 & 231950 & 12470 & 219480 & 0,946 & 6184 & 2492 & 3692 & 765 & 559 & 573 & 595 \\
\hline 14 & 76,026 & 3020,619 & 2878,785 & 229348 & 10778 & 218570 & 0,953 & $\mathbf{5 3 8 0}$ & 2292 & 3088 & 751 & 555 & 434 & 552 \\
\hline 15 & 75,954 & 3028,369 & 2880,179 & 229802 & 11248 & 218554 & 0,951 & 5729 & 2382 & 3347 & 703 & 568 & 558 & 553 \\
\hline Média & 76,137 & & & & & & 0,951 & 5613 & & & & & & \\
\hline
\end{tabular}




\begin{tabular}{|c|c|c|c|c|c|c|c|c|c|c|c|c|c|c|}
\hline \multirow[b]{2}{*}{ Execução } & \multirow[b]{2}{*}{$\begin{array}{c}\text { Tempo } \\
\text { Total }\end{array}$} & \multirow{2}{*}{$\begin{array}{l}\text { Eventos } \\
\text { Processados } \\
\text { p/ segundo }\end{array}$} & \multirow[b]{2}{*}{$\begin{array}{l}\text { Realizados } \\
\text { p/ segundo }\end{array}$} & \multirow[b]{2}{*}{$\begin{array}{l}\text { Total Pro- } \\
\text { cessados }\end{array}$} & \multirow[b]{2}{*}{$\begin{array}{c}\text { Total Can- } \\
\text { celados }\end{array}$} & \multirow[b]{2}{*}{$\begin{array}{c}\text { Total Rea- } \\
\text { lizados }\end{array}$} & \multicolumn{3}{|c|}{ Rollbacks } & \multicolumn{5}{|c|}{ Causados por: } \\
\hline & & & & & & & Eficiência & Total & $\begin{array}{l}\text { Primá- } \\
\text { rios }\end{array}$ & Secundários & 0 & 1 & 2 & 3 \\
\hline 1 & 153,373 & 2936,869 & 2763,759 & 449867 & 26543 & 423324 & 0,941 & 9970 & 4422 & 5548 & 1344 & 1204 & 784 & 1090 \\
\hline 2 & 153,536 & 2935,351 & 2770,488 & 450144 & 25298 & 424846 & 0,944 & 9424 & 4263 & 5161 & 1281 & 1090 & 737 & 1155 \\
\hline 3 & 152,909 & 2934,198 & 2769,347 & 448333 & 25184 & 423149 & 0,944 & 9426 & 4357 & 5069 & 1305 & 1147 & 772 & 1133 \\
\hline 4 & 153,450 & 2936,770 & 2773,407 & 449879 & 25063 & 424816 & 0,944 & 9322 & 4197 & 5125 & 1249 & 1052 & 780 & 1116 \\
\hline 5 & 154,756 & 2932,097 & 2758,154 & 452888 & 26882 & 426006 & 0,941 & 10033 & 4437 & 5596 & 1325 & 1165 & 812 & 1135 \\
\hline 6 & 153,218 & 2936,220 & 2765,361 & 448752 & 26089 & 422663 & 0,942 & 9691 & 4414 & 5277 & 1308 & 1173 & 813 & 1120 \\
\hline 7 & 154,285 & 2926,486 & 2762,324 & 451012 & 25313 & 425699 & 0,944 & 9572 & 4253 & 5319 & 1233 & 1127 & 777 & 1116 \\
\hline 8 & 153,064 & 2949,177 & 2788,694 & 451194 & 24557 & 426637 & 0,946 & 9179 & 4159 & 5020 & 1230 & 1084 & 746 & 1099 \\
\hline 9 & 153,663 & 2931,591 & 2778,901 & 449675 & 23424 & 426251 & 0,948 & 8762 & 4078 & 4684 & 1192 & 1058 & 696 & 1132 \\
\hline 10 & 153,411 & 2942,224 & 2771,784 & 450538 & 26106 & 424432 & 0,942 & 9714 & 4337 & 5377 & 1319 & 1114 & 771 & 1133 \\
\hline 11 & 154,073 & 2934,222 & 2764,395 & 451126 & 26121 & 425005 & 0,942 & 9674 & 4411 & 5263 & 1341 & 1158 & 790 & 1122 \\
\hline 12 & $\mathbf{1 5 3 , 5 5 8}$ & 2938,369 & 2776,720 & 450413 & 24804 & 425609 & 0,945 & 9447 & 4254 & 5193 & 1284 & 1103 & 767 & 1100 \\
\hline 13 & 153,115 & 2939,789 & 2781,223 & 449729 & 24265 & 425464 & 0,946 & 9118 & 4200 & 4918 & 1273 & 1141 & 701 & 1085 \\
\hline 14 & 153,853 & 2938,703 & 2767,677 & 451846 & 26292 & 425554 & 0,942 & 9832 & 4353 & 5479 & 1313 & 1150 & 762 & 1128 \\
\hline 15 & 153,674 & 2932,993 & 2768,061 & 450356 & 25345 & 425011 & 0,944 & 9363 & 4215 & 5148 & 1279 & 1069 & 743 & 1124 \\
\hline Média & 153,596 & & & & & & 0,944 & 9502 & & & & & & \\
\hline
\end{tabular}

Tabela B. 22 - Dados da execução do Modelo D com Round Robin. 


\begin{tabular}{|c|c|c|c|c|c|c|c|c|c|c|c|c|c|c|}
\hline \multirow[b]{2}{*}{ Execução } & \multirow[b]{2}{*}{$\begin{array}{c}\text { Tempo } \\
\text { Total }\end{array}$} & \multirow{2}{*}{$\begin{array}{l}\text { Eventos } \\
\text { Processados } \\
\text { p/ segundo }\end{array}$} & \multirow[b]{2}{*}{$\begin{array}{l}\text { Realizados } \\
\text { p/ segundo }\end{array}$} & \multirow[b]{2}{*}{$\begin{array}{l}\text { Total Pro- } \\
\text { cessados }\end{array}$} & \multirow[b]{2}{*}{$\begin{array}{c}\text { Total Can- } \\
\text { celados }\end{array}$} & \multirow[b]{2}{*}{$\begin{array}{c}\text { Total Rea- } \\
\text { lizados }\end{array}$} & \multicolumn{3}{|c|}{ Rollbacks } & \multicolumn{5}{|c|}{ Causados por: } \\
\hline & & & & & & & Eficiência & Total & $\begin{array}{l}\text { Primá- } \\
\text { rios }\end{array}$ & Secundários & 0 & 1 & 2 & 3 \\
\hline 1 & 156,075 & 2928,912 & 2720,532 & 456221 & 32490 & 423731 & 0,929 & 11857 & 5652 & 6205 & 1735 & 1305 & 1180 & 1432 \\
\hline 2 & 156,474 & 2927,954 & 2728,121 & 457505 & 31241 & 426264 & $\mathbf{0 , 9 3 2}$ & 11418 & 5622 & 5796 & 1792 & 1275 & 1122 & 1433 \\
\hline 3 & 156,486 & 2922,482 & 2710,402 & 456625 & 33181 & 423444 & $\mathbf{0 , 9 2 7}$ & 11931 & 5813 & 6118 & 1848 & 1419 & 1168 & 1378 \\
\hline 4 & 155,053 & 2926,735 & 2735,280 & 453304 & 29665 & 423639 & $\mathbf{0 , 9 3 5}$ & 10695 & 5288 & 5407 & 1642 & 1270 & 1029 & 1347 \\
\hline 5 & 154,526 & 2929,157 & 2734,295 & 452306 & 30102 & 422204 & $\mathbf{0 , 9 3 3}$ & 10860 & 5373 & 5487 & 1613 & 1295 & 1085 & 1380 \\
\hline 6 & 155,363 & 2923,575 & 2732,915 & 453487 & 29567 & 423920 & $\mathbf{0 , 9 3 5}$ & 10704 & 5311 & 5393 & 1575 & 1244 & 1082 & 1410 \\
\hline 7 & 154,453 & 2922,360 & 2723,222 & 450447 & 30713 & 419734 & $\mathbf{0 , 9 3 2}$ & 11065 & 5562 & 5503 & 1775 & 1358 & 1108 & 1321 \\
\hline 8 & 155,970 & 2922,149 & 2723,825 & 455300 & 30887 & 424413 & $\mathbf{0 , 9 3 2}$ & 11406 & 5652 & 5754 & 1870 & 1255 & 1119 & 1408 \\
\hline 9 & 154,748 & 2925,987 & 2735,595 & 451992 & 29412 & 422580 & $\mathbf{0 , 9 3 5}$ & 10608 & 5288 & 5320 & 1601 & 1323 & 1051 & 1313 \\
\hline 10 & 155,681 & 2927,589 & 2725,367 & 455052 & 31466 & 423586 & 0,931 & 11412 & 5603 & 5809 & 1770 & 1362 & 1070 & 1401 \\
\hline 11 & 154,969 & 2922,267 & 2737,847 & 451880 & 28553 & 423327 & $\mathbf{0 , 9 3 7}$ & 10441 & 5320 & 5121 & 1628 & 1281 & 1061 & 1350 \\
\hline 12 & 153,756 & 2933,515 & 2750,160 & 450253 & 28170 & 422083 & $\mathbf{0 , 9 3 7}$ & 10168 & 5179 & 4989 & 1625 & 1225 & 954 & 1375 \\
\hline 13 & 155,510 & 2917,013 & 2719,094 & 452812 & 30763 & 422049 & 0,932 & 11216 & 5537 & 5679 & 1816 & 1322 & 1085 & 1314 \\
\hline 14 & 155,305 & 2923,026 & 2736,642 & 453317 & 28912 & 424405 & 0,936 & 10497 & 5249 & 5248 & 1636 & 1186 & 1051 & 1376 \\
\hline 15 & 154,383 & 2923,437 & 2727,100 & 450302 & 30284 & 420018 & $\mathbf{0 , 9 3 3}$ & 10950 & 5429 & 5521 & 1695 & 1266 & 1053 & 1415 \\
\hline Média & 155,250 & & & & & & 0,933 & 11015 & & & & & & \\
\hline
\end{tabular}




\begin{tabular}{|c|c|c|c|c|c|c|c|c|c|c|c|c|c|c|}
\hline \multirow[b]{2}{*}{ Execução } & \multirow[b]{2}{*}{$\begin{array}{c}\text { Tempo } \\
\text { Total }\end{array}$} & \multirow{2}{*}{$\begin{array}{l}\text { Eventos } \\
\text { Processados } \\
\text { p/ segundo }\end{array}$} & \multirow[b]{2}{*}{$\begin{array}{l}\text { Realizados } \\
\text { p/ segundo }\end{array}$} & \multirow[b]{2}{*}{$\begin{array}{l}\text { Total Pro- } \\
\text { cessados }\end{array}$} & \multirow[b]{2}{*}{\begin{tabular}{|c} 
Total Can- \\
celados
\end{tabular}} & \multirow[b]{2}{*}{$\begin{array}{c}\text { Total Rea- } \\
\text { lizados }\end{array}$} & \multicolumn{3}{|c|}{ Rollbacks } & \multicolumn{5}{|c|}{ Causados por: } \\
\hline & & & & & & & Eficiência & Total & $\begin{array}{c}\text { Primá- } \\
\text { rios }\end{array}$ & Secundários & 0 & 1 & 2 & 3 \\
\hline 1 & 330,153 & 1489,065 & 1385,280 & 491008 & 34236 & 456772 & $\mathbf{0 , 9 3 0}$ & 16742 & 5835 & 10907 & 1958 & 1259 & 1484 & 1134 \\
\hline 2 & 330,395 & 1493,368 & 1384,379 & 492434 & 35921 & 456513 & 0,927 & 17343 & 6084 & 11259 & 2079 & 1341 & 1499 & 1165 \\
\hline 3 & 330,484 & 1491,952 & 1383,509 & 492746 & 35815 & 456931 & 0,927 & 17363 & 6116 & 11247 & 2136 & 1310 & 1543 & 1127 \\
\hline 4 & $\mathbf{3 3 2 , 5 2 7}$ & 1492,329 & 1388,522 & 495486 & 34465 & 461021 & $\mathbf{0 , 9 3 0}$ & 16988 & 5757 & 11231 & 1991 & 1180 & 1451 & 1135 \\
\hline 5 & $\mathbf{3 2 8 , 5 3 0}$ & 1499,377 & 1392,236 & 492036 & 35137 & 456899 & $\mathbf{0 , 9 2 9}$ & 17183 & 5965 & 11218 & 2060 & 1297 & 1490 & 1118 \\
\hline 6 & 329,303 & 1494,240 & 1387,279 & 491619 & 35175 & 456444 & 0,928 & 16886 & 5877 & 11009 & 2024 & 1319 & 1390 & 1144 \\
\hline 7 & 329,068 & 1494,429 & 1390,572 & 490916 & 34101 & 456815 & $\mathbf{0 , 9 3 1}$ & 16743 & 5970 & 10773 & 1961 & 1289 & 1598 & 1122 \\
\hline 8 & 332,097 & 1489,853 & 1383,735 & 494343 & 35206 & 459137 & 0,929 & 17123 & 5864 & 11259 & 2000 & 1249 & 1496 & 1119 \\
\hline 9 & 331,410 & 1492,501 & 1381,706 & 494070 & 36661 & 457409 & $\mathbf{0 , 9 2 6}$ & 17718 & 6113 & 11605 & 2119 & 1287 & 1512 & 1195 \\
\hline 10 & 333,329 & 1489,177 & 1386,242 & 495645 & 34257 & 461388 & 0,931 & 16867 & 5980 & 10887 & 2081 & 1196 & 1491 & 1212 \\
\hline 11 & 330,279 & 1489,326 & 1385,071 & 490892 & 34327 & 456565 & $\mathbf{0 , 9 3 0}$ & 16611 & 5842 & 10769 & 1924 & 1260 & 1484 & 1174 \\
\hline 12 & 328,461 & 1496,746 & 1391,157 & 490359 & 34584 & 455775 & 0,929 & 16861 & 5864 & 10997 & 2009 & 1250 & 1497 & 1108 \\
\hline 13 & 331,489 & 1494,673 & 1385,621 & 494642 & 36075 & 458567 & $\mathbf{0 , 9 2 7}$ & 17300 & 5966 & 11334 & 2096 & 1243 & 1500 & 1127 \\
\hline 14 & 329,076 & 1494,143 & 1389,503 & 490251 & 34527 & 455724 & $\mathbf{0 , 9 3 0}$ & 16802 & 5829 & 10973 & 2014 & 1243 & 1480 & 1092 \\
\hline 15 & 332,712 & 1498,032 & 1392,907 & 497258 & 34871 & 462387 & $\mathbf{0 , 9 3 0}$ & 17097 & 5852 & 11245 & 2086 & 1223 & 1465 & 1078 \\
\hline Média & 330,621 & & & & & & 0,929 & 17042 & & & & & & \\
\hline
\end{tabular}

Tabela B. 24 - Dados da execução do Modelo F com Round Robin. 


\begin{tabular}{|c|c|c|c|c|c|c|c|c|c|c|c|c|c|c|}
\hline \multirow[b]{2}{*}{ Execução } & \multirow[b]{2}{*}{$\begin{array}{c}\text { Tempo } \\
\text { Total }\end{array}$} & \multirow{2}{*}{$\begin{array}{l}\text { Eventos } \\
\text { Processados } \\
\text { p/ segundo }\end{array}$} & \multirow[b]{2}{*}{$\begin{array}{l}\text { Realizados } \\
\text { p/ segundo }\end{array}$} & \multirow[b]{2}{*}{$\begin{array}{l}\text { Total Pro- } \\
\text { cessados }\end{array}$} & \multirow[b]{2}{*}{$\begin{array}{c}\text { Total Can- } \\
\text { celados }\end{array}$} & \multirow[b]{2}{*}{$\begin{array}{c}\text { Total Rea- } \\
\text { lizados }\end{array}$} & \multicolumn{3}{|c|}{ Rollbacks } & \multicolumn{5}{|c|}{ Causados por: } \\
\hline & & & & & & & Eficiência & Total & $\begin{array}{c}\text { Primá- } \\
\text { rios }\end{array}$ & Secundários & 0 & 1 & 2 & 3 \\
\hline 1 & $\mathbf{5 3 2 , 5 8 5}$ & 2015,530 & 1666,316 & 1072453 & 185784 & 886669 & $\mathbf{0 , 8 2 7}$ & 65587 & 16462 & 49125 & 10462 & 3295 & 1265 & 1440 \\
\hline 2 & $\mathbf{5 3 0 , 0 5 4}$ & 1955,975 & 1638,914 & 1036053 & 167902 & 868151 & $\mathbf{0 , 8 3 8}$ & 59288 & 14828 & 44460 & 11415 & 1634 & 349 & 1430 \\
\hline 3 & 534,336 & 2013,319 & 1664,483 & 1075065 & 186249 & 888816 & 0,827 & 65669 & 16608 & 49061 & 10539 & 3230 & 1311 & 1528 \\
\hline 4 & 532,053 & 2016,395 & 1669,186 & 1071791 & 184569 & 887222 & 0,828 & 65272 & 16448 & 48824 & 10534 & 3236 & 1226 & 1452 \\
\hline 5 & 533,030 & 2018,982 & 1659,582 & 1075871 & 191564 & 884307 & 0,822 & 67704 & 17007 & 50697 & 10887 & 3310 & 1297 & 1513 \\
\hline 6 & $\mathbf{5 3 1 , 9 7 4}$ & 2011,173 & 1665,795 & 1069493 & 183713 & 885780 & 0,828 & 65286 & 16526 & 48760 & 10498 & 3292 & 1291 & 1445 \\
\hline 7 & 533,919 & 2011,923 & 1658,764 & 1073131 & 188378 & 884753 & 0,824 & 66197 & 16546 & 49651 & 10488 & 3255 & 1311 & 1492 \\
\hline 8 & 534,365 & 2018,821 & 1661,160 & 1078331 & 191098 & 887233 & $\mathbf{0 , 8 2 3}$ & 66703 & 16626 & 50077 & 10497 & 3336 & 1361 & 1432 \\
\hline 9 & 534,392 & 2018,065 & 1666,983 & 1077649 & 187512 & 890137 & 0,826 & 66505 & 16794 & 49711 & 10636 & 3409 & 1283 & 1466 \\
\hline 10 & 532,995 & 2016,659 & 1659,037 & 1074105 & 190543 & 883562 & 0,823 & 67032 & 16780 & 50252 & 10647 & 3331 & 1355 & 1447 \\
\hline 11 & 534,093 & 2011,578 & 1663,732 & 1073716 & 185759 & 887957 & $\mathbf{0 , 8 2 7}$ & 65824 & 16781 & 49043 & 10648 & 3395 & 1294 & 1444 \\
\hline 12 & 536,118 & 2016,044 & 1662,494 & 1080232 & 189444 & 890788 & $\mathbf{0 , 8 2 5}$ & 67488 & 16911 & 50577 & 10828 & 3278 & 1327 & 1478 \\
\hline 13 & $\mathbf{5 3 3 , 7 9 7}$ & 2018,197 & 1663,044 & 1077022 & 189549 & 887473 & 0,824 & 66868 & 16794 & 50074 & 10666 & 3252 & 1350 & 1526 \\
\hline 14 & 530,768 & 2021,828 & 1668,685 & 1072307 & 187236 & 885071 & 0,825 & 66160 & 16388 & 49772 & 10571 & 3176 & 1210 & 1431 \\
\hline 15 & 532,639 & 2016,541 & 1667,282 & 1073304 & 185930 & 887374 & $\mathbf{0 , 8 2 7}$ & 66192 & 16632 & 49560 & 10712 & 3248 & 1220 & 1452 \\
\hline Média & 533,141 & & & & & & 0,826 & 65852 & & & & & & \\
\hline
\end{tabular}




\begin{tabular}{|c|c|c|c|c|c|c|c|c|c|c|c|c|c|c|}
\hline \multirow[b]{2}{*}{ Execução } & \multirow[b]{2}{*}{$\begin{array}{c}\text { Tempo } \\
\text { Total }\end{array}$} & \multirow{2}{*}{$\begin{array}{l}\text { Eventos } \\
\text { Processados } \\
\text { p/ segundo }\end{array}$} & \multirow[b]{2}{*}{$\begin{array}{l}\text { Realizados } \\
\text { p/ segundo }\end{array}$} & \multirow[b]{2}{*}{$\begin{array}{l}\text { Total Pro- } \\
\text { cessados }\end{array}$} & \multirow[b]{2}{*}{$\begin{array}{c}\text { Total Can- } \\
\text { celados }\end{array}$} & \multirow[b]{2}{*}{$\begin{array}{c}\text { Total Rea- } \\
\text { lizados }\end{array}$} & \multicolumn{3}{|c|}{ Rollbacks } & \multicolumn{5}{|c|}{ Causados por: } \\
\hline & & & & & & & Eficiência & Total & $\begin{array}{l}\text { Primá- } \\
\text { rios }\end{array}$ & Secundários & 0 & 1 & 2 & 3 \\
\hline 1 & 354,361 & 1130,310 & 1060,474 & 399931 & 24702 & 375229 & $\mathbf{0 , 9 3 8}$ & 14809 & 4459 & 10350 & 1578 & 888 & 1199 & 794 \\
\hline 2 & $\mathbf{3 5 4 , 5 3 2}$ & 1127,543 & 1054,401 & 399296 & 25885 & 373411 & 0,935 & 15515 & 4669 & 10846 & 1665 & 908 & 1322 & 774 \\
\hline 3 & 352,399 & 1127,359 & 1054,350 & 396300 & 25685 & 370615 & $\mathbf{0 , 9 3 5}$ & 15514 & 4678 & 10836 & 1609 & 914 & 1317 & 838 \\
\hline 4 & $\mathbf{3 5 0 , 3 0 7}$ & 1125,973 & 1061,999 & 393680 & 22386 & 371294 & 0,943 & 13502 & 4214 & 9288 & 1479 & 848 & 1109 & 778 \\
\hline 5 & 356,082 & 1125,719 & 1045,727 & 400002 & 28404 & 371598 & 0,929 & 16786 & 4945 & 11841 & 1795 & 977 & 1284 & 889 \\
\hline 6 & 353,558 & 1124,306 & 1055,214 & 397290 & 24420 & 372870 & 0,939 & 14835 & 4377 & 10458 & 1450 & 863 & 1239 & 825 \\
\hline 7 & 358,754 & 1125,964 & 1048,838 & 402757 & 27554 & 375203 & $\mathbf{0 , 9 3 2}$ & 16781 & 4880 & 11901 & 1738 & 884 & 1364 & 894 \\
\hline 8 & $\mathbf{3 5 4 , 5 9 3}$ & 1123,552 & 1048,079 & 398099 & 26742 & 371357 & $\mathbf{0 , 9 3 3}$ & 15954 & 4761 & 11193 & 1641 & 942 & 1338 & 840 \\
\hline 9 & $\mathbf{3 5 5 , 3 4 7}$ & 1126,671 & 1050,451 & 399352 & 27006 & 372346 & $\mathbf{0 , 9 3 2}$ & 16314 & 4835 & 11479 & 1689 & 946 & 1364 & 836 \\
\hline 10 & 352,892 & 1124,625 & 1049,997 & 396221 & 26273 & 369948 & 0,934 & 15639 & 4780 & 10859 & 1709 & 954 & 1290 & 827 \\
\hline 11 & 354,293 & 1127,855 & 1056,522 & 399276 & 25270 & 374006 & 0,937 & 15129 & 4557 & 10572 & 1670 & 862 & 1244 & 781 \\
\hline 12 & 352,718 & 1125,129 & 1051,196 & 395621 & 25989 & 369632 & 0,934 & 15516 & 4644 & 10872 & 1600 & 910 & 1295 & 839 \\
\hline 13 & 358,705 & 1128,266 & 1049,387 & 403561 & 28174 & 375387 & $\mathbf{0 , 9 3 0}$ & 16981 & 4835 & 12146 & 1661 & 947 & 1403 & 824 \\
\hline 14 & 357,041 & 1128,047 & 1054,230 & 401626 & 26279 & 375347 & $\mathbf{0 , 9 3 5}$ & 15798 & 4692 & 11106 & 1686 & 893 & 1290 & 823 \\
\hline 15 & 355,139 & 1127,862 & 1051,863 & 399782 & 26916 & 372866 & 0,933 & 16286 & 4793 & 11493 & 1773 & 915 & 1272 & 833 \\
\hline Média & 354,715 & & & & & & 0,935 & 15691 & & & & & & \\
\hline
\end{tabular}

Tabela B. 26 - Dados da execução do Modelo H com Round Robin. 


\begin{tabular}{|c|c|c|c|c|c|c|c|c|c|c|c|c|c|c|}
\hline \multirow[b]{2}{*}{ Execução } & \multicolumn{6}{|c|}{ Eventos } & \multicolumn{4}{|c|}{ Rollbacks } & \multicolumn{4}{|c|}{ Causados por: } \\
\hline & $\begin{array}{c}\text { Tempo } \\
\text { Total }\end{array}$ & $\begin{array}{c}\text { Processados } \\
\text { p/ segundo }\end{array}$ & $\begin{array}{l}\text { Realizados } \\
\text { p/ segundo }\end{array}$ & \begin{tabular}{|c|} 
Total Pro- \\
cessados
\end{tabular} & \begin{tabular}{|c|} 
Total Can- \\
celados
\end{tabular} & $\begin{array}{c}\text { Total Rea- } \\
\text { lizados }\end{array}$ & Eficiência & Total & $\begin{array}{l}\text { Primá- } \\
\text { rios }\end{array}$ & Secundários & 0 & 1 & 2 & 3 \\
\hline 1 & 354,480 & 1125,325 & 1116,066 & 398421 & 3279 & 395142 & 0,992 & 1916 & 712 & 1204 & 180 & 183 & 130 & 219 \\
\hline 2 & 354,626 & 1125,343 & 1116,529 & 398328 & 3120 & 395208 & 0,992 & 1766 & 669 & 1097 & 166 & 187 & 124 & 192 \\
\hline 3 & 356,051 & 1125,840 & 1116,293 & 399433 & 3386 & 396047 & 0,992 & 1889 & 680 & 1209 & 169 & 189 & 136 & 186 \\
\hline 4 & 351,645 & 1126,288 & 1117,170 & 395390 & 3201 & 392189 & 0,992 & 1750 & 661 & 1089 & 166 & 198 & 111 & 186 \\
\hline 5 & 352,725 & 1126,399 & 1117,954 & 396290 & 2968 & 393322 & 0,993 & 1663 & 626 & 1037 & 163 & 191 & 104 & 168 \\
\hline 6 & 353,709 & 1127,198 & 1117,353 & 397804 & 3470 & 394334 & 0,991 & 1897 & 707 & 1190 & 160 & 197 & 150 & 200 \\
\hline 7 & 354,800 & 1125,921 & 1116,096 & 398887 & 3483 & 395404 & 0,991 & 1921 & 707 & 1214 & 162 & 204 & 135 & 206 \\
\hline 8 & 355,979 & 1122,199 & 1112,682 & 398852 & 3380 & 395472 & 0,992 & 1884 & 719 & 1165 & 156 & 206 & 147 & 210 \\
\hline 9 & 351,791 & 1126,325 & 1116,167 & 395900 & 3569 & 392331 & 0,991 & 1980 & 701 & 1279 & 177 & 219 & 102 & 203 \\
\hline 10 & 356,249 & 1122,802 & 1112,869 & 399086 & 3533 & 395553 & 0,991 & 1820 & 630 & 1190 & 160 & 193 & 101 & 176 \\
\hline 11 & 352,227 & 1129,394 & 1119,055 & 396973 & 3630 & 393343 & 0,991 & 1975 & 700 & 1275 & 155 & 214 & 140 & 191 \\
\hline 12 & 350,997 & 1127,663 & 1117,841 & 394872 & 3438 & 391434 & 0,991 & 1823 & 676 & 1147 & 142 & 202 & 137 & 195 \\
\hline 13 & 351,144 & 1123,728 & 1113,327 & 394007 & 3648 & 390359 & 0,991 & 2019 & 767 & 1252 & 166 & 238 & 147 & 216 \\
\hline 14 & 352,026 & 1124,856 & 1116,022 & 395088 & 3100 & 391988 & 0,992 & 1645 & 624 & 1021 & 130 & 190 & 132 & 172 \\
\hline 15 & 353,553 & 1129,097 & 1118,941 & 398492 & 3580 & 394912 & 0,991 & 1938 & 696 & 1242 & 169 & 203 & 125 & 199 \\
\hline Média & 353,467 & & & & & & 0,991 & 1859 & & & & & & \\
\hline
\end{tabular}




\begin{tabular}{|c|c|c|c|c|c|c|c|c|c|c|c|c|c|c|}
\hline \multirow[b]{2}{*}{ Execução } & \multirow[b]{2}{*}{$\begin{array}{c}\text { Tempo } \\
\text { Total }\end{array}$} & \multirow{2}{*}{$\begin{array}{l}\text { Eventos } \\
\text { Processados } \\
\text { p/ segundo }\end{array}$} & \multirow[b]{2}{*}{$\begin{array}{l}\text { Realizados } \\
\text { p/ segundo }\end{array}$} & \multirow[b]{2}{*}{$\begin{array}{l}\text { Total Pro- } \\
\text { cessados }\end{array}$} & \multirow[b]{2}{*}{$\begin{array}{c}\text { Total Can- } \\
\text { celados }\end{array}$} & \multirow[b]{2}{*}{$\begin{array}{c}\text { Total Rea- } \\
\text { lizados }\end{array}$} & \multicolumn{3}{|c|}{ Rollbacks } & \multicolumn{5}{|c|}{ Causados por: } \\
\hline & & & & & & & Eficiência & Total & $\begin{array}{l}\text { Primá- } \\
\text { rios }\end{array}$ & Secundários & 0 & 1 & 2 & 3 \\
\hline 1 & 35,222 & 1909,065 & 1521,968 & 67040 & 13615 & 53425 & $\mathbf{0 , 7 9 7}$ & 6243 & 1171 & 5072 & 649 & 154 & 294 & 74 \\
\hline 2 & 35,210 & 1911,491 & 1566,597 & 65523 & 11842 & 53681 & $\mathbf{0 , 8 1 9}$ & 5438 & 1026 & 4412 & 580 & 134 & 238 & 74 \\
\hline 3 & 35,301 & 1916,275 & 1552,823 & 66461 & 12515 & 53946 & 0,812 & 5739 & 1199 & 4540 & 727 & 152 & 247 & 73 \\
\hline 4 & $\mathbf{3 5 , 3 7 7}$ & 1910,111 & 1543,823 & 67087 & 12880 & 54207 & $\mathbf{0 , 8 0 8}$ & 5913 & 1151 & 4762 & 670 & 148 & 236 & 97 \\
\hline 5 & 35,126 & 1917,167 & 1566,687 & 66976 & 12262 & 54714 & $\mathbf{0 , 8 1 7}$ & 5679 & 1133 & 4546 & 665 & 129 & 246 & 93 \\
\hline 6 & 36,193 & 1907,941 & 1555,631 & 68534 & 12657 & 55877 & 0,815 & 5975 & 1141 & 4834 & 665 & 154 & 228 & 94 \\
\hline 7 & 35,315 & 1916,617 & 1556,866 & 67114 & 12612 & 54502 & $\mathbf{0 , 8 1 2}$ & 5758 & 1091 & 4667 & 631 & 125 & 237 & 98 \\
\hline 8 & 36,089 & 1913,825 & 1542,781 & 68516 & 13285 & 55231 & 0,806 & 6274 & 1230 & 5044 & 635 & 149 & 315 & 131 \\
\hline 9 & 36,007 & 1915,014 & 1539,537 & 68580 & 13461 & 55119 & $\mathbf{0 , 8 0 4}$ & 6341 & 1168 & 5173 & 695 & 125 & 249 & 99 \\
\hline 10 & 35,303 & 1916,995 & 1567,404 & 65408 & 11913 & 53495 & $\mathbf{0 , 8 1 8}$ & 5517 & 1144 & 4373 & 649 & 133 & 241 & 121 \\
\hline 11 & 35,168 & 1916,266 & 1535,969 & 66982 & 13307 & 53675 & 0,801 & 6130 & 1221 & 4909 & 745 & 132 & 247 & 97 \\
\hline 12 & 35,208 & 1918,949 & 1579,711 & 66588 & 11705 & 54883 & 0,824 & 5380 & 1052 & 4328 & 645 & 137 & 218 & 52 \\
\hline 13 & 36,095 & 1911,089 & 1534,732 & 68453 & 13487 & 54966 & 0,803 & 6467 & 1244 & 5223 & 734 & 132 & 267 & 111 \\
\hline 14 & 35,180 & 1918,655 & 1566,719 & 67033 & 12312 & 54721 & 0,816 & 5726 & 1134 & 4592 & 664 & 130 & 253 & 87 \\
\hline 15 & 35,593 & 1912,364 & 1514,891 & 67087 & 13953 & 53134 & 0,792 & 6390 & 1312 & 5078 & 750 & 172 & 296 & 94 \\
\hline Média & 35,492 & & & & & & 0,810 & 5931 & & & & & & \\
\hline
\end{tabular}

Tabela B. 28 - Dados da execução do Modelo J com Round Robin. 


\begin{tabular}{|c|c|c|c|c|c|c|c|c|c|c|c|c|c|c|}
\hline \multirow[b]{2}{*}{ Execução } & \multicolumn{6}{|c|}{ Eventos } & \multicolumn{4}{|c|}{ Rollbacks } & \multicolumn{4}{|c|}{ Causados por: } \\
\hline & $\begin{array}{c}\text { Tempo } \\
\text { Total }\end{array}$ & $\begin{array}{c}\text { Processados } \\
\text { p/ segundo }\end{array}$ & $\begin{array}{l}\text { Realizados } \\
\text { p/ segundo }\end{array}$ & \begin{tabular}{|c|} 
Total Pro- \\
cessados
\end{tabular} & $\begin{array}{l}\text { Total Can- } \\
\text { celados }\end{array}$ & $\begin{array}{c}\text { Total Rea- } \\
\text { lizados }\end{array}$ & Eficiência & Total & $\begin{array}{l}\text { Primá- } \\
\text { rios }\end{array}$ & Secundários & 0 & 1 & 2 & 3 \\
\hline 1 & 52,850 & 1280,191 & 1051,078 & 66922 & 11977 & 54945 & $\mathbf{0 , 8 2 1}$ & 5596 & 1101 & 4495 & 598 & 148 & 270 & 85 \\
\hline 2 & 53,502 & 1297,580 & 1047,339 & 69089 & 13309 & 55780 & $\mathbf{0 , 8 0 7}$ & 6144 & 1228 & 4916 & 613 & 141 & 314 & 160 \\
\hline 3 & 53,485 & 1263,149 & 1029,771 & 66851 & 12332 & 54519 & $\mathbf{0 , 8 1 6}$ & 5944 & 1213 & 4731 & 624 & 158 & 326 & 105 \\
\hline 4 & 53,393 & 1292,077 & 1042,401 & 68642 & 13290 & 55352 & 0,806 & 6135 & 1047 & 5088 & 576 & 129 & 236 & 106 \\
\hline 5 & 52,650 & 1283,406 & 1036,458 & 67144 & 12946 & 54198 & $\mathbf{0 , 8 0 7}$ & 5954 & 1169 & 4785 & 650 & 153 & 245 & 121 \\
\hline 6 & 51,884 & 1281,922 & 1070,168 & 65540 & 10843 & 54697 & $\mathbf{0 , 8 3 5}$ & 4997 & 980 & 4017 & 477 & 120 & 255 & 128 \\
\hline 7 & 53,068 & 1271,576 & 1026,078 & 67036 & 12971 & 54065 & $\mathbf{0 , 8 0 7}$ & 5888 & 1177 & 4711 & 583 & 163 & 299 & 132 \\
\hline 8 & 53,390 & 1281,513 & 1050,090 & 67655 & 12151 & 55504 & $\mathbf{0 , 8 2 0}$ & 5626 & 1032 & 4594 & 584 & 142 & 227 & 79 \\
\hline 9 & 52,633 & 1289,736 & 1057,949 & 66052 & 11873 & 54179 & $\mathbf{0 , 8 2 0}$ & 5315 & 1095 & 4220 & 563 & 135 & 265 & 132 \\
\hline 10 & 52,006 & 1294,557 & 1060,676 & 66660 & 12019 & 54641 & $\mathbf{0 , 8 2 0}$ & 5561 & 1135 & 4426 & 575 & 144 & 293 & 123 \\
\hline 11 & 53,391 & 1279,152 & 1044,882 & 67161 & 12313 & 54848 & $\mathbf{0 , 8 1 7}$ & 5623 & 1124 & 4499 & 615 & 141 & 254 & 114 \\
\hline 12 & 52,753 & 1261,377 & 1063,040 & 65896 & 10322 & 55574 & 0,843 & 4871 & 972 & 3899 & 500 & 117 & 226 & 129 \\
\hline 13 & 52,113 & 1285,353 & 1056,233 & 66584 & 11894 & 54690 & $\mathbf{0 , 8 2 1}$ & 5523 & 1141 & 4382 & 616 & 137 & 277 & 111 \\
\hline 14 & 53,473 & 1294,289 & 1033,837 & 68577 & 13787 & 54790 & 0,799 & 6408 & 1207 & 5201 & 669 & 150 & 252 & 136 \\
\hline 15 & 53,708 & 1278,054 & 1044,176 & 68189 & 12450 & 55739 & $\mathbf{0 , 8 1 7}$ & 5772 & 1148 & 4624 & 598 & 150 & 285 & 115 \\
\hline Média & 52,953 & & & & & & 0,817 & 5690 & & & & & & \\
\hline
\end{tabular}




\begin{tabular}{|c|c|c|c|c|c|c|c|c|c|c|c|c|c|c|}
\hline \multirow[b]{2}{*}{ Execução } & \multirow[b]{2}{*}{$\begin{array}{c}\text { Tempo } \\
\text { Total }\end{array}$} & \multirow{2}{*}{$\begin{array}{l}\text { Eventos } \\
\text { Processados } \\
\text { p/ segundo }\end{array}$} & \multirow[b]{2}{*}{$\begin{array}{l}\text { Realizados } \\
\text { p/ segundo }\end{array}$} & \multirow[b]{2}{*}{$\begin{array}{l}\text { Total Pro- } \\
\text { cessados }\end{array}$} & \multirow[b]{2}{*}{$\begin{array}{c}\text { Total Can- } \\
\text { celados }\end{array}$} & \multirow[b]{2}{*}{$\begin{array}{c}\text { Total Rea- } \\
\text { lizados }\end{array}$} & \multicolumn{3}{|c|}{ Rollbacks } & \multicolumn{5}{|c|}{ Causados por: } \\
\hline & & & & & & & Eficiência & Total & $\begin{array}{c}\text { Primá- } \\
\text { rios }\end{array}$ & Secundários & 0 & 1 & 2 & 3 \\
\hline 1 & 33,641 & 1954,142 & 1600,578 & 64988 & 11733 & 53255 & 0,819 & 5433 & 1143 & 4290 & 583 & 164 & 314 & 82 \\
\hline 2 & $\mathbf{3 3 , 3 3 7}$ & 1955,258 & 1643,098 & 63865 & 10199 & 53666 & $\mathbf{0 , 8 4 0}$ & 4667 & 1012 & 3655 & 472 & 144 & 300 & 96 \\
\hline 3 & $\mathbf{3 3 , 3 3 5}$ & 1953,657 & 1627,297 & 64840 & 10847 & 53993 & $\mathbf{0 , 8 3 3}$ & 5099 & 1102 & 3997 & 559 & 131 & 277 & 135 \\
\hline 4 & $\mathbf{3 3 , 5 7 0}$ & 1947,273 & 1601,833 & 64743 & 11494 & 53249 & 0,822 & 5402 & 1071 & 4331 & 579 & 150 & 291 & 51 \\
\hline 5 & 33,373 & 1975,925 & 1654,100 & 65298 & 10629 & 54669 & $\mathbf{0 , 8 3 7}$ & 4991 & 999 & 3992 & 533 & 141 & 269 & 56 \\
\hline 6 & 33,964 & 1972,248 & 1629,786 & 66516 & 11615 & 54901 & $\mathbf{0 , 8 2 5}$ & 5483 & 1038 & 4445 & 547 & 133 & 279 & 79 \\
\hline 7 & 33,361 & 1970,752 & 1622,381 & 65502 & 11580 & 53922 & $\mathbf{0 , 8 2 3}$ & 5454 & 1111 & 4343 & 590 & 137 & 277 & 107 \\
\hline 8 & 33,936 & 1976,722 & 1635,633 & 66514 & 11536 & 54978 & $\mathbf{0 , 8 2 7}$ & 5315 & 1050 & 4265 & 568 & 135 & 284 & 63 \\
\hline 9 & 34,031 & 1969,764 & 1628,615 & 66499 & 11553 & 54946 & 0,826 & 5367 & 1032 & 4335 & 520 & 120 & 278 & 114 \\
\hline 10 & 33,297 & 1980,304 & 1638,574 & 64889 & 11168 & 53721 & $\mathbf{0 , 8 2 8}$ & 5171 & 1098 & 4073 & 619 & 139 & 255 & 85 \\
\hline 11 & $\mathbf{3 4 , 3 1 7}$ & 1968,627 & 1616,918 & 67043 & 12006 & 55037 & 0,821 & 5656 & 1150 & 4506 & 610 & 149 & 287 & 104 \\
\hline 12 & $\mathbf{3 3 , 4 5 3}$ & 1975,822 & 1631,614 & 65825 & 11469 & 54356 & 0,826 & $\mathbf{5 3 3 0}$ & 1167 & 4163 & 639 & 158 & 281 & 89 \\
\hline 13 & 33,367 & 1977,232 & 1625,140 & 65407 & 11666 & 53741 & $\mathbf{0 , 8 2 2}$ & 5403 & 1065 & 4338 & 580 & 148 & 265 & 72 \\
\hline 14 & 33,390 & 1980,564 & 1627,862 & 64870 & 11576 & 53294 & 0,822 & 5249 & 1070 & 4179 & 581 & 142 & 281 & 66 \\
\hline 15 & 34,022 & 1961,704 & 1608,255 & 66108 & 11949 & 54159 & 0,819 & 5489 & 1083 & 4406 & 548 & 145 & 308 & 82 \\
\hline Média & 33,626 & & & & & & 0,826 & 5301 & & & & & & \\
\hline
\end{tabular}

Tabela B. 30 - Dados da execução do Modelo L com Round Robin. 


\begin{tabular}{|c|c|c|c|c|c|c|c|c|c|c|c|c|c|c|}
\hline \multirow[b]{2}{*}{ Execução } & \multirow[b]{2}{*}{$\begin{array}{c}\text { Tempo } \\
\text { Total }\end{array}$} & \multicolumn{5}{|l|}{ Eventos } & \multicolumn{4}{|c|}{ Rollbacks } & \multicolumn{4}{|c|}{ Causados por: } \\
\hline & & $\begin{array}{c}\text { Processados } \\
\text { p/ segundo }\end{array}$ & $\begin{array}{l}\text { Realizados } \\
\text { p/ segundo }\end{array}$ & $\begin{array}{c}\text { Total Pro- } \\
\text { cessados }\end{array}$ & \begin{tabular}{|c|} 
Total Can- \\
celados
\end{tabular} & $\begin{array}{c}\text { Total Rea- } \\
\text { lizados }\end{array}$ & Eficiência & Total & $\begin{array}{l}\text { Primá- } \\
\text { rios }\end{array}$ & Secundários & 0 & 1 & 2 & 3 \\
\hline 1 & 248,456 & 1187,745 & 1034,742 & 294654 & 37982 & 256672 & $\mathbf{0 , 8 7 1}$ & 17616 & 4009 & 13607 & 2057 & 673 & 990 & 289 \\
\hline 2 & 250,669 & 1191,041 & 1024,053 & 297426 & 41723 & 255703 & $\mathbf{0 , 8 6 0}$ & 19538 & 4374 & 15164 & 2205 & 678 & 1165 & 326 \\
\hline 3 & 250,366 & 1186,116 & 1023,735 & 295922 & 40527 & 255395 & 0,863 & 18825 & 4234 & 14591 & 2175 & 712 & 1059 & 288 \\
\hline 4 & 250,860 & 1191,100 & 1025,743 & 298581 & 41430 & 257151 & $\mathbf{0 , 8 6 1}$ & 19479 & 4225 & 15254 & 2167 & 652 & 1074 & 332 \\
\hline 5 & 248,999 & 1189,105 & 1031,975 & 295624 & 39100 & 256524 & 0,868 & 18398 & 4167 & 14231 & 2064 & 669 & 1116 & 318 \\
\hline 6 & 250,879 & 1190,047 & 1030,127 & 296827 & 39880 & 256947 & 0,866 & 18737 & 4259 & 14478 & 2140 & 674 & 1149 & 296 \\
\hline 7 & 248,259 & 1188,767 & 1024,425 & 294519 & 40770 & 253749 & 0,862 & 18853 & 4303 & 14550 & 2157 & 687 & 1150 & 309 \\
\hline 8 & 250,639 & 1190,265 & 1024,707 & 296765 & 41240 & 255525 & $\mathbf{0 , 8 6 1}$ & 19193 & 4347 & 14846 & 2140 & 715 & 1168 & 324 \\
\hline 9 & 250,876 & 1186,774 & 1020,994 & 297196 & 41491 & 255705 & $\mathbf{0 , 8 6 0}$ & 19446 & 4218 & 15228 & 2094 & 684 & 1141 & 299 \\
\hline 10 & 250,518 & 1190,132 & 1024,601 & 297213 & 41372 & 255841 & $\mathbf{0 , 8 6 1}$ & 19226 & 4306 & 14920 & 2163 & 690 & 1145 & 308 \\
\hline 11 & 250,385 & 1191,025 & 1016,888 & 296843 & 43398 & 253445 & $\mathbf{0 , 8 5 4}$ & 19974 & 4506 & 15468 & 2257 & 707 & 1233 & 309 \\
\hline 12 & 247,986 & 1187,849 & 1024,290 & 294296 & 40515 & 253781 & $\mathbf{0 , 8 6 2}$ & 18750 & 4293 & 14457 & 2208 & 715 & 1075 & 295 \\
\hline 13 & 250,317 & 1190,780 & 1022,399 & 297537 & 42099 & 255438 & $\mathbf{0 , 8 5 9}$ & 19889 & 4394 & 15495 & 2236 & 697 & 1134 & 327 \\
\hline 14 & 250,024 & 1187,625 & 1027,468 & 296330 & 39950 & 256380 & 0,865 & 18376 & 4209 & 14167 & 2079 & 686 & 1120 & 324 \\
\hline 15 & 247,861 & 899,671 & 1026,103 & 294702 & 40689 & 254013 & 0,862 & 18551 & 4253 & 14298 & 2112 & 696 & 1134 & 311 \\
\hline Média & 249,806 & & & & & & 0,862 & 18990 & & & & & & \\
\hline
\end{tabular}




\begin{tabular}{|c|c|c|c|c|c|c|c|c|c|c|c|c|c|c|}
\hline \multirow[b]{2}{*}{ Execução } & \multirow[b]{2}{*}{$\begin{array}{c}\text { Tempo } \\
\text { Total }\end{array}$} & \multirow{2}{*}{$\begin{array}{l}\text { Eventos } \\
\text { Processados } \\
\text { p/ segundo }\end{array}$} & \multirow[b]{2}{*}{$\begin{array}{l}\text { Realizados } \\
\text { p/ segundo }\end{array}$} & \multirow[b]{2}{*}{$\begin{array}{l}\text { Total Pro- } \\
\text { cessados }\end{array}$} & \multirow[b]{2}{*}{$\begin{array}{c}\text { Total Can- } \\
\text { celados }\end{array}$} & \multirow[b]{2}{*}{$\begin{array}{l}\text { Total Rea- } \\
\text { lizados }\end{array}$} & \multicolumn{3}{|c|}{ Rollbacks } & \multicolumn{5}{|c|}{ Causados por: } \\
\hline & & & & & & & Eficiência & Total & $\begin{array}{l}\text { Primá- } \\
\text { rios }\end{array}$ & Secundários & 0 & 1 & 2 & 3 \\
\hline 1 & $\mathbf{3 5 1 , 3 7 1}$ & 901,410 & 755,454 & 316239 & 51226 & 265013 & $\mathbf{0 , 8 3 8}$ & 23797 & 5027 & 18770 & 2666 & 688 & 1168 & 505 \\
\hline 2 & 354,726 & 897,970 & 748,526 & 318065 & 52972 & 265093 & $\mathbf{0 , 8 3 3}$ & 24942 & 5269 & 19673 & 2882 & 676 & 1186 & 525 \\
\hline 3 & 356,907 & 896,726 & 735,507 & 319301 & 57420 & 261881 & $\mathbf{0 , 8 2 0}$ & 26441 & 5507 & 20934 & 2851 & 728 & 1330 & 598 \\
\hline 4 & 352,296 & 896,530 & 744,108 & 315395 & 53620 & 261775 & $\mathbf{0 , 8 3 0}$ & 24860 & 5252 & 19608 & 2772 & 699 & 1227 & 554 \\
\hline 5 & 354,646 & 894,331 & 742,445 & 316883 & 53842 & 263041 & $\mathbf{0 , 8 3 0}$ & 24902 & 5171 & 19731 & 2706 & 662 & 1225 & 578 \\
\hline 6 & 348,453 & 903,070 & 761,178 & 314368 & 49396 & 264972 & 0,843 & 22931 & 4871 & 18060 & 2619 & 657 & 1082 & 513 \\
\hline 7 & 339,284 & 906,425 & 770,936 & 306963 & 45927 & 261036 & $\mathbf{0 , 8 5 0}$ & 21441 & 4755 & 16686 & 2441 & 698 & 1111 & 505 \\
\hline 8 & 340,488 & 911,192 & 769,496 & 308694 & 47977 & 260717 & 0,845 & 22449 & 4956 & 17493 & 2593 & 700 & 1142 & 521 \\
\hline 9 & 343,076 & 900,040 & 758,463 & 307950 & 48406 & 259544 & 0,843 & 22726 & 4873 & 17853 & 2607 & 704 & 1112 & 450 \\
\hline 10 & 332,452 & 902,339 & 768,537 & 299661 & 44457 & 255204 & 0,852 & 20877 & 4753 & 16124 & 2609 & 691 & 942 & 511 \\
\hline 11 & $\mathbf{3 3 8 , 3 7 7}$ & 904,155 & 774,419 & 304887 & 43734 & 261153 & $\mathbf{0 , 8 5 7}$ & 20564 & 4668 & 15896 & 2480 & 666 & 1003 & 519 \\
\hline 12 & $\mathbf{3 3 7 , 4 1 7}$ & 901,341 & 764,313 & 303716 & 46196 & 257520 & 0,848 & 21329 & 4682 & 16647 & 2735 & 684 & 920 & 343 \\
\hline 13 & 336,670 & 905,741 & 766,920 & 303312 & 46466 & 256846 & 0,847 & 21607 & 4799 & 16808 & 2739 & 694 & 962 & 404 \\
\hline 14 & 338,191 & 902,456 & 765,352 & 304401 & 46263 & 258138 & 0,848 & 21626 & 4752 & 16874 & 2642 & 642 & 986 & 482 \\
\hline 15 & 337,204 & 896,359 & 761,399 & 301344 & 45346 & 255998 & 0,850 & 21200 & 4777 & 16423 & 2637 & 688 & 996 & 456 \\
\hline Média & 344,104 & & & & & & 0,842 & 22779 & & & & & & \\
\hline
\end{tabular}

Tabela B. 32 - Dados da execução do Modelo N com Round Robin. 


\begin{tabular}{|c|c|c|c|c|c|c|c|c|c|c|c|c|c|c|}
\hline \multirow[b]{2}{*}{ Execução } & \multirow[b]{2}{*}{$\begin{array}{c}\text { Tempo } \\
\text { Total }\end{array}$} & \multicolumn{3}{|l|}{ Eventos } & \multirow[b]{2}{*}{\begin{tabular}{|c|} 
Total Can- \\
celados
\end{tabular}} & \multirow[b]{2}{*}{$\begin{array}{c}\text { Total Rea- } \\
\text { lizados }\end{array}$} & \multicolumn{3}{|c|}{ Rollbacks } & \multicolumn{5}{|c|}{ Causados por: } \\
\hline & & $\begin{array}{c}\text { Processados } \\
\text { p/ segundo }\end{array}$ & $\begin{array}{l}\text { Realizados } \\
\text { p/ segundo }\end{array}$ & $\begin{array}{c}\text { Total Pro- } \\
\text { cessados }\end{array}$ & & & Eficiência & Total & $\begin{array}{l}\text { Primá- } \\
\text { rios }\end{array}$ & Secundários & 0 & 1 & 2 & 3 \\
\hline 1 & 245,245 & 1208,413 & 1043,609 & 295885 & 40392 & 255493 & 0,863 & 18897 & 4328 & 14569 & 2116 & 722 & 1133 & 357 \\
\hline 2 & 242,289 & 1218,245 & 1055,825 & 294852 & 39330 & 255522 & $\mathbf{0 , 8 6 7}$ & 18252 & 4290 & 13962 & 2162 & 674 & 1120 & 334 \\
\hline 3 & 245,055 & 1204,088 & 1038,450 & 294438 & 40554 & 253884 & $\mathbf{0 , 8 6 2}$ & 18700 & 4376 & 14324 & 2204 & 754 & 1111 & 307 \\
\hline 4 & 242,037 & 1211,597 & 1049,297 & 292930 & 39263 & 253667 & 0,866 & 18366 & 4198 & 14168 & 2153 & 675 & 1049 & 321 \\
\hline 5 & 244,857 & 1211,024 & 1050,657 & 295203 & 39111 & 256092 & 0,868 & 18316 & 4083 & 14233 & 2060 & 632 & 1048 & 343 \\
\hline 6 & 242,631 & 1216,594 & 1051,204 & 294655 & 40058 & 254597 & 0,864 & 18700 & 4238 & 14462 & 2233 & 652 & 1009 & 344 \\
\hline 7 & 244,712 & 1213,533 & 1055,171 & 296216 & 38651 & 257565 & 0,870 & 18294 & 4221 & 14073 & 2172 & 665 & 1044 & 340 \\
\hline 8 & 245,856 & 1209,227 & 1040,350 & 296859 & 41491 & 255368 & $\mathbf{0 , 8 6 0}$ & 19507 & 4455 & 15052 & 2216 & 700 & 1181 & 358 \\
\hline 9 & 247,809 & 1213,034 & 1042,369 & 300463 & 42285 & 258178 & $\mathbf{0 , 8 5 9}$ & 19679 & 4391 & 15288 & 2211 & 636 & 1189 & 355 \\
\hline 10 & 244,672 & 1212,400 & 1052,311 & 295196 & 38993 & 256203 & 0,868 & 18373 & 4229 & 14144 & 2167 & 678 & 1088 & 296 \\
\hline 11 & 244,650 & 1207,061 & 1045,334 & 294768 & 39523 & 255245 & 0,866 & 18481 & 4226 & 14255 & 2265 & 686 & 996 & 279 \\
\hline 12 & 246,416 & 1213,912 & 1034,284 & 298514 & 44203 & 254311 & $\mathbf{0 , 8 5 2}$ & 20659 & 4578 & 16081 & 2354 & 691 & 1164 & 369 \\
\hline 13 & 245,818 & 1210,560 & 1044,400 & 297138 & 40838 & 256300 & $\mathbf{0 , 8 6 3}$ & 19206 & 4413 & 14793 & 2233 & 652 & 1183 & 345 \\
\hline 14 & 241,743 & 1214,136 & 1051,502 & 292940 & 39233 & 253707 & 0,866 & 18319 & 4243 & 14076 & 2159 & 727 & 1039 & 318 \\
\hline 15 & 245,624 & 1213,385 & 1048,969 & 296986 & 40264 & 256722 & 0,864 & 18994 & 4241 & 14753 & 2144 & 670 & 1110 & 317 \\
\hline Média & 244,628 & & & & & & 0,864 & 18850 & & & & & & \\
\hline
\end{tabular}




\begin{tabular}{|c|c|c|c|c|c|c|c|c|c|c|c|c|c|c|}
\hline \multirow[b]{2}{*}{ Execução } & \multirow[b]{2}{*}{$\begin{array}{c}\text { Tempo } \\
\text { Total }\end{array}$} & \multirow{2}{*}{$\begin{array}{l}\text { Eventos } \\
\text { Processados } \\
\text { p/ segundo }\end{array}$} & \multirow[b]{2}{*}{$\begin{array}{l}\text { Realizados } \\
\text { p/ segundo }\end{array}$} & \multirow[b]{2}{*}{$\begin{array}{l}\text { Total Pro- } \\
\text { cessados }\end{array}$} & \multirow[b]{2}{*}{$\begin{array}{c}\text { Total Can- } \\
\text { celados }\end{array}$} & \multirow[b]{2}{*}{$\begin{array}{c}\text { Total Rea- } \\
\text { lizados }\end{array}$} & \multicolumn{3}{|c|}{ Rollbacks } & \multicolumn{5}{|c|}{ Causados por: } \\
\hline & & & & & & & Eficiência & Total & $\begin{array}{c}\text { Primá- } \\
\text { rios }\end{array}$ & Secundários & 0 & 1 & 2 & 3 \\
\hline 1 & $\mathbf{3 5 9 , 7 0 7}$ & 1392,295 & 1196,271 & 499901 & 70386 & 429515 & 0,859 & 24747 & 6656 & 18091 & 4863 & 799 & 224 & 770 \\
\hline 2 & 356,476 & 1392,124 & 1198,279 & 495184 & 68950 & 426234 & $\mathbf{0 , 8 6 1}$ & 24519 & 6637 & 17882 & 4848 & 842 & 214 & 733 \\
\hline 3 & 357,293 & 1390,639 & 1198,678 & 496252 & 68542 & 427710 & 0,862 & 24462 & 6490 & 17972 & 4804 & 805 & 185 & 696 \\
\hline 4 & $\mathbf{3 5 7 , 9 3 7}$ & 1389,852 & 1197,630 & 496693 & 68663 & 428030 & 0,862 & 24050 & 6418 & 17632 & 4706 & 742 & 237 & 733 \\
\hline 5 & 356,721 & 1391,680 & 1200,237 & 495576 & 68143 & 427433 & 0,862 & 24139 & 6313 & 17826 & 4681 & 739 & 219 & 674 \\
\hline 6 & 355,951 & 1393,621 & 1201,248 & 495259 & 68312 & 426947 & 0,862 & 24181 & 6512 & 17669 & 4826 & 783 & 180 & 723 \\
\hline 7 & 357,896 & 1390,352 & 1196,496 & 496757 & 69209 & 427548 & 0,861 & 24554 & 6682 & 17872 & 4915 & 829 & 213 & 725 \\
\hline 8 & 356,275 & 1394,163 & 1202,885 & 496151 & 68074 & 428077 & 0,863 & 24317 & 6592 & 17725 & 4891 & 753 & 185 & 763 \\
\hline 9 & $\mathbf{3 5 5 , 9 3 7}$ & 1390,944 & 1196,538 & 494856 & 69154 & 425702 & 0,860 & 24150 & 6474 & 17676 & 4757 & 772 & 231 & 714 \\
\hline 10 & $\mathbf{3 5 7 , 5 5 3}$ & 1394,656 & 1201,331 & 497827 & 68956 & 428871 & $\mathbf{0 , 8 6 1}$ & 24399 & 6615 & 17784 & 4827 & 843 & 236 & 709 \\
\hline 11 & 360,866 & 1390,500 & 1197,918 & 501274 & 69446 & 431828 & 0,861 & 24743 & 6557 & 18186 & 4737 & 812 & 297 & 711 \\
\hline 12 & 355,429 & 1395,080 & 1201,578 & 494940 & 68636 & 426304 & 0,861 & 24241 & 6603 & 17638 & 4871 & 854 & 159 & 719 \\
\hline 13 & 357,020 & 1389,678 & 1191,518 & 495540 & 70703 & 424837 & $\mathbf{0 , 8 5 7}$ & 25143 & 6709 & 18434 & 5057 & 754 & 130 & 768 \\
\hline 14 & $\mathbf{3 5 4 , 5 7 0}$ & 1386,686 & 1190,874 & 491175 & 69428 & 421747 & 0,859 & 24625 & 6491 & 18134 & 4894 & 749 & 126 & 722 \\
\hline 15 & 355,212 & 1389,106 & 1193,608 & 492691 & 69404 & 423287 & 0,859 & 24316 & 6679 & 17637 & 4912 & 869 & 121 & 777 \\
\hline Média & 356,990 & & & & & & 0,861 & 24439 & & & & & & \\
\hline
\end{tabular}

Tabela B. 34 - Dados da execução do Modelo P com Round Robin. 


\begin{tabular}{|c|c|c|c|c|c|c|c|c|c|c|c|c|c|c|}
\hline \multirow[b]{2}{*}{ Execução } & \multirow[b]{2}{*}{$\begin{array}{c}\text { Tempo } \\
\text { Total }\end{array}$} & \multicolumn{3}{|l|}{ Eventos } & \multirow[b]{2}{*}{\begin{tabular}{|c|} 
Total Can- \\
celados
\end{tabular}} & \multirow[b]{2}{*}{$\begin{array}{c}\text { Total Rea- } \\
\text { lizados }\end{array}$} & \multicolumn{3}{|c|}{ Rollbacks } & \multicolumn{5}{|c|}{ Causados por: } \\
\hline & & $\begin{array}{c}\text { Processados } \\
\text { p/ segundo }\end{array}$ & $\begin{array}{l}\text { Realizados } \\
\text { p/ segundo }\end{array}$ & $\begin{array}{c}\text { Total Pro- } \\
\text { cessados }\end{array}$ & & & Eficiência & Total & $\begin{array}{l}\text { Primá- } \\
\text { rios }\end{array}$ & Secundários & 0 & 1 & 2 & 3 \\
\hline 1 & 346,589 & 1439,707 & 1236,615 & 497961 & 70203 & 427758 & 0,859 & 24758 & 6608 & 18150 & 4976 & 752 & 163 & 717 \\
\hline 2 & 346,905 & 1436,094 & 1225,367 & 496911 & 72829 & 424082 & $\mathbf{0 , 8 5 3}$ & 25685 & 6586 & 19099 & 5035 & 735 & 124 & 692 \\
\hline 3 & 348,853 & 1430,523 & 1224,290 & 497706 & 71800 & 425906 & 0,856 & 25338 & 6651 & 18687 & 5044 & 785 & 102 & 720 \\
\hline 4 & 345,787 & 1445,080 & 1232,985 & 499325 & 73319 & 426006 & $\mathbf{0 , 8 5 3}$ & 25668 & 6562 & 19106 & 5008 & 799 & 102 & 653 \\
\hline 5 & 345,148 & 1438,556 & 1227,041 & 495665 & 72823 & 422842 & $\mathbf{0 , 8 5 3}$ & 25293 & 6674 & 18619 & 5079 & 763 & 82 & 750 \\
\hline 6 & 345,361 & 1439,640 & 1225,581 & 496291 & 73813 & 422478 & $\mathbf{0 , 8 5 1}$ & 25841 & 6720 & 19121 & 5155 & 767 & 103 & 695 \\
\hline 7 & 346,856 & 1442,841 & 1236,120 & 499456 & 71530 & 427926 & $\mathbf{0 , 8 5 7}$ & 25118 & 6624 & 18494 & 4890 & 809 & 214 & 711 \\
\hline 8 & 345,762 & 1446,684 & 1232,627 & 499312 & 73916 & 425396 & 0,852 & 26244 & 6830 & 19414 & 5170 & 760 & 161 & 739 \\
\hline 9 & $\mathbf{3 4 4 , 8 7 7}$ & 1444,619 & 1237,594 & 497536 & 71397 & 426139 & $\mathbf{0 , 8 5 6}$ & 25166 & 6563 & 18603 & 4941 & 738 & 150 & 734 \\
\hline 10 & 345,733 & 1442,163 & 1237,105 & 497749 & 70800 & 426949 & 0,858 & 24962 & 6586 & 18377 & 4959 & 745 & 157 & 726 \\
\hline 11 & 346,333 & 1441,389 & 1228,997 & 498112 & 73373 & 424739 & $\mathbf{0 , 8 5 3}$ & 25965 & 6708 & 19257 & 5103 & 748 & 143 & 716 \\
\hline 12 & 347,854 & 1436,682 & 1230,205 & 498581 & 71665 & 426916 & 0,856 & 25228 & 6638 & 18591 & 4967 & 797 & 158 & 716 \\
\hline 13 & 345,574 & 1442,360 & 1229,283 & 497808 & 73566 & 424242 & $\mathbf{0 , 8 5 2}$ & 25755 & 6641 & 19114 & 5082 & 783 & 103 & 674 \\
\hline 14 & 347,721 & 1435,115 & 1230,453 & 497834 & 71002 & 426832 & $\mathbf{0 , 8 5 7}$ & 25048 & 6630 & 18419 & 5010 & 769 & 133 & 719 \\
\hline 15 & 345,574 & 1442,360 & 1229,283 & 497808 & 73566 & 424242 & 0,852 & 25755 & 6641 & 19114 & 5082 & 783 & 103 & 674 \\
\hline Média & 346,329 & & & & & & 0,855 & 25455 & & & & & & \\
\hline
\end{tabular}




\section{B.1.5. Modelos executados com benchmarks mistos}

\begin{tabular}{|c|c|c|c|c|c|c|c|c|c|c|c|c|c|c|}
\hline \multirow[b]{2}{*}{ Execução } & \multirow[b]{2}{*}{$\begin{array}{c}\text { Tempo } \\
\text { Total }\end{array}$} & \multicolumn{5}{|l|}{ Eventos } & \multicolumn{3}{|c|}{ Rollbacks } & \multicolumn{5}{|c|}{ Causados por: } \\
\hline & & $\begin{array}{c}\text { Processados } \\
\text { p/segundo }\end{array}$ & $\begin{array}{l}\text { Realizados } \\
\text { p/ segundo }\end{array}$ & $\begin{array}{l}\text { Total Pro- } \\
\text { cessados }\end{array}$ & $\begin{array}{c}\text { Total Can- } \\
\text { celados }\end{array}$ & $\begin{array}{l}\text { Total Rea- } \\
\text { lizados }\end{array}$ & Eficiência & Total & $\begin{array}{c}\text { Primá- } \\
\text { rios }\end{array}$ & Secundários & 0 & 1 & 2 & 3 \\
\hline 1 & $\mathbf{7 4 9 , 7 8 1}$ & 1814,468 & 1279,932 & 1358547 & 400078 & 958469 & 0,706 & 141395 & 31508 & 109887 & 3089 & 9142 & 8688 & 10589 \\
\hline 2 & 586,395 & 1908,562 & 1588,557 & 1118729 & 187555 & 931174 & 0,832 & 66051 & 18827 & 47224 & 2829 & 4862 & 4371 & 6765 \\
\hline 3 & 563,455 & 1921,230 & 1627,964 & 1081865 & 165098 & 916767 & 0,847 & 59472 & 16546 & 42926 & 2552 & 4394 & 3814 & 5786 \\
\hline 4 & 553,603 & 1925,552 & 1637,218 & 1065748 & 159583 & 906165 & $\mathbf{0 , 8 5 0}$ & 57158 & 16709 & 40449 & 2735 & 4271 & 3874 & 5829 \\
\hline 5 & 603,436 & 1898,103 & 1543,964 & 1144852 & 213582 & 931270 & $\mathbf{0 , 8 1 3}$ & 76421 & 20351 & 56070 & 2849 & 5558 & 4911 & 7033 \\
\hline 6 & 573,533 & 1919,567 & 1603,804 & 1100335 & 180966 & 919369 & $\mathbf{0 , 8 3 6}$ & 64621 & 16719 & 47902 & 2464 & 4562 & 3953 & 5740 \\
\hline 7 & 475,089 & 2003,933 & 1868,067 & 951604 & 64511 & 887093 & 0,932 & 23450 & 8341 & 15109 & 2042 & 1806 & 1596 & 2897 \\
\hline 8 & 492,627 & 1993,537 & 1831,377 & 981308 & 79790 & 901518 & 0,919 & 29284 & 9964 & 19320 & 2218 & 2287 & 1947 & 3512 \\
\hline 9 & 633,852 & 1888,987 & 1531,485 & 1195889 & 226250 & 969639 & 0,811 & 80052 & 19130 & 60922 & 2362 & 5248 & 4852 & 6668 \\
\hline 10 & 657,281 & 1856,016 & 1429,854 & 1218705 & 279741 & 938964 & $\mathbf{0 , 7 7 0}$ & 99777 & 24785 & 74992 & 2905 & 7002 & 6520 & 8358 \\
\hline 11 & $\mathbf{5 5 0 , 8 0 5}$ & 1927,860 & 1662,975 & 1061285 & 145781 & 915504 & $\mathbf{0 , 8 6 3}$ & 52741 & 15841 & 36900 & 2673 & 4022 & 3454 & 5692 \\
\hline 12 & 525,680 & 1959,754 & 1735,308 & 1029728 & 117921 & 911807 & $\mathbf{0 , 8 8 5}$ & 42343 & 13322 & 29021 & 2490 & 3156 & 2864 & 4812 \\
\hline 13 & 522,882 & 1956,444 & 1741,486 & 1022764 & 112380 & 910384 & $\mathbf{0 , 8 9 0}$ & 40450 & 13049 & 27401 & 2525 & 3154 & 2840 & 4530 \\
\hline 14 & 609,269 & 1907,631 & 1599,885 & 1160382 & 187091 & 973291 & $\mathbf{0 , 8 3 9}$ & 67242 & 17502 & 49740 & 2552 & 4693 & 4097 & 6160 \\
\hline 15 & 754,973 & 1814,006 & 1281,369 & 1368188 & 401643 & 966545 & 0,706 & 140838 & 30925 & 109913 & 2926 & 9010 & 8611 & 10378 \\
\hline Média & 590,177 & & & & & & $\mathbf{0 , 8 3 3}$ & 69420 & & & & & & \\
\hline
\end{tabular}

Tabela B. 36 - Dados da execução do Modelo G com benchmarks de memória e rede. 


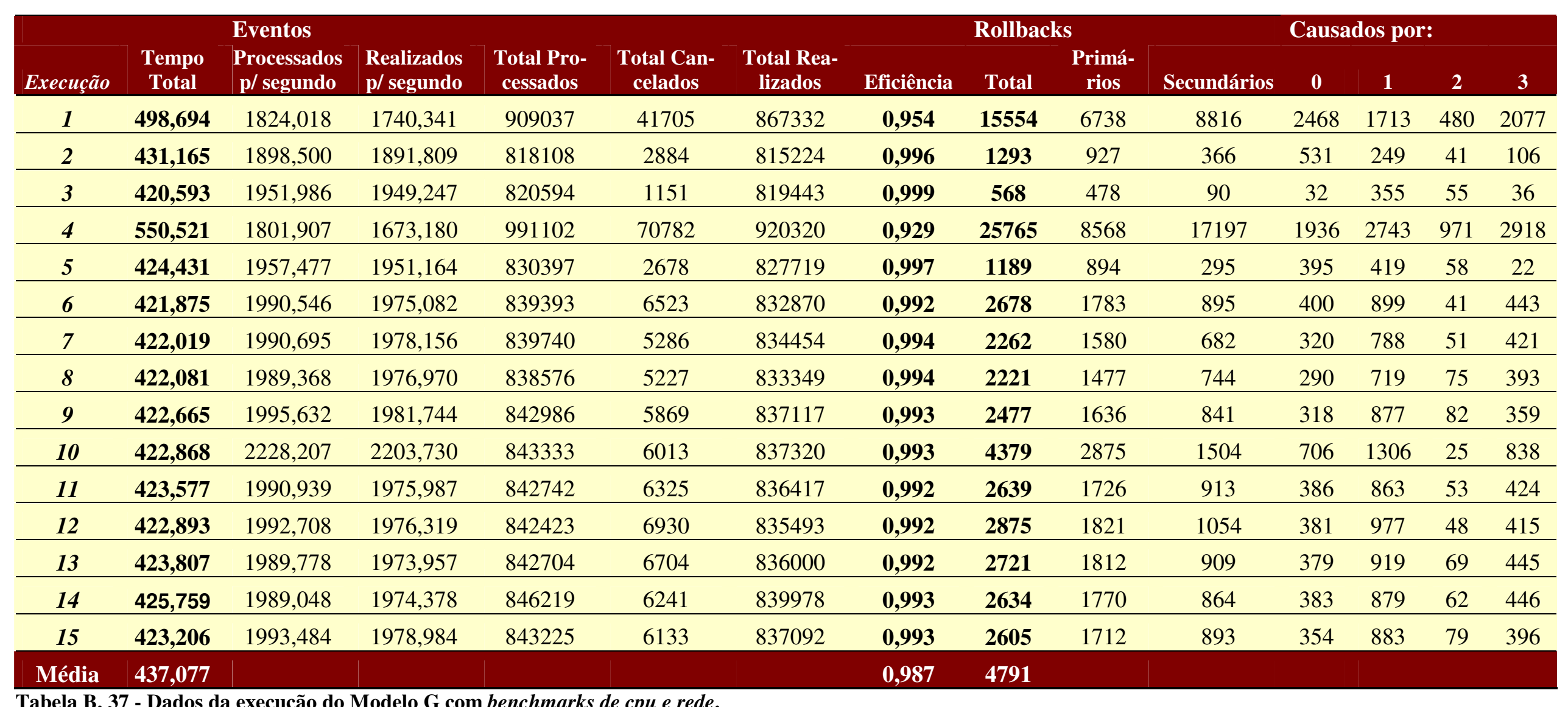




\begin{tabular}{|c|c|c|c|c|c|c|c|c|c|c|c|c|c|c|}
\hline \multirow[b]{2}{*}{ Execução } & \multirow[b]{2}{*}{$\begin{array}{c}\text { Tempo } \\
\text { Total }\end{array}$} & \multirow{2}{*}{$\begin{array}{l}\text { Eventos } \\
\text { Processados } \\
\text { p/ segundo }\end{array}$} & \multirow[b]{2}{*}{$\begin{array}{l}\text { Realizados } \\
\text { p/ segundo }\end{array}$} & \multirow[b]{2}{*}{$\begin{array}{l}\text { Total Pro- } \\
\text { cessados }\end{array}$} & \multirow[b]{2}{*}{$\begin{array}{c}\text { Total Can- } \\
\text { celados }\end{array}$} & \multirow[b]{2}{*}{$\begin{array}{l}\text { Total Rea- } \\
\text { lizados }\end{array}$} & \multicolumn{3}{|c|}{ Rollbacks } & \multicolumn{5}{|c|}{ Causados por: } \\
\hline & & & & & & & Eficiência & Total & $\begin{array}{l}\text { Primá- } \\
\text { rios }\end{array}$ & Secundários & 0 & 1 & 2 & 3 \\
\hline 1 & 528,790 & 2051,126 & 1732,054 & 1083653 & 168557 & 915096 & 0,844 & 60131 & 16424 & 43707 & 2451 & 3106 & 4647 & 6220 \\
\hline 2 & 530,287 & 2048,908 & 1725,046 & 1085794 & 171584 & 914210 & $\mathbf{0 , 8 4 2}$ & 61435 & 17123 & 44312 & 2519 & 3120 & 4869 & 6615 \\
\hline 3 & 528,436 & 2047,039 & 1730,737 & 1080739 & 166921 & 913818 & 0,846 & 60225 & 16401 & 43824 & 2377 & 3017 & 4717 & 6290 \\
\hline 4 & 528,436 & 2047,039 & 1730,737 & 1080739 & 166921 & 913818 & 0,846 & 60225 & 16401 & 43824 & 2377 & 3017 & 4717 & 6290 \\
\hline 5 & 526,736 & 2050,463 & 1729,350 & 1079689 & 169092 & 910597 & 0,843 & 60214 & 16656 & 43558 & 2519 & 3035 & 4746 & 6356 \\
\hline 6 & 529,976 & 2052,352 & 1730,915 & 1086684 & 170089 & 916595 & $\mathbf{0 , 8 4 3}$ & 61388 & 16771 & 44617 & 2425 & 3054 & 4755 & 6537 \\
\hline 7 & 527,906 & 2048,889 & 1725,202 & 1080887 & 170713 & 910174 & 0,842 & 60835 & 16923 & 43912 & 3751 & 4711 & 4824 & 6447 \\
\hline 8 & 529,541 & 2050,704 & 1727,296 & 1085481 & 171170 & 914311 & 0,842 & 61694 & 16787 & 44907 & 2488 & 3073 & 4791 & 6435 \\
\hline 9 & $\mathbf{5 2 7 , 7 7 2}$ & 2050,443 & 1731,789 & 1081010 & 167902 & 913108 & 0,845 & 60096 & 16566 & 43530 & 2536 & 3044 & 4613 & 6373 \\
\hline 10 & $\mathbf{5 2 5 , 7 8 9}$ & 2047,695 & 1729,305 & 1075946 & 167204 & 908742 & 0,845 & 59552 & 16534 & 43018 & 2547 & 3055 & 4608 & 6324 \\
\hline 11 & 529,155 & 2047,891 & 1723,976 & 1082743 & 171241 & 911502 & $\mathbf{0 , 8 4 2}$ & 61993 & 16930 & 45063 & 2478 & 3085 & 4831 & 6536 \\
\hline 12 & $\mathbf{5 2 8 , 6 5 5}$ & 2050,807 & 1723,078 & 1083648 & 173167 & 910481 & 0,840 & 61748 & 16897 & 44851 & 2497 & 3001 & 4869 & 6530 \\
\hline 13 & 526,270 & 2050,850 & 1734,655 & 1078205 & 166176 & 912029 & 0,846 & 59423 & 16456 & 42967 & 2476 & 2923 & 4638 & 6419 \\
\hline 14 & 528,211 & 2047,591 & 1719,429 & 1081138 & 173226 & 907912 & 0,840 & 61391 & 16946 & 44445 & 2608 & 3022 & 4846 & 6470 \\
\hline 15 & 529,504 & 2046,675 & 1723,660 & 1083064 & 170864 & 912200 & 0,842 & 61135 & 16517 & 44618 & 2534 & 3149 & 4548 & 6286 \\
\hline Média & 528,364 & & & & & & 0,843 & 60766 & & & & & & \\
\hline
\end{tabular}

Tabela B. 38 - Dados da execução do Modelo G com benchmarks de cpu, rede e memória. 


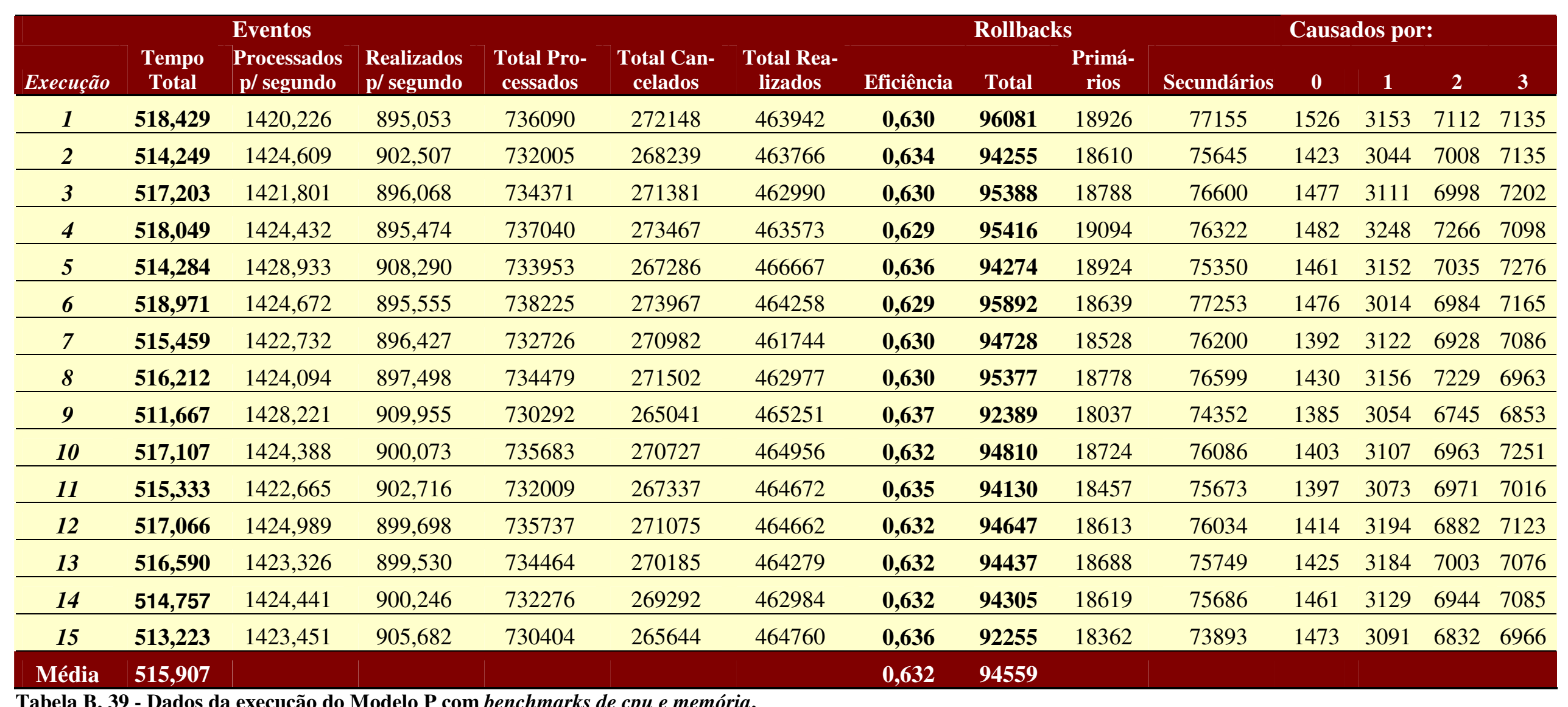




\begin{tabular}{|c|c|c|c|c|c|c|c|c|c|c|c|c|c|c|}
\hline \multirow[b]{2}{*}{ Execução } & \multirow[b]{2}{*}{$\begin{array}{c}\text { Tempo } \\
\text { Total }\end{array}$} & \multirow{2}{*}{$\begin{array}{l}\text { Eventos } \\
\text { Processados } \\
\text { p/ segundo }\end{array}$} & \multirow[b]{2}{*}{$\begin{array}{l}\text { Realizados } \\
\text { p/ segundo }\end{array}$} & \multirow[b]{2}{*}{$\begin{array}{l}\text { Total Pro- } \\
\text { cessados }\end{array}$} & \multirow[b]{2}{*}{$\begin{array}{c}\text { Total Can- } \\
\text { celados }\end{array}$} & \multirow[b]{2}{*}{$\begin{array}{c}\text { Total Rea- } \\
\text { lizados }\end{array}$} & \multicolumn{3}{|c|}{ Rollbacks } & \multicolumn{5}{|c|}{ Causados por: } \\
\hline & & & & & & & Eficiência & Total & $\begin{array}{l}\text { Primá- } \\
\text { rios }\end{array}$ & Secundários & 0 & 1 & 2 & 3 \\
\hline 1 & $\mathbf{3 2 9 , 1 7 8}$ & 1380,996 & 1333,880 & 453894 & 15506 & 438388 & 0,966 & 5921 & 2554 & 3367 & 1046 & 932 & 175 & 401 \\
\hline 2 & $\mathbf{3 2 8 , 3 8 2}$ & 1379,833 & 1333,580 & 452086 & 15168 & 436918 & 0,966 & 5736 & 2579 & 3157 & 993 & 946 & 241 & 399 \\
\hline 3 & 326,756 & 1378,668 & 1333,422 & 450128 & 14775 & 435353 & 0,967 & 5595 & 2522 & 3073 & 980 & 965 & 204 & 373 \\
\hline 4 & $\mathbf{3 2 8 , 7 9 5}$ & 1376,294 & 1329,622 & 451764 & 15339 & 436425 & 0,966 & 5740 & 2570 & 3170 & 991 & 969 & 216 & 394 \\
\hline 5 & 329,943 & 1376,509 & 1326,863 & 453103 & 16363 & 436740 & 0,964 & 6156 & 2626 & 3530 & 1071 & 1002 & 182 & 371 \\
\hline 6 & 328,759 & 1362,123 & 1323,011 & 447183 & 12848 & 434335 & $\mathbf{0 , 9 7 1}$ & 4941 & 2303 & 2638 & 872 & 917 & 177 & 337 \\
\hline 7 & $\mathbf{3 3 1}, \mathbf{3 7 3}$ & 1374,460 & 1327,477 & 454524 & 15541 & 438983 & 0,966 & 5859 & 2559 & 3300 & 1005 & 929 & 225 & 400 \\
\hline 8 & $\mathbf{3 2 6 , 3 3 0}$ & 1381,004 & 1335,056 & 450054 & 14988 & 435066 & 0,967 & 5510 & 2480 & 3030 & 981 & 944 & 188 & 367 \\
\hline 9 & $\mathbf{3 2 9 , 5 3 5}$ & 1373,764 & 1328,879 & 451837 & 14766 & 437071 & 0,967 & 5675 & 2552 & 3123 & 992 & 951 & 237 & 372 \\
\hline 10 & 326,611 & 1379,632 & 1332,353 & 450102 & 15431 & 434671 & 0,966 & 5598 & 2450 & 3148 & 943 & 1004 & 205 & 298 \\
\hline 11 & $\mathbf{3 2 8 , 4 7 2}$ & 1376,360 & 1327,526 & 451600 & 16030 & 435570 & 0,965 & 5934 & 2616 & 3318 & 1016 & 988 & 232 & 380 \\
\hline 12 & 328,779 & 1378,862 & 1328,970 & 453048 & 16401 & 436647 & 0,964 & 6071 & 2643 & 3428 & 1074 & 990 & 204 & 375 \\
\hline 13 & 328,244 & 1379,226 & 1329,088 & 452293 & 16446 & 435847 & 0,964 & 6071 & 2629 & 3442 & 1081 & 1008 & 207 & 333 \\
\hline 14 & 328,708 & 1379,090 & 1331,828 & 452567 & 15521 & 437046 & 0,966 & 5858 & 2567 & 3291 & 1029 & 964 & 161 & 413 \\
\hline 15 & $\mathbf{3 2 9 , 5 9 0}$ & 1375,250 & 1326,736 & 452426 & 15965 & 436461 & 0,965 & 5864 & 2607 & 3257 & 1047 & 973 & 188 & 399 \\
\hline Média & 328,630 & & & & & & 0,966 & 5769 & & & & & & \\
\hline
\end{tabular}

Tabela B. 40 - Dados da execução do Modelo P com benchmarks de cpu e rede. 


\begin{tabular}{|c|c|c|c|c|c|c|c|c|c|c|c|c|c|c|}
\hline \multirow[b]{2}{*}{ Execução } & \multirow[b]{2}{*}{$\begin{array}{c}\text { Tempo } \\
\text { Total }\end{array}$} & \multicolumn{5}{|l|}{ Eventos } & \multicolumn{4}{|c|}{ Rollbacks } & \multicolumn{4}{|c|}{ Causados por: } \\
\hline & & $\begin{array}{c}\text { Processados } \\
\text { p/ segundo }\end{array}$ & $\begin{array}{l}\text { Realizados } \\
\text { p/ segundo }\end{array}$ & \begin{tabular}{|c} 
Total Pro- \\
cessados
\end{tabular} & \begin{tabular}{|c|} 
Total Can- \\
celados
\end{tabular} & $\begin{array}{c}\text { Total Rea- } \\
\text { lizados }\end{array}$ & Eficiência & Total & $\begin{array}{l}\text { Primá- } \\
\text { rios }\end{array}$ & Secundários & 0 & 1 & 2 & 3 \\
\hline 1 & 328,215 & 1386,775 & 1291,393 & 454206 & 31196 & 423010 & 0,931 & 11111 & 3723 & 7388 & 624 & 694 & 1182 & 1223 \\
\hline 2 & 329,293 & 1385,797 & 1288,865 & 455666 & 31883 & 423783 & $\mathbf{0 , 9 3 0}$ & 11785 & 3759 & 8026 & 642 & 637 & 1200 & 1280 \\
\hline 3 & 327,780 & 1388,250 & 1291,895 & 454217 & 31492 & 422725 & 0,931 & 11417 & 3712 & 7705 & 613 & 645 & 1272 & 1182 \\
\hline 4 & 327,676 & 1386,205 & 1289,608 & 454059 & 31635 & 422424 & $\mathbf{0 , 9 3 0}$ & 11288 & 3712 & 7576 & 599 & 679 & 1183 & 1251 \\
\hline 5 & 328,716 & 1388,417 & 1291,533 & 455848 & 31836 & 424012 & 0,930 & 11454 & 3730 & 7724 & 633 & 621 & 1255 & 1221 \\
\hline 6 & 327,704 & 1386,592 & 1290,391 & 453846 & 31464 & 422382 & $\mathbf{0 , 9 3 1}$ & 11176 & 3665 & 7511 & 622 & 671 & 1201 & 1171 \\
\hline 7 & $\mathbf{3 2 7 , 5 5 1}$ & 1387,272 & 1291,871 & 453689 & 31194 & 422495 & $\mathbf{0 , 9 3 1}$ & 11268 & 3843 & 7425 & 631 & 695 & 1272 & 1245 \\
\hline 8 & 325,194 & 1389,487 & 1296,457 & 451669 & 30226 & 421443 & $\mathbf{0 , 9 3 3}$ & 10843 & 3583 & 7260 & 603 & 618 & 1144 & 1218 \\
\hline 9 & 323,940 & 1392,316 & 1298,090 & 450595 & 30501 & 420094 & $\mathbf{0 , 9 3 2}$ & 10977 & 3667 & 7310 & 634 & 657 & 1198 & 1178 \\
\hline 10 & 335,680 & 1374,066 & 1268,568 & 460685 & 35396 & 425289 & 0,923 & 12622 & 4074 & 8548 & 723 & 674 & 1342 & 1335 \\
\hline 11 & 329,569 & 1381,488 & 1281,355 & 454867 & 32989 & 421878 & 0,927 & 11720 & 3758 & 7962 & 613 & 648 & 1307 & 1190 \\
\hline 12 & 351,061 & 1352,457 & 1228,592 & 474654 & 43475 & 431179 & 0,908 & 15494 & 4973 & 10521 & 691 & 913 & 1965 & 1404 \\
\hline 13 & 335,792 & 1375,110 & 1273,111 & 461225 & 34219 & 427006 & 0,926 & 12221 & 4005 & 8216 & 691 & 693 & 1262 & 1359 \\
\hline 14 & 332,624 & 1377,777 & 1274,962 & 457776 & 34193 & 423584 & 0,925 & 12171 & 3916 & 8255 & 668 & 661 & 1325 & 1263 \\
\hline 15 & 330,493 & 1382,298 & 1284,784 & 456447 & 32223 & 424225 & 0,929 & 11532 & 3794 & 7738 & 647 & 656 & 1203 & 1289 \\
\hline Média & 330,753 & & & & & & 0,928 & 11805 & & & & & & \\
\hline
\end{tabular}




\section{B.2. Execução do modelo $\mathrm{G}$ em Ambiente Compartilhado}

\section{B.2.1 Com carga parasita determinística}

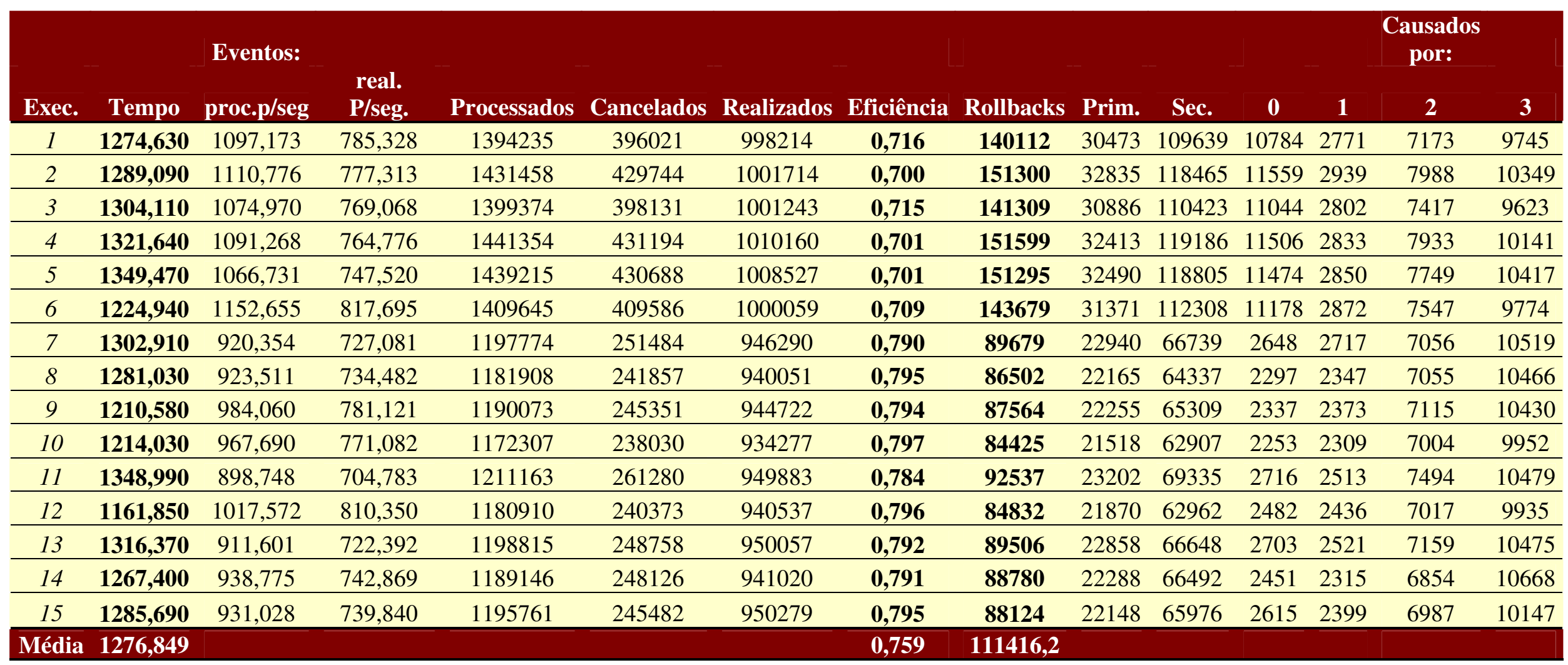

Tabela B. 42 - Dados da execução com o round-robin. 


\begin{tabular}{|c|c|c|c|c|c|c|c|c|c|c|c|c|c|c|}
\hline Exec. & Tempo & $\begin{array}{l}\text { Eventos: } \\
\text { proc.p/seg }\end{array}$ & real. P/seg. & Processados & Cancelados & Realizados & Eficiência & Rollbacks & Prim. & Sec. & 0 & 1 & $\begin{array}{c}\text { Causados } \\
\text { por: } \\
2\end{array}$ & 3 \\
\hline 1 & 863,107 & 1289,507 & 1094,018 & 1112179 & 168614 & 943565 & 0,848 & 59691 & 15356 & 44335 & 2116 & 5441 & 3626 & 4173 \\
\hline 2 & 1016,910 & 1011,280 & 879,056 & 1023836 & 133791 & 890045 & 0,869 & 47640 & 12722 & 34918 & 3233 & 2762 & 4946 & 1781 \\
\hline 3 & 1056,290 & 1120,159 & 916,403 & 1181367 & 215018 & 966349 & 0,818 & 77348 & 19539 & 57809 & 2634 & 4192 & 6414 & 6299 \\
\hline 4 & 802,416 & 1072,353 & 1042,941 & 854207 & 23414 & 830793 & 0,973 & 9023 & 4297 & 4726 & 700 & 901 & 1774 & 922 \\
\hline 5 & 785,803 & 1108,825 & 1050,557 & 870198 & 45707 & 824491 & 0,947 & 17127 & 7190 & 9937 & 1679 & 1573 & 1778 & 2160 \\
\hline 6 & 1034,210 & 1017,640 & 936,772 & 1047985 & 83273 & 964712 & 0,921 & 30113 & 9554 & 20559 & 1515 & 3219 & 2752 & 2068 \\
\hline 7 & 945,274 & 980,823 & 892,132 & 926796 & 83807 & 842989 & 0,910 & 30161 & 9615 & 20546 & 1923 & 2366 & 4367 & 959 \\
\hline 8 & 898,495 & 1146,619 & 1048,187 & 1027941 & 88191 & 939750 & 0,914 & 31461 & 8650 & 22811 & 1234 & 3127 & 1338 & 2951 \\
\hline 9 & 961,753 & 1082,030 & 911,966 & 1039977 & 163415 & 876562 & 0,843 & 58168 & 15056 & 43112 & 4096 & 3937 & 4740 & 2283 \\
\hline 10 & 869,600 & 1060,510 & 990,771 & 916815 & 60312 & 856503 & 0,934 & 22157 & 7961 & 14196 & 2078 & 1438 & 2468 & 1977 \\
\hline 11 & 897,003 & 1015,181 & 940,919 & 909552 & 66504 & 843048 & 0,927 & 23879 & 7963 & 15916 & 1744 & 1374 & 1487 & 3358 \\
\hline 12 & 1135,040 & 1031,795 & 808,438 & 1165659 & 252477 & 913182 & 0,783 & 88945 & 19227 & 69718 & 2515 & 6143 & 2202 & 8367 \\
\hline 13 & 719,227 & 1171,368 & 1138,728 & 840931 & 23427 & 817504 & 0,972 & 8957 & 4605 & 4352 & 1269 & 1185 & 1204 & 947 \\
\hline 14 & $\mathbf{7 8 5 , 3 3 8}$ & 1108,982 & 1052,110 & 870395 & 44631 & 825764 & 0,949 & 16316 & 5679 & 10637 & 1308 & 1956 & 885 & 1530 \\
\hline 15 & 865,211 & 1134,023 & 1031,900 & 979622 & 88208 & 891414 & 0,910 & 31991 & 11545 & 20446 & 2402 & 2945 & 2463 & 3735 \\
\hline Média & 909,045 & & & & & & 0,901 & 36865,133 & & & & & & \\
\hline
\end{tabular}




\begin{tabular}{|c|c|c|c|c|c|c|c|c|c|c|c|c|c|c|}
\hline Exec. & Tempo & $\begin{array}{l}\text { Eventos: } \\
\text { proc.p/seg }\end{array}$ & real. P/seg. & Processados & Cancelados & Realizados & Eficiência & Rollbacks & Prim. & Sec. & 0 & 1 & $\begin{array}{c}\text { Causados } \\
\text { por: } \\
\mathbf{2}\end{array}$ & 3 \\
\hline 1 & 1397,900 & 1178,421 & 712,894 & 1646062 & 650165 & 995897 & 0,605 & 226968 & 41474 & 185494 & 3007 & 12134 & 11694 & 14639 \\
\hline 2 & 1933,910 & 1324,909 & 572,808 & 2556930 & 1450891 & 1106039 & 0,433 & 501311 & 65085 & 436226 & 2930 & 24265 & 17583 & 20307 \\
\hline 3 & 1699,770 & 1252,026 & 606,159 & 2125887 & 1096447 & 1029440 & 0,484 & 379756 & 51811 & 327945 & 2922 & 17632 & 15981 & 15276 \\
\hline 4 & 2035,100 & 1270,820 & 533,634 & 2585180 & 1499742 & 1085438 & 0,420 & 518524 & 65042 & 453482 & 3037 & 22232 & 18109 & 21664 \\
\hline 5 & 2522,050 & 1570,281 & 440,701 & 3959044 & 2847868 & 1111176 & 0,281 & 987636 & 115832 & 871804 & 2913 & 46803 & 41367 & 24749 \\
\hline 6 & 1461,590 & 1231,496 & 701,871 & 1798509 & 773339 & 1025170 & 0,570 & 270431 & 46356 & 224075 & 2862 & 15649 & 12204 & 15641 \\
\hline 7 & 1955,320 & 1531,819 & 555,939 & 2992836 & 1906424 & 1086412 & 0,363 & 656451 & 82824 & 573627 & 2922 & 37872 & 18054 & 23976 \\
\hline 8 & 2452,030 & 1696,411 & 463,055 & 4156769 & 3021923 & 1134846 & 0,273 & 1040954 & 121240 & 919714 & 3032 & 53192 & 24798 & 40218 \\
\hline 9 & 1924,965 & 1437,416 & 587,974 & 2901416 & 1836044 & 1065372 & 0,439 & 633961 & 81357 & 552604 & 3020 & 32663 & 18246 & 27429 \\
\hline 10 & 1944,615 & 1428,364 & 564,374 & 2774883 & 1678658 & 1096226 & 0,398 & 578881 & 73955 & 504927 & 2926 & 31069 & 17819 & 22142 \\
\hline 11 & 2440,392 & 1420,550 & 487,168 & 3272112 & 2173805 & 1098307 & 0,350 & 753080 & 90437 & 662643 & 2975 & 34518 & 29738 & 23207 \\
\hline 12 & 1580,680 & 1241,761 & 654,015 & 1962198 & 934893 & 1027305 & 0,527 & 325094 & 49084 & 276010 & 2892 & 16641 & 14093 & 15459 \\
\hline 13 & 1872,525 & 1297,864 & 553,221 & 2571055 & 1475317 & 1095739 & 0,426 & 509918 & 65064 & 444854 & 2984 & 23249 & 17846 & 20986 \\
\hline 14 & 2075,900 & 1474,218 & 534,607 & 3141328 & 2059185 & 1082143 & 0,379 & 710355 & 86526 & 623830 & 2977 & 35412 & 20390 & 27747 \\
\hline 15 & 1580,680 & 1241,761 & 654,015 & 1962198 & 934893 & 1027305 & 0,527 & 325094 & 49084 & 276010 & 2892 & 16641 & 14093 & 15459 \\
\hline Média & 1925,162 & & & & & & 0,432 & 561228 & & & & & & \\
\hline
\end{tabular}

Tabela B. 44 - Dados da execução considerando informações estáticas e o índice de carga de memória. 


\begin{tabular}{|c|c|c|c|c|c|c|c|c|c|c|c|c|c|c|}
\hline Exec. & Tempo & $\begin{array}{l}\text { Eventos: } \\
\text { proc.p/seg }\end{array}$ & real. P/seg. & Processados & Cancelados & Realizados & Eficiência & Rollbacks & Prim. & Sec. & 0 & 1 & $\begin{array}{c}\text { Causados } \\
\text { por: } \\
2 \\
\end{array}$ & 3 \\
\hline 1 & 1373,540 & 1241,213 & 751,765 & 1698580 & 669988 & 1028592 & 0,606 & 235654 & 41826 & 193828 & 2947 & 12134 & 12216 & 14529 \\
\hline 2 & 2424,150 & 1444,047 & 458,167 & 3498097 & 2387971 & 1110126 & $\mathbf{0 , 3 1 7}$ & 822140 & 99835 & 722305 & 2940 & 35627 & 36759 & 24509 \\
\hline 3 & 1029,080 & 1149,054 & 912,202 & 1181707 & 243498 & 938209 & 0,794 & 84896 & 19624 & 65272 & 1534 & 2965 & 4127 & 10998 \\
\hline 4 & 1119,200 & 1119,182 & 813,251 & 1252045 & 342181 & 909864 & $\mathbf{0 , 7 2 7}$ & 120454 & 27851 & 92603 & 9719 & 2986 & 3063 & 12083 \\
\hline 5 & 1079,660 & 1112,155 & 896,219 & 1200017 & 232898 & 967119 & 0,806 & 82569 & 21090 & 61479 & 1898 & 4108 & 4516 & 10568 \\
\hline 6 & 944,156 & 1135,355 & 950,374 & 1070877 & 174485 & 896392 & $\mathbf{0 , 8 3 7}$ & 60910 & 15080 & 45830 & 3639 & 1827 & 1418 & 8196 \\
\hline 7 & 1140,230 & 1086,419 & 815,882 & 1235144 & 307332 & 927812 & 0,751 & 108381 & 24898 & 83483 & 3038 & 2437 & 6647 & 12776 \\
\hline 8 & 1444,580 & 1150,712 & 710,038 & 1658392 & 635307 & 1023085 & 0,617 & 221573 & 39343 & 182230 & 14671 & 2879 & 6238 & 15555 \\
\hline 9 & 2080,390 & 1209,253 & 539,162 & 2511645 & 1391555 & 1120090 & 0,446 & 480958 & 62560 & 418398 & 28232 & 2987 & 11156 & 20185 \\
\hline 10 & 1473,830 & 1153,938 & 705,285 & 1696928 & 659803 & 1037125 & 0,611 & 231531 & 43796 & 187735 & 8381 & 2785 & 12442 & 20188 \\
\hline 11 & 2597,910 & 1236,124 & 453,106 & 3209754 & 2033054 & 1176700 & 0,367 & 697061 & 81489 & 615572 & 20625 & 3028 & 20549 & 37287 \\
\hline 12 & 815,300 & 1162,201 & 1088,840 & 942387 & 59433 & 882954 & $\mathbf{0 , 9 3 7}$ & 22018 & 7881 & 14137 & 1795 & 1072 & 1326 & 3688 \\
\hline 13 & 1947,220 & 1637,856 & 464,962 & 2905715 & 1930605 & 975110 & $\mathbf{0 , 3 3 6}$ & 785396 & 94559 & 690837 & 2812 & 60530 & 29307 & 1910 \\
\hline 14 & 1873,170 & 1155,727 & 585,847 & 2159586 & 1064649 & 1094937 & $\mathbf{0 , 5 0 7}$ & 371843 & 58973 & 312870 & 13932 & 2873 & 19123 & 23045 \\
\hline 15 & 1839,460 & 1220,354 & 574,325 & 2243997 & 1187932 & 1056065 & 0,471 & 412937 & 61336 & 351601 & 29373 & 2995 & 8593 & 20375 \\
\hline Média & 1545,458 & & & & & & 0,609 & 315888,07 & & & & & & \\
\hline
\end{tabular}

Tabela B. 45 - Dados da execução considerando informações estáticas e o índice de carga de fila do processador. 


\begin{tabular}{|c|c|c|c|c|c|c|c|c|c|c|c|c|c|c|}
\hline \multirow[b]{2}{*}{ Exec. } & \multirow[b]{2}{*}{ Tempo } & \multirow{2}{*}{$\begin{array}{l}\text { Eventos: } \\
\text { proc.p/seg }\end{array}$} & \multirow[b]{2}{*}{ real. P/seg. } & \multirow[b]{2}{*}{ Processados } & \multirow[b]{2}{*}{ Cancelados } & \multirow[b]{2}{*}{ Realizados } & \multirow[b]{2}{*}{ Eficiência } & \multirow[b]{2}{*}{ Rollbacks } & \multirow[b]{2}{*}{ Prim. } & \multirow[b]{2}{*}{ Sec. } & \multirow[b]{2}{*}{0} & \multicolumn{3}{|c|}{$\begin{array}{l}\text { Causados } \\
\text { por: }\end{array}$} \\
\hline & & & & & & & & & & & & 1 & 2 & 3 \\
\hline 1 & $\mathbf{8 5 6 , 8 7 9}$ & 1207,923 & 1076,601 & 1034315 & 112411 & 921904 & 0,891 & 40586 & 12895 & 27691 & 2529 & 3120 & 2591 & 4655 \\
\hline 2 & 1099,650 & 1099,323 & 865,594 & 1208101 & 256812 & 951289 & 0,787 & 90554 & 22448 & 68106 & 2771 & 6181 & 5827 & 7669 \\
\hline 3 & 1176,120 & 1059,114 & 813,235 & 1243605 & 288595 & 955010 & 0,768 & 103465 & 25701 & 77764 & 2819 & 7721 & 8179 & 6982 \\
\hline 4 & 992,467 & 1257,306 & 963,247 & 1247198 & 291675 & 955523 & 0,766 & 103536 & 25058 & 78478 & 2721 & 9217 & 7799 & 5321 \\
\hline 5 & 1045,700 & 1044,453 & 889,777 & 1091347 & 161584 & 929763 & 0,852 & 57574 & 16596 & 40978 & 2566 & 4776 & 4028 & 5226 \\
\hline 6 & 1092,420 & 1186,041 & 883,372 & 1288411 & 328276 & 960135 & 0,745 & 115352 & 26756 & 88596 & 2862 & 8140 & 7352 & 8402 \\
\hline 7 & $\mathbf{8 8 8 , 9 7 5}$ & 987,530 & 955,938 & 877327 & 28069 & 849258 & 0,968 & 10579 & 4753 & 5826 & 703 & 1243 & 1873 & 934 \\
\hline 8 & 1141,490 & 1123,880 & 843,157 & 1282485 & 320313 & 962172 & 0,750 & 112603 & 26140 & 86463 & 2841 & 7029 & 7258 & 9012 \\
\hline 9 & 1089,800 & 1217,313 & 896,915 & 1325662 & 348867 & 976795 & 0,737 & 123387 & 27113 & 96274 & 2844 & 9530 & 6185 & 8554 \\
\hline 10 & 1160,020 & 1086,342 & 826,702 & 1259146 & 300871 & 958275 & 0,761 & 106242 & 25168 & 81074 & 2821 & 7535 & 6345 & 8467 \\
\hline 11 & 1038,870 & 1149,778 & 906,153 & 1193477 & 252823 & 940654 & 0,788 & 89493 & 23003 & 66490 & 2700 & 5596 & 7586 & 7121 \\
\hline 12 & 1127,700 & 1112,745 & 842,096 & 1252878 & 304592 & 948286 & 0,757 & 107640 & 25883 & 81757 & 2704 & 6226 & 8138 & 8815 \\
\hline 13 & 1072,320 & 1087,952 & 879,876 & 1165816 & 222913 & 942903 & $\mathbf{0 , 8 0 9}$ & 79216 & 20599 & 58617 & 2733 & 4650 & 5774 & 7442 \\
\hline 14 & 1067,390 & 1182,784 & 897,610 & 1261391 & 304062 & 957329 & $\mathbf{0 , 7 5 9}$ & 107159 & 25810 & 81349 & 2824 & 8280 & 7498 & 7208 \\
\hline 15 & 1195,450 & 1047,548 & 807,756 & 1250710 & 286203 & 964507 & 0,771 & 100604 & 23864 & 76740 & 2897 & 8446 & 4685 & 7836 \\
\hline Média & 1069,683 & & & & & & 0,794 & 89866 & & & & & & \\
\hline
\end{tabular}




\section{B.2.2 Com carga parasita aleatória}

\begin{tabular}{|c|c|c|c|c|c|c|c|c|c|c|c|c|c|c|}
\hline \multirow[b]{2}{*}{ Exec. } & \multirow[b]{2}{*}{ Tempo } & \multirow{2}{*}{$\begin{array}{l}\text { Eventos: } \\
\text { proc.p/seg }\end{array}$} & \multirow[b]{2}{*}{ real. P/seg. } & \multirow[b]{2}{*}{ Processados } & \multirow[b]{2}{*}{ Cancelados } & \multirow[b]{2}{*}{ Realizados } & \multirow[b]{2}{*}{ Eficiência } & \multirow[b]{2}{*}{ Rollbacks } & \multirow[b]{2}{*}{ Prim. } & \multirow[b]{2}{*}{ Sec. } & \multirow[b]{2}{*}{0} & \multicolumn{3}{|c|}{$\begin{array}{l}\text { Causados } \\
\text { por: }\end{array}$} \\
\hline & & & & & & & & & & & & 1 & 2 & 3 \\
\hline 1 & 1670,290 & 1075,954 & 613,417 & 1795256 & 771814 & 1023442 & $\mathbf{0 , 5 7 0}$ & 268327 & 43547 & 224780 & 16262 & 2761 & 11941 & 12583 \\
\hline 2 & 1347,350 & 1099,390 & 746,284 & 1479146 & 475167 & 1003979 & 0,679 & 165267 & 30476 & 134791 & 11604 & 2437 & 5785 & 10650 \\
\hline 3 & 1299,730 & 1039,813 & 779,068 & 1350530 & 338698 & 1011832 & 0,749 & 119448 & 25483 & 93965 & 4974 & 2678 & 9509 & 8322 \\
\hline 4 & $\mathbf{1 2 7 9 , 5 7 0}$ & 1045,233 & 756,024 & 1336476 & 369789 & 966687 & $\mathbf{0 , 7 2 3}$ & 129160 & 25806 & 103354 & 11948 & 2708 & 4375 & 6775 \\
\hline 5 & 1333,860 & 1115,343 & 802,668 & 1485817 & 416461 & 1069356 & $\mathbf{0 , 7 2 0}$ & 145720 & 29592 & 116128 & 12531 & 2732 & 7397 & 6932 \\
\hline 6 & $\mathbf{1 3 5 5 , 5 3 0}$ & 1113,503 & 790,290 & 1504829 & 436759 & 1068070 & 0,710 & 152582 & 29981 & 122601 & 12248 & 2486 & 7737 & 7510 \\
\hline 7 & 1685,140 & 1034,325 & 649,658 & 1741546 & 647696 & 1093850 & 0,628 & 226003 & 40425 & 185578 & 14237 & 2902 & 12451 & 10835 \\
\hline 8 & $\mathbf{1 3 2 5 , 5 9 0}$ & 968,527 & 733,174 & 1283676 & 311923 & 971753 & $\mathbf{0 , 7 5 7}$ & 108684 & 22261 & 86423 & 8565 & 2024 & 5074 & 6598 \\
\hline 9 & 1175,090 & 1059,754 & 806,004 & 1244507 & 298020 & 946487 & 0,761 & 105462 & 23198 & 82264 & 7795 & 2459 & 5491 & 7453 \\
\hline 10 & 1256,840 & 1065,845 & 782,655 & 1337629 & 355363 & 982266 & $\mathbf{0 , 7 3 4}$ & 126436 & 28100 & 98336 & 9003 & 2820 & 7432 & 8845 \\
\hline 11 & 1100,310 & 1013,210 & 841,794 & 1113228 & 188334 & 924894 & $\mathbf{0 , 8 3 1}$ & 66881 & 18485 & 48396 & 6796 & 2538 & 4691 & 4460 \\
\hline 12 & 1156,050 & 1050,022 & 796,718 & 1209853 & 291949 & 917904 & $\mathbf{0 , 7 5 9}$ & 103102 & 22241 & 80861 & 11524 & 2542 & 3537 & 4638 \\
\hline 13 & 1692,960 & 1055,260 & 614,999 & 1782949 & 743885 & 1039064 & $\mathbf{0 , 5 8 3}$ & 257316 & 42812 & 214504 & 16199 & 2766 & 11117 & 12730 \\
\hline 14 & 1540,190 & 1062,808 & 702,312 & 1635520 & 554725 & 1080795 & 0,661 & 193586 & 36204 & 157382 & 12852 & 2604 & 8697 & 12051 \\
\hline 15 & 1153,670 & 1047,906 & 856,958 & 1207807 & 220197 & 987610 & $\mathbf{0 , 8 1 8}$ & 77199 & 18394 & 58805 & 7320 & 2870 & 5910 & 2294 \\
\hline Média & 1358,145 & & & & & & 0,712 & 149678,2 & & & & & & \\
\hline
\end{tabular}

Tabela B. 47 - Dados da execução com o round-robin. 


\begin{tabular}{|c|c|c|c|c|c|c|c|c|c|c|c|c|c|c|}
\hline \multirow[b]{2}{*}{ Exec. } & \multirow[b]{2}{*}{ Tempo } & \multirow{2}{*}{$\begin{array}{l}\text { Eventos: } \\
\text { proc.p/seg }\end{array}$} & \multirow[b]{2}{*}{ real. P/seg. } & \multirow[b]{2}{*}{ Processados } & \multirow[b]{2}{*}{ Cancelados } & \multirow[b]{2}{*}{ Realizados } & \multirow[b]{2}{*}{ Eficiência } & \multirow[b]{2}{*}{ Rollbacks } & \multirow[b]{2}{*}{ Prim. } & \multirow[b]{2}{*}{ Sec. } & \multirow[b]{2}{*}{ 0 } & \multicolumn{3}{|c|}{$\begin{array}{l}\text { Causados } \\
\text { por: }\end{array}$} \\
\hline & & & & & & & & & & & & 1 & 2 & 3 \\
\hline 1 & 2667,170 & 694,021 & 407,044 & 1850500 & 765202 & 1085298 & 0,586 & 267668 & 46263 & 221405 & 14192 & 16590 & 3046 & 12435 \\
\hline 2 & 2575,160 & 699,377 & 417,242 & 1800121 & 726113 & 1074008 & $\mathbf{0 , 5 9 7}$ & 253952 & 43174 & 210778 & 13591 & 17011 & 2829 & 9743 \\
\hline 3 & 2663,840 & 754,965 & 405,901 & 2010547 & 929574 & 1080973 & $\mathbf{0 , 5 3 8}$ & 322127 & 52602 & 269525 & 17301 & 20074 & 3018 & 12209 \\
\hline 4 & 2601,990 & 757,642 & 427,759 & 1967066 & 856230 & 1110836 & $\mathbf{0 , 5 6 5}$ & 299237 & 51105 & 248132 & 17286 & 18585 & 2944 & 12290 \\
\hline 5 & 2653,280 & 706,943 & 401,365 & 1872166 & 808997 & 1063169 & 0,568 & 282375 & 48476 & 233899 & 15858 & 17865 & 3104 & 11649 \\
\hline 6 & 2679,100 & 806,566 & 412,789 & 2158569 & 1053703 & 1104866 & 0,512 & 365482 & 57992 & 307490 & 20477 & 20892 & 3023 & 13600 \\
\hline 7 & 2718,860 & 706,052 & 402,779 & 1917086 & 823282 & 1093804 & $\mathbf{0 , 5 7 1}$ & 287268 & 48822 & 238446 & 17208 & 19428 & 2973 & 9213 \\
\hline 8 & 2689,020 & 769,274 & 407,093 & 2065832 & 972495 & 1093337 & $\mathbf{0 , 5 2 9}$ & 336765 & 53159 & 283606 & 18697 & 20046 & 2981 & 11435 \\
\hline 9 & 2716,480 & 766,804 & 415,033 & 2080873 & 954485 & 1126388 & 0,541 & 332119 & 53464 & 278655 & 18872 & 19564 & 2954 & 12074 \\
\hline 10 & 2837,360 & 742,663 & 395,595 & 2106230 & 984231 & 1121999 & $\mathbf{0 , 5 3 3}$ & 341635 & 53261 & 288374 & 16207 & 22657 & 2978 & 11419 \\
\hline 11 & 2737,200 & 721,618 & 400,653 & 1972463 & 877143 & 1095320 & $\mathbf{0 , 5 5 5}$ & 305875 & 50497 & 255378 & 15903 & 19118 & 2972 & 12504 \\
\hline 12 & 2630,750 & 800,577 & 422,182 & 2102899 & 993968 & 1108931 & $\mathbf{0 , 5 2 7}$ & 345041 & 55133 & 289908 & 19090 & 20844 & 3066 & 12133 \\
\hline 13 & 2592,310 & 807,847 & 437,252 & 2089912 & 958815 & 1131097 & 0,541 & 334939 & 51604 & 283335 & 16921 & 22012 & 2835 & 9836 \\
\hline 14 & 2616,330 & 750,038 & 417,729 & 1958788 & 868073 & 1090715 & $\mathbf{0 , 5 5 7}$ & 301355 & 50498 & 250857 & 16578 & 19475 & 3001 & 11444 \\
\hline 15 & 2786,820 & 780,785 & 413,108 & 2174609 & 1024107 & 1150502 & $\mathbf{0 , 5 2 9}$ & 358716 & 55124 & 303592 & 19792 & 19867 & 2918 & 12547 \\
\hline Média & 2677,711 & & & & & & 0,550 & 15636,93 & & & & & & \\
\hline
\end{tabular}

Tabela B. 48 - Dados da execução considerando apenas as informações estáticas. 


\begin{tabular}{|c|c|c|c|c|c|c|c|c|c|c|c|c|c|c|}
\hline \multirow[b]{2}{*}{ Exec. } & \multirow[b]{2}{*}{ Tempo } & \multirow{2}{*}{$\begin{array}{l}\text { Eventos: } \\
\text { proc.p/seg }\end{array}$} & \multirow[b]{2}{*}{ real. P/seg. } & \multirow[b]{2}{*}{ Processados } & \multirow[b]{2}{*}{ Cancelados } & \multirow[b]{2}{*}{ Realizados } & \multirow[b]{2}{*}{ Eficiência } & \multirow[b]{2}{*}{ Rollbacks } & \multirow[b]{2}{*}{ Prim. } & \multirow[b]{2}{*}{ Sec. } & \multirow[b]{2}{*}{0} & \multicolumn{3}{|c|}{$\begin{array}{l}\text { Causados } \\
\text { por: }\end{array}$} \\
\hline & & & & & & & & & & & & 1 & 2 & 3 \\
\hline 1 & 1193,310 & 830,307 & 729,732 & 988929 & 119833 & 869096 & 0,879 & 42428 & 11898 & 30530 & 1240 & 3658 & 5274 & 1726 \\
\hline 2 & 1713,380 & 879,206 & 561,400 & 1505320 & 544174 & 961146 & 0,638 & 191850 & 33858 & 157992 & 2567 & 11241 & 15449 & 4601 \\
\hline 3 & 1898,280 & 943,799 & 512,601 & 1790560 & 817874 & 972686 & 0,543 & 286780 & 47448 & 239332 & 2917 & 12867 & 23582 & 8082 \\
\hline 4 & 1877,470 & 998,968 & 516,216 & 1874361 & 905660 & 968701 & 0,517 & 314184 & 49201 & 264983 & 2826 & 18964 & 19589 & 7822 \\
\hline 5 & 2083,690 & 929,115 & 477,355 & 1933748 & 940234 & 993514 & 0,514 & 329430 & 50134 & 279296 & 2733 & 13886 & 24073 & 9442 \\
\hline 6 & 2126,980 & 1031,705 & 470,008 & 2193905 & 1194391 & 999514 & 0,456 & 414215 & 58059 & 356156 & 2878 & 20495 & 24858 & 9828 \\
\hline 7 & 1856,370 & 938,694 & 525,432 & 1741813 & 766713 & 975100 & 0,560 & 270150 & 44975 & 225175 & 2942 & 13628 & 18717 & 9688 \\
\hline 8 & 1535,350 & 905,818 & 598,500 & 1390569 & 471782 & 918787 & 0,661 & 164091 & 29654 & 134437 & 2338 & 13499 & 10862 & 2955 \\
\hline 9 & 1537,750 & 870,591 & 637,159 & 1338090 & 358680 & 979410 & 0,732 & 124527 & 23478 & 101049 & 2024 & 10589 & 7656 & 3209 \\
\hline 10 & 1660,550 & 926,354 & 566,229 & 1533758 & 596604 & 937154 & 0,611 & 208459 & 36972 & 171487 & 2792 & 13243 & 14983 & 5954 \\
\hline 11 & 2515,950 & 1133,092 & 417,419 & 2849221 & 1799436 & 1049785 & 0,368 & 622414 & 84736 & 537678 & 2913 & 29383 & 43515 & 8925 \\
\hline 12 & 2387,650 & 1095,448 & 429,648 & 2609957 & 1585563 & 1024394 & 0,392 & 550633 & 74458 & 476175 & 2860 & 33207 & 28595 & 9796 \\
\hline 13 & 1944,340 & 966,795 & 517,195 & 1875049 & 871440 & 1003609 & 0,535 & 303009 & 46512 & 256497 & 2891 & 15866 & 16826 & 10929 \\
\hline 14 & 1390,530 & 847,083 & 676,963 & 1176586 & 236179 & 940407 & 0,799 & 83519 & 18615 & 64904 & 2212 & 7284 & 6078 & 3041 \\
\hline 15 & 1350,900 & 917,032 & 667,421 & 1234863 & 335958 & 898905 & 0,728 & 119518 & 27045 & 92473 & 2690 & 5549 & 13087 & 5719 \\
\hline Média & 1804,833 & & & & & & 0,596 & 268347,13 & & & & & & \\
\hline
\end{tabular}

Tabela B. 49 - Dados da execução considerando informações estáticas e o índice de carga de memória. 


\begin{tabular}{|c|c|c|c|c|c|c|c|c|c|c|c|c|c|c|}
\hline Exec. & Tempo & $\begin{array}{l}\text { Eventos: } \\
\text { proc.p/seg }\end{array}$ & real. P/seg. & Processados & Cancelados & Realizados & Eficiência & Rollbacks & Prim. & Sec. & 0 & 1 & $\begin{array}{c}\text { Causados } \\
\text { por: } \\
2\end{array}$ & 3 \\
\hline 1 & 1300,750 & 1301,218 & 735,465 & 1691881 & 735549 & 956332 & 0,565 & 254983 & 39111 & 215872 & 2773 & 15633 & 6002 & 14703 \\
\hline 2 & 1057,990 & 1191,722 & 880,499 & 1260039 & 328980 & 931059 & 0,739 & 116162 & 24412 & 91750 & 2526 & 8591 & 8768 & 4527 \\
\hline 3 & 1415,570 & 1225,319 & 740,581 & 1733523 & 685635 & 1047888 & 0,604 & 238459 & 40352 & 198107 & 2996 & 19955 & 7382 & 10019 \\
\hline 4 & 953,506 & 1112,956 & 949,125 & 1060601 & 156063 & 904538 & $\mathbf{0 , 8 5 3}$ & 55488 & 13902 & 41586 & 1580 & 2321 & 1932 & 8069 \\
\hline 5 & 1367,290 & 1153,092 & 772,755 & 1575573 & 519616 & 1055957 & 0,670 & 179993 & 31883 & 148110 & 2902 & 4157 & 9458 & 15366 \\
\hline 6 & 1006,940 & 1165,973 & 896,030 & 1172617 & 271630 & 900987 & 0,768 & 95176 & 19883 & 75293 & 6923 & 3510 & 2399 & 7051 \\
\hline 7 & 1545,660 & 1161,719 & 688,352 & 1793314 & 730549 & 1062765 & 0,593 & 252606 & 40523 & 212083 & 14663 & 2289 & 2954 & 20617 \\
\hline 8 & 1285,490 & 1084,091 & 775,800 & 1393214 & 396246 & 996968 & 0,716 & 139163 & 26912 & 112251 & 8904 & 2667 & 10380 & 4961 \\
\hline 9 & $\mathbf{1 2 9 4 , 8 8 0}$ & 1190,646 & 740,401 & 1536206 & 580542 & 955664 & 0,622 & 201474 & 36022 & 165452 & 2864 & 4595 & 18976 & 9587 \\
\hline 10 & 1115,660 & 1212,476 & 867,905 & 1351939 & 384421 & 967518 & 0,716 & 134481 & 27733 & 106748 & 2209 & 15928 & 3389 & 6207 \\
\hline 11 & 1448,390 & 1210,026 & 679,369 & 1751349 & 767958 & 983391 & 0,562 & 267625 & 42852 & 224773 & 2470 & 16560 & 3621 & 20201 \\
\hline 12 & 1025,480 & 1166,220 & 917,333 & 1193854 & 254699 & 939155 & 0,787 & 89246 & 20825 & 68421 & 3453 & 4857 & 2277 & 10238 \\
\hline 13 & 956,504 & 1085,268 & 923,867 & 1037527 & 154273 & 883254 & 0,851 & 55149 & 15606 & 39543 & 5028 & 2635 & 3157 & 4786 \\
\hline 14 & 1286,830 & 1148,716 & 769,811 & 1477819 & 487479 & 990340 & 0,670 & 171728 & 31092 & 140636 & 2414 & 8986 & 7245 & 12447 \\
\hline 15 & 1150,830 & 1135,701 & 812,753 & 1305493 & 370980 & 934513 & 0,716 & 127901 & 24082 & 103819 & 2308 & 3117 & 3589 & 15068 \\
\hline Média & 1214,118 & & & & & & 0,695 & 158642,27 & & & & & & \\
\hline
\end{tabular}

Tabela B. 50 - Dados da execução considerando informações estáticas e o índice de carga de fila do processador. 


\begin{tabular}{|c|c|c|c|c|c|c|c|c|c|c|c|c|c|c|}
\hline Exec. & Tempo & $\begin{array}{c}\text { Eventos: } \\
\text { proc.p/seg }\end{array}$ & real. P/seg. & Processados & Cancelados & Realizados & Eficiência & Rollbacks & Prim. & Sec. & 0 & 1 & $\begin{array}{l}\text { Causados } \\
\text { por: } \\
2\end{array}$ & 3 \\
\hline 1 & 991,964 & 1162,343 & 941,098 & 1150604 & 218958 & 931646 & $\mathbf{0 , 8 1 0}$ & 78060 & 18434 & 59626 & 4230 & 4802 & 7253 & 2149 \\
\hline 2 & $\mathbf{8 7 0 , 8 8 3}$ & 1145,118 & 1039,008 & 996196 & 92279 & 903917 & 0,907 & 33342 & 10976 & 22366 & 2353 & 2227 & 4568 & 1828 \\
\hline 3 & 1040,450 & 1229,523 & 904,093 & 1278026 & 338162 & 939864 & 0,735 & 118355 & 26521 & 91834 & 2920 & 10395 & 8175 & 5031 \\
\hline 4 & 1162,180 & 1280,840 & 847,119 & 1486659 & 503493 & 983166 & 0,661 & 174668 & 31908 & 142760 & 2780 & 18547 & 8267 & 2314 \\
\hline 5 & 1381,180 & 1208,860 & 753,595 & 1669117 & 628576 & 1040541 & 0,623 & 218012 & 33440 & 184572 & 2795 & 13412 & 11228 & 6005 \\
\hline 6 & 1296,440 & 1333,143 & 805,143 & 1726224 & 683875 & 1042349 & 0,604 & 237794 & 39635 & 198159 & 2362 & 16604 & 12906 & 7763 \\
\hline 7 & 1294,950 & 1517,424 & 797,450 & 1963145 & 931234 & 1031911 & 0,526 & 323296 & 49119 & 274177 & 2857 & 26180 & 14112 & 5970 \\
\hline 8 & 1153,070 & 1228,123 & 857,172 & 1415222 & 427403 & 987819 & 0,698 & 150649 & 28243 & 122406 & 2490 & 8472 & 11143 & 6138 \\
\hline 9 & 1415,290 & 1275,739 & 765,199 & 1804027 & 721838 & 1082189 & 0,600 & 251843 & 41679 & 210164 & 2820 & 10010 & 14863 & 13986 \\
\hline 10 & 1287,840 & 1267,054 & 799,079 & 1626805 & 600558 & 1026247 & 0,631 & 210205 & 36925 & 173280 & 2886 & 14192 & 12860 & 6987 \\
\hline 11 & 1067,520 & 1304,847 & 901,815 & 1390473 & 429334 & 961139 & 0,691 & 150446 & 32037 & 118409 & 2764 & 9668 & 11215 & 8390 \\
\hline 12 & 1346,980 & 1792,777 & 773,409 & 2409318 & 1369393 & 1039925 & 0,432 & 473803 & 61942 & 411861 & 2931 & 35753 & 13712 & 9546 \\
\hline 13 & 1171,950 & 1243,410 & 848,186 & 1452838 & 461471 & 991367 & 0,682 & 161301 & 30276 & 131025 & 2515 & 12857 & 10301 & 4603 \\
\hline 14 & 1015,110 & 1199,522 & 888,258 & 1214570 & 315134 & 899436 & 0,741 & 110418 & 24001 & 86417 & 6689 & 4086 & 10468 & 2758 \\
\hline 15 & 852,751 & 1237,602 & 1058,944 & 1052343 & 151734 & 900609 & 0,856 & 54013 & 14395 & 39618 & 2141 & 4678 & 5579 & 1997 \\
\hline Média & 1156,571 & & & & & & 0,680 & 183080 & & & & & & \\
\hline
\end{tabular}

Tabela B. 51 - Dados da execução considerando informações estáticas e os dois índices de carga. 